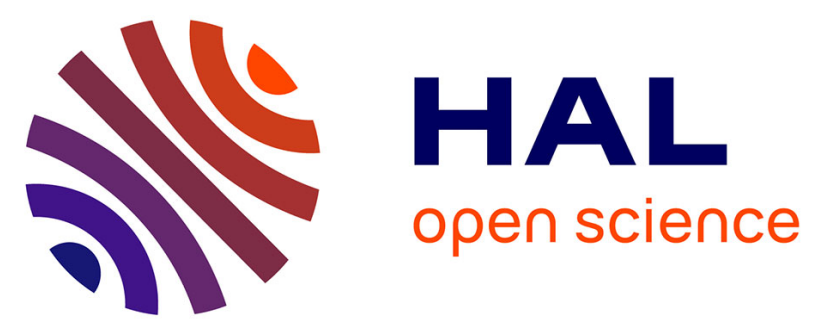

\title{
Le sanctuaire de Mars Mullo chez les Aulerques Cénomans (Allonnes, Sarthe) Ve s. av. J.-C. - IVe s. apr. J.-C. : état des recherches actuelles
}

Véronique Brouquier-Reddé, Katherine Gruel, Claudine Allag, Bruno Bazin, François Bérard, Vincent Bernollin, Estelle Bertrand, Sébastien Cormier, Arnaud Coutelas, Richard Delage, et al.

\section{To cite this version:}

Véronique Brouquier-Reddé, Katherine Gruel, Claudine Allag, Bruno Bazin, François Bérard, et al.. Le sanctuaire de Mars Mullo chez les Aulerques Cénomans (Allonnes, Sarthe) Ve s. av. J.-C. - IVe s. apr. J.-C.: état des recherches actuelles. Gallia - Archéologie de la France antique, 2004, 61, pp.291-386. 10.3406/galia.2004.3066 . hal-01910870

\section{HAL Id: hal-01910870 \\ https://hal.science/hal-01910870}

Submitted on 6 Feb 2020

HAL is a multi-disciplinary open access archive for the deposit and dissemination of scientific research documents, whether they are published or not. The documents may come from teaching and research institutions in France or abroad, or from public or private research centers.
L'archive ouverte pluridisciplinaire HAL, est destinée au dépôt et à la diffusion de documents scientifiques de niveau recherche, publiés ou non, émanant des établissements d'enseignement et de recherche français ou étrangers, des laboratoires publics ou privés.

\section{(이) $\$$}

Distributed under a Creative Commons Attribution - NonCommercial - NoDerivatives $\mid 4.0$ 


\title{
LE SANCTUAIRE DE MARS MULLO CHEZ LES AulerQues CÉNOMANS (AllonNes, SARThE) V ${ }^{e}$ S. AV. J.-C.-IV ${ }^{e}$ S. APR. J.-C.
} État des recherches actuelles

\author{
Sous la direction de Véronique BrouQuier-REDDÉ et Katherine GrueL ${ }^{*}$ \\ Avec la collaboration de Claudine Allag, Bruno Bazin, François Bérard, \\ Vincent Bernollin, Estelle Bertrand, Sébastien Cormier, Arnaud Coutelas, \\ Richard Delage, Georges DePeyrot, Vincent Drost, Jean-Paul Gulllaumet, \\ Françoise GurY, Cathy LefĖvre, Thierry Lejars, Christophe Loiseau, Frédéric POuPON
}

Mots-clés. Allonnes, Aulerques Cénomans, Gaule lyonnaise, Mars Mullo, époques gauloise el romaine, archilecture monumentale, temple carré sans podium, temple à cella circulaire sur podium, chantier de construction, atelier du travail des métaux, fontaine 1 lexagonale, quadriportique, exèdre, ordre corinthien, pilastre, décor lapidaire d'applique, matériel laténien, épigraphie latine, céramique s'gillée, céramique commune, iconographie, peinture murale, faune, monnaies gauloises et romaines.

Résumé. Le sanctuaire d'Allonnes, aux portes du Mans dans la vallée de la Sarthe, est connu depuis les fouilles de P. Térouanne par son

vatériel laténien, ses dédicaces à Mars Mullo, ses inscriptions aux Aulerques Cénomans et ses sculptures. Depuis 1994, les fouilles programmées ont repris l'examen des vestiges gaulois, dont le matériel remonte au v ${ }^{p}$ s. av. J.-C., du temple du Haut-Empire et du sanctuaire du It' s. apr. J.-C., fréquenté jusqu'au $\mathrm{V}^{\circ}$ s. La découverte exceptionnelle du chantier de construction du temple à cella circulaire sur podium permet de dater les différentes étapes de la réalisation de ce complexe cultuel monumental. Les blocs abandonnés de l'atelier lapidaire et de l'atelier de travail des métaux précisent le travail et l'organisation des ouvriers et des artisans. Ce sanctuaire de Gaule lyonnaise, dédié à un dieu régional en association avec le culte impérial, adopte les mêmes caractéristiques que les monuments du sud-ouest de la Gaule. Les études du mobilier (armes celtiques, épigraphie, numismatique, céramique, faune, sculptures) révèlent la richesse de ce monument édifié à proximité de la capitale de la civitas des Aulerques Cénomans, dont il est l'un des principaux lieux de culte.

Key-words. Allonnes, Aulerci Cenomani, Gallia Lugdunensis, Mars Mullo, Celtic and Roman periods, monumental architecture, square temple without podium, temple with round cella on a podium, builder's yard, metal workshop, hexagonal fountain, quadriportico, exedra, Corinthian order; pilaster; stone revetment, Latenian material, Latin epigraphy, terra sigillata, common ware, iconography; mural painting, fauna, Celtic and Roman coins.

Abstract. Since the excavations by P. Térouanne the sanctuary at Allonnes, close to Le Mans in the Sarthe valley, has been known for its Latenian material, its dedications to Mars Mullo, inscriptions mentioning the Cenomani Aulerci, and its sculptures. Planned excavations initiated in 1994 have resumed the study of the Celtic remains (with material going back to the $5^{\text {th }}$ century BC), of the temple from the High Empire, and of the sanctuary built in the $2^{\text {nd }}$ century $A D$ and still frequented in the $4^{\text {th }}$. The exceptional discovery of the builder's yard of the temple with a round cella on a podium allows to date the different construction stages of this monumental cult complex. The abandoned blocks in the stonecotters' workshop and the metal workshop show in greater detail the work and organization of labourers and craftsmen. This sanctuary in Gallia Lugdunensis, dedicated to a regional god in association with the imperial cult, adopted the same characteristics as the monuments in the Southwest of Gauls. Study of the material (Celtic weapons, inscriptions, coins, fauna, sculpture) demonstrate the wealth of this monument, which was erected near the capital of the civitas of the Aulerci Cenomani to become one of their main cult places.

\footnotetext{
* Voir la liste des auteurs et le crédit des illustrations, p. 380.
} 


\begin{abstract}
Schlagwörter. Allonnes, Aulerci Cenomani, Gallia Lugdunensis, Mars Mullo, keltische und römische Zeit, Monumentalarchitektur: Tempel mit quadratischem Grundriß ohne Podium, Podiumstempel mil runder cella, Baustelle, Werkstatt für metallbearbeitung, hexagonaler Brunnen, Quadriportikus, Exedra, korinthische Ordnung, Pilaster, steinerne Wandvertäfelung, latènezeitliches Material, lateinische Inschriften, Terra Sigillata, Gelrauchskeramik, Ikonographie, Wandmalerei, Fauna, keltische und römische Münzen.
\end{abstract}

Zusammenfassung. Das vor den Toren von Le Mans im Tal der Sarthe gelegene Heiligtum von Allones ist seit den Ausgrabungen von P. Térouanne durch sein latènezeitliches Material, seine Weihinschriften an Mars Mullo, die Inschriften der Aulerci Cenomani und seine Skulpturenfunde ein fester Begriff. Seit 1994 wurden durch systematische Grabungen die Untersuchungen wiederaufgenommen. Sie gelten den keltischen Überresten, die bis ins 5. Jahrhundert v. Chr: zurückreichen, dem frühkaiserzeitlichen Tempelbau, und dem Heiligtum. des 2. Jahrhunderts n. Chr, das bis ins 4. Jahrhundert hinein in Benutzung blieb. Die außergewöhnliche Entdeckung der Baustelle des Podiumstempels mit runder cella erlaubt eine Datierung der verschiedenen Bauphasen dieses monumentalen Kultkomplexes. Die von den Steinmetzen zurückgelassenen Blöcke und die Werkstatt der Metallhandwerker geben Finblick in die Aufgaben und Arbeitsabläufe der Bauleute und Kunsthandwerker. Dieses zur Lugdunensis rechnende Heiligtum, das in Verbindung mil dem Kaiserkult einer lokalen Gottheit gewvidmet war, weist die selben Charakteristika auf, die von den Denkmälern im Südwesten Galliens bekannt sind. Die Untersuchung des Fundmaterials (keltische Waffen, Inschriftentexte, Münzen, Keramik, Tierknochen, Skulpturen) bestätigt den Reichtum dieser Anlage, die in unmittelbarer Nähe des Civitashauptstadtes der Aulerci Cenomani errichtet wurde, für den sie einer der wichtigsten Kultorte war:

Übersetzung : Stefan WIRTH

À $5 \mathrm{~km}$ au sud-ouest du Mans, Allonnes s'étend sur une plaine alluvionnaire traversée par la Sarthe, dominée par la butte du Vieux-Mans, sur la rive gauche, et par la butte des Fondues, sur la rive droite : alt. $82 \mathrm{~m}$ (Aubin dir., 1980). C'est sur ce promontoire, en aval du confluent de l'Huisne, à la cote 67-68 m, qu'est établi le sanctuaire de Mars Mullo, aux lieux-dits La Tour-aux-Fées et La Forêterie. Il domine, à l'est, le gué de Chaoué qui permet de relier Allonnes au Mans (fig. 1 et 2). Une voie qui relie la ville antique au gué passe au nord du sanctuaire. Or, à hauteur de ce gué, il existe un point de rupture de charge sur la Sarthe qui nécessitait probablement le débarquement des marchandises apportées du sud par voie fluviale. $\grave{1} 1 \mathrm{~km}$ au sudouest, sur le flanc nord d'une colline peu élevée, au lieu-dit Les Perrières, a été construit un second sanctuaire. Au nordouest (rue Pasteur), de grands thermes publics, situés à $600 \mathrm{~m}$ du premier et à $900 \mathrm{~m}$ du deuxième sanctuaire, complètent les bâtiments publics romains actuellement connus (Bernier et al., 2002). Un peu plus au sud, une quarantaine de puits romains ont été transformés en fosses-dépotoirs. Des découvertes ponctuelles de vestiges romains (mobiliers, fosses, portions de murs ou de sols, trous de poteau...) dessinent une agglomération assez étendue selon, d'une part, un axe nord-sud entre le sanctuaire des Perrières et les thermes, et, d'autre part, un axe estouest entre ces derniers et le sanctuaire de Mars Mullo (fig. 2).

Le site de La Forêterie est occupé dès la phase récente de La Tène A, c'est-à-dire dès le $V^{\prime \prime}$ s. ou le début du IV's. av. J.-C., jusqu'au $\mathrm{N}^{*}$ s. apr. J.-C. À partir de l'époque augustéenne, le sanctuaire a évolué parallèlement à Vindinum, la capitale de la puissante cité des Aulerques Cénomans (fig. 3). Les fouilles révèlent en effet une occupation gauloise importante, avec un premier sanctuaire en bois attesté dès le deuxième tiers du $\mathrm{l}^{\mathrm{er}} \mathrm{s}$. av. J.-C., suivi de l'édification d'un sanctuairc en pierre, particulièrement prospère sous Claude, alors même que Vindinum connaît une forte extension. Dans le courant du II"s., comme d'autres monuments ' de la cité toute proche, le sanctuaire de

1. En particulier les thermes de la rue Claude-Chappe (Deschamps, Vaginay dir., 1990).
Mars Mullo fait l'objet d'un vaste programme de reconstruction. Il semble alors avoir profité de la prospérité des Aulerques Cénomans et on perçoit une éventuelle baisse de sa fréquentation à la fin du ${ }^{\prime \prime} I^{\prime} s$. alors que Vindinum s'enferme derrière d'épais remparts (Guilleux, 2000). Le sanctuaire est détruit et définitivement abandonné entre 330 et 350 apr. J.-C.

\section{L'HISTORIQUE DES FOUILLES}

Le site antique de La Forêterie à Allonnes, connu depuis le $\mathrm{XVI}^{\mathrm{c}} \mathrm{s}$., a suscité l'intérêt de tous les érudits locaux et de savants renommés, comme le montre l'importante bibliographie rassemblée dans la Carte archéologique de la Sarthe (Bernier et al., 2002). Il a connu bien des vicissitudes, car il fut utilisé en particulier comme carrière de pierre pour la construction de l'église ou des routes de la Sarthe, comme celle du Mans à Sablé. Son classement comme monument historique en 1961 et son achat par la communauté urbaine du Mans en 1980 lui ont permis d'échapper aux destructions massives du patrimoine archéologique, dues à l'expansion urbaine des années 1960 .

C'est en 1953, à la suite d'une tempête qui mit à nu le stylobate nord, que le gendre du propriétaire du lieu, P. Térouanne, réalisa l'importance du monument de La Forêterie et entreprit des fouilles qui se poursuivirent jusqu'en 1979. Il identifia La Tour-aux-Fées à la cella d'un temple (fig. 4) et détermina l'étendue du site. S'intéressant plus particulièrement au dernier état du sanctuaire et à l'établissement de son plan, il effectua des fouilles en tranchées. Le dégagement de la zone du temple livre, en particulier, des éléments de statuaire et de bases épigraphiques d'une importance majeure. Ces travaux firent l'objet d'une série d'articles, mais aucune monographie d'ensemble du sanctuaire ne fut publiée. Dans Allonnes dans l'Antiquité (Biarne dir., 1974), P. Térouanne reprend l'essentiel de ses conclusions. Après une rapide évaluation des potentialités du site par G. Guillier (AFAN), des fouilles extensives furent reprises en 1994, sous l'égide de l'UMR 8546 (CNRS-ENS Paris) et sous la direction de K. Gruel et 


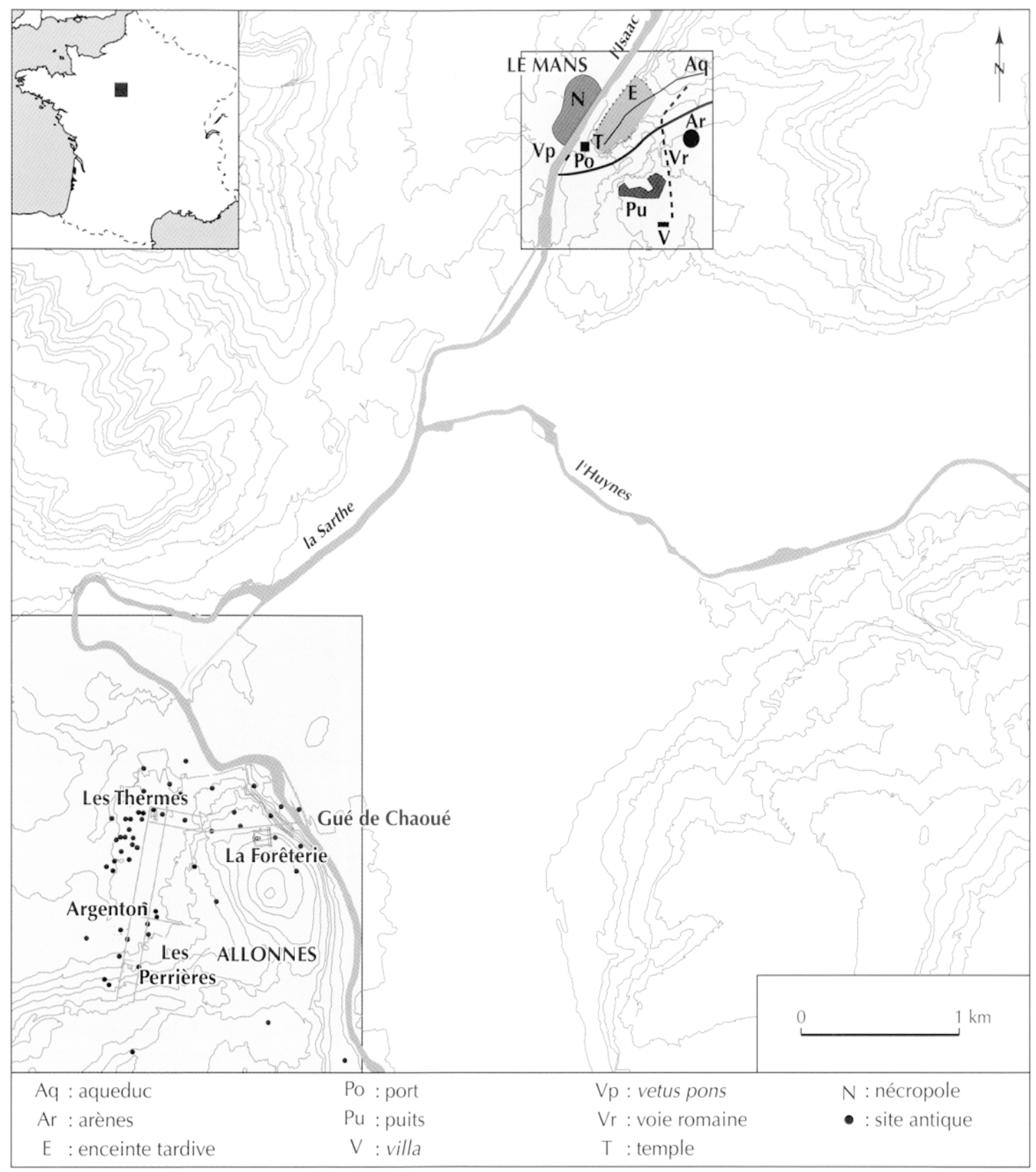

Fig. 1 - Localisation du sanctuaire de Mars Mullo par rapport à la cité de Vindinum/Le Mans.

V. Brouquier-Reddé ${ }^{2}$, pour préciser la chronologie du sanctuaire, reprendre l'analyse complète du monument et évalucr ce qui subsiste des états antérieurs (fig. $5 \mathrm{cf}$. pl. I hors texte et fig. 6).

L'essentiel des travaux réalisés jusqu'ici, qu'il s'agisse des fouilles actuelles ou des travaux effectués par P. Térouanne, a privilégié l'étude des importants vestiges monumentaux d'époque romaine. Les niveaux et le mobilier attestant une

2. Gruel, Brouquier-Reddé dir., 2003. On se reportera à cet ouvrage pour une description synthétique des principaux objets. Nous ne présentons ici qu'une sélection. Nous remercions $M^{\text {mes }}$ Térouanne et M. J.-L. Avice de nous avoir largement ouvert la documentation personnelle de P. Térouanne. occupation antérieure sont, de fait, encore peu nombreux en l'ctat actucl de la recherche ct constituent l'un des objectifs des fouilles programmées qui se poursuivent actuellement dans le cadre du programme triennal (2002-2004).

Cependant, la reprise de l'étude de l'ensemble du mobilier des fouilles effectuées depuis 1953 et les résultats des fouilles programmées menées sur le dernier état du sanctuaire de Mars Mullo, justifient sans plus attendre la publication de ce premier bilan ${ }^{3}$, avant la réalisation d'une monographie complète aıx termes des travaux de terrain.

3. L'étude du matériel ne prend pas en compte les données des campagnes 2002 et 2003. 


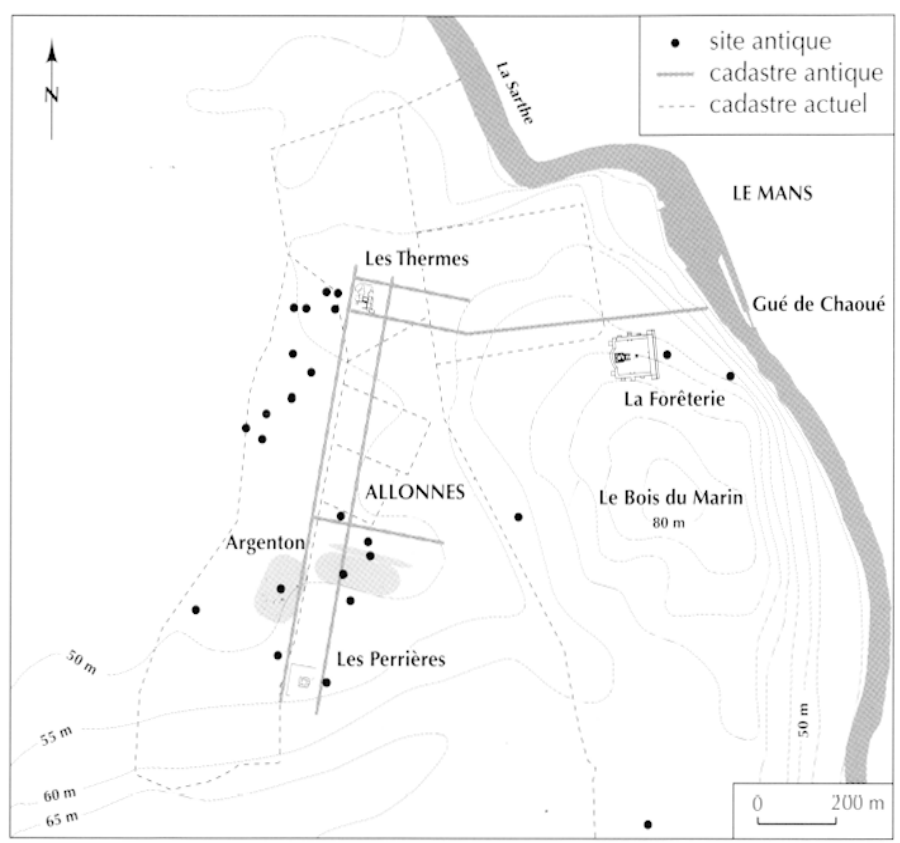

Fig. 2 - L'environnement archéologique du sanctuaire de Mars Mullo à Allonnes.

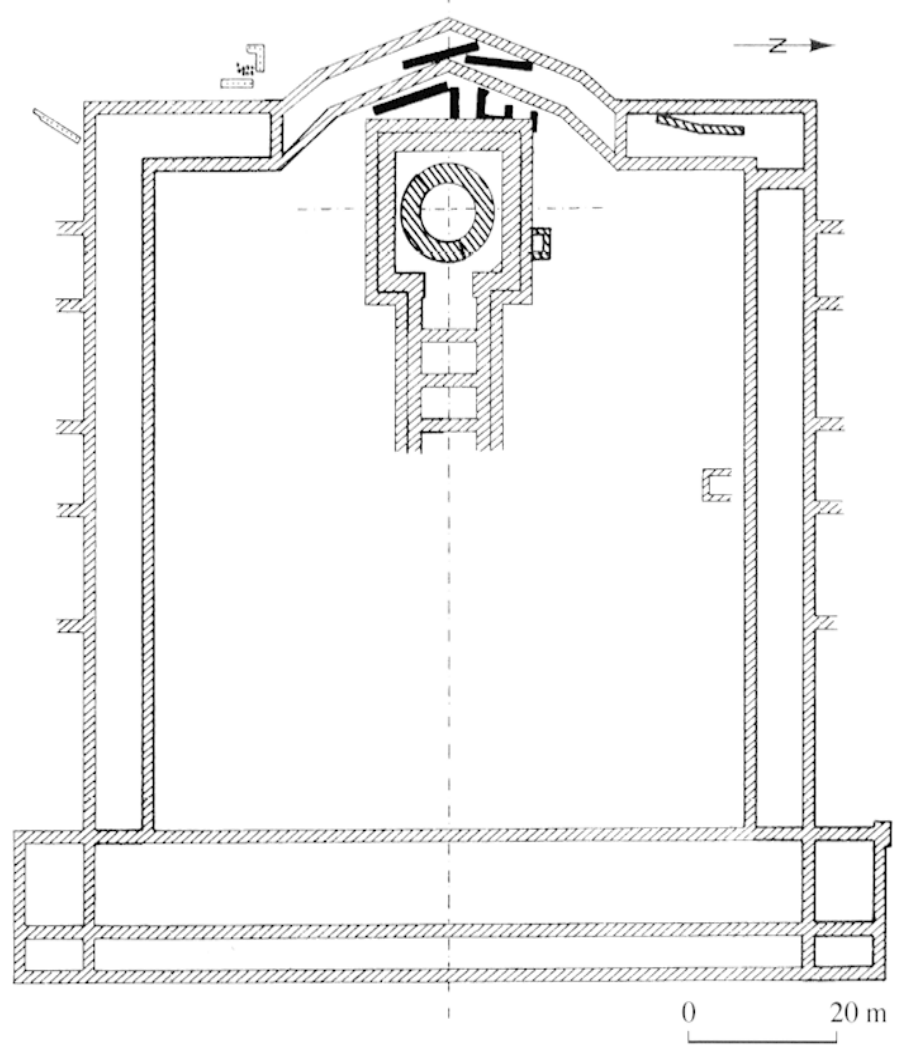

Fig. 4 - Plan du sanctuaire d'après P. Térouanne (Biarne dir., 1974).

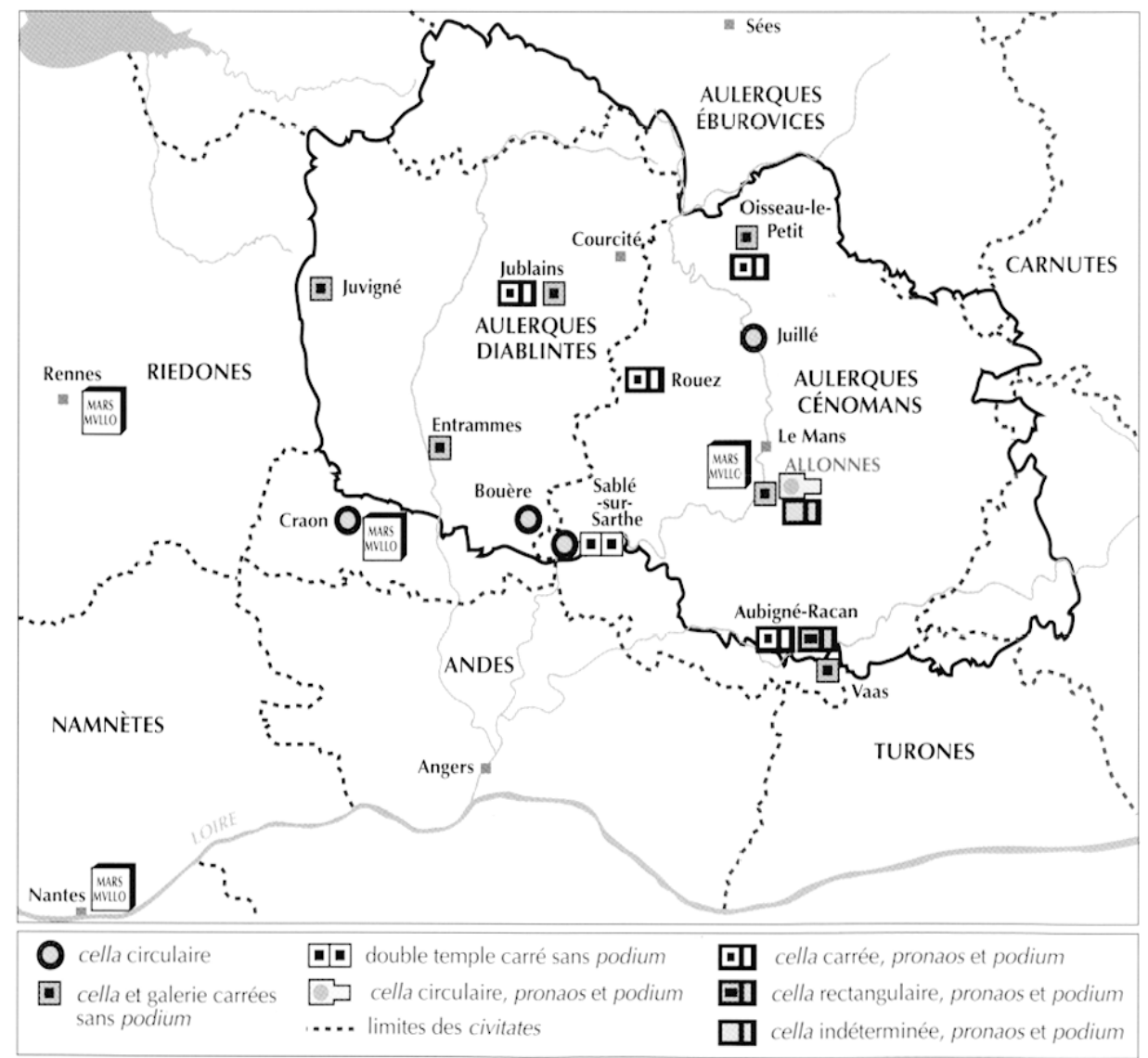

Fig. 3 - Les civitates des Aulerci Cenomani et des Aulerci Diablintes. 


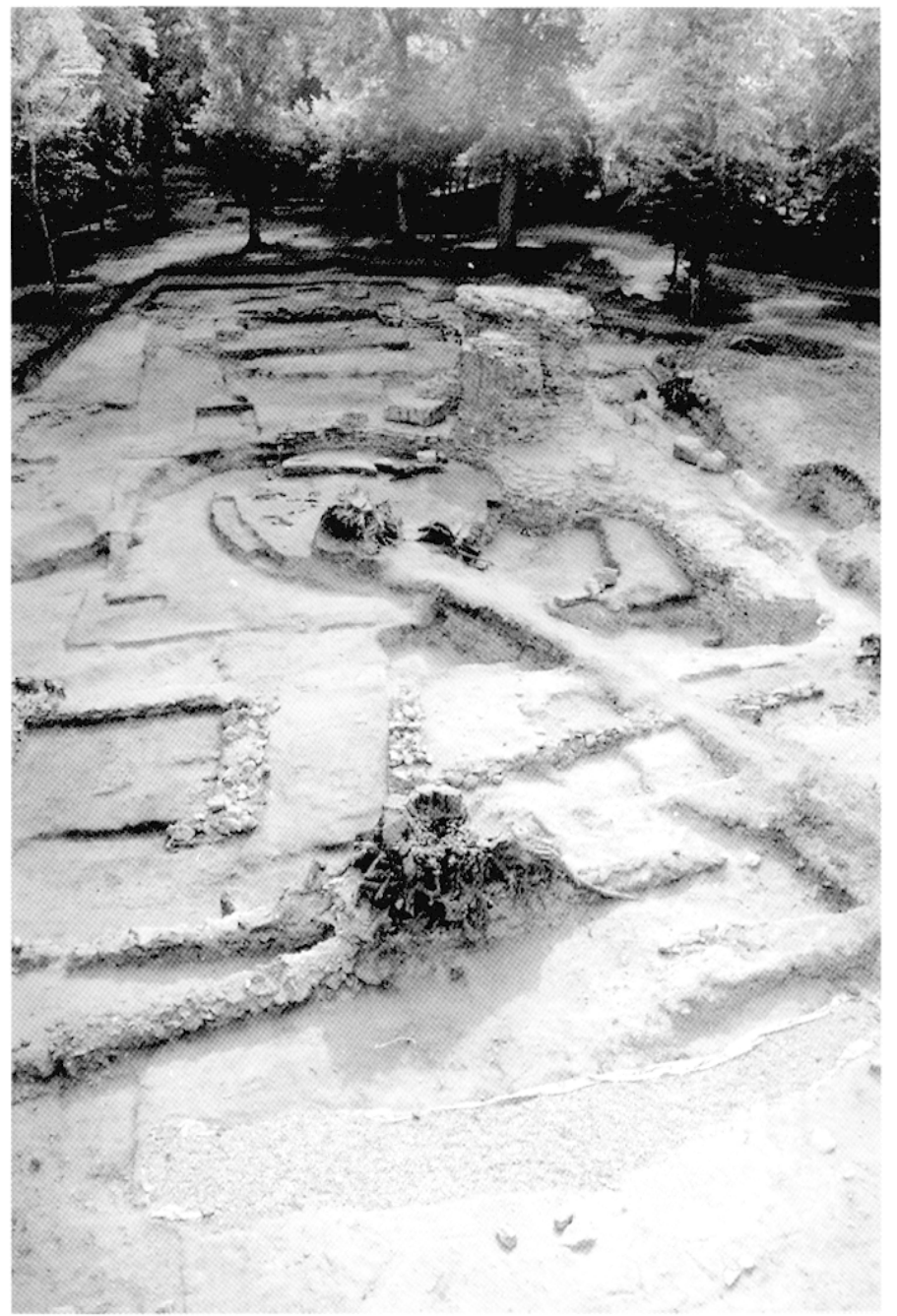

Fig. 6 - Vue générale des vestiges depuis l'ouest en 1996, au centre La Tour-aux-Fées.

\section{L'ÉVOLUTION ARCHÉOLOGIQUE DU SITE}

La construction du sanctuaire à flanc de colline a entraîné à chaque agrandissement des travaux importants de nivellement après la destruction des constructions antérieures. À l'ouest, les remblais d'horizons différents ont été perturbés à plusieurs reprises. Sous la cour et à l'extérieur de la porte nord, la fouille s'est arrètée sur les sols de construction du milieu du II $^{\circ} \mathrm{s}$. apr. J.-C.; les niveaux plus anciens semblent préservés. À l'ouest, la fouille des niveaux gaulois a débuté en 2001.

On peut donc définir dès à présent sept horizons (fig. 7 cf. pl. II hors texte).

Horizon 1 : fin du ve s. av. J.-C., La Tène A. Cette phase est connue uniquement par du mobilier résiduel en remblais.

Horizon 2a : fin du IV'-III' s. av. J.-C., La Tène B2 - début de La Tène $\mathrm{Cl}$.

Horizon 2b: $\mathrm{III}^{\mathrm{e}}-\mathrm{II}^{\mathrm{c}}$ s. av. J.-C., fin de La Tène Cl/ La Tène C2. Dans les deux phases de cet horizon, des dépôts d'armes gauloises, trouvés en remblais, sont concentrés au- dessus de structures excavées protohistoriques. Certaines monnaies dont les imitations rhodiennes peuvent ĉtre associées à cet horizon.

Horizon 3a : deuxième tiers du $\mathrm{I}^{\mathrm{cr}} \mathrm{s}$. av. J.-C., La Tène D2a, fin de l'Indépendance gauloise. Le faciès monétaire gaulois du site montre, dans la partie ouest, autour de l'édifice la, une dominante de monnaies de la fin de l'Indépendance (7050 av. J.-C.). Il n'est pas exclu que l'éventuel état a de l'édifice 1, construit en bois, dont on a localisé trois poteaux sous les fondations de l'état b, soit contemporain de ces dépôts. Cet état ne peut être précisé sans le démontage de l'édifice lb en pierre.

Horizon $3 b$ : de la conquête romaine à la fin de la période augustéenne. Le mobilier évolue peu par rapport à la période précédente en dehors de la présence de monnaies augustéennes qui sont mélangées avec le matériel gaulois dans les remblais liés à l'aménagement de l'édifice $\mathbf{l b}$.

Horizon $4: \mathrm{I}^{\mathrm{rr}}$ s. apr. J.-C., sous Tibère-Claude. L'ensemble de la zone ouest est nivelé par étalement des couches sableuses contenant du mobilier des horizons 1 à 3 . Un monument en pierre avec tour carrée et galerie (édifice 1, état b) est construit. Sa fréquentation est attestée par du matériel monétaire, des bases dédicacées à Mars Mullo. Tout lien stratigraphique entre les murs et le mobilier a disparu.

Horizon 5a : 80-90 apr. J.-C. La construction du temple (édifice 3) débute avec les travaux de gros ceuvre.

Horizon 5b : 90-110 apr. J.-C. Un remblai de construction après l'achèvement du gros œuvre du temple recouvre l'aire de travail inférieure.

Horizon 5c: 110-130 apr. J.-C. Les travaux de finition du temple (décoration en bronze, toiture, décoration architecturale) se déroulent et l'équipe d'artisans utilise l'édifice 6 pour le travail des métaux. Deux états de cet atelier sont identifiés. Une fosse-dépotoir F 507 est creusée à l'ouest de celui-ci.

Horizon 5d : 120-140 apr. J.-C. La construction du temple (édifice 3) est achevée. L'édifice 6 est démonté.

Horizon 5e : 140-160 apr. J.-C. La construction de la cour et des portiques termine l'ouvrage.

Horizon 6a : 170-début du $\mathbb{N}^{*}$ s. apr. J.-C. Le sanctuaire à quadriportique est fréquenté et une série de dédicaces sont offertes par la civitas.

Horizon 6b: milieu du Iv" s. apr. J.-C. Le sanctuaire est progressivement abandonné, fermé, puis incendié.

Horizon 7 : seconde moitié du $\mathrm{IV}^{\mathrm{t}} \mathrm{s}$. apr. J.-C. et après. Le monument est démoli et ses matériaux sont récupérés.

Cette chronologie relative et absolue extrêmement fine a pu être établie pour les étapes de la construction de l'édifice 3, car chacune d'entre elles est scellée par des remblais d'argile stérile. Les fourchettes chronologiques, fondées sur l'étude de la céramique, sont des datations extrêmes et la fouille des niveaux antérieurs au chantier de construction devra permettre d'affiner et de réduire la durée de celui-ci. En revanche, les autres périodes, bien marquées par le mobilier, sont plus difficiles à préciser sur le terrain du fait de l'histoire même du site. Cette présentation reste provisoire car certaines zones intermédiaires n'ont pas encore été fouillées ; elles pourront apporter des précisions, en particulier sur l'occupation du sanctuaire aux ${ }^{\text {er }}$ s. av. et apr. J.-C. 


\section{L'OCCUPATION GAULOISE (HORIZONS 1 À 3 A, DU Ve S. AV. J.-C. AU MILIEU DU I ${ }^{\text {er }}$ S. AV. J.-C.)}

La tradition a parfois situé, sur ce promontoire d'Allonnes, la capitale du peuple des Aulerques Cénomans, connu essentiellement par son monnayage d'or et par le témoignage de César dans la Cuerre des Gaules (VII, 75, 3). Toutefois, en dehors du sanctuaire et d'un gisement repéré en prospection au nordouest de la ville d'Allonnes, les vestiges protohistoriques sont relativement peu nombreux sur le territoire de la commune. Malgré tout, et en l'absence de fouilles sur la butte du VieuxMans, l'hypothèse d'un oppidum gaulois et d'une agglomération sous la ville moderne d'Allonnes ne peut être écartée, dans l'état actuel des recherches (Gruel et al., 2003).

Les niveaux antérieurs à l'époque romaine ont été atteints essentiellement à l'ouest de La Tour-aux-Fées (la cella circulaire du temple à podium) et à l'extérieur du sanctuaire à quadriportique, au nord; mais il reste à préciser, dans la mesure du possible, le contexte de ces découvertes afin de retracer les grandes lignes des occupations à l'époque gauloise. Le secteur situé à l'ouest du temple à podium a déjà été exploré en 1965 par P. Térouanne (Térouanne, 1967) dont la fouille a été reprise en 2001. C'est dans cette partie du site que la plupart des vestiges d'époque gauloise ont été découverts. Il est probable qu'une partie d'entre eux a été détruite lors des différentes phases de construction et d'aménagement du sanctuaire à l'époque romaine. Ces éléments résiduels sont importants pour esquisser une reconstitution des occupations antérieures. Par chance, les nouvelles recherches ont montré qu'il subsistait à l'ouest du péribole des zones encore relativement bien préservées qui s'avèrent extrêmement importantes pour la compréhension du site à l'époque gauloise.

Les différents mobiliers, composés principalement d'armes et de monnaies, ont été trouvés dans des remblais sableux scellés par le sol du portique ouest du dernier état. Les objets les plus anciens, du début du $v^{*}$ s. av. J.-C., côtoyaient les plus récents. Ces derniers peuvent être datés de la fin de l'époque gauloise ou du tout début de la période romaine. Les répartitions des armes et des monnaies semblent légèrement différentes. Les monnaies s'organisent autour de l'édifice l, le " fanum " dans son état romain ou dans un état antérieur, tandis que les armes apparaissent plus dispersées vers l'ouest et vers le nord. On arrive à établir une chronologie relative entre certaines de ces structures excavées, mais leur datation absolue reste difficile. Ces fosses sont partout scellées par ce remblai sableux, riche en mobilier laténien, recouvert d'un remblai d'argile plus ou moins épais.

\section{LES STRUCTURES}

Les structures identifiées et partiellement fouillées se composent de trous de poteau et de fosses, mais la plupart, très arasées, sont conscrvées au-dessous des sols ct attestent une fréquentation longue de cette zone : horizons $1 ?, 2$ et 3 a. Elles ont été détruites lors de l'édification du sanctuaire romain. Cinq structures ont actucllement pu être identifićes et leur

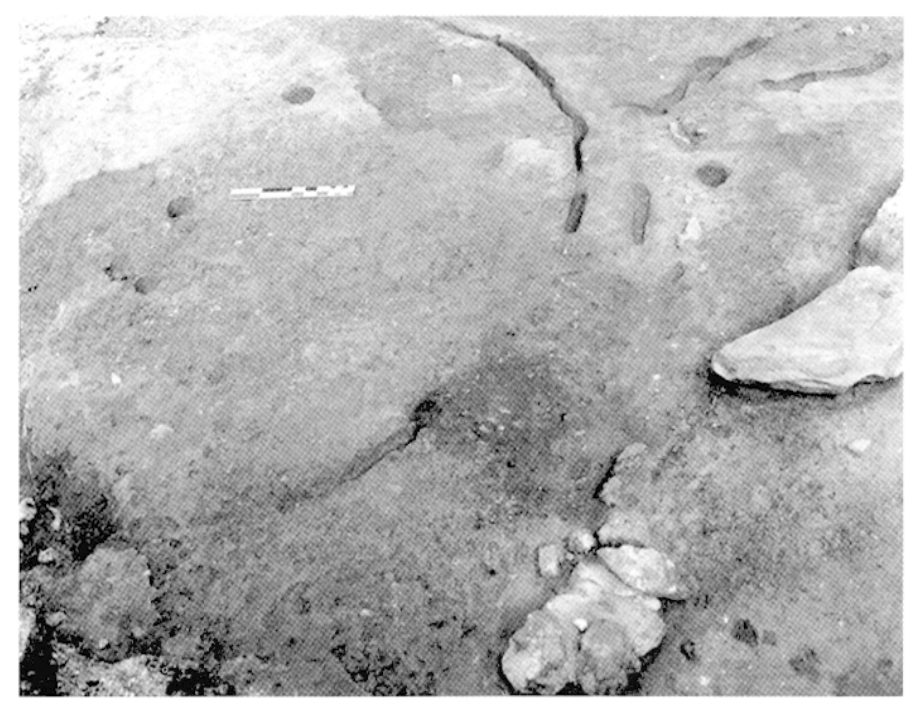

Fig. 8 - L'édifice 8 circulaire.

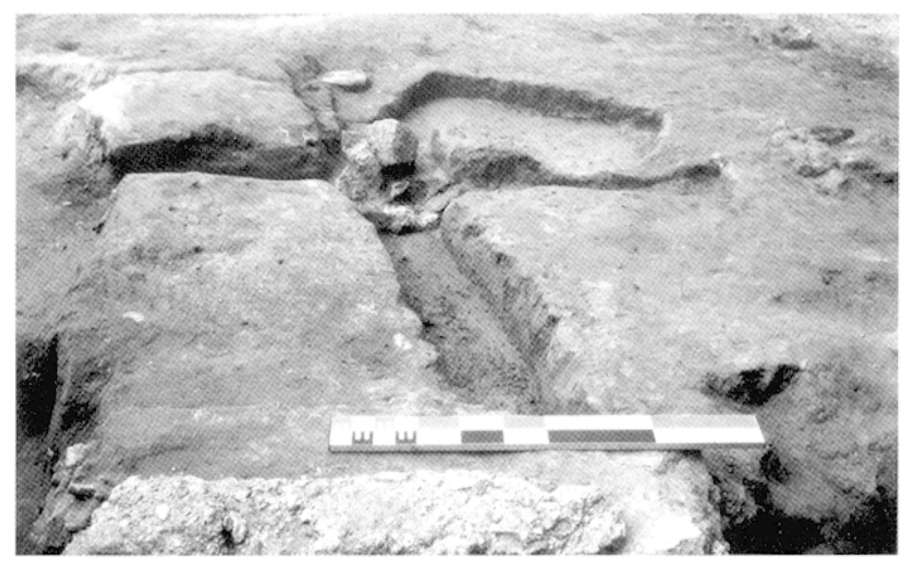

Fig. 9 - Les sablières de l'édifice 5 de La Tène D.

étude est en cours. D'autres bâtiments, de plan rectangulaire, restent à identifier.

Une palissade nord-sud (édifice 20), sur sablières et poteaux, barre la zone sur toute la longueur fouillée (environ $40 \mathrm{~m}$ ) à l'ouest du "fanum ", pratiquement sous le portique ouest, semblant marquer ainsi une limite à l'ouest. Les poteaux sont implantés tous les mètres et sont généralement un peu plus larges (30 à $40 \mathrm{~cm}$ ) que les sablières.

Une structure circulaire (édifice 8), bâtie sur un demi-cercle non détruit par la cella ronde du temple à podium, a laissé une trace au sol dans laquelle neuf trous de poteau de petites dimensions ont été identifiés (fig. 8). Son diamètre de $6 \mathrm{~m}$ est marqué en son centre par un trou de poteau, quatre autres extérieurs à l'est feraient penser à un porche. Ce bâtiment est recouvert par l'édifice 5 composé de quatre sablières qui se croisent sur un poteau solidement planté et calé. Un second poteau fixe la longueur de la sablière ouest (fig. 9).

Un bâtiment circulaire (édifice 15), de même diamètre que l'édifice 8, a été mis en évidence sous l'angle d'une structure rectangulaire sur sablière (édifice 10), vuc au nord de l'édifice 1. Il est matérialisé par une empreinte circulaire très arasée de $20 \mathrm{~cm}$ de large et, à la périphérie, par une série de 


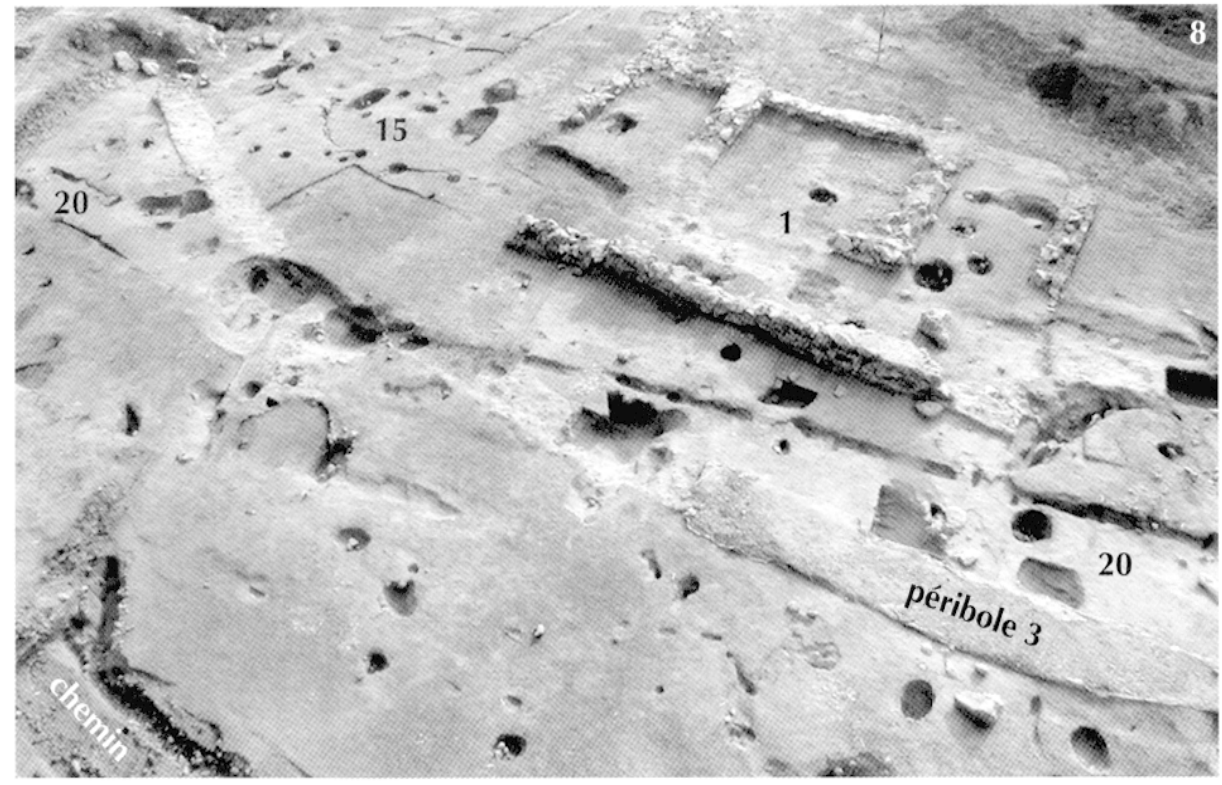

Fig. 10 - Vue générale à l'ouest en 2002 : l'édifice circulaire 15 et la palissade nord-sud 20.

potcaux disposés en un cercle concentrique au premier, avec un intervalle d'environ $1 \mathrm{~m}$ (fig. 10). À l'ouest, deux poteaux scmblent encadrer un seuil $(80 \mathrm{~cm})$.

Il apparait que ces deux structures circulaires correspondent aux niveaux les plus anciens actuellement connus. Des structures protohistoriques comparables ont été repérées sous d'autres sanctuaires comme à Hayling Island, Hampshire et Harlow près de Londres (Horne, King, 1980; King, Soffe, 1994). Cependant, leurs dimensions rappellent aussi les plans d'habitations circulaires protohistoriques de Bretagne insulaire.

\section{LE MOBILIER MÉTALLIQUE LATÉNIEN}

Le matériel d'époque gauloise provient pour l'essentiel des terres de nivellement de la zone de l'édifice 1 et de ses abords occidentaux (tabl. I). C'est dans ce secteur également qu'ont été retrouvées la plupart des monnaies gauloises et romaines d'époque républicaine. L'attribution du mobilier métallique à l'époque gauloise repose sur des considérations typologiques. Il s'agit principalement d'objets métalliques en fer puisque le bronze n'entre que pour une très faible part dans cet échantillonnage ${ }^{4}$.

I.e mobilier laténien comprend un peu plus de 150 objets dont un grand nombre fragmentaire. La catégorie la mieux représentée est de loin celle qui réunit l'ensemble des pièces d'armement. Il est probable qu'il faille ajouter à ce premier décompte les nombreux morccaux de tôles classés avec les " divers " dans la mesure où l'usage de tôles fines semble avoir été limité, à l'époque gauloise, à la fabrication des fourreaux d'épée et des umbos de bouclier. La tôle utilisée pour les bandeaux de chaudron est beaucoup plus épaisse. La prépon-

4. Les mobiliers présentés couvrent une fourchette chronologique d'environ cinq siècles. P. Térouanne y voyait le résultat d'offrandes rituelles (Biarne dir., 1974, p. 65). dérance du mobilier lié à la guerre (les armes proprement dites et les équipements associés comme le char) livre une première information sur la nature de l'occupation et rappelle à bien des égards les installations à caractère cultuel d'époque préromaine de Gournay-sur-Aronde (Oise) et Ribemont-sur-Ancre (Somme). Ce mobilier offre en outre des indications extrêmement précises pour l'étude des équipements et pour la chronologie. Les autres catégories d'objets sont documentées par un petit nombre d'individus seulement. C'est le cas notamment des fibules. La part des objets non métalliques paraît relativement faible. Il en va ainsi non seulement du verre et du lignite, mais aussi et surtout de la céramique (tabl. II).

Les objets métalliques sont le plus souvent brisés, incomplets ou en fort mauvais état. Seuls les petits objets sont parfois intacts. L'état extrêmement lacunaire des pièces s'accompagne d'une disparition quasi complète des parties organiques qui entrent dans la composition de certains assemblages (le bois des hampes de lance et des poignées d'épéc ou encore le cuir des ceintures). Si la plupart des pièces caractérisent un horizon chronologique correspondant à La Tène B2/C1 (fin IV"s.-début III s. av. J.-C.), d'autres sont datées de la fin de La Tène A (fin du ves. av. J.-C.) ou de périodes plus tardives. Pour certains objets, leur attribution chronologique est problématique dans la mesure où l'on ne dispose que très rarement de pièces

Tabl. I - Comparaison des découvertes d'époque gauloise avant et après 2001.

\begin{tabular}{|l|c|c|c|}
\hline & av. 2001 & $\mathbf{2 0 0 1}$ & Total \\
\hline fer & $\mathbf{4 8}$ & $\mathbf{7 7}$ & $\mathbf{1 2 5}$ \\
\hline bronze & 7 & 10 & 17 \\
\hline verre & 2 & 1 & 3 \\
\hline lignite & 1 & 0 & 1 \\
\hline Total & 58 & 88 & $\mathbf{1 4 6}$ \\
\hline
\end{tabular}


Tabl. II - Principales catégories d'objets laténiens présentes sur le site, en dehors des monnaies.

\begin{tabular}{|c|c|c|c|c|c|}
\hline Catégorie & Type & Partie & Nombre de restes & Sous-Totaux & Totaux \\
\hline \multirow[t]{16}{*}{ armement } & épée & lame & 12 & 69 & 146 \\
\hline & & rivet & 1 & & \\
\hline & fourreau & pontet & 5 & & \\
\hline & & bouterolle & 11 & & \\
\hline & & frette & 1 & & \\
\hline & & tôle & 23 & & \\
\hline & lance & pointe & 3 & & \\
\hline & & talon à douille & 4 & & \\
\hline & & talon à soie & 1 & & \\
\hline & flèche & & 1 & & \\
\hline & bouclier & umbo (ailette) & 1 & & \\
\hline & & rivet & 1 & & \\
\hline & & manipule & 1 & & \\
\hline & & orle & 2 & & \\
\hline & casque & paragnathide & 1 & & \\
\hline & cuirasse & cotte de mailles & 1 & & \\
\hline \multirow[t]{4}{*}{ équipement } & suspension & anneau & 5 & 8 & \\
\hline & & anneau bivalve & 1 & & \\
\hline & & anneau « 8 » & 1 & & \\
\hline & char & piton articulé & 1 & & \\
\hline \multirow[t]{5}{*}{ ustensile } & récipient & chaudron & 4 & 10 & \\
\hline & & anse de seau & 1 & & \\
\hline & & applique ornée & 3 & & \\
\hline & toilette & forces & 1 & & \\
\hline & & rasoir & 1 & & \\
\hline \multirow[t]{6}{*}{ parure } & fibule & bronze & 2 & 11 & \\
\hline & & fer & 1 & & \\
\hline & bracelet/brassard & bronze & 4 & & \\
\hline & & verre & 1 & & \\
\hline & & lignite & 1 & & \\
\hline & perles & verre & 2 & & \\
\hline \multirow[t]{3}{*}{ divers } & produit semi-fini & barre & 2 & 48 & \\
\hline & tôle/tige & & 43 & & \\
\hline & autre & & 3 & & \\
\hline
\end{tabular}

complètes. C'est le cas notamment des objets volumineux comme les épées et les fourreaux. En dépit de ces difficultés, les données devraient, à terme, permettre de mieux cerner la chronologie des mobiliers métalliques et d'esquisser une première approche de cette occupation.

\section{LE MATÉRIEL DE L'HORIZON 1 :}

\section{LA TÈne A (FIN dU Ve S. AV. J.-C.)}

La phase ancienne de La Tène est encore mal documentée. Cependant, le fait que plusieurs objets se rattachent de façon certaine à la phase récente de Ia Tène A est une nouveauté importante dans le débat sur la genèse des installations cultuelles (fig. 11).

Parmi les pièces les plus significatives se rapportant à cette période figurent deux fibules en bronze de type Marzabotto et un élément de char: piton articulé (fig. 11, $\left.\mathrm{n}^{\circ \mathrm{s}} 1,2,5\right)$. Cet accessoire, composé d'une barre articulée montée sur une tige coudée en $\mathrm{U}$, est un élément caractéristique des chars de I a Tène A, en particulier des productions de la région rhénane à Hunsrück-Eifel notamment (Verger, 1994, p. 527-531).

C'est à cette même phase ancienne qu'il faut certainement attribuer une pointe de flèche en bronze de type gréco-oriental (fig. 11, n'3). Ce type, très fréquent en Europe orientale, figure 
aussi dans le mobilier de quelques ensembles occidentaux comme I.a "Cité d'Affrique " à Messcin, en Meurthe-et-Moselle, qui a livré un abondant matériel métallique couvrant la fin du Hallstatt, La Tène A et le début de La Tène Bl (Lagadec et al., 1993). Un fragment de perle tubulaire en verre polychrome d'origine méditerranéenne $^{5}$ (fig. 11, $n^{\circ} 4$ ) (Feugère, 1989) et une possible plaque de revêtement de roue de char de type hallstattien ${ }^{6}$ complètent cet ensemble.

Si le mobilier du début de La Tène paraît discret dans la plupart des régions occidentales, cela tient sans aucun doute à la rareté des ensembles funéraires de cette période. C'est au hasard des travaux réalisés sur les habitats et les lieux de culte que l'on doit le plus souvent la découverte de ces précieux indicateurs.

\section{LE MATÉRIEL DE L'HORIZON 2A : LA TÈNE B2 ET LE DÉBUT DE LA TÈNE C1 (FIN DU IV ${ }^{e}$ S.-DÉBUT DU III ${ }^{\mathrm{e}}$ S. AV. J.-C.)}

Pour une majeure partie du IVt s. av. J.-C. (La Tène B1) les données sont inexistantes ou, tout au moins, nous ne sommes pas en mesure de les identifier. En effet, il faut attendre la fin de cette période pour trouver les indices significatifs d'une véritable fréquentation. C'est de cette époque, qui englobe d'ailleurs une partie de la phase suivante, soit le début de La Tène C1, que date la majeure partie des pièces métalliques (fig. 12 et 13). C'est le cas notamment des tronçons d'épées à section nervuréc ou losangée ainsi que de la plupart des éléments de fourreaux d'épée et de boucliers (rivet, fragments d'umbo et de manipule).

Les lames les plus ćtroites (de 28 à $40 \mathrm{~mm}$ de large) caractérisent des armes d'estoc de petite dimension comme il en existe à La Tène $\mathrm{B}$ avec les épées équipées de fourreaux à bouterolle circulaire ajourée ou type d'Hatvan Boldog (Rapin, 2000). Les extrémités de bouterolles de fourreaux donnent un nombre minimal de dix individus, un chiffre qui est loin d'être négligeable. Les deux exemplaires complets (fig. $13, \mathrm{n}^{\circ 5} 5$ et 6 ) appartiennent à des formes caractéristiques du début de La Tène $\mathrm{Cl}$ (Lejars, 1994, p. 39-47 et 55-56). Les autres évoquent des formes contemporaines ou légèrement plus anciennes comme la série des bouterolles à extrémité circulaire ajourée. Malgré la fragilité et l'état de dégradation des tôies, le nettoyage minutieux d'une partie du mobilier a permis, dans plusieurs cas, de retrouver la trace d'ornements. Ces décors incisés (des motifs curvilignes inspirés du thème des animaux fantastiques affrontés) ou estampés (ocelles et trame losangéc) caractérisent les productions de la période de transition B2-C1 (Szabó, Petres, 1992, p. 21-23 et 30-36; Lejars, 1994, p. 73-75). Si ce type d'ornement est connu par différents spécimens tant en France qu'en Europe centrale, les exemplaires d'Allonnes trouvent un parallèle immédiat dans la petite série provenant d'Aubigné-

5. Rares en Gaule non-méditerranéenne, de tels objets sont signalés en Bourgogne à Bragny-sur-Saône et en Gironde à Grayan-et-l'Hôpital dans des contextes datés de la fin du Hallstatt-début La Tène anciemne. L'usage de ces perles semble avoir perduré jusqu'au II" s. ar: J.-C.

6. Il s'agirait d'un élément de revêtement de rayon de roue analogue aux exemplaires de la Butte à Sainte-Colombe-sur-Seine en Côte-d'Or (MAN, n"18268018) et de Byci Skala en Slovaquie (Eckart Barth, 1987).
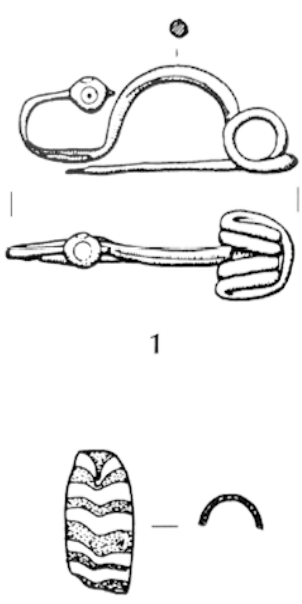

4
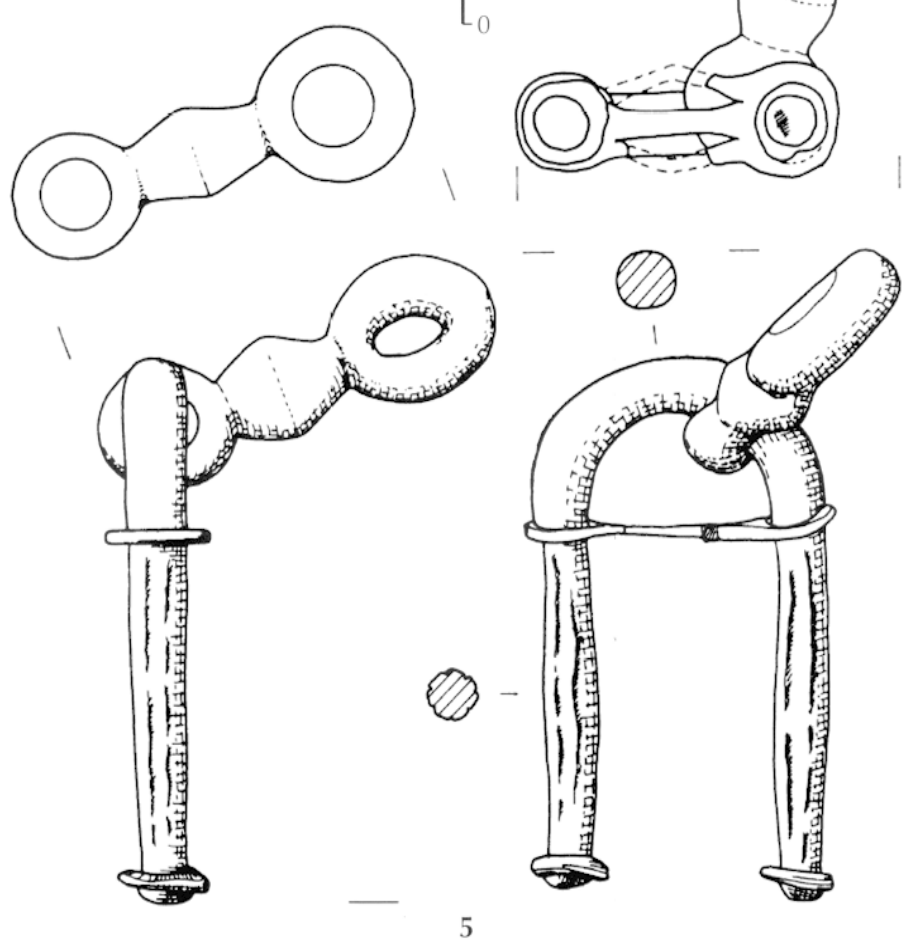

Fig. 11 - Mobilier représentatif de La Tène A : 1, 2, fibules et 3, pointe de flèche de type gréco-oriental, en bronze; 4, fragment de vase en verre sur noyau d'argile, fond bleu foncé avec décor bleu clair à gris; 5 , piton à aillet en fer.

Racan, également situé dans le territoire cénoman (Lcjars $e t$ cl., à paraître). C'est à cette même phase chronologique qu'il faut attribuer les appliques décoratives en bronze qui offrent localement un excellent aperçu des productions du "Style Plastique " (fig. 12, $\mathrm{n}^{\circ} 2$ ). Les deux pièces, initialement montées sur un même support, probablement en bois, se caractérisent par une figuration anthropomorphe d'une excellente facture. Leur morphologie donne en outre une idée de la complexité du support. Traitées en léger relief, elles se présentent l'une et l'autre comme la juxtaposition de deux esses opposées réunies par leur base. Un masque figurant deux yeux globulaires encadrant un large nez, en goutte, occupe l'espace inférieur alors que les esses dessinent au-dessus une impressionnante 


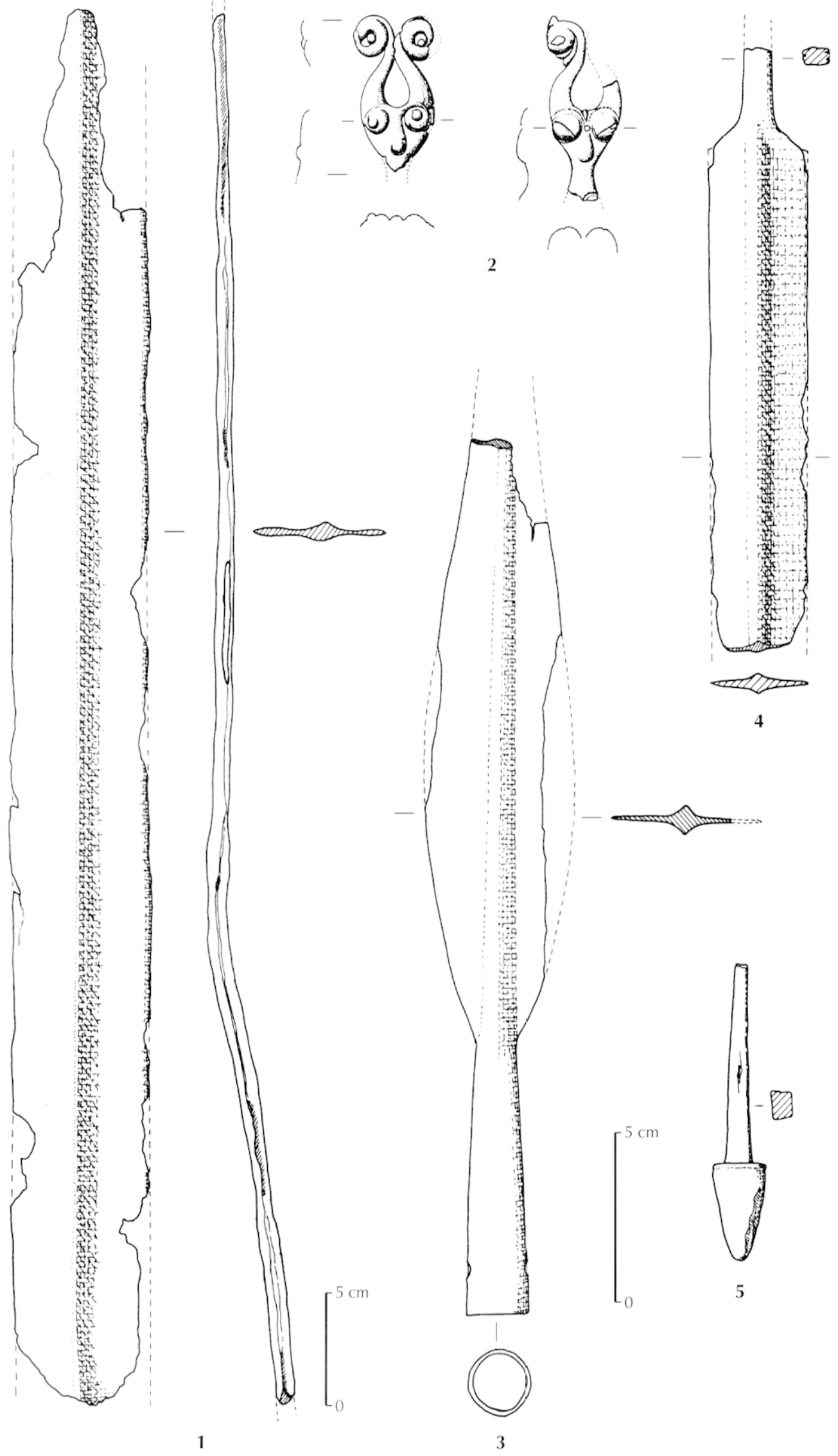

Fig. 12 - Mobilier représentatif de La Tène $B 2 / C 1$ :

1, 4, lames d'épée en fer, à nervure médiane; 2, appliques décoratives en bronze; 3, fer de lance; 5 , talon à soie en fer. 

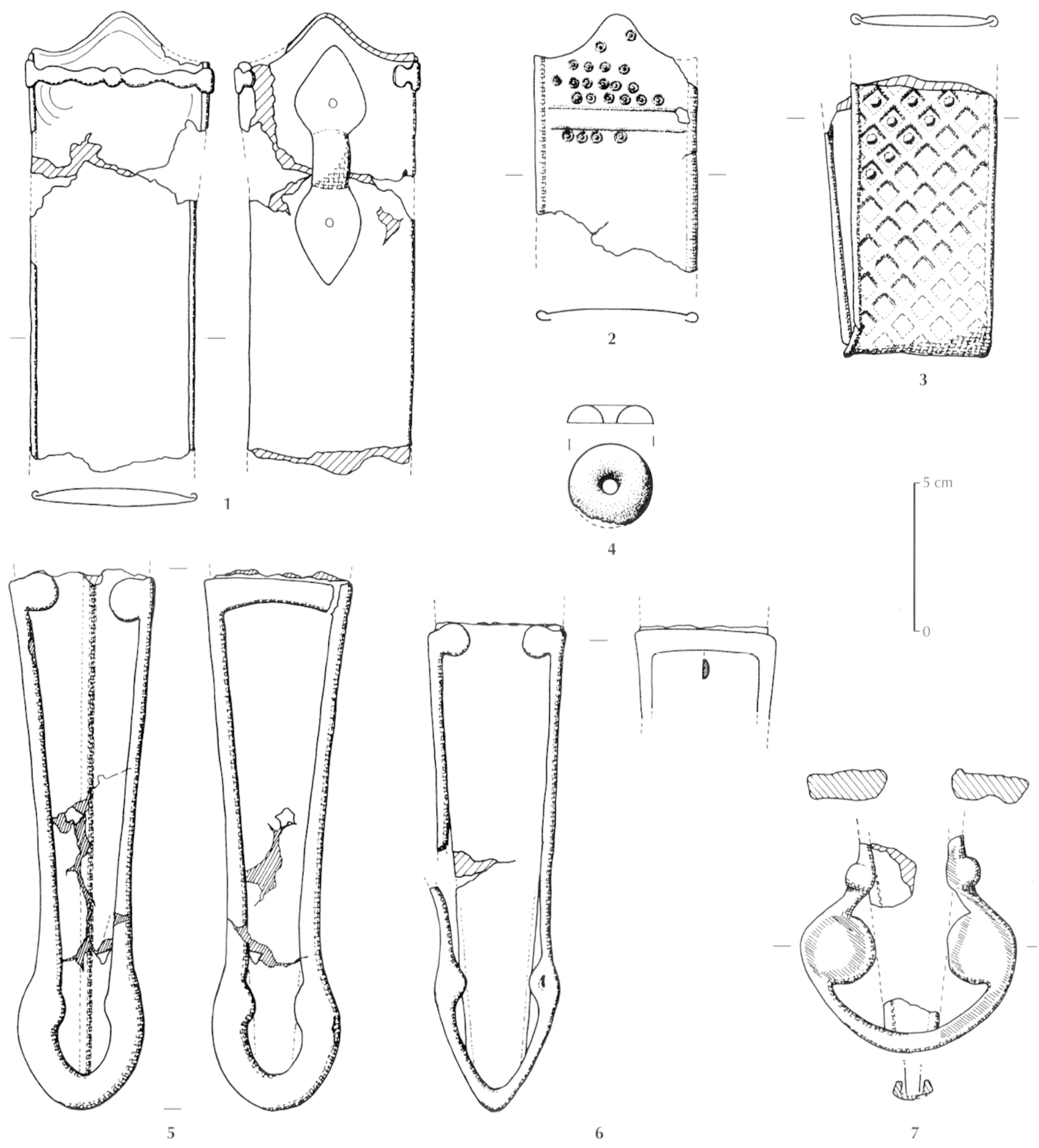

Fig. 13 - Mobilier représentatif de La Tène $B 2 / C 1$ :

1-3, 5-7, fourreaux d'épée en fer; 4, coque d'anneau bivalve en tôle de bronze. 


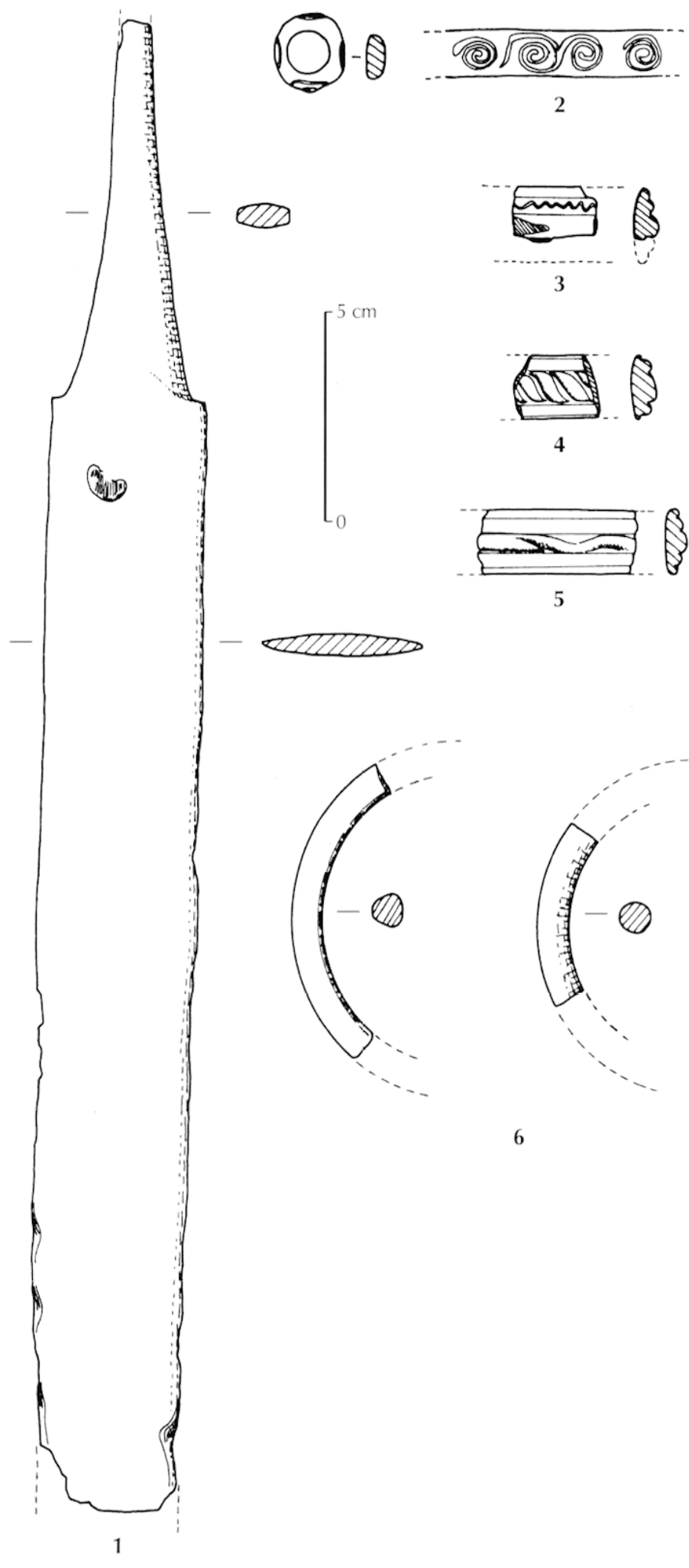

Fig. 14 - Mobilier représentatif de La Tène $(: 1 / C 2: 1$, lame d'épée en fer avec marque estampée près de la garde; 2 , perle en verre bleu à décor spiralé blanc; 3-5, fragmenis de bracelets en verre (verre bleu avec décor à fil jaune, verre bleu et verre transparent à fond jaune) ; 6, fragments d'anneaux de bras en lignite. coiffe avec ses deux volutes jointives. Un appendice supplémentaire prolongeait initialement les deux pièces sous le visage. Une différence dans l'expression des visages permet cependant de comprendre à quel point ces deux éléments disjoints sont complémentaires. Alors que le premier est représenté les yeux grands ouverts (la bossette centrale saillante dessinant la pupille), le second se singularise par des yeux clos (signalés par deux incisions obliques convergentes). Le dessin du nez et les sourcils sont également traités différemment sur les deux pièces. Ce type d'objet évoque, par le traitement des volumes et les thèmes figurés, certaines réalisations majeures du «Style Plastique " qui marque, à la fin de La Tène ancienne et au début de la période suivante, une étape importante du développement de l'art celtique. Parmi les comparaisons, les appliques en bronze de la cruche de Brno-Malomerice en Moravie (Meduna, 1991), ou celles de la nécropole du Dürrnberg en Autriche (Moosleitner et al., 1974, pl. 48, tombe 44: La Tène $\mathrm{A}$ ), retiendront plus particulièrement l'attention. De plus, le traitement des masques avec leurs larges volutes déployées au-dessus de la tête peut être rapproché de certaines œuvres réalisées à la cire perdue comme les garnitures de chars ou encore l'agrafe de ceinture de Loisy-sur-Marne, en Champagne (Roualet, Charpy, 1991, p. 265-266). Il est également important d'insister sur cette opposition récurrente dans l'expression des visages (yeux clos-yeux ouverts) qui se retrouve de la même façon sur la cruche morave et les nombreuses pièces en bronze des chars de Roissy dans le Val-d'Oise (fouille T. Lejars, inédit), et de Mezek, en Bulgarie (Fol, 1991).

\section{LE MATÉRIEL DE L'HORIZON 2B : FIN de La Tène C1 eT La TÈne C2 (SECONDE MOITIÉ DU III ${ }^{\mathrm{e}}$ S.-MILIEU DU II ${ }^{\mathrm{e}}$ S. AV. J.-C.)}

La fin de La Tène Cl et la période suivante occupent dans cet ensemble une place encore mal définie dans la mesure où le mobilier métallique de nature militaire est peu représenté (fig. 14, $\mathrm{n}^{\circ} \mathrm{l}$ ). Il faut cependant signaler la présence de deux fragments proximaux d'épée caractérisés par une section lenticulaire. La forme très évasée, presque triangulaire, de la soie de l'une des épées incite à la dater du II $^{*}$ s. av. J.-C., comme le suggère par ailleurs la marque d'une estampille, malheureusement illisible, située quelques centimètres sous la garde. Ce type d'empreintes, parfois qualifiées de marques de fabrique, est une des caractéristiques des productions de la Tène ('2. Si les éléments de parure sont plutôt rares et souvent incomplets, les productions en verre (fig. 14, $n^{\circ \times} 2-5$ ) et en lignite (fig. 14, $n^{\circ} 6$ ) se rapportent pour l'essenticl à cette phase. Il s'agit de perles en verre bleu, avec parfois un décor spiralé blanc ou jaunc, et d'anneaux de bras en verre jaune ou bleu.

\section{LE MATÉRIEL DE L'HORIZON 3A : LA TĖNE D (SECONDE MOITIÉ DU II ${ }^{\mathrm{e}}$ S.-MILIEU DU I ${ }^{\mathrm{er}}$ S. AV. J.-C.)}

La période qui précède la mise en place du sanctuaire augustéen est celle qui fournit le moins d'objets métalliques, à l'exception des monnaies qui apparaissent en nombre. Les témoignages de cette période se limitent en effet à un fragment 

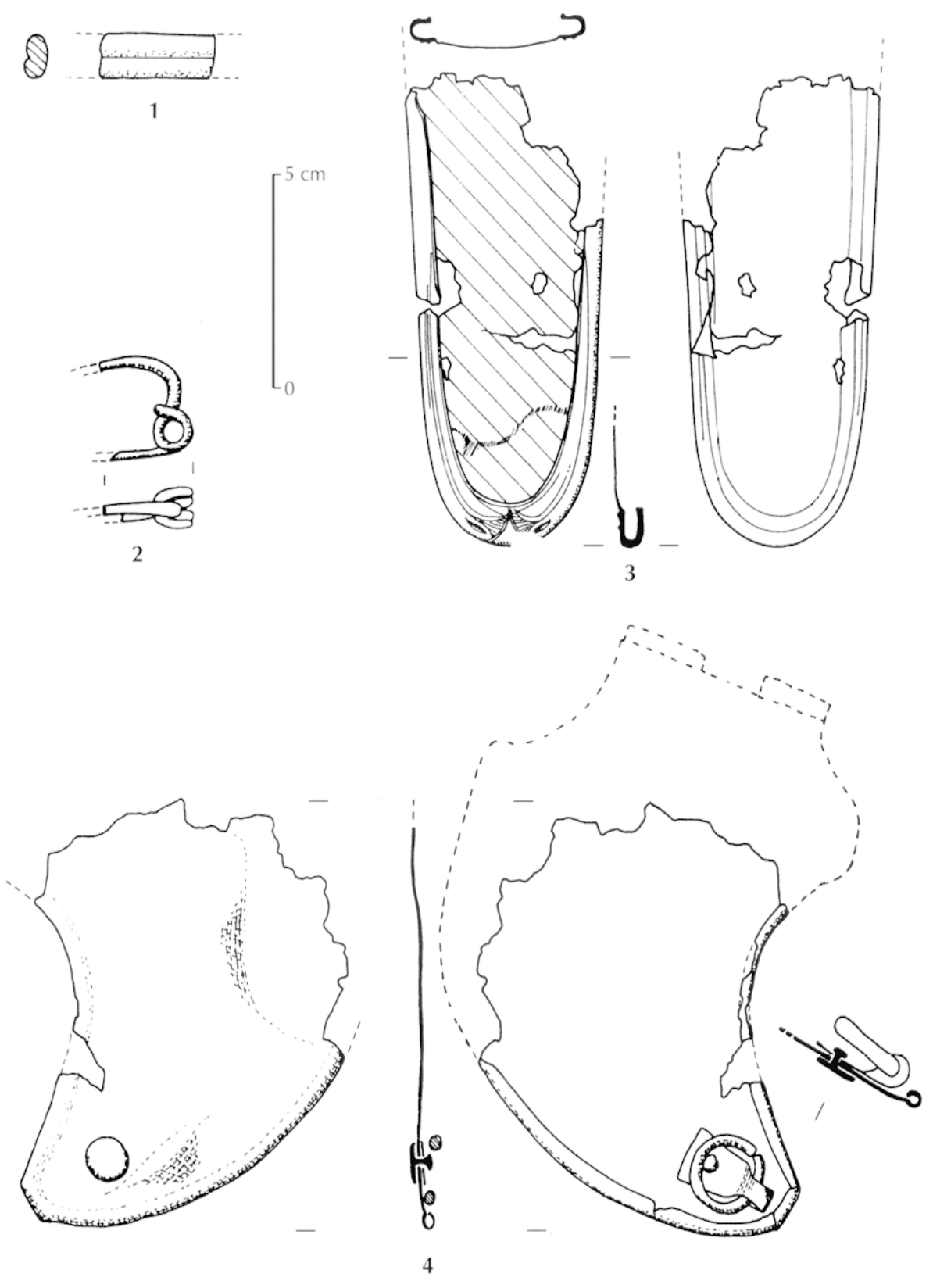

Fig. 15 - Mobilier représentatif de La Tène $D: 1$, fragment de bracelet en verre de couleur vert clair; 2, fibule en fer à arc outrepassé; 3, extrémité de fourreau d'épée en bronze; 4, fragment de paragnathide de casque en fer:

de fibule en fer à arc outrepassé et un bracelet en verre (fig. 15, $\mathrm{n}^{\mathrm{os}} 1$ et 2 ).

L'essentiel des monnaies gauloises et romaines antérieures à l'époque augustéenne a été trouvé dans la même zone que le mobilier métallique, à l'ouest de La Tour-aux-Fées, à proximité de l'édifice 1, tant par P. Térouanne entre 1955 et 1979 que par notre équipe en 1995 et 2001. Elles sont particulièrement concentrées autour de cet édifice, au nord, au sud et surtout à l'ouest de la galerie, dans les niveaux sableux sur lesquels reposent les fondations de son état b. Sur les 541 monnaies de cet ensemble, 314 sont des potins à tête diabolique (fig. 16, $\mathrm{n}^{\mathrm{O}} 1$ ), 51 sont des pièces d'argent à la tête casquée et au carnyx attribuables aux Aulerques Cénomans (fig. 16, $\mathrm{n}^{\text {os }} 2$ ), 2 des statères (fig. $16, n^{\text {os }} 3$ ) et 2 des quarts de statères en or allié, au personnage allongé sous le cheval ailé, monnayage d'or classique de la cité gauloise ${ }^{7}$ (Aubin, 1994 et 1997). Les drachmes et les petits billons au carnyx circulent dans les sanctuaircs de Mars Mullo d'Allonncs, d'Oisscau-lc-Petit (nord de la Sarthe), d'Aunou-sur-Orne et de Montchevrel (Orne) ${ }^{8}$. On

7. Un statère et un quart de statère proviennent des fouilles Térouanne, le deuxième quart de statère a étć trouvé durant les dernières fouilles, un statère vient d'un pillage du site au détecteur en 2001, tous deux dans la zone ouest. Quatre monnaies d'or sur le site, c'est plus que sur le sanctuaire d'Aubigné-Racan (Sarthe), autant que sur celui de Juvigné (Mayenne) et autant que sur l'ensemble des autres sites du Mans et des alentours d'après l'inventaire de G. Aubin, 1994 et 1997. GTA = grosse tête, type A (cf. Gruel, Geiser, 1995).

8. Étude des monnaies de l'Orne en cours, K. Gruel ; fouilles d'Aunousur-Orne, T. Lejars (inédit). 


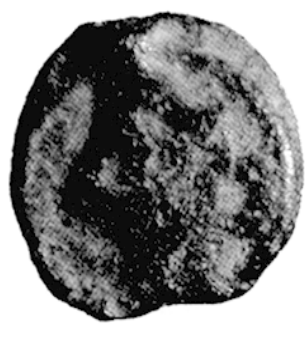

a

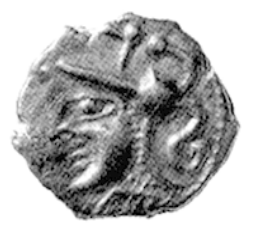

a

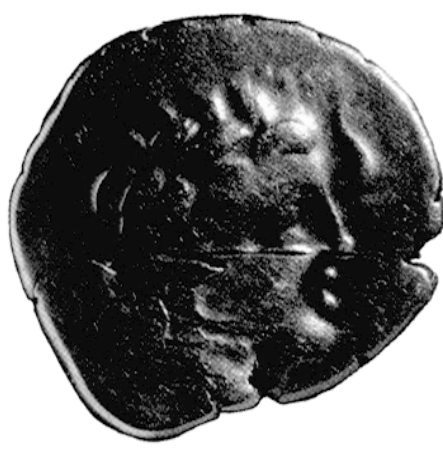

a

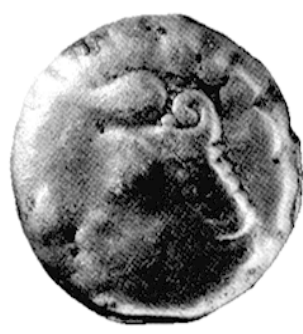

a

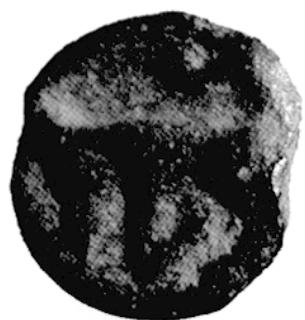

b

1

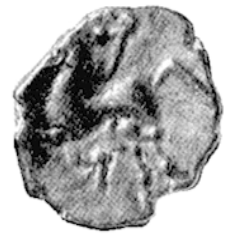

b

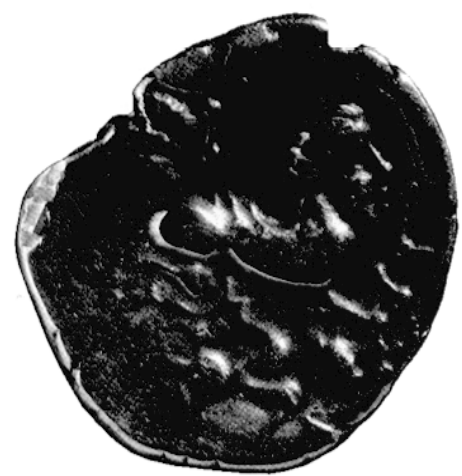

b

3

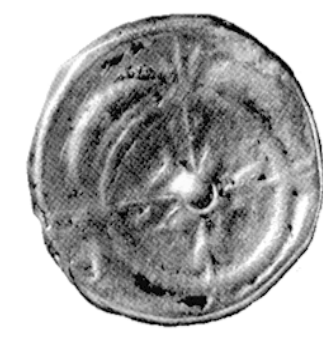

b
4

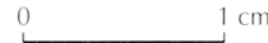

Fig. 16 - Monnaies antérieures à l'époque romaine: 1 , potin à la tête diabolique; 2 , petit billon cénoman à la tête casquée et au carnyx; 3, statère en or des Aulerques Cénomans; 4, imitation d'une drachme de Rhodé ( $a$, droil ; b, revers).

date actuellement leur émission de la fin de l'Indépendance gauloise et plus probablement du début de la conquêtc romaine, dans les amnées 40-30 av. J.-C. (Gruel, Taccoën, 1992, p. 170-174). Les potins du reste de la Gaule restent rares: on compte 1 potin à la grosse tête (GTA), 1 potin au triskèle (LT 2935) et 1 potin à la tête d'indien et au cheval (IT 7417). Cependant, l'émission de l'ensemble de ces séries de potins débute à La Tène $\mathrm{D} 1$ et leur circulation continue à La Tène D2. Les cités voisines sont peu représentées à l'exception des Carnutes (13 pièces) et des Aulerques Éburovices ( 5 pièces). Les bronzes frappés viennent essentiellement de Gaule belgique et du territoire carnute. I.es statères armoricains sont sous-représentés.

Le faciès monétaire gaulois du sanctuaire de Mars Mullo est atypique sur plusieurs points (Aubin, Meissonier, 1994 ; Gruel, à paraître c). Même si ce faciès se caractérise par une dominante locale indiscutable de petits billons armoricains de type cénoman et une masse de potins à la tête diabolique (Barthélemy, 1995), le sanctuaire recevait du numéraire d'argent venant de beaucoup plus loin, dont des drachmes et des oboles de Marseille, des drachmes de Rhodé " (fig. 16, n4) en Espagne et leurs imitations. De ces deux provenances monétaires extrêmes convergent deux routes, l'une par la Loire et le centre-ouest de la Gaule, l'autre par le centre-est, la Saône et la Loire, jalonnées par les peuples émetteurs des pièces offertes dans le sanctuaire de Mars Mullo. À l'est du Massif central, on notera les Voconces, les Allobroges, les Éduens, les Séquanes, les Ségusiaves et les Carnutes. De l'ouest de la Gaule viennent les pièces lémovices, pictones et bituriges. On remarque en particulier un nombre non négligeable de monnaies, d'une part, des Bituriges Cubi et des Éduens et, d'autre part, des Séquanes. Ces deux ensembles monétaires en argent sont composés en majorité de types à la tête casquée et d'une quinzaine de pièces au nom des chefs mentionnés par César. On s’interroge de plus en plus sur une éventuelle fonction militaire de ce numéraire (fig. 17).

Ces monnaies, émises pour la majeure partie d'entre elles à la fin de l'Indépendance gauloise, ont connu une diffusion particulière qui pourrait être liée aux déplacements de troupes auxiliaires romaines payées en deniers gaulois (Gruel, à paraître a). Les quelques deniers républicains associés datent des années 50-30 av. J.-C.; ce sont en partie des deniers de légions ( $V^{\mathrm{re}}$ et $\mathrm{XI}^{\mathrm{e}}$ légions de Marc-Antoine, denier de César à l'éléphant). Seuls, un denier de C. Fundanius, émis en 101 av. J.-C., et un de L. Flaminius Chilo, émis en 109 av. J.-C., trouvés dans les niveaux sableux, ont pu parvenir dans le sanctuaire avant la conquête romaine. Dix des onze monnaies républicaines sont en argent (deniers et quinaires), mais la plupart viennent d'un contexte tardif.

Les quelque 150 objets métalliques identifiés et ces 541 monnaies, appartenant à différentes phases de l'époque gauloise, donnent l'impression d'un assemblage hétéroclite. Il s'agit en effet des restes épars d'ensembles perturbés et remaniés lors du nivellement du sol pour l'édification de l'édifice $1 b$.

9. Leur dispersion sur le site exclut tout trésor unique. I a présence dans le nord de la Gaule de ces monnaies de Rhodé (comptoir grec d'Espagne) reste exceptionnclle, on en connaî unc à l.evoux, chez les Bituriges. I.es émissions des drachmes de Rhodé à la rose s’arrêtent au III" s. av. J.-C. La datation de leurs imitations demeure tres incertaine. L. Villaronga (1986 et 1994) les place juste après leur prototype (III" s.début II" s.), mais la tendance est plutôt de les dater du I" s. av. J.-C., en raison de leur présence dans des trésors en association avec des monnaies à la croix (Saves, 1976, p. 24-35). 
une moindre mesure, des fragments d'épées, de lances et un umbo à ailettes rectangulaires hautes et à gros rivets hémisphériques.

Les récipients (seaux et chaudrons) et les ustensiles liés à la consommation de la viande (broches, fourchettes et crocs à viande) présents à Allonnes et Aubignć-Racan sont également attestés dans la plupart des dépôts, dont Saint-Jean-Trolimon, Auverse en Maine-et-Loire, (inédit), Nalliers en Vendée (Lejars, 1989), Naintré dans la Vienne (inédit) et Muron en CharenteMaritime ${ }^{10}$. Il en va de même des produits semi-finis ou barres, qu'il s'agisse de currency bars ou de "barres à douille ». Les garnitures de chars, qui figurent en différents lieux comme Saint-Jean-Trolimon et Saumeray en Eure-et-Loir (Lejars, à paraître) sont en revanche absentes du dépôt d'AubignéRacan dont on n'a qu'une vision extrêmement partielle. Ce type de mobilier, même s'il n'est jamais très abondant, caractérise certains ensembles exceptionnels comme le Massenfund de Tiefenau en Suisse (Müller, 1990) ou encore certains dépôts en milieu humide comme le site éponyme de La Tène en Suisse (Vouga, 1923) ou celui de Llyn Cerrig Bach, au Pays de Galles ${ }^{11}$.

Les analogies avec l'ensemble de Tronoën en Saint-JeanTrolimon ne se limitent pas au mobilier, mais concernent aussi la chronologie des dépôts. L'examen de la documentation de Saint-Jean, bien qu'elle soit ancienne et fort incomplète, permet de déceler un étalement relativement important dans le temps. Si certaines pièces se rapportent indiscutablement à La Tène moyenne (La Tène Cl : chaînes de ceinture et certains talons de lance massifs avec soie), l'essentiel du mobilier peut être attribué à une époque nettement antérieure couvrant la majeure partie du IV" s. et le début du III $^{c}$ s. av. J.-C. La totalité des fourreaux et des épées (nervurées et effilées) et la plupart des fers de lance appartiennent à cette phase ancienne. Le casque et les débris de tôle de bronze ornés, datés du début du $\mathrm{IV}^{\mathrm{e}}$ s. av. J.-C., confirment l'importance du mobilier ancien au sein de cet ensemble. Les fibules, quant à elles, appartiennent aussi bien à La Tène $\mathrm{C}$ qu'à La Tène $\mathrm{B}$ (arc de fibule de type Dux), voire pour quelques exemplaires à La Tène $A$.

Le mobilier d'Allonnes, comme celui d'Aubigné-Racan, est composé d'objets ruinés de différentes époques, abandonnés sans ordre dans un remblai sableux, nivelé lors de l'édification de l'édifice $1 \mathrm{~b}$. L'absence de trace organique minéralisée confirme le caractère résiduel de ce mobilier.

\section{LE SANCTUAIRE DE MARS MULLO AU DÉBUT DE L'ÉPOQUE ROMAINE (HORIZONS 3B ET 4, L'EMPIRE JULIO- CLAUDIEN, DU I ${ }^{\text {er }}$ S. AV. J.-C. AU I I ${ }^{\text {er }}$ S. APR. J.-C.)}

Le plan de l'édifice 1, associé aux découvertes de bases de statue du dieu Mars Mullo, confirme l'identification certaine du site comme sanctuaire, au moins à partir de cette période.

10. Fouille J. Gomez de Soto et T. L.jars.

11. Ce site, comme celui de La Tène, a livré plusieurs barres de fer (Fox, 1946).

\section{L'ÉDIFICE 1 (HORIZONS 3 ET 4)}

Au nord-ouest des ruines de La Tour-aux-Fées, un temple du type dit à la tour (édifice lb) présente un plan carré avec une galerie externe de $11,70 \mathrm{~m}$ de côté et une cella de $5,80 \mathrm{~m}$ de côté hors tout $(4,10 \mathrm{~m}$ intérieur). Le mur de la cella, en grès éocène, fondé plus profondément, est plus large $(0,85 \mathrm{~m})$ que celui de la galerie $(0,65 \mathrm{~m})$ : on peut restituer une élévation plus haute de la cella par rapport à la galerie (horizon 4 : fig. 18 et 19). Le mortier de type MS 5 employé dans les murs de l'édifice lb est caractéristique des structures primitives du site ; la qualité du matériau est moyenne, avec un mortier de faible tenue, poreux, riche en éléments fins (limons quartzeux) et en grumeaux de chaux. Une monnaie de Claude (AL-05.95.1595) découverte sur le sol est l'un des rares témoins de la fréquentation de cet état $b$ de l'édifice 1 .

Un premier état (a), construit en bois, selon le même plan, semble avoir précédé cet édifice. De ce premier état très arasé subsistent une fosse à l'intérieur de la cella et deux trous de poteau, parfaitement circulaires, de $0,70 \mathrm{~m}$ de diamètre, faiblement creusés dans le substrat (Cénomanien). Ces trous de poteau, placés à égale distance des angles de la cella de l'état $b$, sont recoupés par le mur ouest de celle-ci ${ }^{12}$. Les remblais sableux contenant des monnaies gauloises de la fin de l'Indépendance et du début de l'occupation romaine et un peu de mobilier céramique scellent l'état a (horizon $3 \mathrm{~b}$ ). Il semble donc que la construction ou reconstruction (état b) du " fanum " soit à l'origine d'un premier nivellement des couches argilo-sableuses contenant du mobilier protohistorique dans cette zone ouest.

\section{LE MATÉRIEL DE L'HORIZON 3B (DE LA CONQUÊTE ROMAINE À LA FIN DE LA PÉRIODE AUGUSTÉENNE)}

La phase comprise entre la conquête romaine et la fin de la période augustéenne est assez mal documentée. La vaisselle céramique caractéristique de cette période est quasiment inexistante. Une extrémité de fourreau d'épée en bronze d'un type peu commun appartient à cette phase tardive, entre La Tène D2 et l'époque augustéenne (fig. 15, $\mathrm{n}^{\circ} 3$ ). Il ne s'agit pas d'une bouterolle à proprement parler mais d'une extrémité de fourreau avec gouttière intégrée. Ce type d'étui, qui fonctionne à la manière d'un plumier, a été comparé à certaines armes trouvées dans les Îles britanniques. En Gaule même, deux exemplaires sont connus, le premier provient des dragages de la Saône (Bonnamour dir., 1990, p. 82), tandis que le second avait été déposé dans une riche tombe augustéenne, à Fléré-laRivière dans l'Indre (Ferdière, Villard, 1993, p. 58-61).

Deux pièces de l'équipement défensif, un fragment de cotte de mailles et une paragnathide de casque en fer, se distinguent

12. Les fondations des murs nord et sud de la cella et de la galerie de l'état b de l'édifice 1 sont conservées sur quelques assises. Le mur ouest de la cella est en négatif, le mur oriental a été détruit par les constructions postérieures. L'état b du " fanum " étant classé, il n'a pas pu ĉtre démonté. lec plan d'un état a antérieur est donc très lacunaire. 


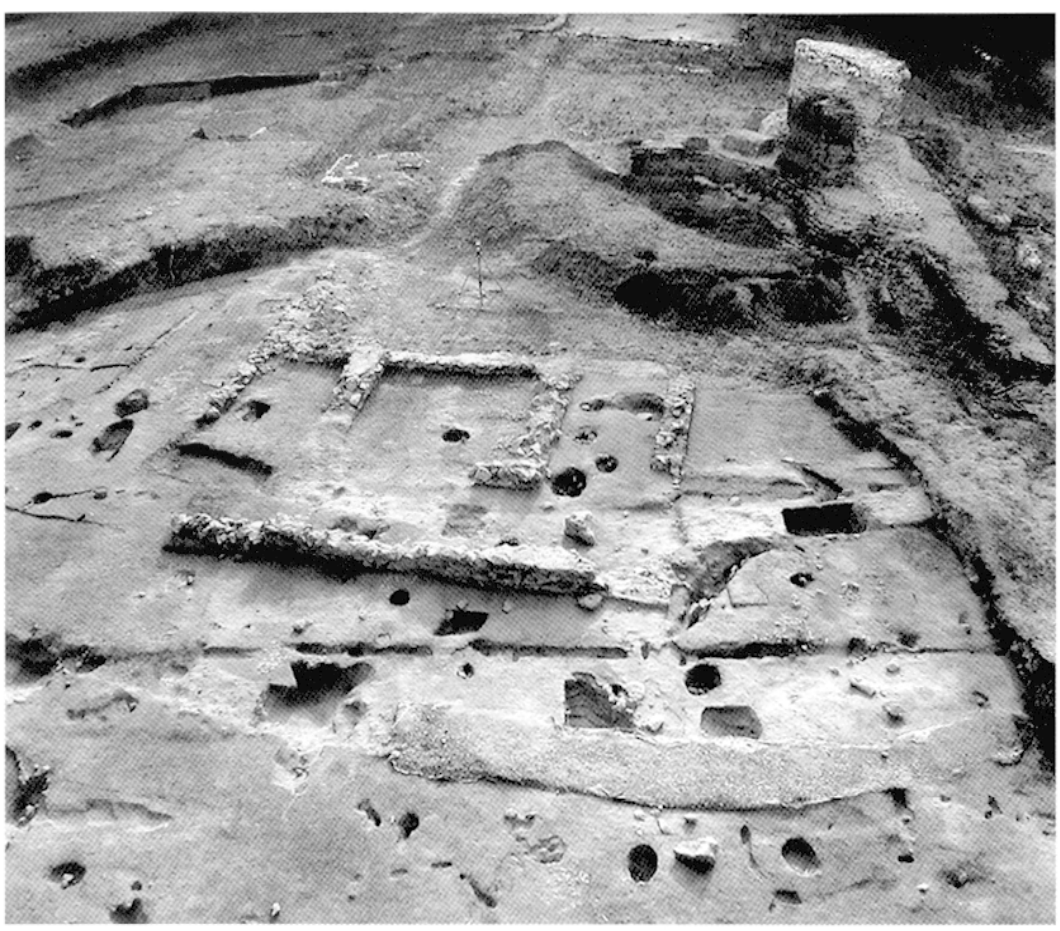

Fig. 18 - L'édifice 1 vu de l'ouest.

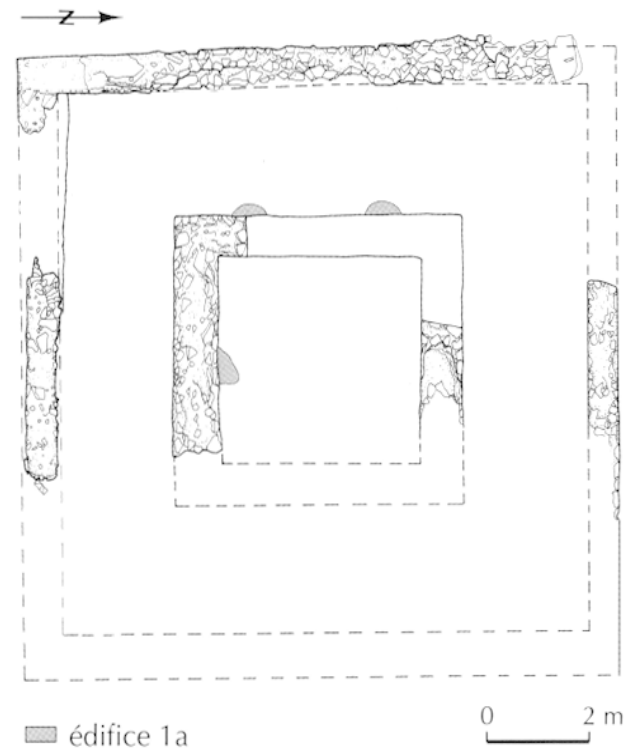

Fig. 19 - États a et b de l'édifice 1 (horizons 3 et 4). des réalisations de la fin de l'époque gauloise (casques de type Port ou Alésia) et s'apparentent davantage aux spécimens du début de la période romaine ${ }^{13}$ (fig. $15, \mathrm{n}^{\prime \prime} 4$ ). Même s’il est difficile d'attribuer ce dernicr fragment à un type précis, il y a de fortes chances pour que nous ayons affaire dans ce cas précis à une pièce romaine apparentée au type de Weisenau. La nature de la corrosion, différente de celle des pièces gauloises, semble également confirmer cette attribution. Ces casques qui apparaissent très tôt (dès l'époque augustéenne) sont utilisés pendant presque toute la période romaine. Les trois fragments de cotte de mailles conservés appartiennent très certainement à une même pièce, constituée d'anneaux en fer, d'environ $10 \mathrm{~mm}$ de diamètre, fermés au moyen de petits rivets. Ce type de protection, attesté dès le $\mathrm{IV}^{*}$ s. av. J.-C. par de nombreux exemples parfaitement documentés, a connu également une grande diffusion à l'époque romaine.

L.e nombre de monnaies de bronze augustéennes est nettement plus faible que sur d'autres sites de l'ouest de la France. En revanche, 3 deniers d'Auguste et 4 quinaires augustéens sont frappés à Pergane (1), Éphèse (2) et Emerita (1). Avec 43 monnaies augustéennes dont seulement 7 bronzes de Nîmes (Gard) et 2 monnaies au premier type de Lyon (Rhône), le pourcentage des monnaies augustéennes du site est nettement inférieur (11\%) aux proportions relevées dans des villes de l'ouest de la Gaule fondées par Auguste comme Rennes et Corseul (Côtes-d'Armor) : 25 à $30 \%$ (Besombes, 2001, p. 209), ou dans d'autres sites plus au sud: plus de $30 \%$ à Niort (Hiernard, 1984, p. 74) et plus de $50 \%$ à Roanne (Rémy, 1985, p. 58).

13. Waurick, 1988. Pour les formes celtiques tardives, voir Schaaff, 1988.

\section{LE MATÉRIEL DE L'HORIZON 4 (I ${ }^{\text {er }}$ S. APR. J.-C.)}

\section{LES MONNAIES}

Ce n'est qu'avec les émissions de la fin du règne d'Auguste que le bronze romain parvient à s'imposer, ce qui se manifeste par la présence de 21 monnaies du deuxième type de Lyon (frappées entre 10 et 15 apr. J.-C.), dont 15 semis. À partir de Claude, le sanctuaire connaît un approvisionnement régulier en numéraire romain. La présence de 14 monnaies de cet empereur est supérieure à la moyenne habituellement observée. Cela dénote une richesse particulière du sanctuaire sous le règne des empereurs qui ont succédé à Auguste. Le processus de romanisation du numéraire, perçu à la fin du règne d'Auguste, se parachève sous les règnes de ses successeurs. 55 monnaies (14,6\% de l'ensemble) vont de Tibère à Domitien, soit une quantité supérieure aux frappes augustéennes. Cette supériorité numérique est notable puisque, dans de nombreux sites, une chute du nombre de monnaies est observée après le règne d'Auguste ${ }^{14}$. Deux explications relatives à cette hausse peuvent être avancées : la romanisation $\mathrm{du}$ numéraire ainsi que le développement du temple julioclaudien, parallèlement à l'expansion que connaît alors la ville de Vindinum.

14. À Rennes et Corseul (Côtes-d’Armor), le monnayage augustéen est presque trois fois plus représenté que celui du reste du $\mathrm{I}^{\mathrm{er}} \mathrm{s}$. En revanche, le faciès du sanctuaire de Jublains est similaire à celui du sanctuaire de Mars Mullo, même si le faible échantillon de monnaies du $\mathrm{I}^{\mathrm{er}}$ s. à Jublains apparaît peu significatif (Aubin, 1997 ; Besombes, 2001, p. 209). 
L'apport de monnaies se poursuit de façon régulière de Tibère aux Flaviens pour parvenir à un pic à la fin du $\mathrm{I}^{\mathrm{er}}$ s., sous les règnes de Domitien et Nerva (respectivement 14 et 5 monnaies). La fermeture de l'atelier lyonnais sous le règne de Vespasien n'a donc pas eu de conséquences sur l'approvisionnement du sanctuaire. I es 5 monnaies correspondant au règne de Nerva constituent une proportion assez exceptionnelle pour ce court règne.

Cette analyse de l'évolution de la pénétration du numéraire romain sur le sanctuaire de Mars Mullo fournit un indice pour identifier l'empereur mentionné dans les dédicaces au dieu comme étant Caligula ou Claude.

\section{LES DÉDICACES À MARS MULLO}

À ces monnaies julio-claudiennes et à l'édifice $1 \mathrm{~b}$ doivent être associées des bases inscrites découvertes dans le remblai de construction de l'abside du portique ouest par $\mathrm{P}$. Térouanne. Deux bases et un bloc donnent le nom de la divinité honorée, Mars Mullo. Élevées par des personnalités privées, elles furent, lors de la reconstruction de sanctuaire, scellées dans le remblai (horizon $5 \mathrm{~b}$ ), sous le sol de la galerie centrale du portique ouest.

Inscription $\mathbf{n}^{\circ} \mathbf{1}=\operatorname{ILTG}, 343^{15}$ (inv. AL.05.54-79.24). Découverte en 1959, " sous une des terrasses, à l'ouest de la tour ", c'est-à-dire sous le sol de l'abside du portique ouest, au voisinage du premier temple carré. Base cylindrique en calcaire coquillier, avec base et couronnement moulurés. Face supérieure plate et restauréc, avec une mortaise $(7 \mathrm{~cm} \mathrm{x} 4 \mathrm{~cm}$ $\mathrm{x} 10 \mathrm{~cm}$ ) et une trace de scellement. Champ épigraphique aménagé dans un cartouche rectangulaire en saillie $(43 \mathrm{~cm}$ x $32 \mathrm{~cm}$ ), lui-même entouré d'une mouluration (fig. 20, n*1). Dimensions : haut. : 91 ; diam. : 46 (base) ; champ épigraphique : haut. : 20,5 ; larg. : 31,5 ; haut.d.1. 1. 1-2 : 3,6 ; 1. $3-4: 3,1$ à 3,3 . Lettres étroites, d'une gravure peu monumentale et de taille irrégulière (en particulier 1. 3-4). E très étroits et dont la barre centrale est aussi longue que les autres, $R$ à boucle très haute (mais à barre inférieure incurvée), $\mathrm{L}$ à barre horizontale très courte, $\mathrm{C}$ et $\mathrm{S}$ très longilignes, $\mathrm{O}$ assez irréguliers, $\mathrm{V}$ dissymétrique l. 3 (mais pas l. 2 et 4). T et I longs à la fin des l. 1 et 2. Pas de ponctuation visible. Mise en page peu satisfaisante, avec une 1. 2 commençant au bord du champ épigraphique, mais présentant un vacat à droite ; 1 . 1 et, dans une moindre mesure, 3 et 4 centrées.

\section{Aug(usto) et \\ Marti Mulloni \\ Crescens, seruos \\ publicus, l(ibens) m(erito).}

"À Auguste et à Mars Mullo Crescens, esclave public (a élevé ce monument) de son bon gré et à bon droit."

Crescens est un nom très courant, pour les esclaves comme pour l'ensemble de la population : 88 affranchis ou esclaves

15. Térouanne, 1960 , p. $185-187$ et fig. $3-4(A E, 1960,319$ a) ; Wuilleumier, 1961, p. 56 et photo ( $A E, 1961,158)$; Duval P.-M., 1961, p. 377 ; Aubin dir., 1980, $\mathrm{n}^{\circ} 1$; (hastagnol, $1980=1995 \mathrm{~b}$, p. 32 ; Fishwick, 1991, p. 444, n. 40 ; Chastagnol, 1995a, p. 600 et 605. pour 919 hommes libres (Kajanto, 1965, p. 234) ; Mócsi recense trois exemples en Lyonnaise et un en Aquitaine, qui est précisément un esclave (Mócsi et al., 1983, p. 92 ; CIL, XIII, 796 : Bordeaux). On ne connaît d'autre esclave public en Gaule qu'à Langres, chez les Lingons (CIL, XIII, 5694-5696 ; Lazzaro, 1993, p. 140-141 et 405-407). On peut dater cette inscription non pas du vivant d'Auguste, comme le voulait P. Wuilleumier, mais plutôt " entre Claude et Hadrien ", datation proposée pour ce formulaire par A. Chastagnol, selon lequel l'emploi d'Augustus pour désigner l'empereur régnant n'apparaît qu'avec Vespasien (ou peut-être Claude). Selon cet auteur, l'inscription pourrait être légèrement postérieure à la base $n^{\circ} 2$, mais se situe encore dans le cours du $\mathrm{l}^{\mathrm{cr}} \mathrm{s}$.

Inscription $\mathrm{n}^{\circ} \mathbf{2}=I L T G, 345^{16}$ (inv. AL.05.54-79.25). Découverte en 1959, au même endroit que la base $n^{\circ} 1$. Base parallélépipédique en calcaire tendre local (tuffeau), avec base et couronnement moulurés, ce dernier presque complètement arasé. Face supérieure aplatie dans sa partie antérieure sur une quinzaine de centimètres, endommagée dans sa partie postérieure, qui devait former une sorte de socle, partiellement conservé à gauche sur une hauteur de 2 ou $3 \mathrm{~cm}$ et dans lequel subsiste un important scellement en plomb de forme ovale $(8,5 \mathrm{~cm} \times 4,5 \mathrm{~cm})$. La face postérieure est polie, ainsi que les deux côtés latéraux. La moulure inférieure de la base a été écornée dans sa partie droite (fig. $20, \mathrm{n}^{\circ} 2$ ). Dimensions : haut. : 96 ; larg. : 55 (dé : 40 à 39) ; ép. : 47,5 (dé : 34 à 32) ; champ épigraphique : haut. : 71,5 ; larg. : 40 à 39 ; haut.d.1. : 1. 1-2 : 5,1; 1. $3: 4,7$; l. $4-5: 4$. Belles lettres, hautes, étroites et de forme plutôt ancienne, avec des $\mathrm{R}$ à barre presque droite, des $\mathrm{V}$ dissymétriques, un peu plus ouverts à gauche, des $\mathrm{E}$ et des $\mathrm{F}$ dont la barre centrale est aussi longue que les autres; empattements très réduits, voire inexistants. Pas de ponctuation visible. Ligatures I. 1 (MA et $\mathrm{ON}$, avec $\mathrm{N}$ dans le $\mathrm{O}$ ). T plus haut à la l. 2. L. 4 centrée, en caractères plus petits et très proche de la 1.3 (interligne de $0,7 \mathrm{~cm}$ ).

Marti Mulloni

et diuo Aug(usto)

Seuerus Nigri

filius)

u(olum) s(oluit) l(ibens) $m$ (erito).

" À Mars Mullo et à Auguste divinisé Seuerus, fils de Niger, s'est acquitté de son vœu, de bon gré et à bon droit. "

L. 1: Mullon(i), Térouanne; Mulloni, Wuilleumier et $A E$; peut-être une trace de haste verticale dans la cassure.

Le dédicant, Seuerus, est un pérégrin, dont le père, Niger, porte comme lui un nom unique. Ces deux noms sont très courants, en Gaule comme dans l'ensemble de l'Empire (Kajanto, 1965, p. 256-257 et 228 ; Mócsi et al., 1983, p. 264 et 201), et on trouve à Saintes un ou deux exemples analogues où Niger se figure de la même façon dans une filiation pérégrine (IIA, Santons, 55 = CIL, XIII, 1087 et peut-être $I I A$, Santons, 38 $=I I T G, 152)$. La datation se place au $\mathrm{I}^{\mathrm{tr}} \mathrm{s}$., peut-être dès le règne

16. Térouanne, 1960, p. 185 et fig. $1-2(A E, 1960,319$ b) ; Wuilleumier, 1961, p. 57 et photo $(A E, 1961,158)$; Duval P.-M., 1961, p. 377 ; Aubin dir., 1980, n' 2; (Chastagnol, $1980=1995$ b, p. 32 ; Raepsact-Charlier, 1993, p. 21, n. 74 ; Chastagnol, 1995a, p. 600 et 605. 


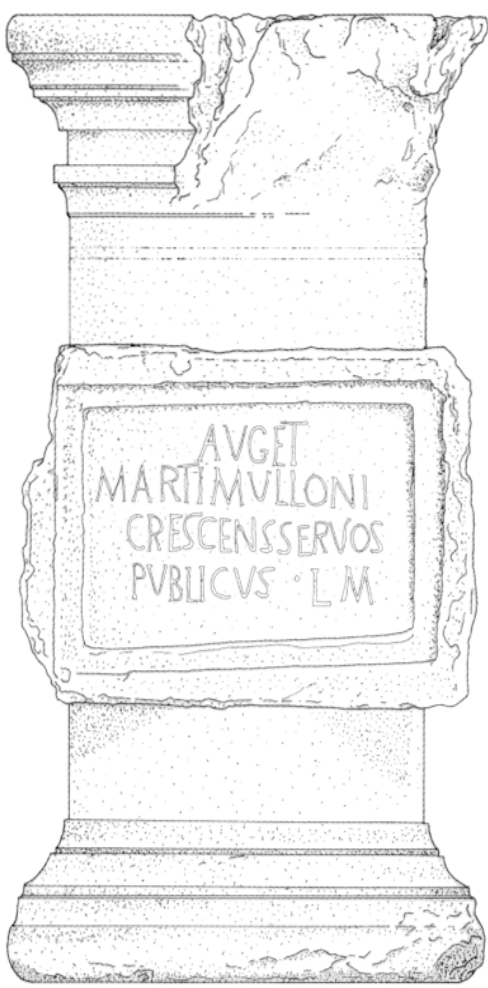

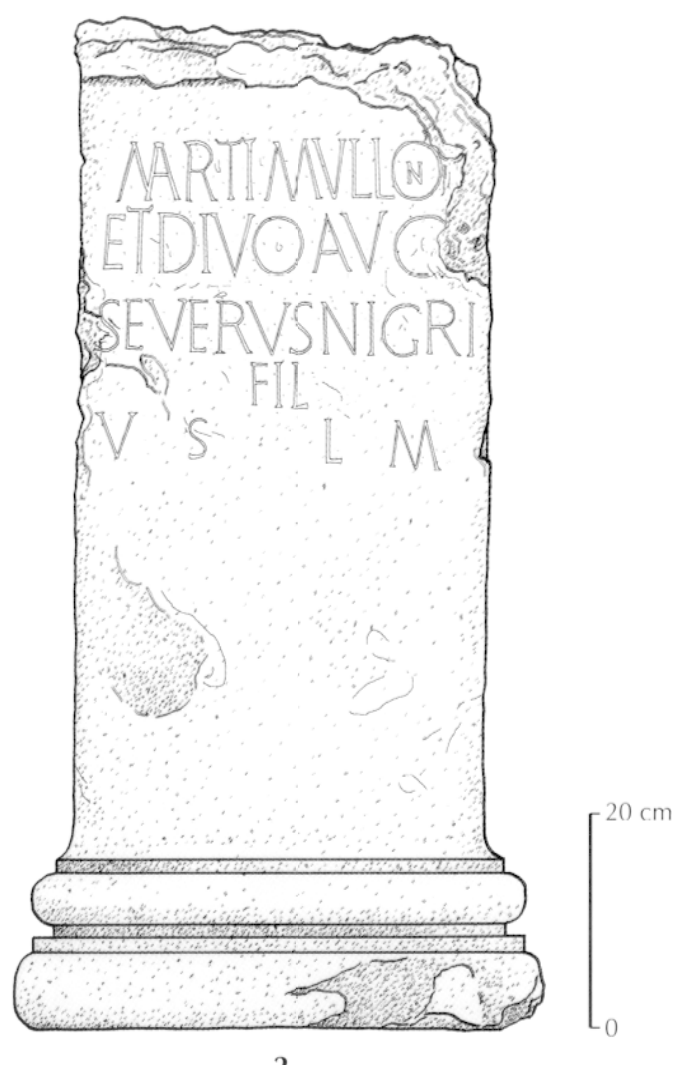

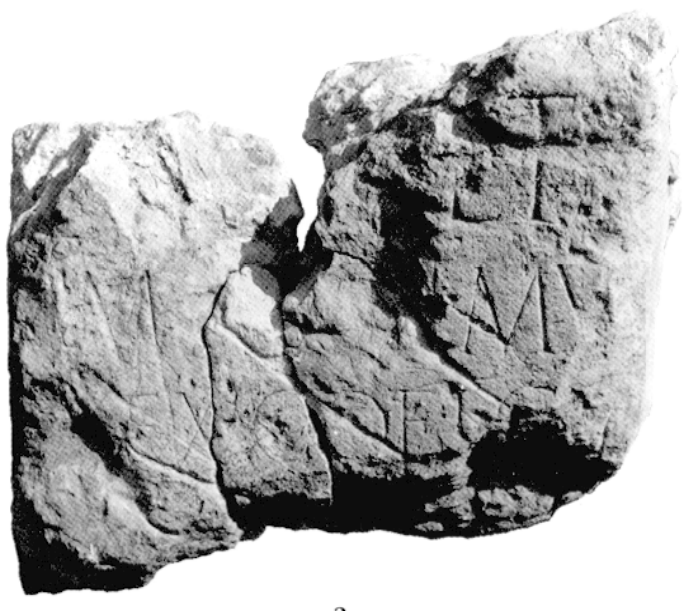

Fig. 20 - Dédicaces à Mars Mullo.

de Claude, selon A. Chastagnol, qui se fonde sur l'analogie avec la dédicace du théâtre de Feurs (CIL, XIII, 1642) ; cette date un peu haute pourrait être confortée par la paléographie, plutôt ancienne.

Inscription $\mathrm{n}^{\circ} \mathbf{3}=\operatorname{ILTG}, 344^{17}$ (inv: AL.05.54-79.114). Découverte en 1959, au même endroit que la base $n^{\circ} 1$. Fragments de tuffeau provenant d'un bloc portant d'un côté un relief représentant un homme (ou un dieu) tenant une lance et de l'autre une inscription très endommagée (fig. 20, $\mathrm{n}^{\circ} 3$ ). Dimensions : haut. : 19 ; larg. : 33 ; ép. : 38 ; champ épigra-

17. Térouanne, 1960, p. 187 et fig. 5 ( $A E, 1960,319$ c) ; Wuilleumier, 1961, p. 57 (AE, 1961, 158) ; Duval P.-M., 1961, p. 377 ; Chastagnol, $1980=1995$ b, p. 32 ; Fishwick, 1991, p. 444, n. 40 ; Chastagnol, 1995a, p. 600 et 605 . phique : haut. : 19 ; larg. : 33 ; haut.d.l. : 5 à 3 . Belles lettres, larges, régulières et bien gravées, avec empattements.

$$
\begin{aligned}
& \text { [---] et } \\
& \text { M[art ?] Mu[l(loni)] } \\
& \text { [S]ex(tus ?) COEIC } \\
& \text {...... }
\end{aligned}
$$

"...et à Mars Mullo [S]ex(tus) Coeic[ius ?] ... "

L. 3 : ex c(onsulto ?) dei $C$ (Wuilleumier). Après $\mathrm{CO}$, on peut hésiter entre $\mathrm{E}$ et $\mathrm{F}$, puis entre I ou, éventuellement, L, la dernière lettre conservée étant sûrement un C.

La formule ex c(onsulto) dei, surtout avec une aussi forte abréviation, est sans parallèles et paraît invraisemblable. Il faut chercher là plutôt le nom d'un dédicant, peut-être, comme l'a suggéré M. Christol, [S]ex(tus) Coeic[ius ?] ou Cofic[ius ?], ou encore Coel(ius) C(aii) lf(ilius) ?] ; une onomastique pérégrine, 
comme dans les deux autres bases, ne peut être complètement exclue, mais paraît moins probable, en raison de l'abréviation du prénom [S]ex(tus). Là encore, on peut proposer une datation dans la seconde moitié du $1^{\text {er }}$ s., un peu après la base $n^{\circ} 2$, selon A. Chastagnol (voir base $n^{\circ} 1$ ) ; au plus tard au début du II $^{e} s$.

\section{LE PROGRAMME DE RECONSTRUCTION DU SANCTUAIRE (HORIZONS 4 ET 5 , 90-160 APR. J.-C.)}

\section{LE PROGRAMME}

La construction d'un nouveau complexe religieux sur le modèle des vastes sanctuaires à quadriportique de l'Urbs est programmée dès la fin du ${ }^{\mathrm{rr}} \mathrm{s}$. apr. J.-C. (fig. $21 \mathrm{cf}$. pl. III hors texte). Le projet adopte des caractéristiques architecturales de l'époque flavienne avec l'aménagement d'exèdres le long des portiques selon le plan du temple de la Paix à Rome et repris dans plusieurs provinces de l'Empire romain (Ribemont-surAncre, Corseul, Le Cigognier à Avenches en Gaule belgique, sanctuaire de Bagnols à Alba en Ardèche, Itálica en Bétique) ${ }^{18}$. Le plan du temple se rapproche des édifices sur podium à pronaos et à cella circulaire qui forment une série bien représentée dans l'ouest de la Gaule, de la Garonne à la Sarthe (Bost, Girardy dir., sous presse), dont l'origine remonte au temple anonyme $\mathrm{B}$ du Largo Argentina à Rome (Tardy, sous presse a) ou au panthéon de Rome (Gros, 1996, p. 184). Les proportions de La Tour-auxFées d'Allonnes sont plus restreintes que les édifices de Barzan (Basalo, 1944; Aupert dir., 1997) et de La Tour de Vésone à Périgueux (Lauffray, 1990). Le quadriportique forme à l'ouest une abside encadrant le temple, plan emprunté à des monuments augustéens toujours visibles au $\mathrm{II}^{\mathrm{e}} \mathrm{s}$., en particulier la Maison Carrée de Nîmes (Amy, Gros, 1979).

Un temple sur podium, à cella circulaire en forme de tour, est édifié à l'intérieur d'une vaste cour ( $80 \mathrm{~m}$ sur 82 à $92 \mathrm{~m}$, soit une superficie de $7185 \mathrm{~m}^{2}$ ) bordée d'un quadriportique (112 m estouest sur $98 \mathrm{~m}$ nord-sud), précédé d'un portique de façade à l'est et rythmé par six exèdres rectangulaires ou quadrangulaires et deux pavillons d'angle à l'est. Plusieurs aménagements dont une fontaine hexagonale et des bases d'offrandes ou de statues sont placés sur l'axe privilégié est-ouest ou de part et d'autre de l'axe nord-sud. Orienté à l'est, le temple est partiellement engagé dans l'espace semi-circulaire à l'ouest de la cour sur $5 \mathrm{~m}$, mais il ne s'intègre pas dans la galerie de l'abside du portique ouest comme à Avenches ou à Corseul ; il en est distant de $2 \mathrm{~m}$. Il est placé à égale distance des portiques nord et sud $(33,90 \mathrm{~m}$ ) et à $54,90 \mathrm{~m}$ du portique oriental (fig. $22 \mathrm{cf}$. pl. IV hors texte, fig. 23 et fig. 24). Le temple a été repoussé sur le côté ouest afin de ménager une grande cour, comme cela semble être la règle dans ces vastes sanctuaires de Gaule, aussi bien ceux du I $\mathrm{I}^{\mathrm{Tr}} \mathrm{s}$. en Narbonnaise que ccux de la seconde moitié du II $^{\circ}$ s. apr. J.-C. en Aquitaine, en Gaule lyonnaise ou en Gaule belgique.

18. Gros, 1996, p. 165, fig. 188 et p. 215-216, fig. 256 ; Brunaux dir., 1999 et Brunaux, 2000 ; Formigé, 1944 et Provost, 1999 ; Bridel, 1982 ; Dupraz, 2000 ; León, 1988 ; Brouquier-Reddé, Gruel, à paraitre.

\section{SA MISE EN GEUVRE : LE CHANTIER DE CONSTRUCTION DU TEMPLE À PODIUM}

La topographie du site a contribué à la conservation des différentes étapes de construction du temple à podium et des bâtiments périphériques. C'est un exemple exceptionnel de vestiges de chantier de construction, à l'image de ceux représentés sur les reliefs et sur les peintures murales, en particulier à la villa San Marco à Stabies ${ }^{19}$. La fouille extensive et la stratigraphie observée autour du temple, sous le radier de la cour, permettent de retracer cette campagne de construction que nous décrirons d'après les résultats de la fouille effectuée au nord du temple (fig. $25 \mathrm{cf}$. pl. V hors texte). Le mobilier de ce chantier donne des références chronologiques pour préciser les dates de commencement du programme et des différentes étapes qui s'étendent sur une durée de 70 ans. Il est probable que le chantier a pu se dérouler sur un laps de temps plus court, d'après le témoignage épigraphique de grands travaux similaires à Rome qui ont duré entre cinq et sept ans. Dans l'état actuel des recherches, il n'a pas été possible de réduire ces fourchettes. Le temple a été construit en premier pour faciliter l'acheminement des matériaux depuis la Sarthe en suivant la pente de la butte des Fondues. Les portiques sont élevés dans un deuxième temps, comme le montre la fondation du stylobate du portique ouest (horizon 5e) qui coupe l'aire de travail supérieure (horizon 5c) liée aux travaux de second œuvre du temple ${ }^{20}$ (fig. 26).

\section{LA CONSTRUCTION DU TEMPLE : LE GROS GEUVE (HORIZON 5A, 80-90 APR. J.-C.)}

Après la destruction des structures antérieures, en particulier le temple sans podium (édifice lb), des déchets de taille en grès roussard attestent la mise en cuuvre d'une nouvelle construction. Une première aire de travail très épaisse, parsemée de déchets de taille de tuffeau, s'étend le long du côté nord du temple et suit la pente du terrain vers le nord (fig. 27 et 28). Des blocs en grand appareil sont abandonnés à $6 \mathrm{~m}$ du podium du nouveau temple (édifice 3) : ce sont des surplus ou des blocs mal taillés? (fig. 29). Un bloc trapézoïdal destiné à la cella circulaire présente l'ébauche des trous de scellement (fig. $30, \mathrm{n}^{\circ} 1$ ). Il s'agit là des vestiges du chantier de gros ocuvre, daté entre 80 et 90 apr. J.-C. Cette datation devra être affinéc par la fouille des niveaux sous l'aire de travail.

\section{Les matériaux de l'architecture monumentale}

Le grès roussard est extrait à proximité de l'agglomération antique d'Allonnes; il sert essentiellement au parement en petit appareil de la cella circulaire du temple et des murs du quadriportique. Les autres types de grès (grès éocène et grès cénomanien et à sabalites) sont des roches géologiques du promontoire bordant la vallée de la Sarthe. Difficiles à tailler, ces roches dures sont utilisées dans les fondations. Elles permettent de stabiliser le

19. ACS 65532. Adam, Varène, 1980 ; Barbet, Miniero, 1999, p. 176-177, fig. 389.

20. Cet ordere de construction a été observé dans d'autres sanctuaires et en particulier à Ribemont-sur-Ancre (Brunaux dir., 1999 et V. Brouquier-Reddé, fouille 2001 inédite). 


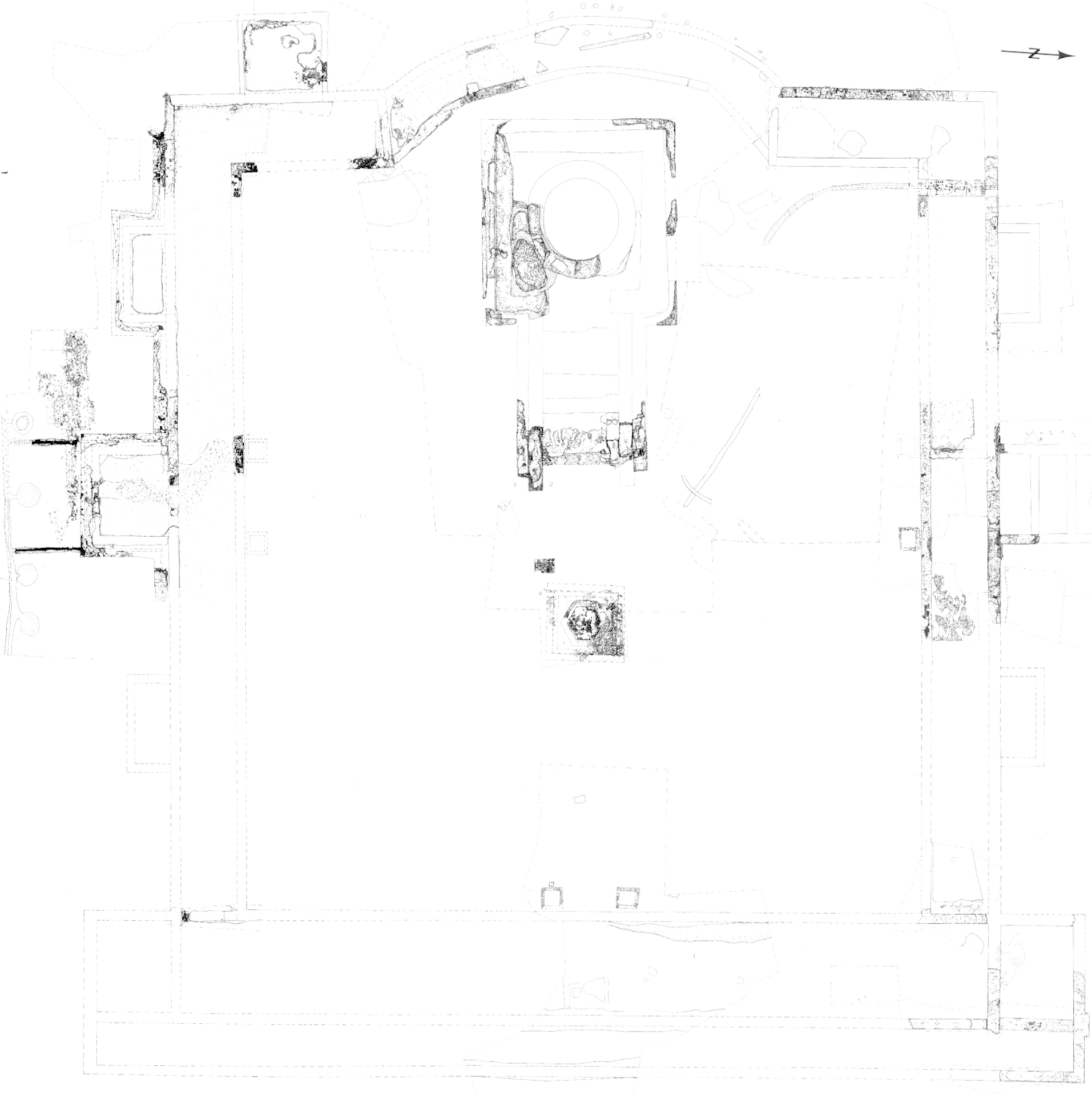

Fig. 23 - Plan architectural du sanctuaire de Mars Mullo (édifice 3, horizon 5).

terrain (niveaux sableux et argileux) et de supporter ainsi des structures hautes. Les calcaires à éléments coquilliers et oolithiques et les tuffeaux sont utilisés dans l'architecture monumentale du sanctuaire: temple à podium et quadriportique. Les premières roches ont des contextes géologiques très proches; elles sont extraites à proximité de la ville antique d'Allonnes. Les lieux d'extraction des tuffeaux sont plus éloignés, de 10 à $30 \mathrm{~km}$.
Cette différence de localisation met en évidence les choix opérés par les architectes. Les calcaires à éléments coquilliers et oolithiques sont des roches dures et sont employés majoritairement pour la structure architecturale du sanctuaire. Ils offrent des qualités de résistance qui répondent aux exigences techniques qu'impose la monumentalité de cet édifice public. Cependant, la dureté de ces matériaux ne permet pas la réalisation de sculptures 

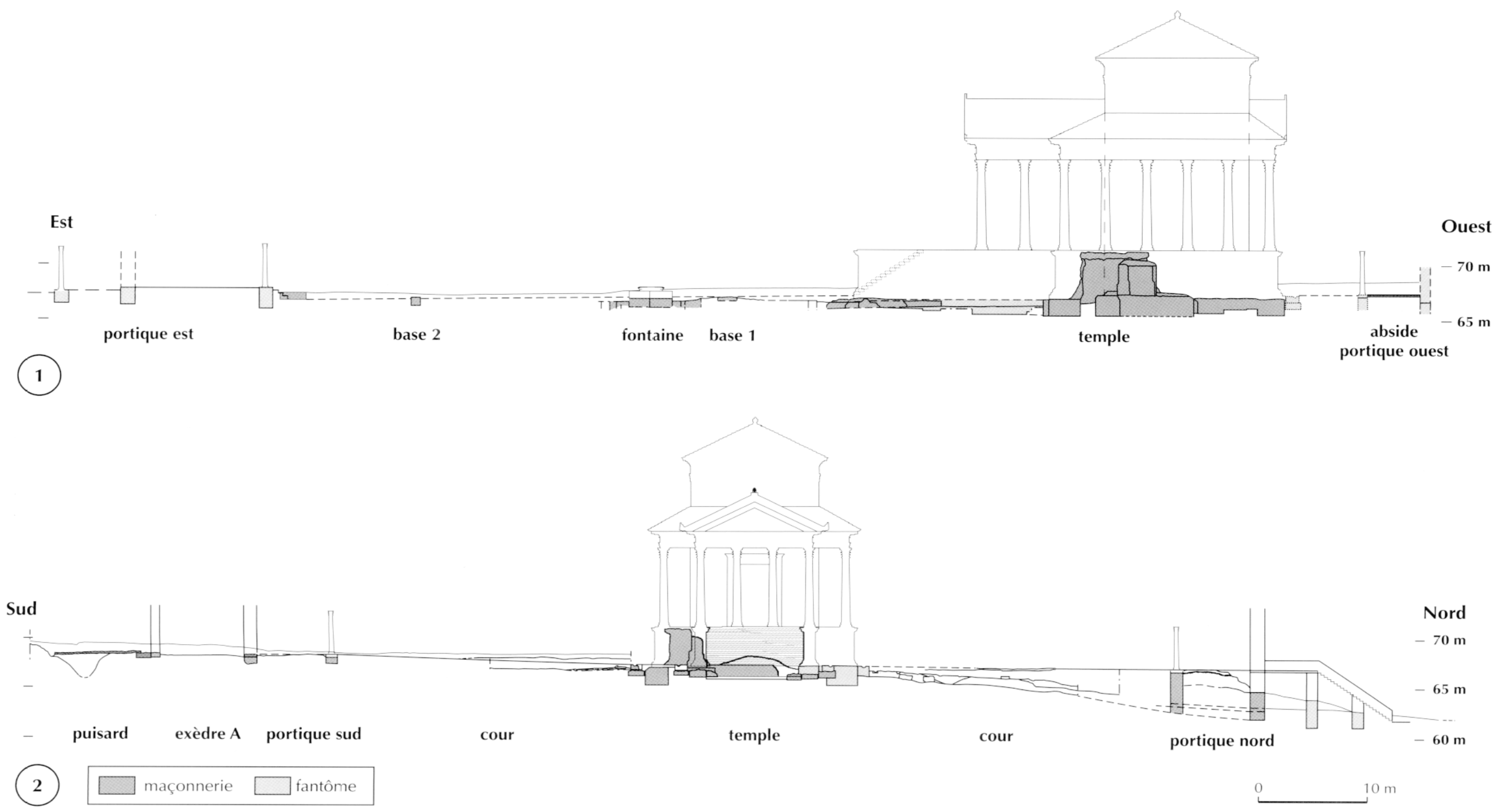

Fig. 24 - Coupes du sanctuaire de Mars Mullo : 1, coupe BB' est-ouest (horizon 5) ; 2, coupe AA'sud-nord (horizons 4 à 7). 

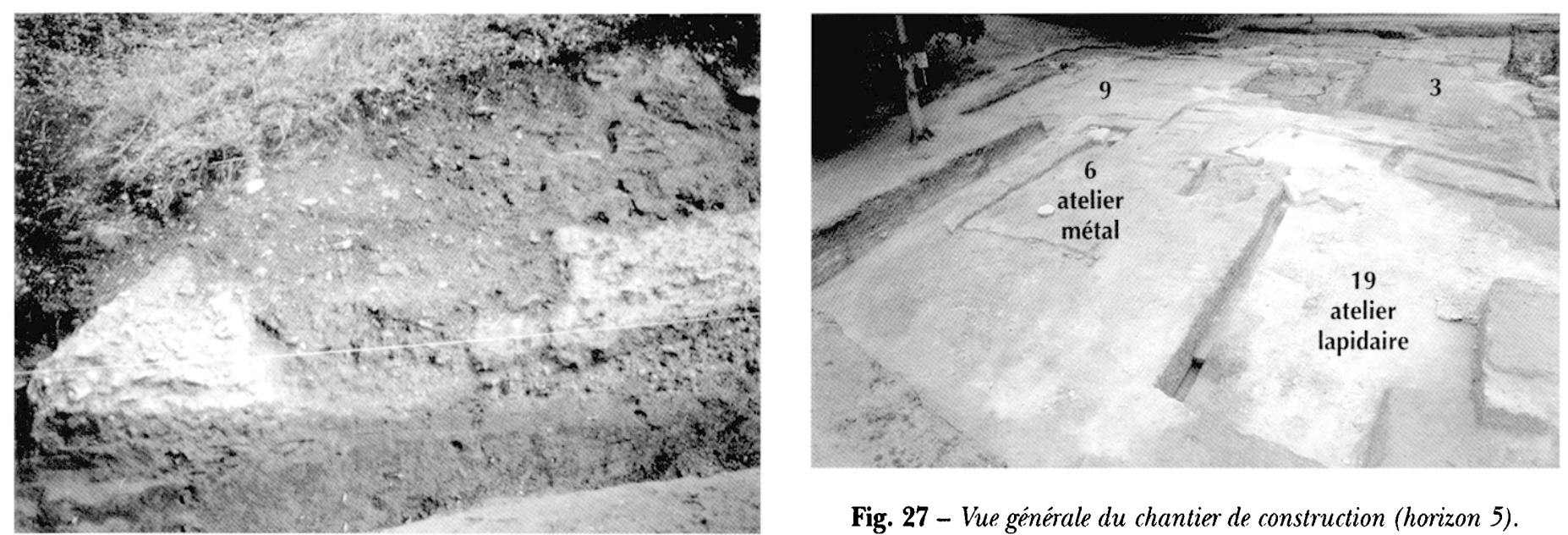

Fig. 26 - La tranchée de fondation du stylobate du portique ouest (horizon 5e) coupe l'aire supérieure de travail du temple (horizon $5 \mathrm{c}$ ).

Fig. 27 - Vue générale du chantier de construction (horizon 5).

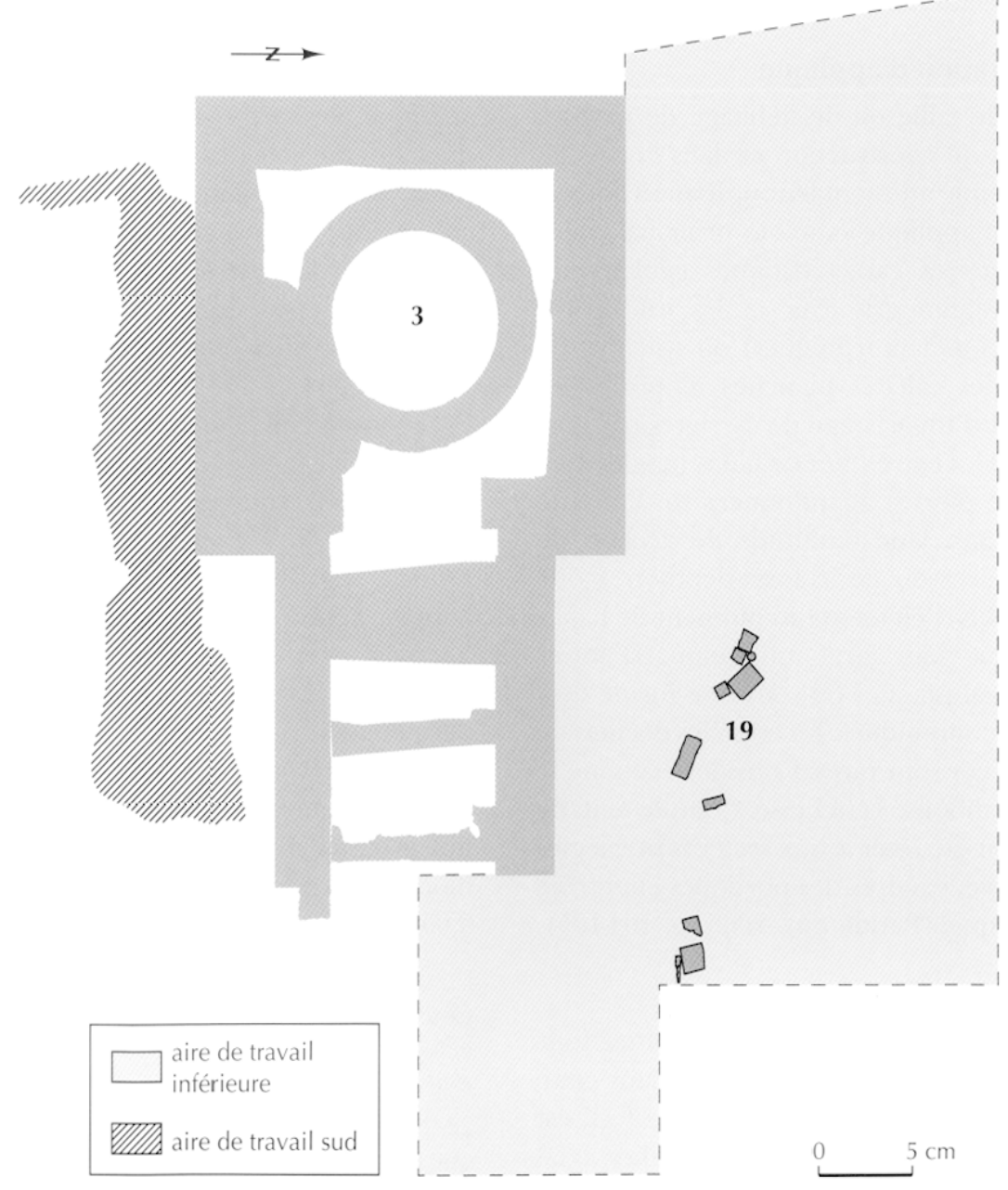

Fig. 28 - Plan de l'aire inférieure et de l'atelier lapidaire (édifice 19), liés à la construction du temple (édifice 3, horizon 5a). 


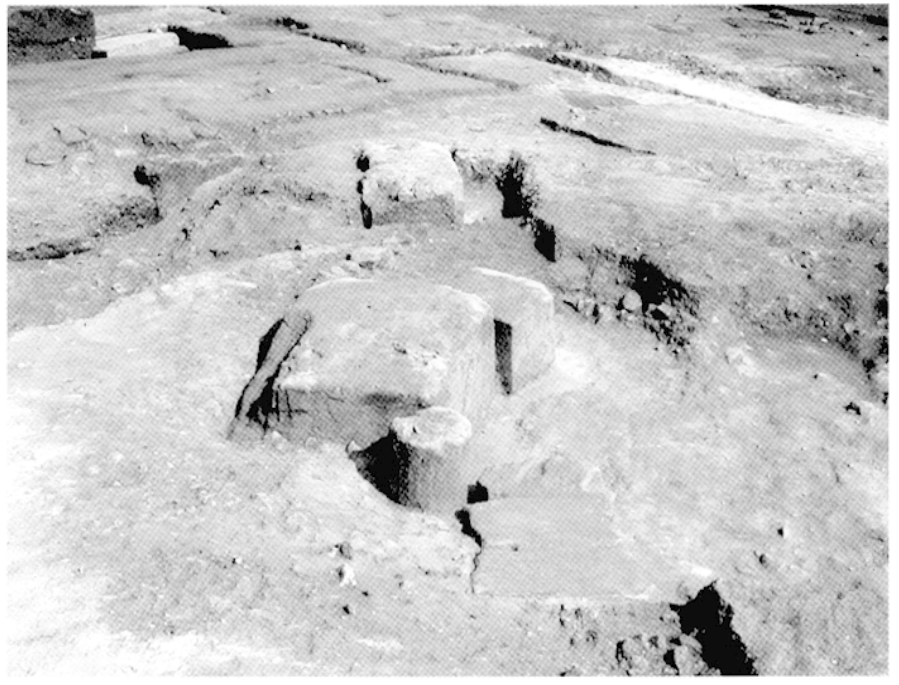

Fig. 29 - Détail de l'atelier lapidaire 19 du temple (édifice 3, horizon 5a).

très fines. Les tuffeaux sont au contraire des roches tendres qui se prêtent aux figurations anthropomorphes, zoomorphes et végétales très élaborées (voir infra). Pourtant, ces roches poreuses n'offrent pas les mêmes qualités de résistance. Ces matériaux sont réservés aux éléments architecturaux décoratifs (tabl. III).

\section{Les matériaux de la décoration d'applique}

De nombreux déchets de taille ou de débitage de plaques décoratives dans les niveaux de construction et dans la couche de destruction autour du temple attestent leur utilisation dans sa décoration. L'architecture d'applique emploie principalement trois matériaux aux couleurs et caractéristiques géologiques différentes. Le calcaire cristallin gris clair et les calcaires à entroques gris foncé (roches métamorphiques) du synclinal de Sablé-sur-Sarthe ainsi que les calcites blanches, importés en grande quantité, font l'objet d'un arrivage de carrières par gros blocs comme en témoignent les extrémités de blocs (angles avec traces d'outils du tailleur de pierre) abandonnées sur l'aire de travail inférieure (horizon 5a). Une multitude de déchets de taille provenant des deux aires ou de la fosse-dépotoir F 507 (éclats, sciages, ratés et surplus d'éléments au moment de l'ajustement, voir infra) confirme leur large utilisation. D'autres roches décoratives arrivent en plaques ou sous une forme déjà ébauchée pour des raisons économiques. En effet, les déchets de roches importées pour le décor sont rares. Considéré comme le matériau noble, le marbre symbolise la richesse. Compte tenu de sa rareté, son usage peut avoir été réservé aux secteurs privilégiés du sanctuaire : cella du temple, exèdres des portiques et entrées du sanctuaire (Gruel, Brouquier-Reddé dir., 2003, p. 104-105).

\section{Le temple}

Le temple s'élève sur un haut podium à cella circulaire à tour entourée d'une galeric carrée, particularité unique dans cette série d'édifices de l'ouest et du sud-ouest de la Gaule ${ }^{21}$. Il est précédé à l'est d'un pronaos moins large et d'un escalier axial

21. Le temple d'Avenches en Suisse s'élève sur un podium dodécagonal (Morel, 1993) ; celui d'Apollon Moritasgus à Alise-Sainte-Reine en encadré par des murs d'échiffre (fig. 31 et fig. 32 cf. pl. VI hors texte). Les deux types de mortier sableux (MS 1 et MS 2) utilisés, de composition très proche, confirment l'unité de la construction du temple.

La semelle de fondation du stylobate de la colonnade, bien conservée au sud, et les creusements des fondations est, ouest et nord permettent de retracer le plan du podium qui mesure $31,21 \mathrm{~m}$ sur $12,40 \mathrm{~m}$ de large en façade antérieure et 19,90 $\mathrm{m}$ en façade postérieure (fig. 30). Des aplats de mortier visibles sur la semelle de fondation confirment la pose de blocs en grand appareil au-dessus. L'empreinte du radier de l'escalier de 5,50 $\mathrm{m}$ de profondeur sur une largeur de 8,90 m est limitée par la semelle de fondation des murs d'échiffre ${ }^{22}$. Un large mur de refend est entièrement récupéré à $4,80 \mathrm{~m}$ environ du mur antérieur.

Le plan restitué du podium permet de rechercher l'emplacement de la colonnade dont les supports de fondation ont tous disparu, en tenant compte du décrochement du couronnement du podium de $0,35 \mathrm{~m}$ attesté par un bloc retrouvé au nord du pronaos (fig. $38, \mathrm{n}^{\circ} 1$ ). L'entraxe peut être calculé sur une distance de $10,78 \mathrm{~m}$, déduite de la longueur de la façade antérieure (Brouquier-Reddé et al., sous presse b). On peut étudier deux hypothèses de restitution de la façade, soit hexastyle, soit tétrastyle. Dans le cas de l'hypothèse 1, l'entraxe moyen de 2,11 m ne peut être reporté sur tout le périmètre du podium, en particulier à la jonction du pronaos et de la peristasis. Dans le cas de l'hypothèse 2, un entraxe moyen de 3,52 m peut être appliqué au tracé régulateur. On obtient le seul tracé techniquement possible de la colonnade (fig. $33 \mathrm{cf}$. pl. VII hors texte). Ainsi nous restituons une façade antérieure tétrastyle, une colonnade de trois colonnes sur le côté du pronaos; les trois façades de la cella sont hexastyles. La façade antérieure est placée au-dessus du large mur de refend, ce qui crée une terrasse de 4,86 m entre l'escalier et le pronaos, profond de $11 \mathrm{~m}$ (Ulrich, 1994, p. 249-303 ; Brouquier-Reddé, 2003, p. 463).

Le niveau de pose de la base du podium est calculé d'après le sommet du caniveau en grand appareil qui entoure le temple ${ }^{23}$. Une portion conservée du blocage interne du podium fixe la hauteur du podium à $4,05 \mathrm{~m}$ en incluant le dallage de la peristasis (fig. 34 et fig. 35 cf. pl. VIII hors texte). À partir de cette hauteur et de l'emprise au sol, le nombre de marches de l'escalier axial peut être établi en fonction d'une hauteur moyenne de 0,19 m et d'une profondeur de 0,31 m. Dix-neuf marches permettaient d'accéder à la terrasse du temple.

Décalées vers le nord-ouest de $0,60 \mathrm{~m}$ par rapport au podium quadrangulaire, les fondations indépendantes d'une cella de forme circulaire, à double parement en petit appareil et à blocage, surnommée La Tour-aux-Fées, sont à empattement de $9,05 \mathrm{~m}$ de diamètre interne et de $13,10 \mathrm{~m}$ de diamètre externe ;

Côte-d'Or (archives du MAN) présente un podium octogonal. Le temple octogonal de Sanxay est entouré d'un portique cruciforme (Aupert et al., 1992).

22. Nous nous alignons sur la semelle de fondation nord plus courte que celle du sud (Brouquier-Reddé et al., sous presse b).

23. Sur ce type de caniveau, voir l'exemple de Champlieu à Orrouy, Oise (Woimant, 1993) et le mausolée de Lanuéjols, Lozère (Joulia et al., 2000). 


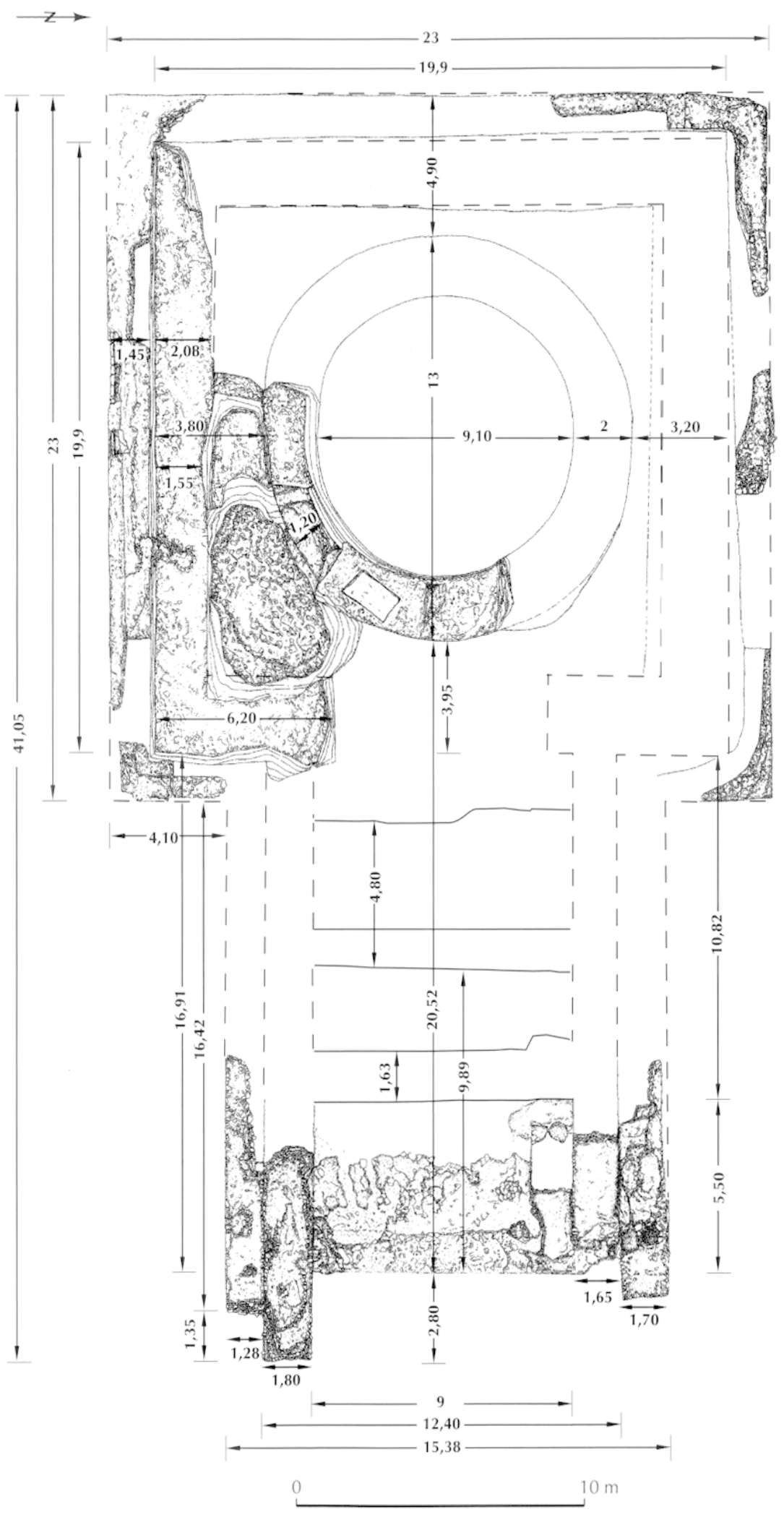

Fig. 30 - Plan architectural du temple (édifice 3, horizon 5). 
Tabl. III - Provenance et usage des roches répertoriées sur le sanctuaire de Mars Mullo : $x$, utilisation principale; o, utilisation ponctuelle.

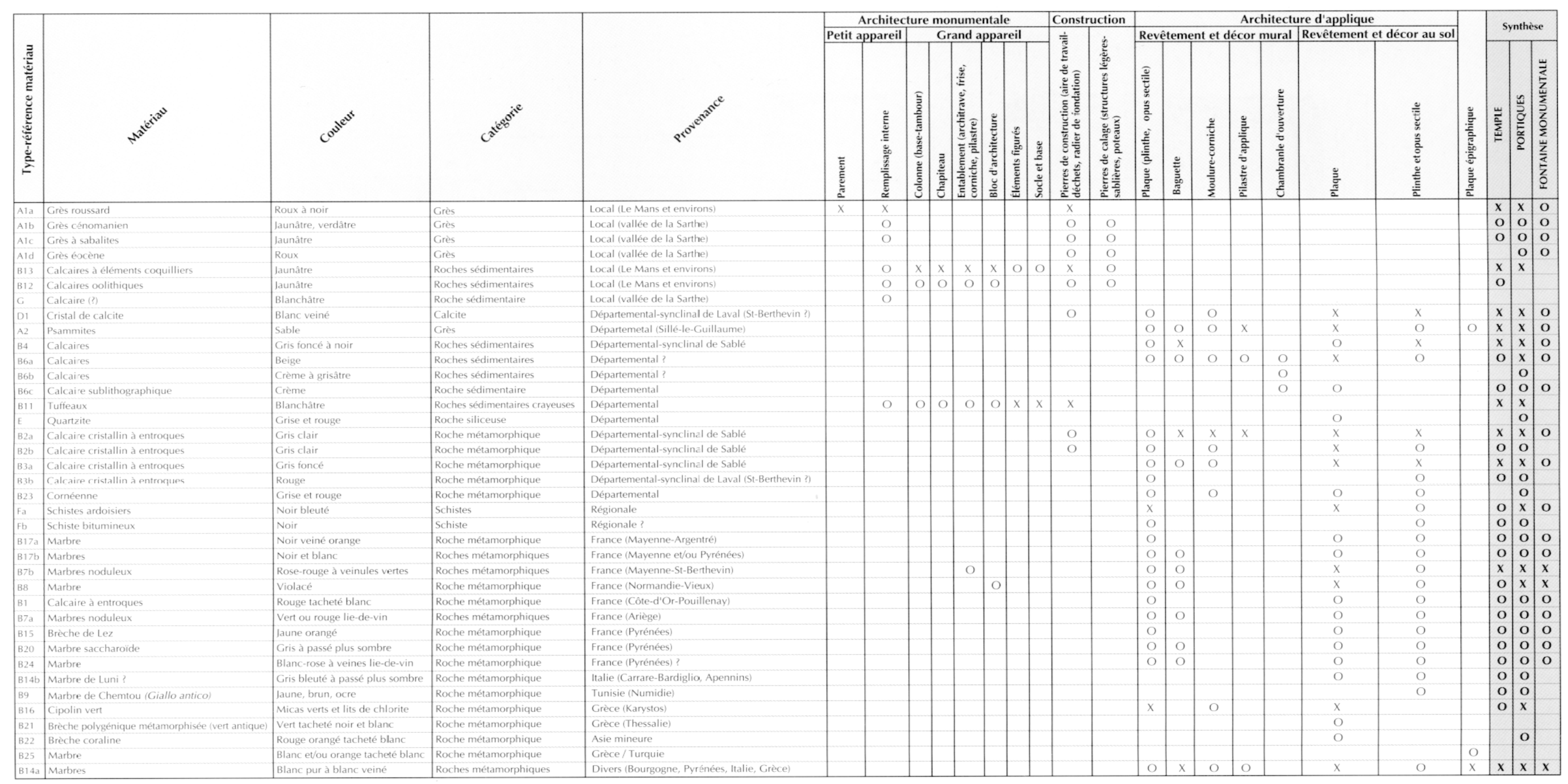




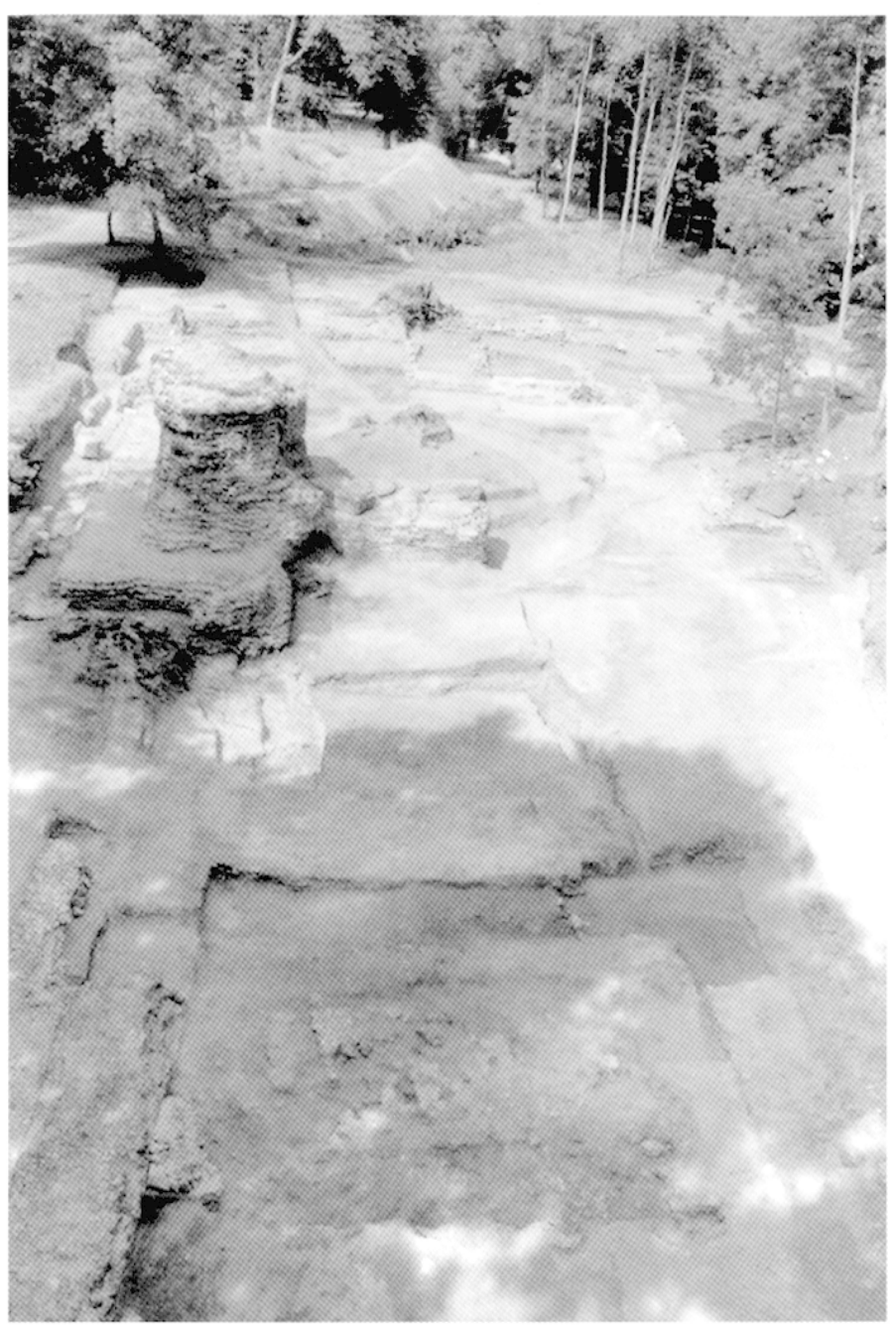

Fig. 31 - Le temple (édifice 3), vu de l'est.

le diamètre de l'arasement supérieur est de $9,60 \mathrm{~m}$ (int.) et de 12,20 m (ext.), soit une largeur de $1,20 \mathrm{~m}$ des fondations (fig. 36). Le sol de la cella est restitué, faute d'indices, au même niveau que le dallage de la peristasis. L'élévation de la tour ne peut être calculée que d'après une comparaison avec d'autres exemples mieux conservés (Brouquier-Reddé et al., sous presse b). Ces tours sont toutes construites en petit appareil : Périgueux, Autun, Corseul, Villetoureix ${ }^{24}$. Deux blocs de frise de forme trapézoïdale (fig. 37) confirment que la cella d'Allonnes s'élevait au-dessus de la façade antérieure. Ce sont les seuls indices de l'existence d'un entablement supérieur des tours qui surmontait vraisemblablement une assise courante en grand appareil d'après la découverte d'autres blocs lisses de même forme. Leur largeur de 0,99 $\mathrm{m}$ donne l'épaisseur de l'élévation de la tour, ce qui permet de restituer un diamètre interne de $10,40 \mathrm{~m}$ et un diamètre externe de $12,38 \mathrm{~m}$. Si on applique un rapport de $\sqrt{2}(1,414)$, déduit des élévations conservées des autres exemples, on obtient une cella haute de $17,50 \mathrm{~m}$ (fig. 36 et 38 ).

24. Lauffray, 1990, fig. 10b ; Rebourg, 1993, p. 97-100, n"s 220-222, fig. 81-88; Formigé, 1944, p. 66-67, fig. 16 et Provost, 1999 ; Gaillard, 1997, p. 259-260, n"586, fig. 167-168.

\section{La restitution de l'ordre corinthien des façades du temple}

Malgré la récupération systématique des blocs en grand apparcil, dont la plupart ont été vendus par les chanoines du Mans (Bernier et al., 2002), et l'état très fragmentaire des rares éléments architecturaux conservés, la restitution de l'ordre des façades du temple s'esquisse progressivement (fig. 24 et 39). Les éléments en calcaire dur appartiennent essentiellement au temple, la décoration figurée de ses frontons est sculptée dans le tuffeau.

Un bloc de courommement à pseudo-krépis permet de restituer la décoration du podium (fig. 38, n¹). Les colomnes, composées de tambours à dix-neuf rudentures et dix-neuf listels ${ }^{25}$ (fig. $38, n^{\circ} 2$ ) de $0,83 \mathrm{~m}$ de diamètre inférieur restitué, reposent sur des bases à double tore (h.: $0,34 \mathrm{~m}$ environ) sur plinthe (l. : 1,12 $\mathrm{m}$ sur h. : $0,12 \mathrm{~m}$ ) de style attique, restituées d'après la base de pilastre d'applique du quadriportique (fig. 57). Le chapitcau corinthien, composé de deux blocs (fig. $38, n^{\circ} 3$ ), donne le diamètre du sommet de la colonne, décoré d'une astragale: $0,66 \mathrm{~m}$ (Tardy, sous presse b). La hauteur restituéc de $8,23 \mathrm{~m}$ de la colonne est calculée en appliquant le schéma $B$ de restitution de l'ordre corinthien de M. Wilson Jones (1989 et 2000, cf. Brouquier-Reddé et al., sous presse b). Si la hauteur de l'architrave n'est pas connue, celle de la frise d'armes mesure $0,47 \mathrm{~m}$ d'après un fragment de bloc (fig. $38, n^{\circ} 4$ ).

Les fragments de corniche sont très fragmentaires. I.e registre inférieur est décoré d'une torsade à filet ou tresse (h. : $0,075 \mathrm{~m})$. Le registre supérieur à bandeau est souligné par une doucine à rang de feuilles droites. La doucine (h. : $0,21 \mathrm{~m}$ ) est ornée de deux motifs que l'on retrouve associés aux différents types de bandeaux : le rai-de-coeur et la feuille dressée. Les bandeaux verticaux (h.: $0,12 \mathrm{~m}$ chacun) du registre supérieur portent quatre types de décor: méandres interrompus Ginouvès 2, feuilles inversées, esses et tresse présentant trois variantes (tressé simple, tressé à œillets, tressé à double oillets).

Le soffite du larmicr d'un des rampants est orné de caissons hexagonaux décorés alternativement de fleurons à rosette circulaire et bouton central à quatre et à six pétales. Les quatre registres d'un des rampants (h. : $0,75 \mathrm{~m}$ ) présentent successivement des méandres interrompus Ginouvès 2, des peltes, des feuilles couchées sur la gauche et des feuilles inversées: anthémion (fig. $38, n^{\circ} \mathbf{5}$ et fig. 39). Un autre motif de méandre en svastikas A2 confirme la présence d'un second fronton, sur la façade postérieure. Les tympans abritaient vraisemblablement une décoration figurée en tuffeau. Un acrotère couronnait le fronton de la façade ${ }^{26}$.

25. Ce nombre non classique n'est pas une exception dans l'architecture romaine (Brouquicr-Reddé et al., sous presse b, p. 9 et 11. 43).

26. Des premiers essais de restitution du sanctuaire ont été proposés. La première tentative de restitution en 3D), présentée dans le cédérom Allonnes la romaine et réaliscéc sur la base des données de fouilles antérieures à 2000 (Gruel ot al., 2003), a été revue et réexaminée à loccasion du colloque de Bordeaux en novembre 2002 (BrouquierReddé et al., sous presse b). Voir aussi (Gruel, Brouquier-Reddé dir., 2003, p. 60-62 n'". $26-64$. 
80

79,57
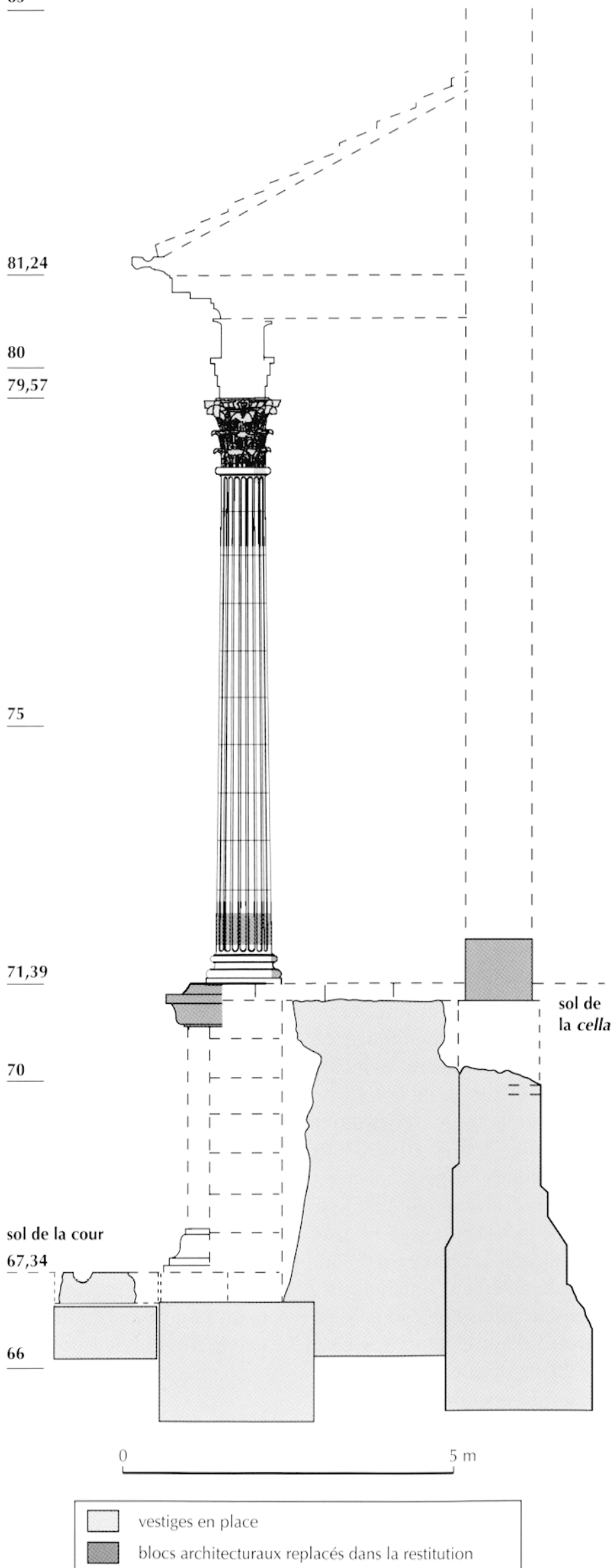

Fig. 34 - Restitution de l'élévation du temple sur les vestiges conservés dans l'axe de la cella (hypothèse 2003). 

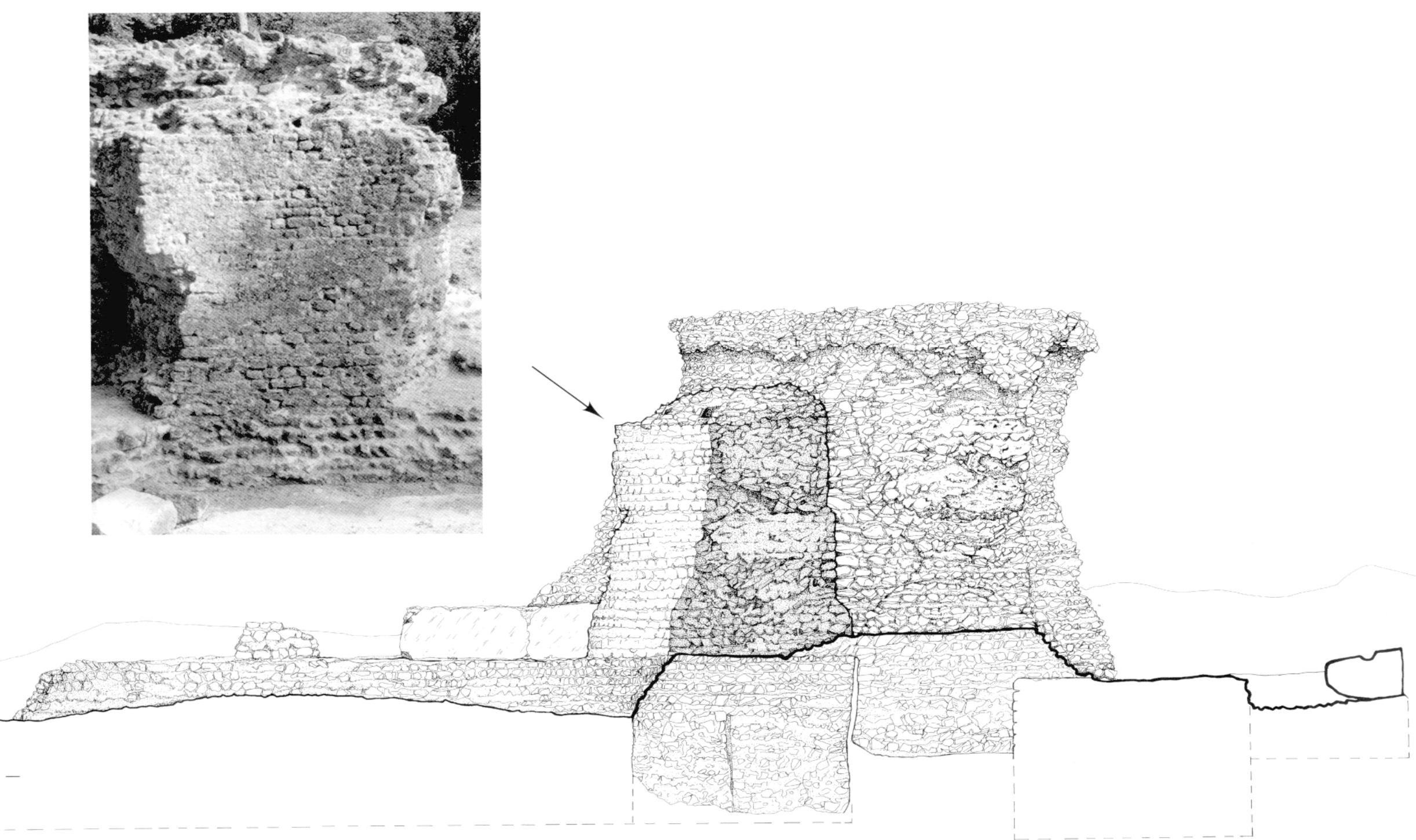

Fig. 36 - La cella circulaire du temple (édifice 3, horizon 5 ; état actuel) : a, le parement interne des fondations : b, coupe nord-sud des fondations de la cella et du podium du temple. 
Fig. 37 - Blocs de l'entablement de la cella circulaire (édifice 3) : 1, bloc trapézoïdal de l'atelier lapidaire (édifice 19), destiné à la construction de la cella (horizon 5a); les trous de scellement en queue d'aronde sont préparés, mais non achevés; le bloc n'a pas été mis en ouvre, mais laissé sur place; 2 , bloc de la frise d'armes (horizon 5).

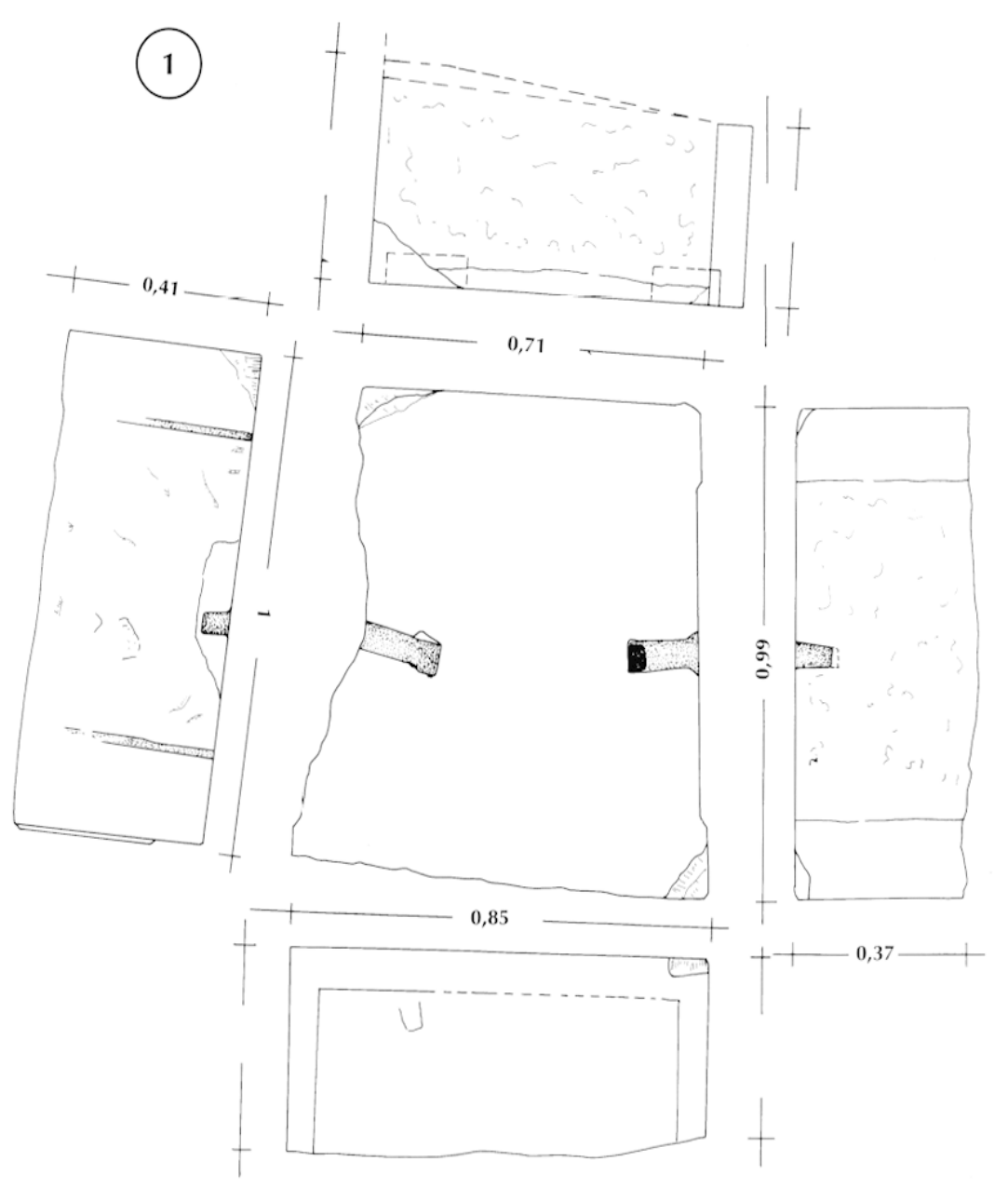

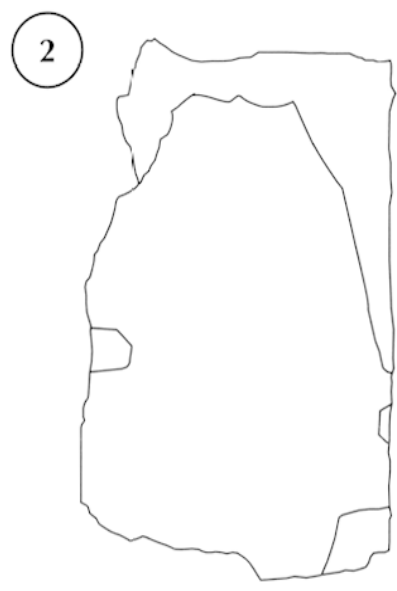

face de joint gauche

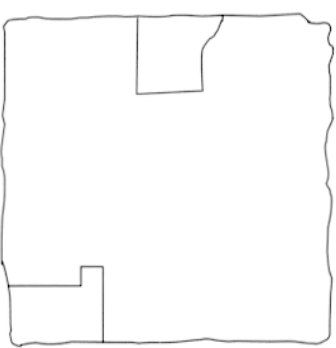

coupe $\mathrm{AA}^{\prime}$

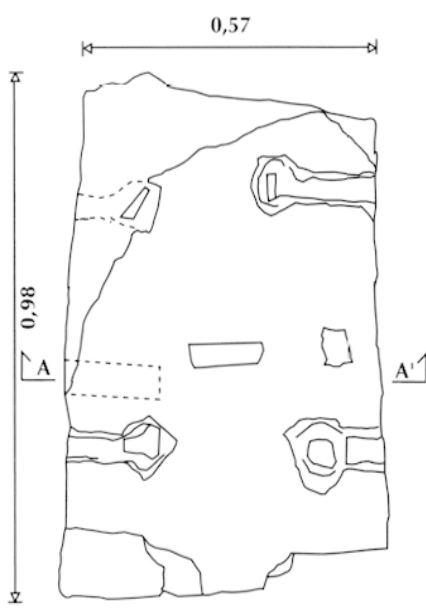

face d'attente

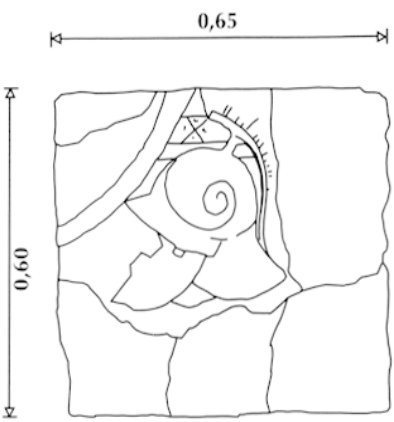

face de parement

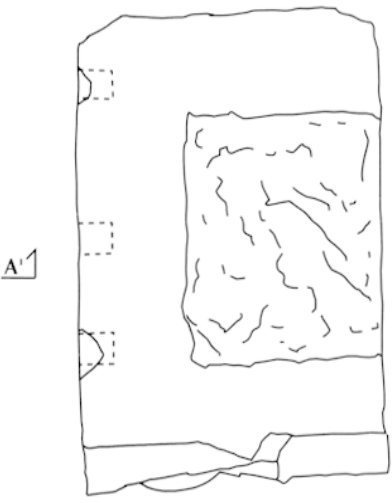

face de joint droite
0 $50 \mathrm{~cm}$ 

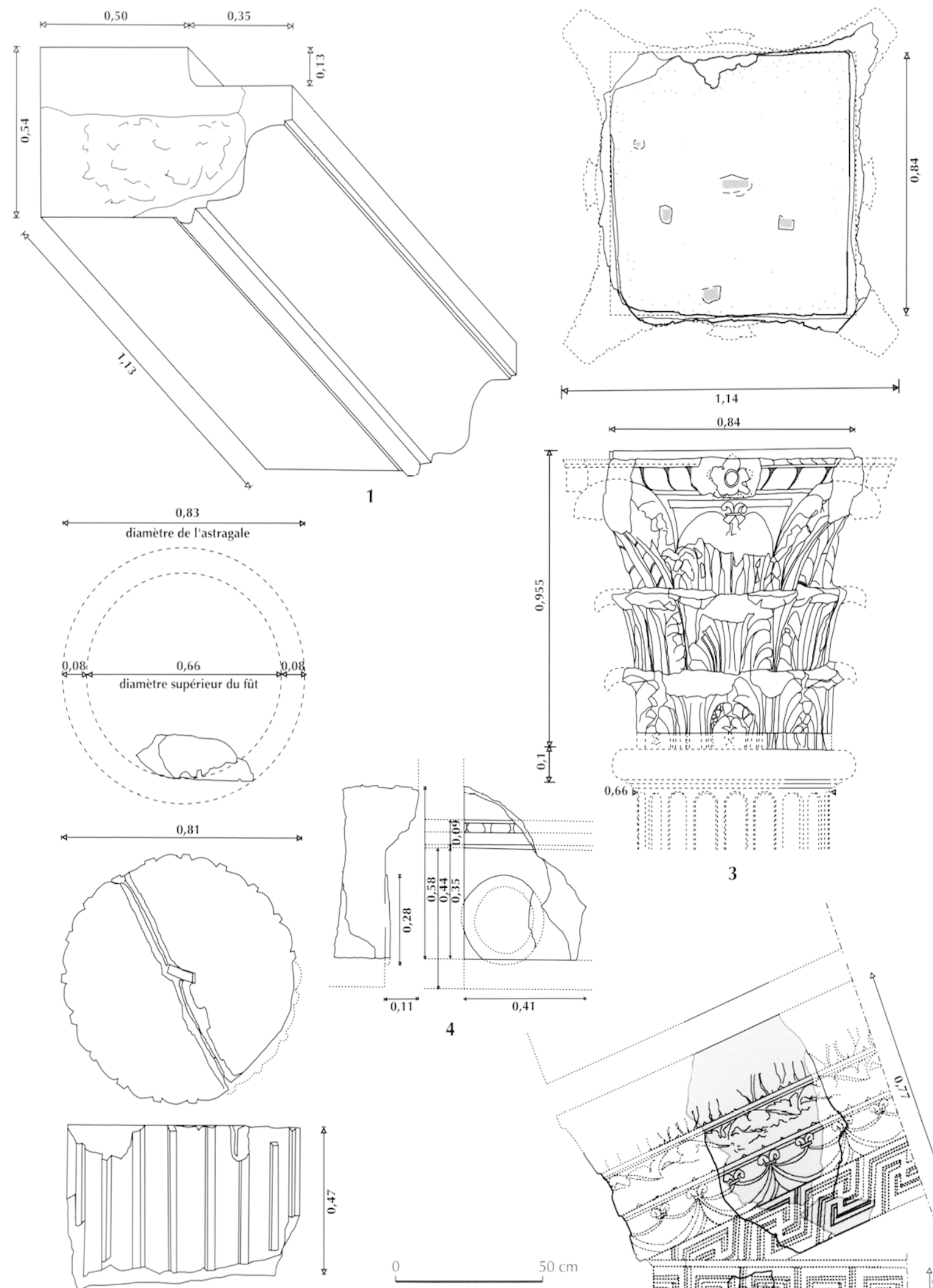

3

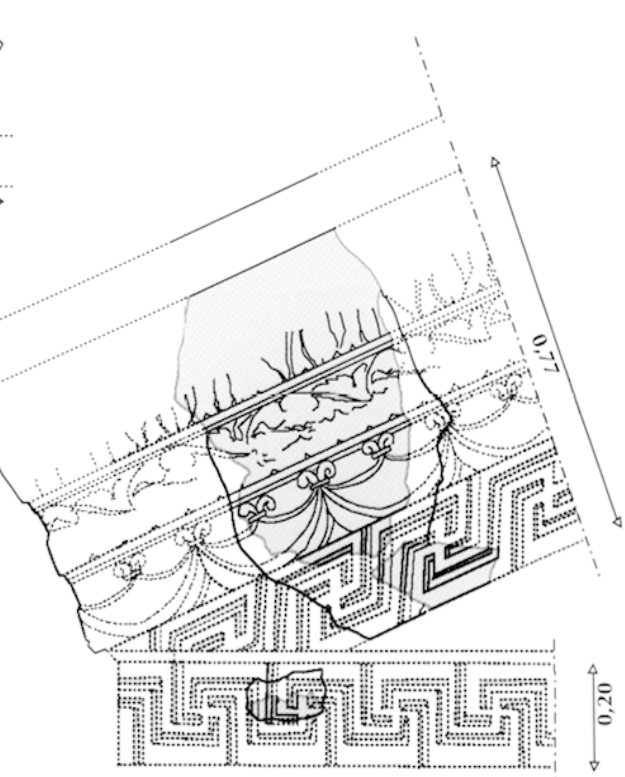

2

5

Fig. 38 - Éléments architecturaux du temple (édifice 3, horizon 5) : 1, bloc de couronnement du podium ; 2, tambour et astragale ; 3, chapiteau corinthien; 4, bloc de frise d'une des façades; 5, rampant gauche du fronton d'une des facades. 


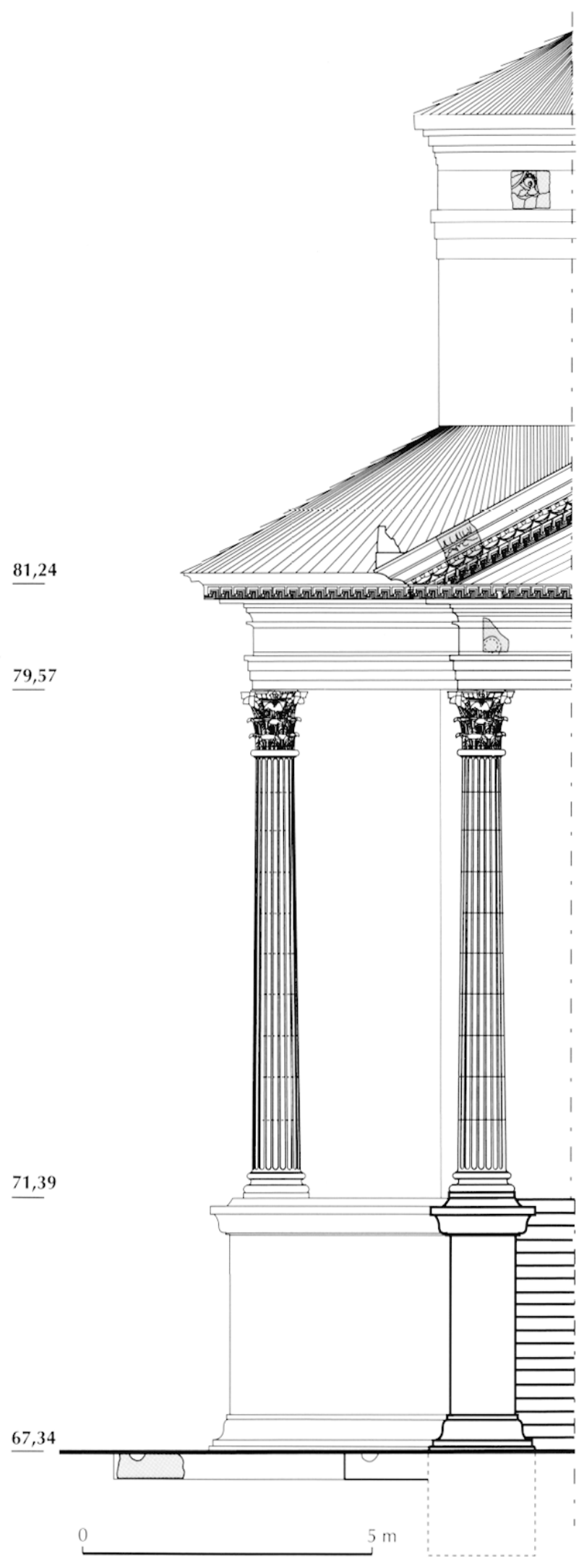

Fig. 39 - Restitution de l'ordre monumental de la façade antérienure du temple, côté gauche.

\section{LES TRAVAUX DE FINITION DU TEMPLE (HORIZON 5B, 90-110 APR. J.-C. ET HORIZON 5C, 110-130 APR. J.-C.) \\ Le remblai de l'horizon $5 b$}

À l'achèvement du travail de gros œuvre, un épais remblai d'argile et de pierres ou de sable (horizon 5 b), daté de 90110 apr. J.-C., rectifie la pente du terrain (fig. 25 et fig. 40 cf. pl. IX hors texte). L'analyse du lot de céramique sigillée montre que la constitution de ce remblai est antérieure aux années 1 10-120. L'absence de vases à pâte calcaire de Lezoux ou des Martres-de-Veyre (dont la diffusion est effective pour ce dernier à partir des années 90-100), mais aussi de vases du centre-ouest de la Gaule, toujours représentés dans les niveaux des premières décennies du II $\mathrm{s}$., permet de considérer que le gros œuvre est entrepris au cours des dernières décennies du $\mathrm{I}^{\mathrm{cr}} \mathrm{s}$. et achevé au tournant du siècle.

Les céramiques sigillées proviennent de deux pôles de production, celui du sud de la Gaule largement majoritaire et celui du centre qui ne compte que deux vases. Les pièces méridionales ont été fabriquées pour la plupart au sein des ateliers de La Graufesenque à Millau. Le seul vase précoce est probablement une coupelle Ritt. $5^{27}$, dont les caractéristiques techniques ne permettent aucun doute quant à sa datation des années 10-40. Les autres sigillées lisses correspondent à des vases du milieu du $\mathrm{r}^{\mathrm{cr}} \mathbf{s}$. (pour les formes identifiées : assiettes Drag. 15/17 et Drag. 18) ou à des pièces au vernis plus mat des dernières décennies du I ${ }^{\mathrm{cr}} \mathrm{s}$. et premières années du $\mathrm{II}^{\mathrm{C}} \mathrm{s}$. Tel est le cas, notamment, de deux assiettes du service Ve. A et de deux coupelles du service Ve. C. Les vases du centre de la Gaule sont représentés par un fragment d'une assiette des années 10-30 (vernis marron mat, poreux, pâte beige foncé, non calcaire, très fortement micacée) et un autre appartenant à une coupclle des années 70-110 (vernis orange brillant, poreux et pâte orangéc, non calcaire, micacée).

\section{L'aire supérieure de finition et l'atelier de travail des métaux à l'horizon $5 \mathrm{c}$}

Sur ce remblai, une nouvelle aire de travail a été constituée à partir de déchets de taille des calcaires liés à la finition du temple : horizon 5c (fig. 41). Elle ne comporte que quatre formes en sigillée qui appartiennent aux productions des ateliers de La Graufesenque et sont contemporaines ou postérieures à la période flavienne: des assiettes Drag. 18 et Drag. $15 / 17$, ainsi que deux coupelles appartenant aux services Ve. A et Ve. C.
27. Abréviations des codes typologiques :

. références typologiques communes : Curle*; Drag.*; Déch.*; Ritt.*; Walt.* (cf. Oswald, Pryce, 1920) ;

. sud de la (Gaule : service Ve. A ou coupelle Ve. A1, assiette Ve. A2, etc. (cf. Vernhet, 1976 ; Passelac, Vernhet, 1993) ;

. centre de la (aule : Lez. 24, ctc. (cf. Bet et al., 1989 ; Bet, Delor, 2000) ; - quelques équivalents typologiques: Drag. $35=$ Lez. $14=\mathrm{Ve}$. Al; Drag. $36=\mathrm{I}$.e $\%$ 15 = Ve. $A 2$; Curle $23=$ Lez. $43=$ Ve. F2 ; Curle $15=$ Lez. $45=$ Ve. $(.2$; Drag. 37 guilloché dénomination impropre mais que I'on rencontre souvent dans les publications $=1 . \% \%$; Drag. 30 guilloché dénomination également impropre = L.ez. 84 . 


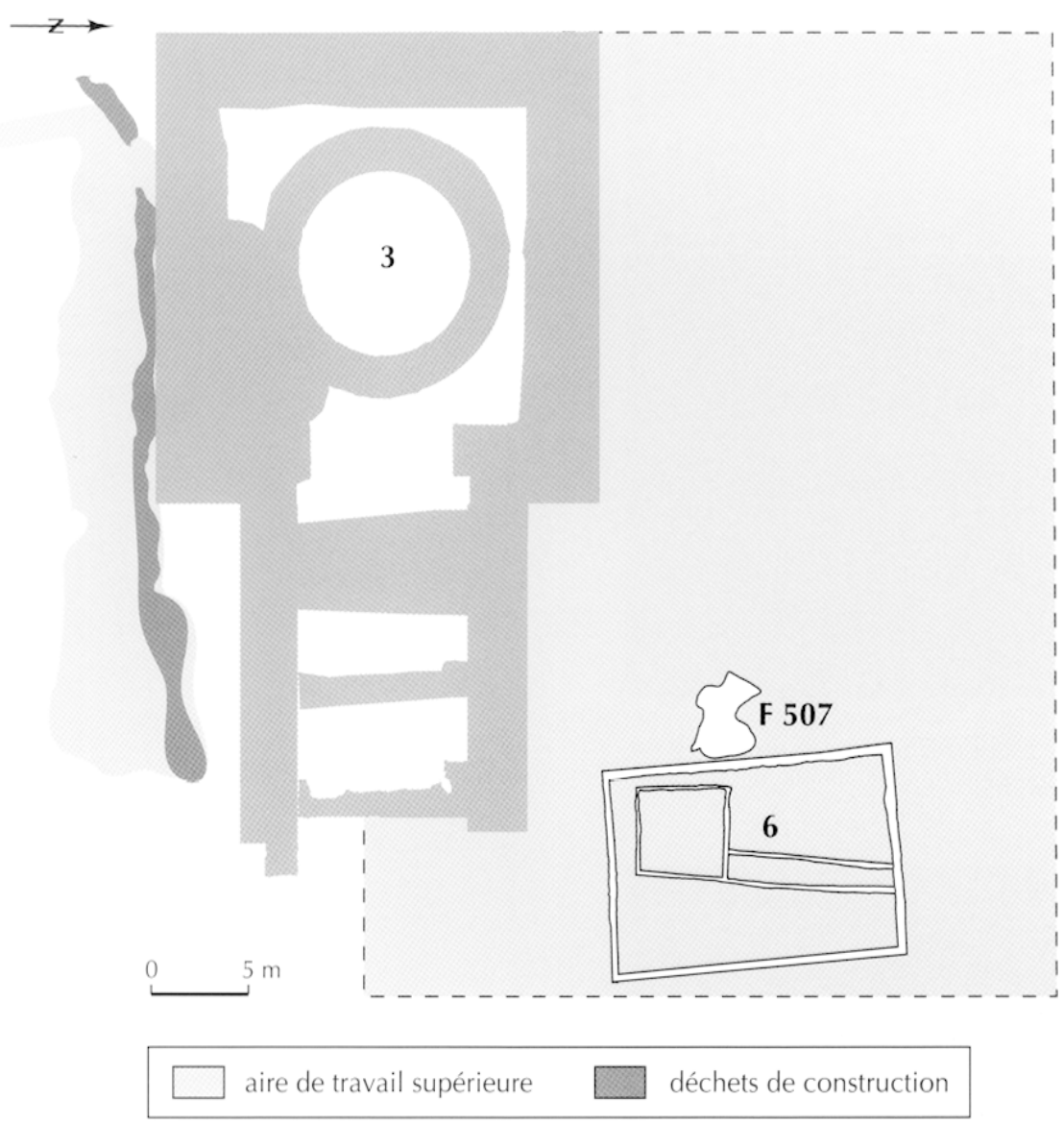

Fig. 41 - Plan de l'aire supérieure de l'atelier de travail du métal (édifice 6) et de la fosse-dépotoir F 507, liés à la finition du temple (édifice 3, horizon 5c).

Au mème niveau que cette aire supérieure, un atelier sur sablières (édifice 6 ), de très grandes dimensions (15,80 m sur $10,70 \mathrm{~m}$ ), est implanté à $3 \mathrm{~m}$ au nord de l'escalier du nouveau temple (fig. 42). Son accès se situe du côté du temple, c'est-àdire au sud (fig. 43). D’après le matériel et les aménagements identifiés, il s'agit d'un bâtiment lié au travail des métaux (fer, bronze et vraisemblablement métal blanc). On peut songer à la fabrication de la décoration en bronze du temple, de la quincaillerie en fer nécessaire à la construction de la charpente et à la mise en place des plaques de revêtement, sans oublier les scellements en plomb des matériaux. Le sol est induré dans les parties sud et est. Plusieurs aires de combustion sont délimitées au sud (fig. 40 et 44). Contre la sablière ouest, le foyer rectangulaire F1 correspond à un four de recuit (bas) destiné aux alliages à base de cuivre. Les vestiges sidérurgiques de ce foyer se composent de $35 \mathrm{~g}$ de reliquats de combustion à base de cuivre et de $10 \mathrm{~g}$ de scories de métal blanc. Le foyer F3 a également fourni $34 \mathrm{~g}$ des déchets de combustion à base de cuivre et $91 \mathrm{~g}$ de scories de fer. Le foyer F4 a livré 88,2 g de reliquats de combustion en alliage à base de cuivre et $4010 \mathrm{~g}$ de scories de fer sur les $5711 \mathrm{~g}$ trouvés à l'intérieur de l'édifice 6 . Une importante concentration de scories de fer et de battitures permet d'affirmer que ce foyer était réservé au travail du fer. Cette hypothèse est renforcée par la présence de plusieurs barres en fer caractéristiques de cette activité. Les deux autres foyers n'ont pas livré de résidus de combustion. Un tas en pierre posé de chant, bloqué par un fort calage, est placé à proximité de la sablière sud ; il servait à casser les moules.

Plusieurs traces d'un nettoyage de l'atelier apparaissent. Dans l'angle sud-ouest, une couche, constituée de briques ou de tuiles pilées, a livré $1386 \mathrm{~g}$ de reliquats de combustion à base de cuivre et $807 \mathrm{~g}$ de scories de fer. Il s'agit vraisemblablement du nettoyage d'un four. Au nord de l'édifice, une zone essentiellement charbonneuse renferme une importante quantité de reliquats de combustion, des objets en alliage à base de cuivre et des fragments de combustibles sous forme de charbonnettes. Deux hypothèses sont possibles. Cette zone correspond à un nettoyage pendant l'activité de l'atelier (état 1) et, dans ce cas, il faut envisager la présence d'un accès sur le côté nord. Dans le second cas, il s'ayit d'un neltoyage de l'état 2 ou concomitant du démontage de l'atelier.

L'aire de travail à froid est située au nord comme l'indiquent un fragment de fût de colonne remployé comme établi et la zone des sels de cuivre, produits par l'oxydation des limailles et des copeaux issus du polissage et du martelage. Sept polissoirs dont un en grès éocène, un en grès fin et cinq pierres ponces découverts au nord de cette zone confirment cette identification. Dans le cas d'ateliers urbains, de dimensions plus restreintes comme ceux de la Porte du Rebout au Mont-Beuvray (Duval et al., 1991) ou du quartier métallurgique d'Autun (Chardron-Picault, Pernot dir., 1999, p. 198), les aires de combustion sont placées dans la moitié nord de la pièce ; le four 


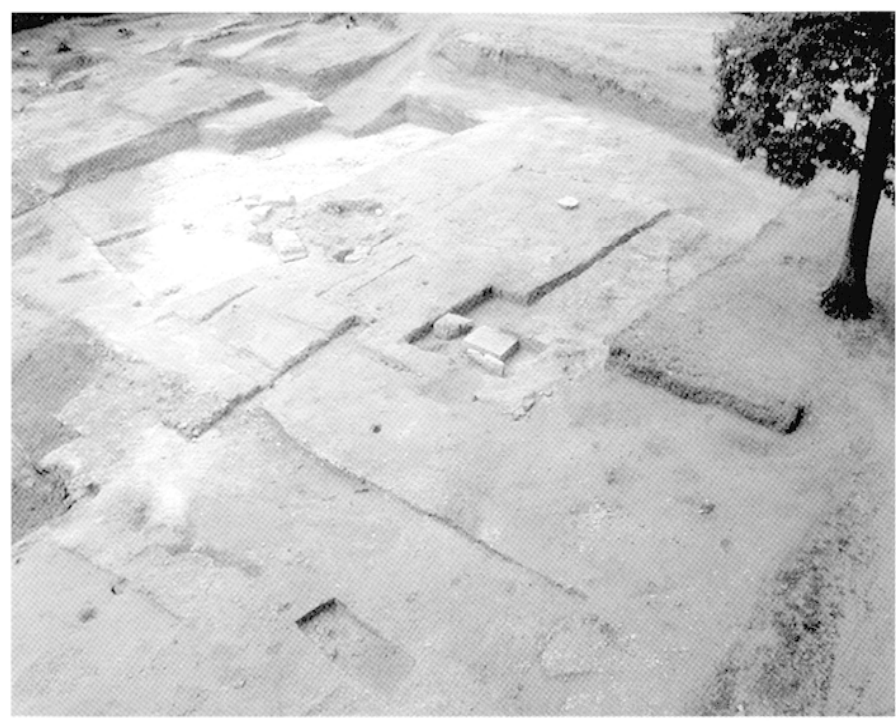

Fig. 42 - L'atelier de travail du métal (édifice 6), vu du sud-est (horizon 5c).

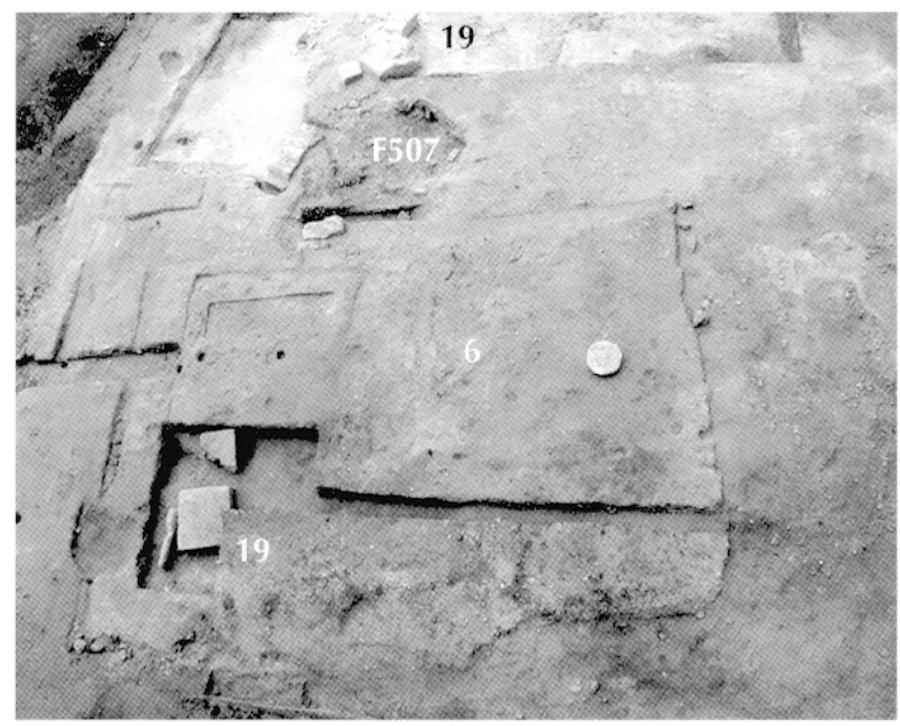

Fig. 43 - L'atelier de travail du métal (édifice 6), vu de l'est (horizon 5c) sur l'atelier lapidaire (édifice 19).

de fusion est le plus au nord; le four de recuit est sur la limite sud de la zone de concentration des installations liées aux travaux à haute température. L'édifice 6 présente une organisation similaire mais inversée (fig. 45).

L'atelier a été transformé au cours de cette étape de construction. Une structure rectangulaire formée par quatre sablières a condamné la plupart des foyers. Cette modification est liée au déroulement du chantier et aux besoins des artisans qui effectuaient les dernières finitions.

Deux observations semblent déterminantes pour caractériser le matéricl céramique de la période des travaux de finition du temple. On constate la présence de sigillées grésées du centre de la Gaule et de vases du centre-ouest. Les premières n’apparaissent pas avant les années 90-100 et commencent à être diffusćes cn Gaule interne au début du II"s. Les seconds, bien que produits dès les dernières décennies du

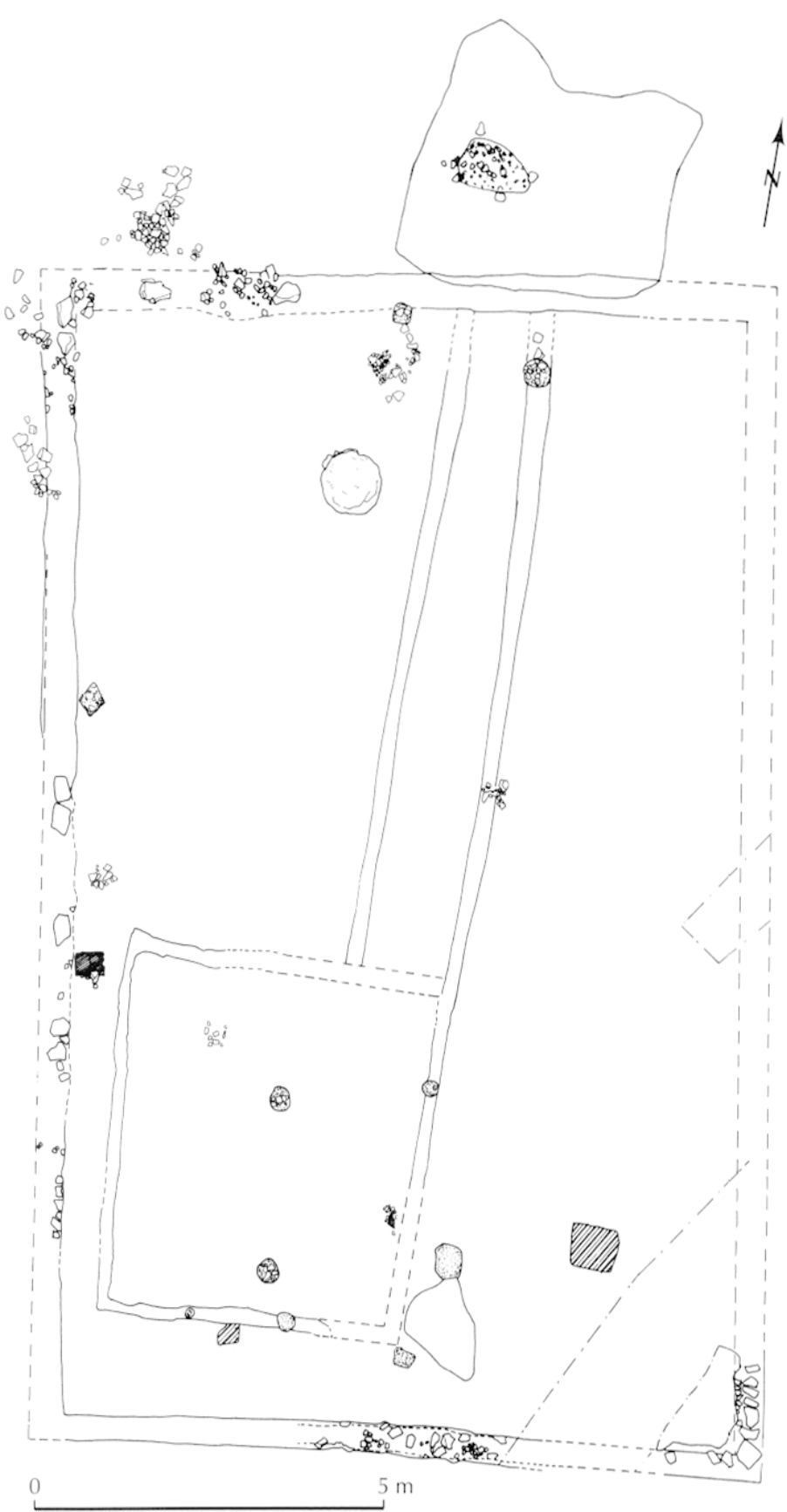

Fig. 44 - Plan de l'atelier de travail du métal (édifice 6, états 1 et 2, horizon 5 c).

$\mathrm{I}^{\mathrm{er}}$ s. apr. J.-C., ne sont attestés au nord de la Loirc qu'entre les années 110 et 140 (Delage, 1997). Les données chronologiques que l'on peut tirer de ces mobiliers sont donc complémentaires. La deuxième observation porte sur l'utilisation de nombreux vases du sud de la Gaule. Il ne s'agit pas, contrairement à ce que l'on pourrait croire, de pièces résiduelles. En effet, les données actuelles montrent de manic̀re nette que les ateliers du sud de la Gaule, grâce à leur capacité de production à nulle autre pareille et malgré les difficultés qu'ils rencontrent, constituent encore, au cours des deux premières décennies du $\mathrm{II}^{\mathrm{e}} \mathrm{s}$., le fournisseur principal, en vaisselle de table, de la partic occidentale du continent européen. Il n'est 
ALLONNES état 1
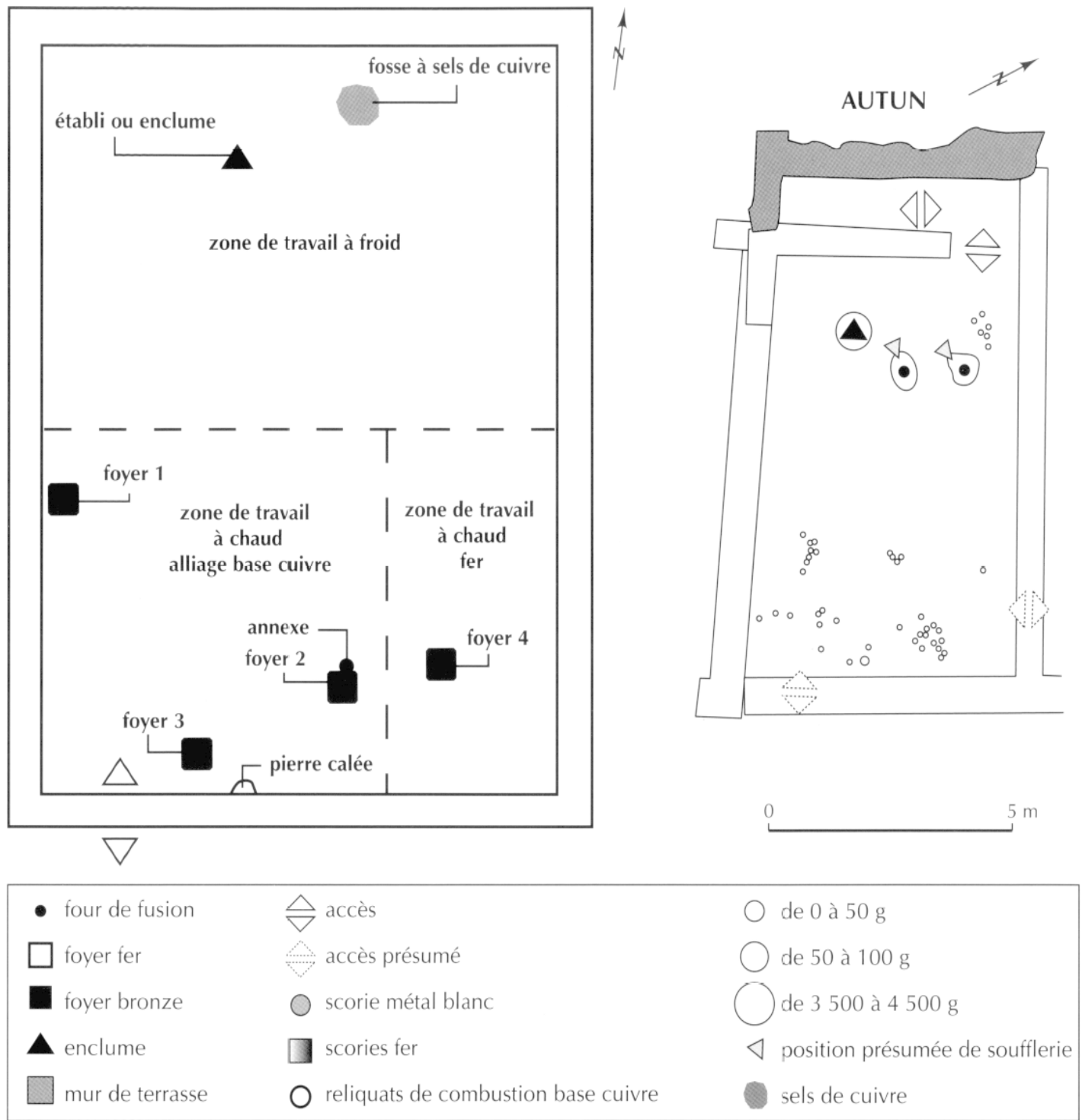

Fig. 45 - Comparaison entre l'atelier métallurgique d'Allonnes (état 1) et celui d'Autun (P1-9EE2) (d'après Chardron-Picault, Pernot dir., 1999, p. 198, fig. 161).

donc guère étonnant que ces niveaux comportent de nombreux services « tardifs » et plusieurs vases hémisphériques moulés (Drag. 37). Il semble ainsi que l'on puisse situer cet horizon entre les années 110 et 130 .

\section{La fosse-dépotoir $\mathrm{F} \mathbf{5 0 7}$}

À l'ouest de l'atelier 6, la fosse-dépotoir F 507 a entaillé le remblai entre les deux aires de travail (fig. 40,41 et 43 ). Les vestiges sidérurgiques sont ici relativement faibles, 532,74 $\mathrm{g}$ pour les alliages à base de cuivre, $157 \mathrm{~g}$ pour le fer et $74 \mathrm{~g}$ pour les alliages de métal blanc. Cette fosse contenait une grande quantité de plaques en alliage à base de cuivre recouvertes d'une fine feuille d'or et avec des traces de découpe. Elle renferme des déchets de matériaux de construction (plaques de revêtement en calcaires métamorphiques et grès), de la faune, de la sigillée et de la céramique commune qui ont permis de dater son comblement vers 110-130 apr. J.-C. Elle est donc contemporaine de l'activité de l'édifice 6 . Son comblement est scellé par la même couche cendreuse qui recouvre l'atelier (fig. 49).

Vingt-quatre individus en sigillée appartiennent majoritairement aux ateliers du sud de la Gaule et plus particulièrement à ceux de La Graufesenque. Les services créés au début de la période flavienne constituent l'essentiel de ce répertoire. Sont ainsi présentes trois assiettes et deux coupelles du service Ve. A, mais aussi deux assiettes et coupelles du service Ve. C. Le répertoire se compose également d'une coupelle Drag. 33 au profil complet, dont il ne reste de l'estampille que la lettre $\mathrm{O}$ (très certainement la première lettre du terme OFFICINA), des coupelles Drag. 24/25, Drag. 27 ainsi qu'une assiette Drag. 18.

Les sigillées du centre-ouest de la Gaule sont représentées par un vase hémisphérique guilloché (dit Drag. 37, équivalent de la forme Lez. 8) ainsi qu'une assiette Drag. 35 (Ve. A2). 

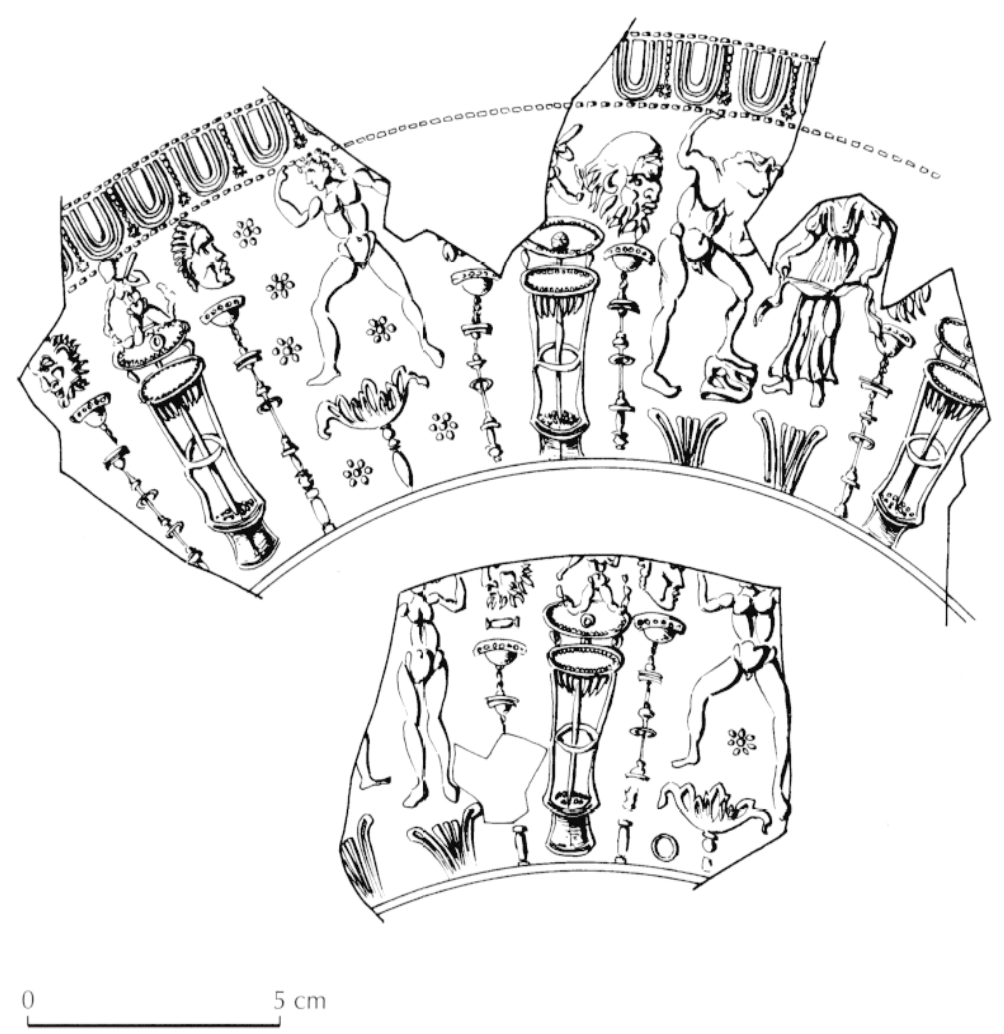

1
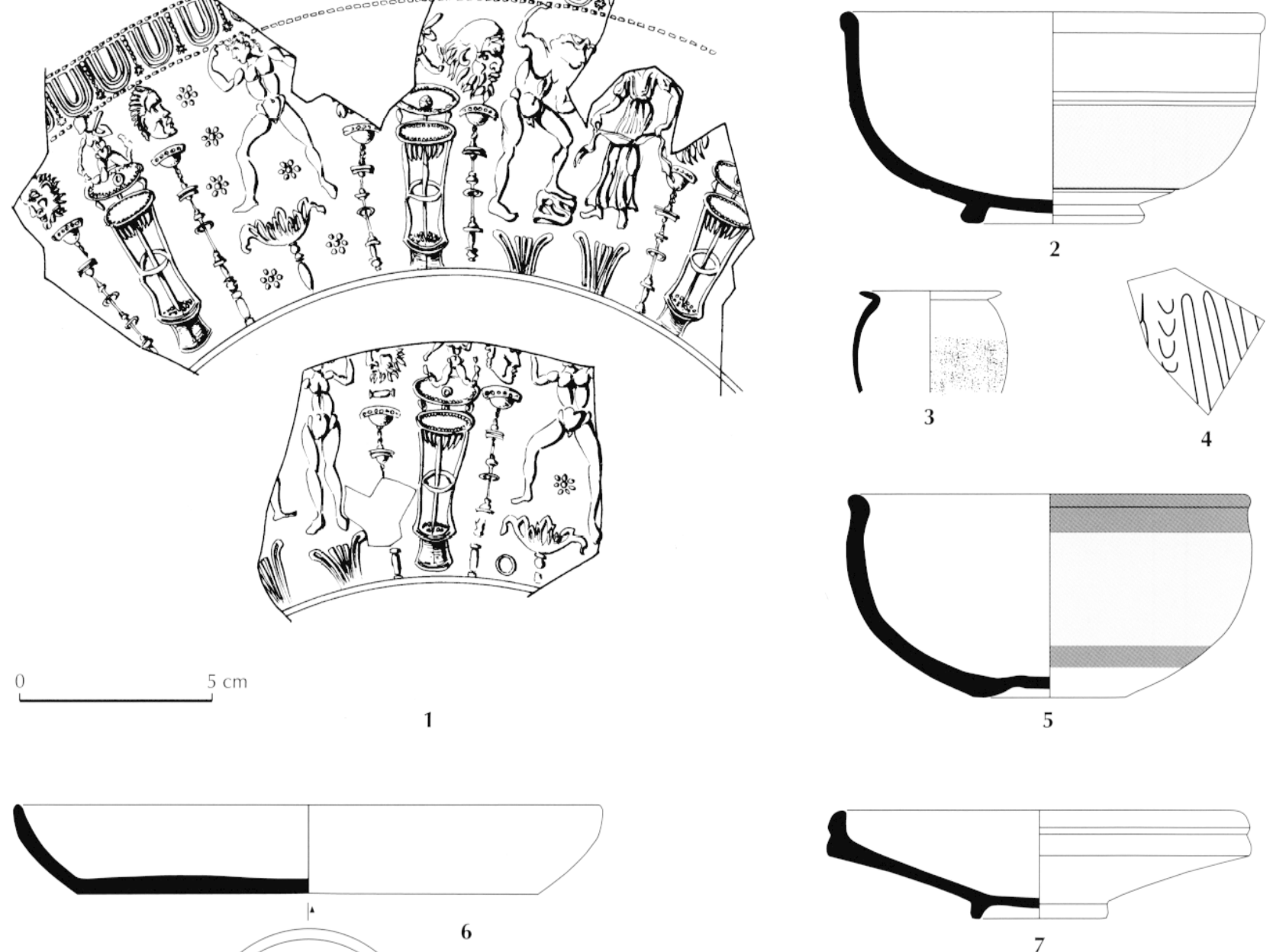

6
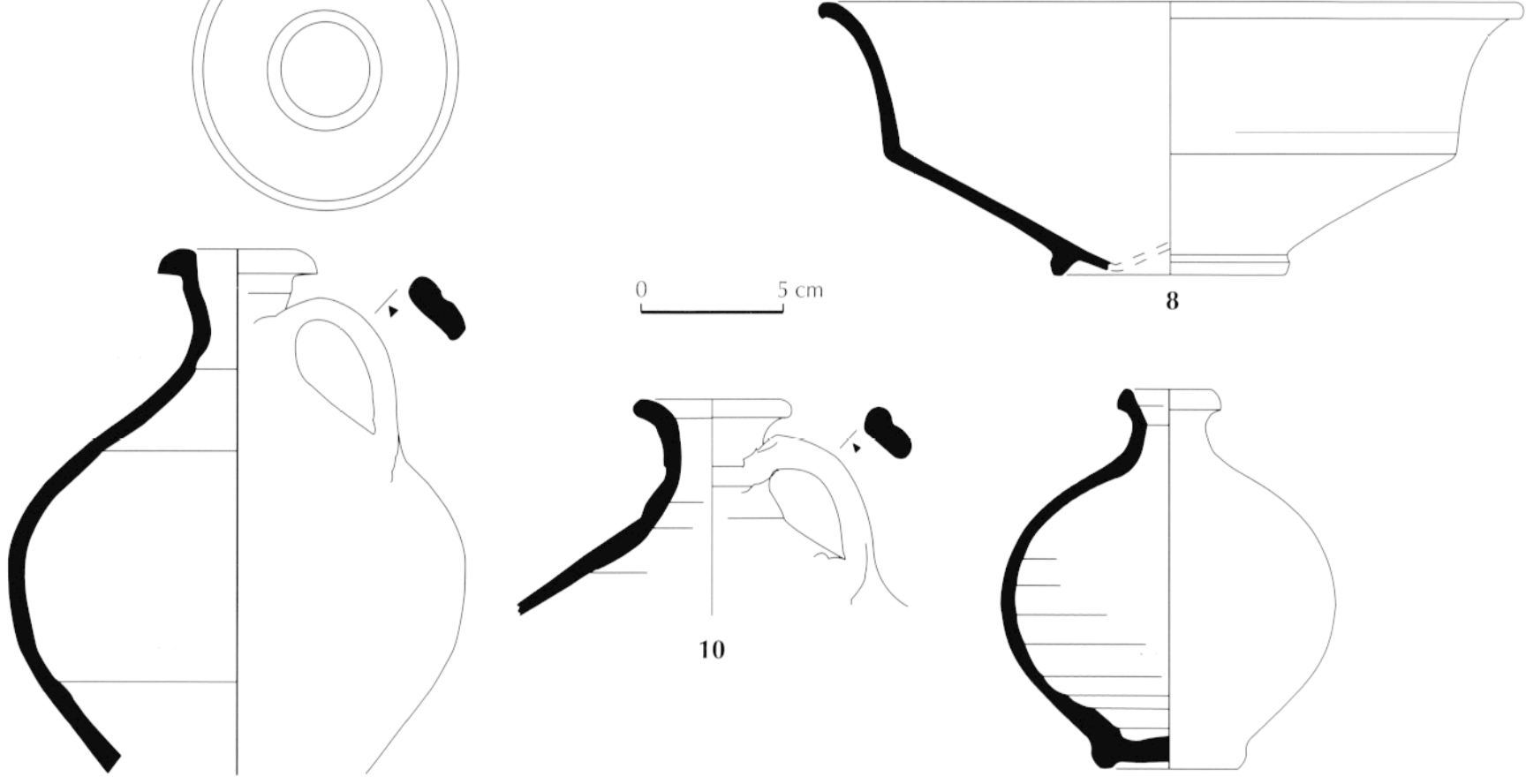

0

$5 \mathrm{~cm}$

8

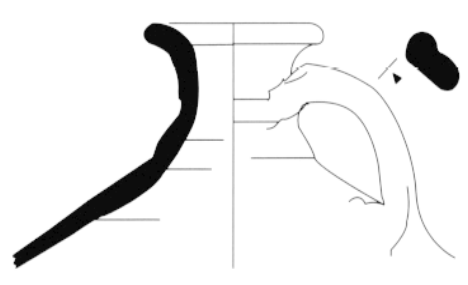

10

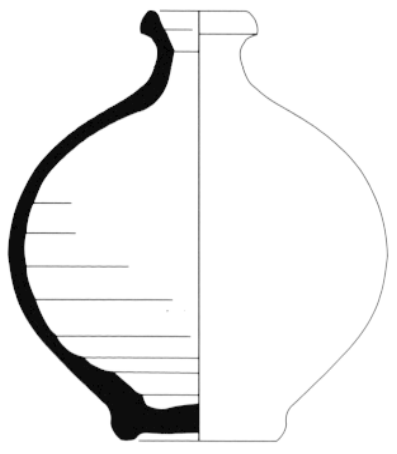

11

Fig. 46 - Phase de travaux de finition du temple (édifice 3, horizon 5c), mobilier céramique issu de la fosse-dépotoir $F 507$ : 1 , sigillée moulée ; 2, sigillée lisse ; 3-4, paroi fine engobée; 5, céramique peinte ; 6-8, fumigée ; 9-11, commune claire tournée. 
Les productions du centre de la Gaule comptent deux vases moulés et plusieurs pièces lisses. Les premiers possèdent des décors dans les styles de P-10 (fig. 46, n'1) et d'AVITVS I VEGETVS. Ils présentent un vernis rouge clair, plus luisant que brillant, et une pâte à dominante orangée, avec des caractéristiques conformes aux premières productions à vernis grésé de Lezoux. Compte tenu de la datation stylistique généralement admise pour ces produits, une fourchette chronologique couvrant les années 110-130 paraît acceptable.

Le répertoire de la sigillée lisse se compose d'une coupe à collerette Lez. 170 (Curle 11), d'une coupe hémisphérique Lez. 8 pourvue d'un décor guilloché (fig. $46, n^{\circ} 2$ ), d'une coupelle Lez. 14 (Ve. Al), mais aussi d'une assiette Lez. 49 (Ve. B2). Les trois premières formes ont un vernis grésé et une pâte calcaire. La dernière présente un vernis imparfaitement grésé, orangé brillant (identique aux pièces flaviennes de Lezoux), associé à une pâte orangée. Ces vases sont issus des ateliers lézoviens et correspondent aux productions des années 110-130.

Les 142 individus en céramique commune ou fine contribuent à définir le répertoire du début du $\mathrm{II}^{\mathrm{C}}$ s. apr. J.-C. La céramique commune de cette période n'était jusqu'à présent connue que par des sondages effectués dans les années 1980 et 1990 dans la ville du Mans et dans celle d'Allonnes.

Deux types de décor sur parois fines engobées sont réalisés sur des gobelets de forme ovoïde de type I (fig. $46, n^{\text {os }} 3$ et 4 ) (Bet, Henrique-Raba, 1989). Le premier se caractérise par des projections de sable sur les faces externes des vases, souvent à mi-hauteur de la panse (fig. 46, n'3). L'un possède une pâte rouge et un engobe noir; l'autre, différent techniquement, a une pâte et un engobe orangé. Ces pots ovoïdes à décor sablé sont commercialisés en Gaule de la période préflavienne jusqu'au début du $\mathrm{II}^{\prime \prime}$ s. apr. J.-C. (Symonds, 1992). Le second décor est matérialisé par des motifs d'épingle à cheveux associé parfois à des lunules ${ }^{28}$. L'engobe varie du brun au noir, les pâtes sont de couleur beige. Ces caractéristiques se rencontrent sur les vases fabriqués dans les ateliers sigillés du centre de la Gaule et plus particulièrement ceux de Lezoux.

La céramique peinte est présente avec un bol de type Roanne ${ }^{29}$, à pâte fine micacée et de couleur beige (fig. 46, $n^{\circ} 5$ ). Cette forme à panse globulaire est terminée par une lèvre simple en bourrelet. Le fond est marqué en son centre par un léger ombilic. La technique de décoration de ce vase, bandes rouges et blanches sans aucun motif, caractérise plus particulièrement les productions du $\mathrm{II}^{\mathrm{e}}$ s. apr. J.-C. à Roanne (Grand, 1995).

Les céramiques fumigées ${ }^{30}$ sont représentées par deux formes d'assiette. L'une à lèvre simple est à fond plat et décors concentriques (fig. 46, $\mathrm{n}^{\circ} 6$ ). L'autre est à fond annulaire

28. Les découvertes de gobelets identiques ne sont pas rares en Sarthe (Lambert, Rioufreyt, 1976, p. 350, n"1 ; Fourmy, Guilleux, 1983, p. 26, photo 10 et 1984 , p. 38 , pl. $\left.4, \mathrm{n}^{\circ} 130\right)$.

29. Très peu de bols de type Roanne ont été découverts dans la région. Quelques exemplaires sont signalés à Jublains en Mayenne (Naveaul, 1992).

30. Ces formes de fumigées sont à pâte plutôt grise ct surface lustrée de couleur gris bleuté à bleu, parfois noire. marqué et à lèvre verticale à cannelures, proche du type Ménez 55́c (fig. 46, n⿳7 7 ). Une forme de bol à fond annulaire, paroi carénée et lèvre éversée ronde, de type Ménez 110 (Méne\%, 1985), complète le répertoire ${ }^{31}$ (fig. 46, $n^{\circ} 8$ ). Les pâtes sont beiges à gris-blanc et les surfaces lustrées vont du noir au gris bleuté.

Les céramiques communes claires tournées sont attestées principalement par des cruches globulaires à lèvre en capuchon recouverte le plus souvent d'un engobe orangé (fig. 46, $n^{\circ} 9$ ) ${ }^{32}$. Les cruches à lèvre simple terminée en bourrelet sont fréquentes (fig. 46, n⿳10). Un type de cruche sans anse est également bien représenté (fig. 46, n'11) ; de petite taille (n'excédant pas $15 \mathrm{~cm}$ de hauteur), la panse est globulaire et la lèvre triangulaire ; le revêtement est un engobe orange clair ; certaines de ces cruches ont des surfaces brutes laissant apparaître la pâte de couleur blanche ou orange ${ }^{33}$. Les mortiers, avec ou sans engobe, sont peu nombreux et se définissent par des formes assez proches à bandeau droit ou oblique et à lèvre massive (fig. $47, \mathrm{n}^{\text {os }} 1$ et 2 ). En céramique commune à engobe orange micacé (fig. 47, ${ }^{\circ}$ 3-5), l'écuelle à lèvre rentrante en bourrelet est la plus fréquente parmi les écuelles tripodes à cuire ${ }^{34}$. Les pots à cuire et à lèvre moulurée ont un engobe orange micacé sur la lèvre et le départ de la panse.

Les céramiques communes à engobe crème sont constituées d'un ensemble de cruches à panses globulaires et à lèvre à double ou triple cannelures (fig. $47, \mathrm{n}^{\text {os }} 6-9$ ). La pâte est orange et les surfaces sont couvertes d'un engobe dure de couleur crème ${ }^{35}$. En association, le groupe des cruches à deux anses ou

31. L'assictte à lèvre à cannelures est répertoriéc dans le temple de Oisseau-le-Petit dans la Sarthe et en Mayenne dans le temple du Portdu-Salut à Fntrammes (Naveau, 1983, pl. 27, n" 5). La datation proposée est le $\mathrm{I}^{\text {tr }}$ s. apr. J.-C. Dans le catalogue de Y. Ménez (1985), la forme est datée du règne de Tibère jusqu'à 70 apr. J.-C. Pour le bol, la datation 30-60 apr. J.-C. est proposée. Cette forme est très présente dans le site des Filles-Dieu au Mans dans le contexte cité précédemment, dans le site du quai Louis-Blanc (Fourmy, Guilleux, 1984, p. 34, pl. 2, n" 85) daté du $\mathrm{I}^{\circ \mathrm{r}}$ s. apr. J.-C., ainsi que dans une structure à Allonnes dont le comblement ne s'est pas effectué après 130 (Darlot, 1986, p. 39, $\mathrm{n}^{\circ}$ 30). La fosse dépotoir F 507 du chantier du temple de Mars Mullo a révélé une proportion d'au moins six exemplaires pour l'assiette et d'au moins dix individus pour le bol. Il semblerait donc que ces céramiques fumigées aient pu perdurer dans la Sarthe jusqu'au premier quart du II" s. apr. J.-C. Toutefois, les traces d'usure assez marquécs sur les exemplaires de la Forêterie ainsi que la présence de trous de réparation sur le bas de la panse peuvent laisser penser à une utilisation assez longue (quelques éléments résiduels sont encore dans le contexte suivant).

32. Lne forme identique est signalée à Entrammes dans le temple du Port-du-Salut (Naveau, 1983, pl. 28, n¹0).

33. Ces cruches sont signalées au Mans dans une fosse du quai I.ouisBlanc (Fourmy, Guilleux, 1983, p. 21, photo 2) et dans deux couches d'un atelier de tissage de L'Étoile/Jacobins au Mans (Guillier, Pouli, 1991 , fig. $\left.6, \mathrm{n}^{\circ} 7\right)$.

34. Des céramiques identiques proviennent d'une fosse du Mans datéc de 80-90 apr. J.-C. (Fourmy, Guilleux, 1983, pl. 3, nos 11 et 12) ainsi que d'une autre fosse d'Allonnes dont le comblement n'est pas postéricur à 130 (Darlot, 1986, p. 39, n"223).

35. Ces céramiques sont simplement signalées en Sarthe dans un atelier de tissage de L'Étoile/Jacobins au Mans et datées de 50-100 apr. J.-C.. (Guillier, Pouli, 1991, p. 42, fig. 7, $\mathrm{n}^{\circ} \mathrm{9}$ et 10 ). 

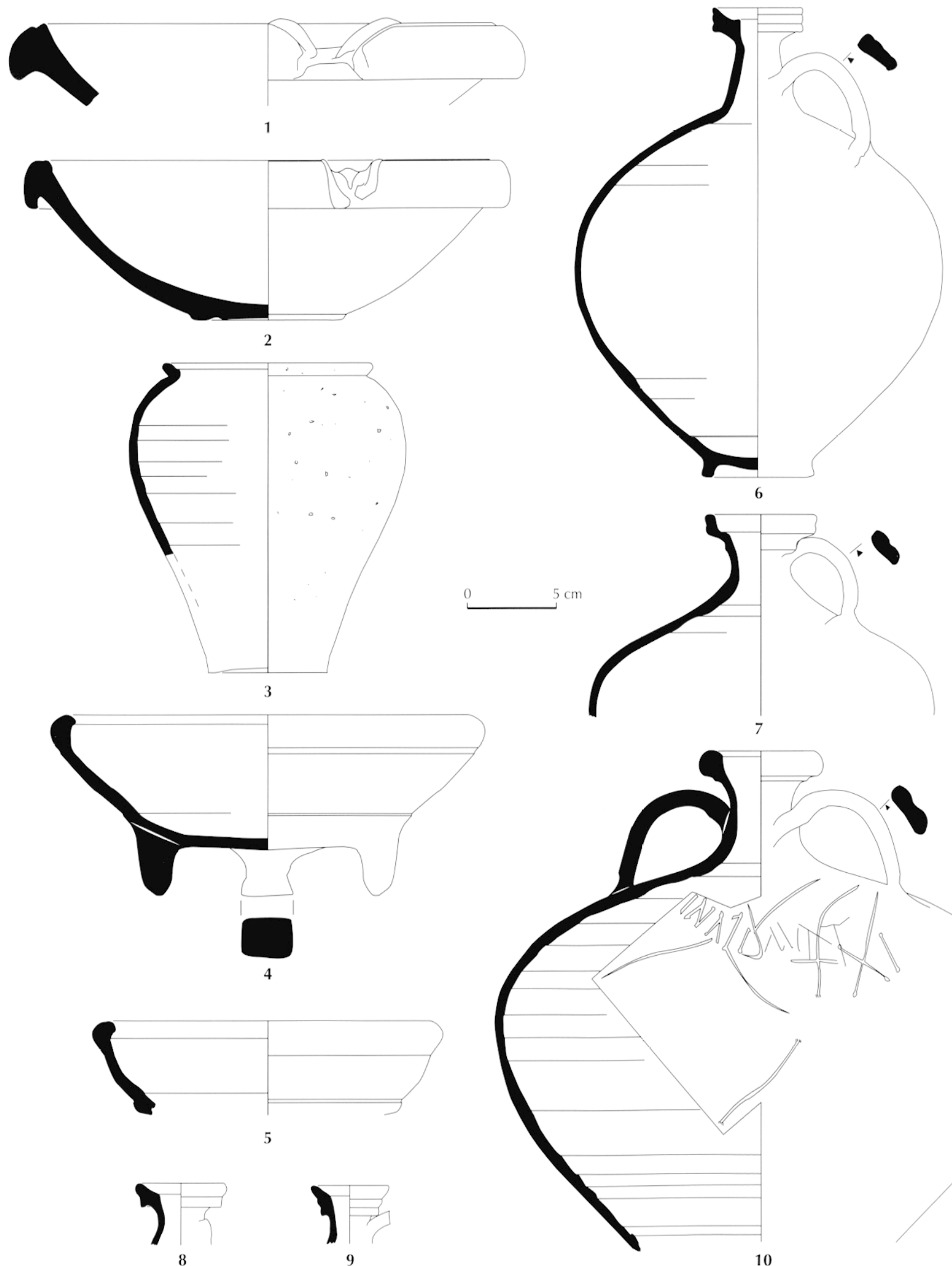

8

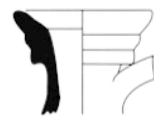

9

Fig. 47 - Phase de travaux de finition du temple (édifice 3, horizon 5c), mobilier céramique issu de la fosse-dépotoir 1507 : 1-2, commune claire tournée; 3-5, commune à engobe orange micacé; 6-10, commune à engobe crème. 


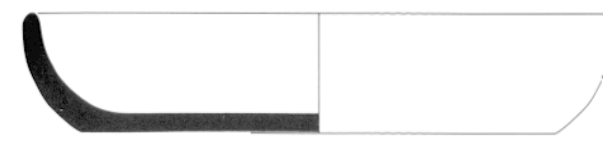

1

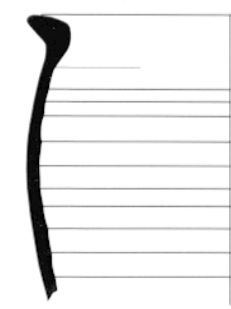

4
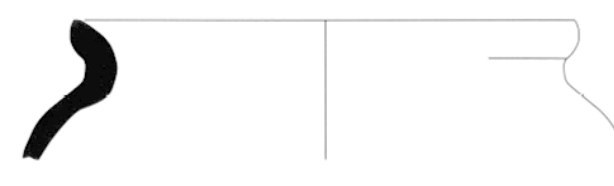

7
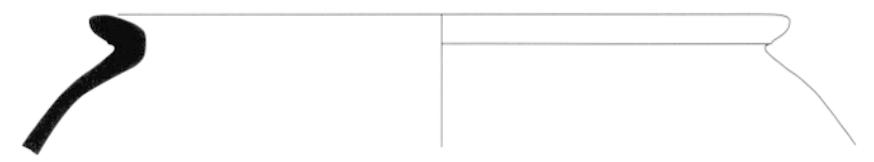

8

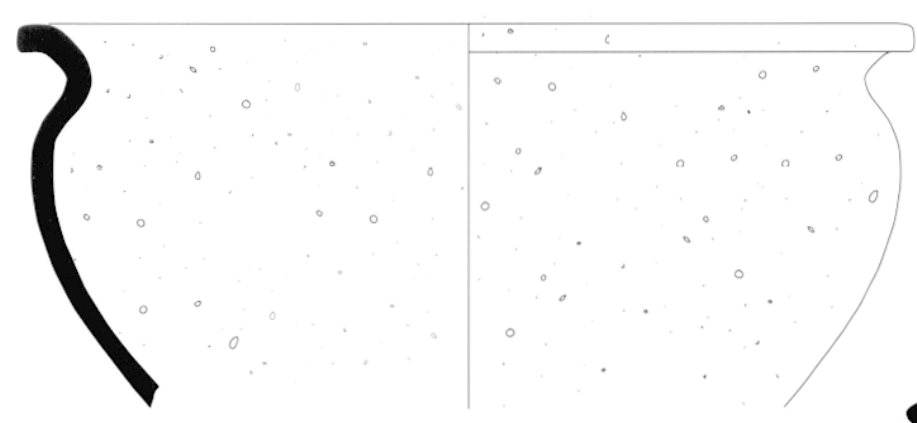

9

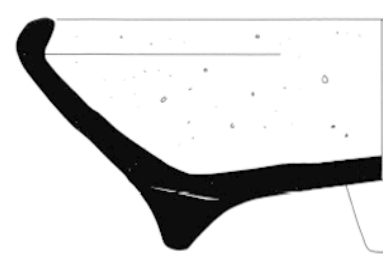

10

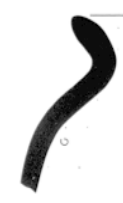

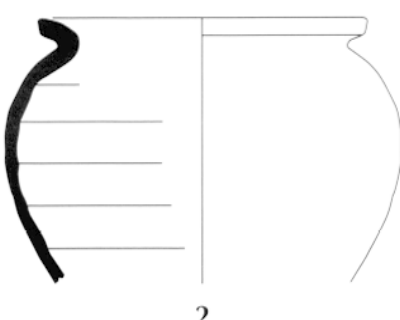

2
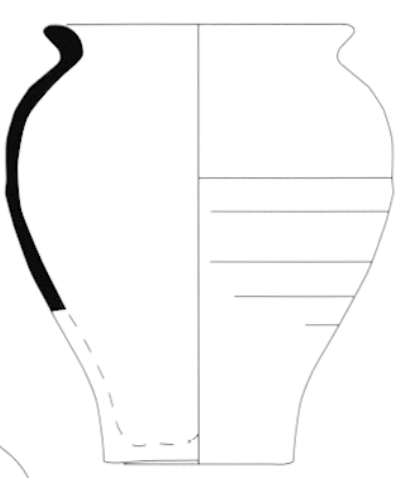

5
7
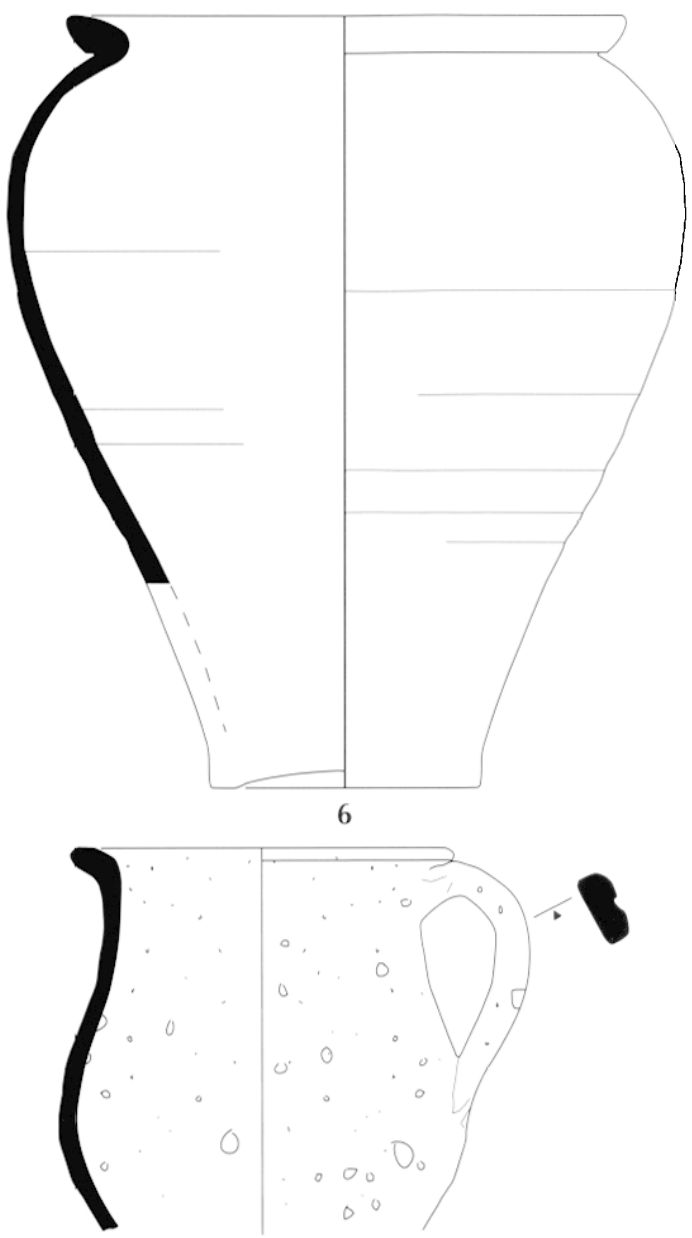

12

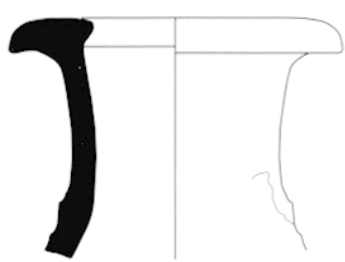

14
$5 \mathrm{~cm}$

(0)

11

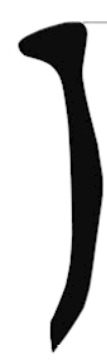

13

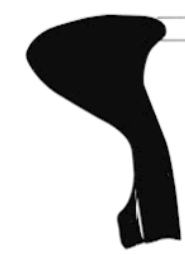

Fig. 48 - Phase de travaux de finition du temple (édifice 3, horizon 5c), mobilier céramique issu de la fosse-dépotoir F 507 :

1-8, commune grise tournée; 9-12, commune sombre grossière tournée; 13-15, amphore. 
amphorettes (fig. 47, $\mathrm{n}^{\circ} 10$ ) se définit par deux formes aux panses très globulaires et aux lèvres parfois proches des amphores de type Gauloise 4. Elles ont une pâte orangée et micacée, et sont couvertes d'un engobe dur et de couleur crème. Les formes et les caractéristiques techniques de cet ensemble sont certainement à associer à la production d'un atelier local. Des cruches à deux anses, proches sur le plan morphologique de celles à engobe crème, se définissent par une pâte dure, marron au cœur gris et une surface extérieure brune.

La céramique commune grise tournée comprend un type d'assiette (ou plat suivant les modules) définie par une paroi oblique convexe et une lèvre simple (fig. $48, \mathrm{n}^{\circ} 1$ ). Les pots sont pour la plupart à panse ovoïde. Les lèvres sont éversées en forme de trapèze plus ou moins détachées de la panse, allongées et rectangulaires ou courtes et rectangulaires 36 (fig. $48, \mathrm{n}^{\text {os }} 2-8$ ). Le pot à lèvre épaisse oblique trapézoïdale est le plus gros module complet (fig. $48, \mathrm{n}^{\circ} 6$ ). Sa fréquence, peu élevée pour cette période (par rapport au contexte suivant), est probablement la marque de son apparition. Tous ces pots ont pour fonction certaine de cuire des aliments. Les dépôts de suie et les coups de feu sur les parties hautes extérieures des panses et sur les fonds en sont les indices. Le pot à lèvre éversée en amande, de plus grande taille, a plus particulièrement pour fonction de contenir des denrées alimentaires (fig. 48, n8). Les types à lèvre fine et trapézoïdale ainsi que ceux à lèvre en amande sont aussi réalisés en commune sombre grossière tournée (fig. 48, n 11). La matrice, de couleur grise à marron, contient de nombreuses particules de mica et de quartz laiteux. Sont associés à ces pots, une jatte à lèvre éversée rectangulaire (fig. 48, no 9), une écuelle tripode à lèvre rentrante (fig. 48, $\left.\mathrm{n}^{\circ} 10\right)$ ainsi qu'un pichet à lèvre ronde ${ }^{37}$ (fig. 48, $\mathrm{n}^{\circ} 12$ ).

Les amphores sont peu nombreuses: un col de Gauloise 4 de Narbonnaise (non représenté), un col de Dressel 20 de Bétique (fig. 48, n 15) qui peut être daté de 110-150 apr. J.-C. (Martin-Kilcher, 1987) et deux cols de Gauloise 5 ou assimilée avec une pâte brune au cœur gris (fig. $48, \mathrm{n}^{\text {os }} 13$ et 14). Il est généralement admis que ce type d'amphore a circulé du dernier quart du $\mathrm{I}^{\mathrm{er}} \mathrm{s}$. apr. J.-C. et durant tout le II ${ }^{\mathrm{e}}$ s. apr. J.-C. (Laubenheimer, 1986).

\section{L'ACHÈVEMENT DE LA CONSTRUCTION DU TEMPLE MONUMENTAL : LE DÉMONTAGE DE L'ATELIER 6 (HORIZON 5D, ENTRE 120 ET 140 APR. J.-C.)}

Une fois l'édifice cultuel achevé, l'atelier 6 est évacué, la plupart des outils et des matériaux sont emportés. Le bâtiment a été ensuite démonté puis détruit, les cendres des foyers ont été étalées sur une grande surface recouvrant également la fosse-dépotoir F 507 (fig. 40 et 49). Cette couche, datée de 120-140 apr. J.-C., scelle les niveaux de construction du temple. Les lots de céramique sigillée de ce niveau permettent d'établir un faciès chronologique similaire au précédent. Seule la

36. Ces formes sont encore peu reconnues en Sarthe. Elles sont identifiées dans un bâtiment du site des Filles-Dieu au Mans dans un contexte de la fin du I"r s.-début du II" s. apr. J.C.C.

37. Ces types d'écuelles et de pichets se retrouvent à Oisseau-le-Petit dans un contexte du $\mathrm{I}^{\mathrm{rr}} \mathrm{s}$. apr. J.-C. (communication J. Rioufreyt).

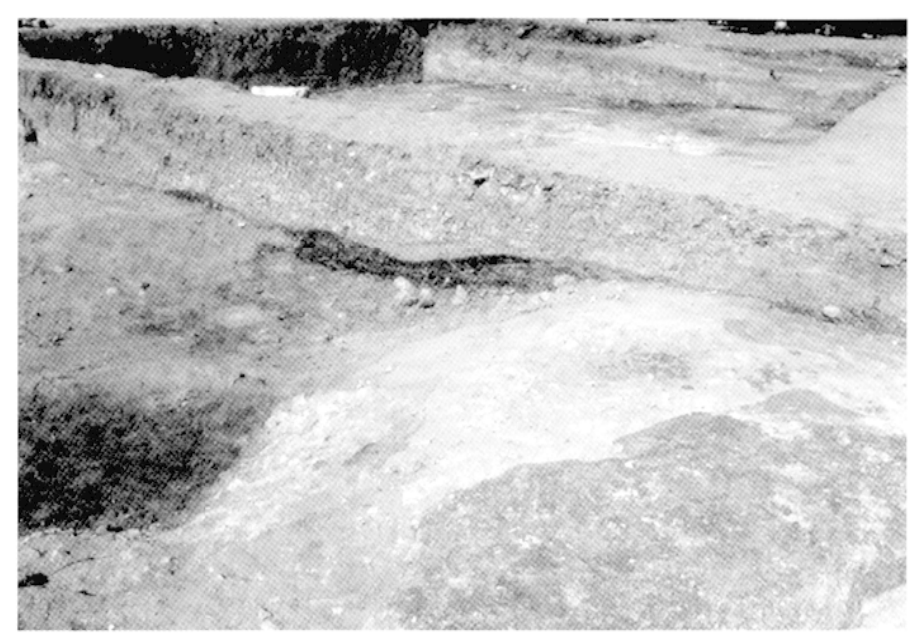

Fig. 49 - Le comblement de la fosse-dépotoir F 507 scellé par la couche de cendres (horizon 5d).

présence de quelques vases non antérieurs aux années 120 , dont la datation (de production) peut être envisagée jusqu'aux années 140 , se démarque des conclusions alors proposées. Il est ainsi possible, à titre d'hypothèse, de décaler d'une décennie la datation de ces niveaux, à savoir entre les années 120 et 140.

Le mobilier sigillé comportant un peu moins d'une trentaine d'individus se compose de pièces provenant de trois origines géographiques différentes. Les productions des ateliers de Gaule du Sud, principalement de La Graufesenque, avec douze individus, constituent le lot le plus important. Toutes les pièces, à l'exception d'une, sont apparues à la période flavienne et peuvent encore avoir été utilisées au cours des premières décennies du II $^{c}$ s. Les services de table Ve. A (deux assiettes, deux coupelles) (fig. 50, $\mathrm{n}^{\text {os }} 1-3$ ), Ve. B (une assiette, une coupelle) et Ve. C (une coupelle) sont présents. Figurent également dans ce lot un mortier Curle 11 et une coupelle Drag. 33 portant une marque de l'atelier de FLAVIVS GERMANVS (graphie : OF.F.GER, cf. fig. 50, n4b), en activité au cours des dernières décennies du I ${ }^{\mathrm{er}} \mathrm{s}$. et au début du $\mathrm{II}^{\mathrm{c}} \mathrm{s} .{ }^{38}$. Le seul vase moulé du sud de la Gaule est une coupe hémisphérique Drag. 37 dont la forme n'est pas antérieure aux années 60-70. Les caractéristiques stylistiques du décor n'offrent guère de précision chronologique supplémentaire.

Les productions du centre-ouest de la Gaule sont représentées par une coupelle Drag. 35 (équivalent Ve. Al), deux vases hémisphériques Drag. 37, et deux coupes hémisphériques à lèvre en bourrelet, forme dite Drag. 37 guillochée qui constitue une des productions les plus importantes de ces ateliers.

Le dernier groupe de production de céramique sigillée est celui du centre de la Gaule, quatre vases moulés possèdent un décor identifiable sur neuf individus. Sont ainsi attestées : une

38. Cette estampille est présente à Vechten (Hollande) et à Saalburg (Allemagne) dans les niveaux de la fin du $\mathrm{I}^{\mathrm{er}} \mathrm{s}$. (Polak, 2000, p. 240, G43). D'autres graphies figurent dans le groupe IV (75-110) des estampilles découvertes dans la petite agglomération de Valkenburg en Hollande (Bloemers, Sarfatij, 1976) et F. Hanuı (à paraître) recense ce nom dans l'horizon II (80-120) de la classification des marqueurs chronologiques du nord de la Gaule. 

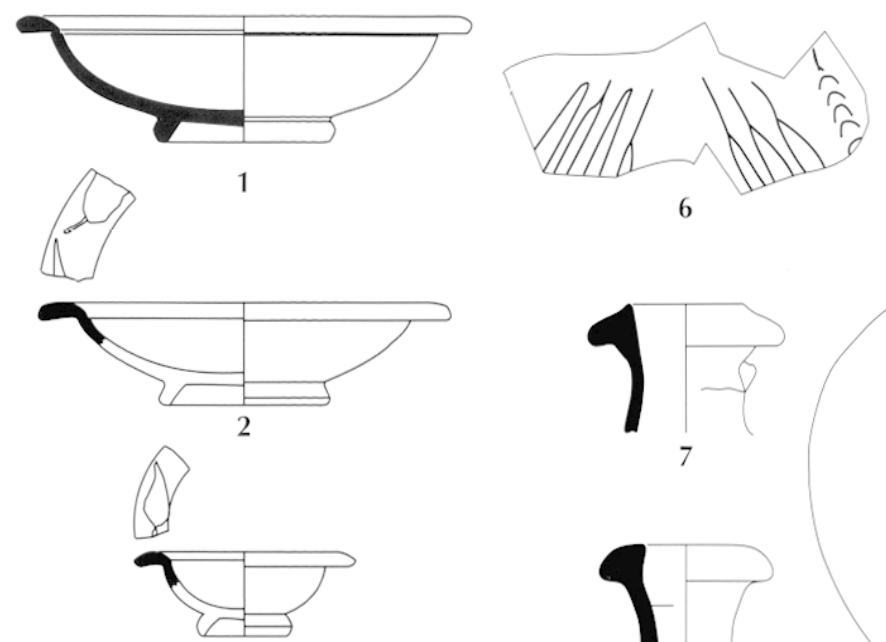

3

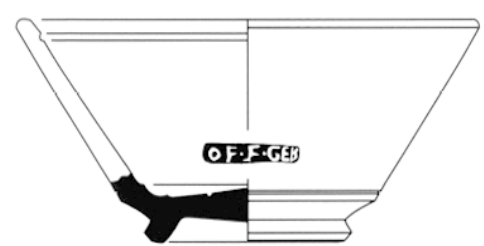

$4 \mathrm{a}$

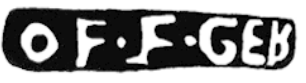

4b
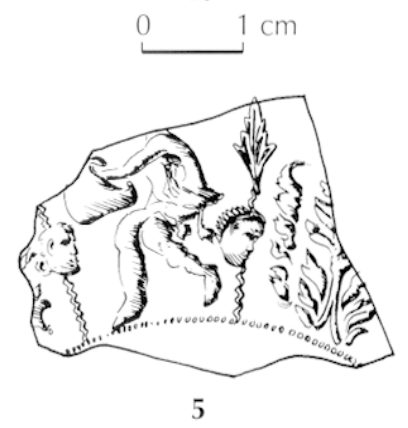

0 $5 \mathrm{~cm}$
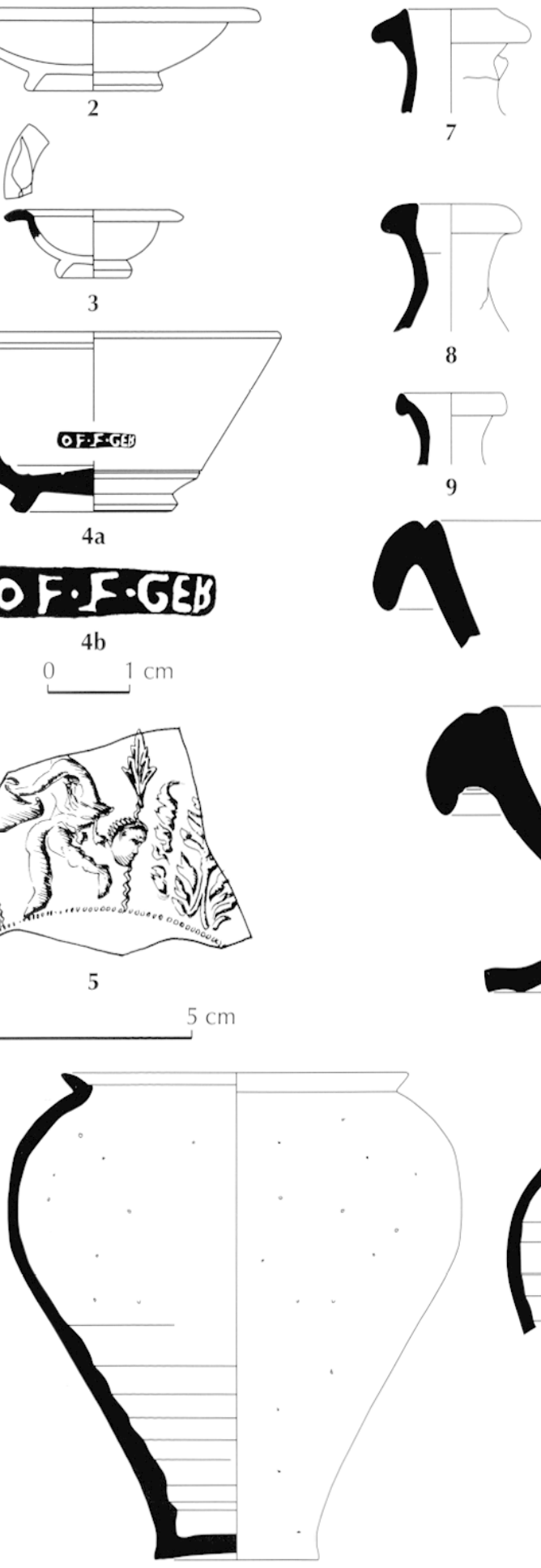

8

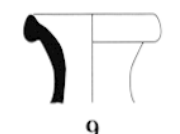

9

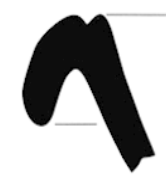

13
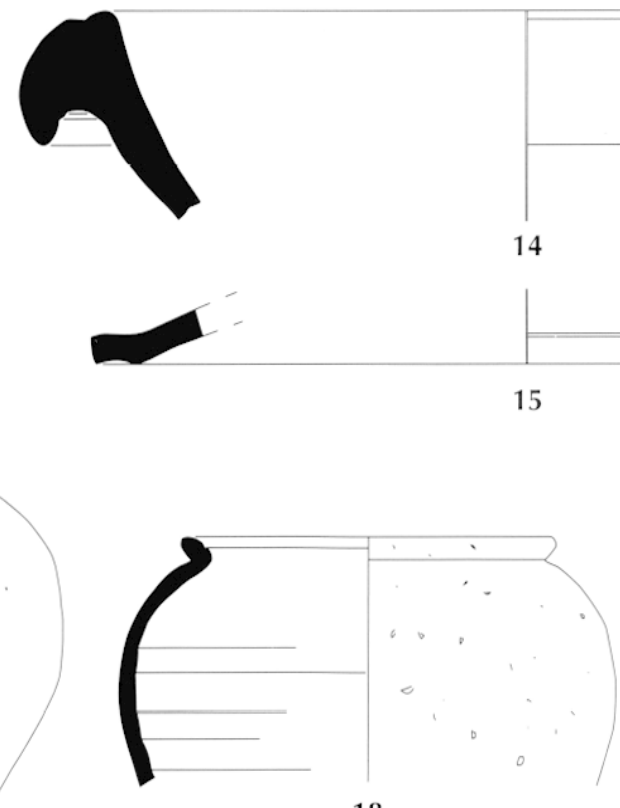

18

0 $5 \mathrm{~cm}$

14

15

19

17

Fig. 50 - Phase d'achèvement de la construction du temple (édifice 3, horizon 5d), mobilier céramique issu des couches de démontage de l'édifice 6 : 1-4, sigillée lisse; 5, sigillée moulée; 6, parois fines engobées; 7-15, commune claire tournée; 16-19, commune à engobe orange micacé. 

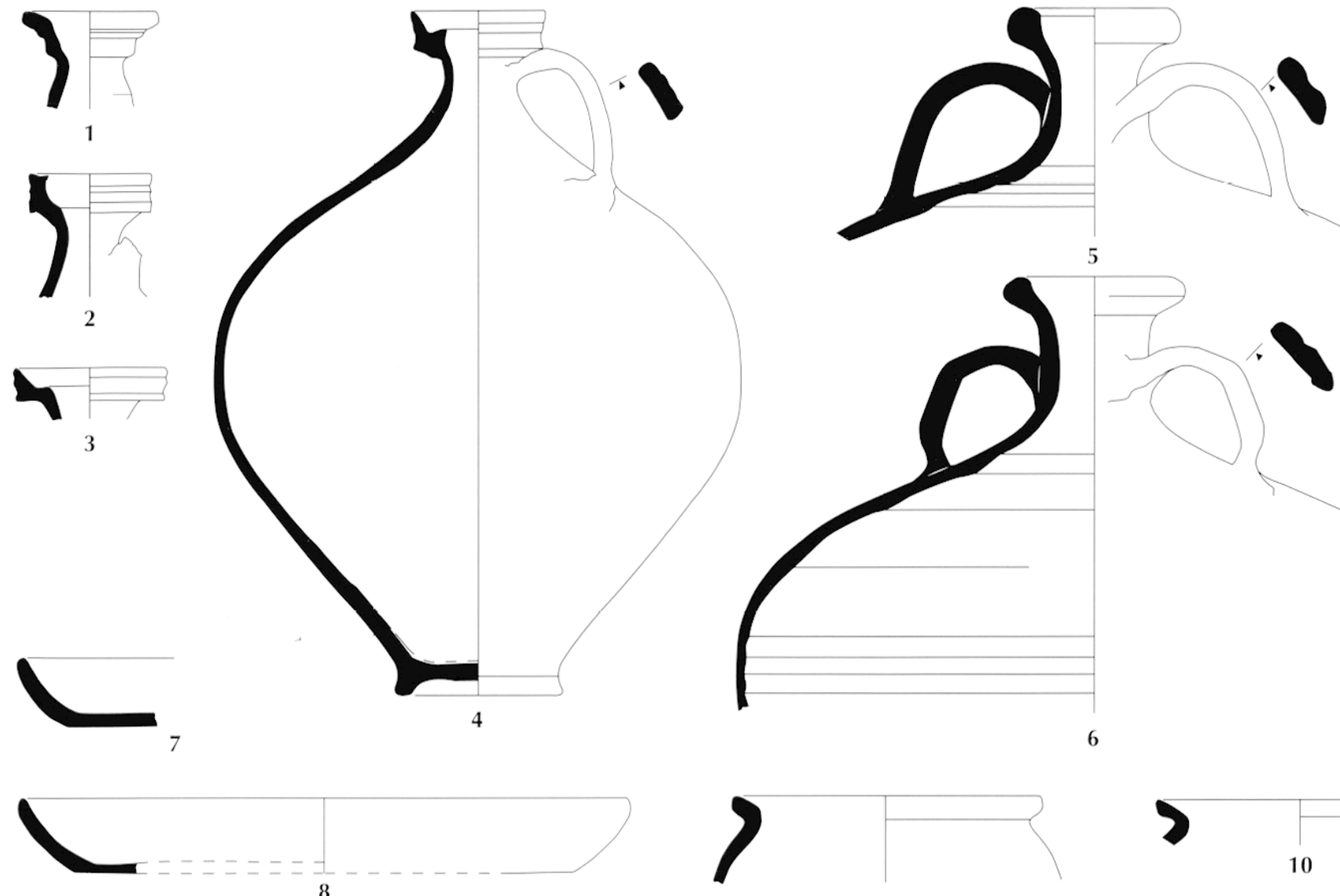

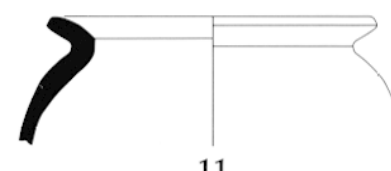

11

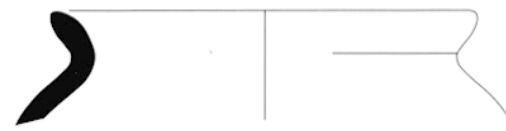

14

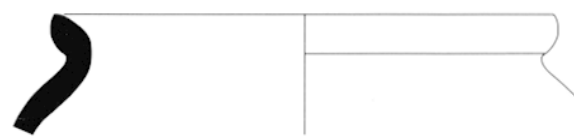

15

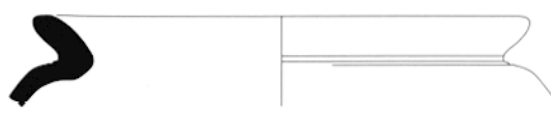

16

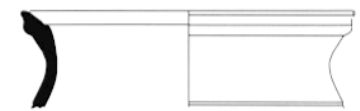

17

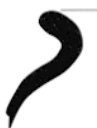

18
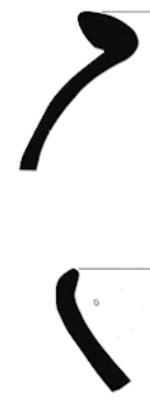

12

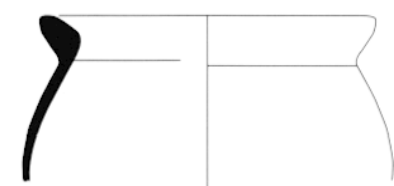

13

Fig. 51 - Phase d'achè̀ement de la construction du temple (édifice 3), mobilier céramique issu des couches de l'édifice 6 :

1-6, commune à engobe crème; 7-17, commune grise tournée ; 18-22, commune sombre grossière tournée. 
composition du "Potier à la Rosette " associée à un vase issu des ateliers des Martres-de-Veyre (datation des annécs 90 à 120), une autre dans le style d'AVITVS I VEGETVS dont le support est originaire de Lezoux (vernis orangé offrant ainsi une datation technique et stylistique des années 110 à 130). Les deux autres décors appartiennent d'une part au style de P-10 et d'autre part à celui de BVTRIO (fig. 50, $\mathrm{n}^{\circ} 5$ ). Les supports sont originaires des ateliers lézoviens et possèdent des qualités techniques identiques au vase moulé portant le décor d'AVITVS I VEGETVS. Ils peuvent de ce fait être datés pour le premier des années 110 à 130 et pour le second entre 120 et 140 . L'absence de vernis rouge brillant pour ce dernier ne permet pas d'envisager une période de production au-delà de 140 , alors que la chronologie admise aujourd'hui pour ce style décoratif (création des décors) se poursuit jusqu'aux années 150 (Rogers, 1999).

Les vases lisses du centre de la Gaule sont représentés par deux coupes à collerette Lez. 170 (Curle 11) des dernières décennies du $\mathrm{I}^{\mathrm{er}}$ s., unc coupelle Lez. 14 (Ve. Al) des années 120 à 140, ainsi que deux coupes hémisphériques guillochées L.cz. 8 antérieures aux années 150 .

Le répertoire des céramiques communes (178 individus) n'évolue que très peu entre le début du II" s. et le dernier quart de la première moitié du II $\mathrm{c}$. apr. J.-C. Les formes et les types de pâte ne varient pas. Seules les quantités changent pour certains vases. Les céramiques dites à parois fines engobées sont en grande majorité des gobelets à décor d'épingle à cheveux (fig. 50, no6).

En céramique commune claire tournée, les mêmes formes de cruche prévalent (fig. 50, $n^{\circ 5} 7-10$ ), à l'exception de la forme à lèvre simple en bourrelet qui disparaît à cette période. Certaines cruches présentent un capuchon plus court (fig. 50, $\left.n^{\circ} 8\right)$. Le mortier à bandeau vertical et lèvre fine et anguleuse est le mieux représenté (fig. 50, $n^{\circ} 11$ et 12). Deux nouvelles formes de mortier, l'un à lèvre fine et ovoïde (fig. $50, \mathrm{n}^{\circ} 13$ ) et l'autre à lèvre épaisse et rentrante marquant un crochet (fig. 50, $n^{\circ} 14$ ), sont également répertoriées. Les pots à lèvre moulurée de même forme que ceux à engobe orange micacé sont en proportion de plus en plus élevée. Ce contexte a aussi livré un couvercle à lèvre plate (fig. $50, n^{\prime \prime} 15$ ).

Les écuelles en céramique commune à engobe orange micacé, à lèvre rentrante à bourrelet, prédominent (fig. j0, $\mathrm{n}^{\circ} 16$ ). Les pots à cuire sont toujours bien présents (fig. $50, \mathrm{n}^{\circ} 17$ et 18). À cette production bien caractéristique, est associée une nouvelle forme définie comme un pichet à lève en bourrelet et à panse globulaire (fig. 50, $\mathrm{n}^{\circ} 19$ ). L'un de ces pichets a la particularité d'avoir été mis au feu, d'après les traces de coups de feu visibles sur le fond et la partie basse de la panse. Les cruches à une ou deux anses en céramique commune à engobe crème sont de moins en moins nombreuses (fig. 51, $n^{\text {os } 1-6) . ~}$

La céramique commune grise tournée est représentée par des assiettes (fig. 51, nos 7 et 8 ) et des pots à cuire caractérisés par différents profils de lèvre (fig. 51, n" 9-17). Les pots à lèvre fine et trapézoïdale sont les plus fréquents (fig. $51, \mathrm{n}^{\circ} 10$ ). Les céramiques communes sombres grossières tournées regroupent toujours les écuelles à lèvre rentrante et anguleuse (fig. 5l, $\left.n^{\circ} 19\right)$, les pots à lèrre en amande et trapézoïdale ainsi que les pichets (fig. $51, n^{\circ} 20$ ). Le répertoire se diversifie avec les pots à lèvre éversée globulaire (fig. $51, n^{\circ} 18$ ), une cruche à bec pincé de forme allongéc (fig. $51, n^{\circ} 22$ ) ainsi qu'un pichet à panse carénćc et lèrre rectangulaire (fig. 51, n”21). Les amphores découvertes sont peu nombreuses avec un seul col de Dresscl 20, daté de 110-150) apr. J.-C. (Martin-Kilcher, 1987), ainsi que des fragments de panse de Gauloise 3/5 de Narbonnaise et de Gauloise avec une pâte brune à cœur gris.

\section{L'AMÉNAGEMENT DE LA COUR (HORIZON 5E, ENTRE 140 ET 160 APR. J.-C.)}

\section{Le remblai}

Un important apport de terre plus ou moins stérile (sable et argile) nivelle tous les abords du temple; son épaisseur croît vers le nord (fig. 25 et 40). Bien que les données obtenues jusqu'à présent sur la phase d'aménagement de la cour soient de qualité et de fiabilité inférieures à celles d'autres séquences du site (notamment la construction des portiques), elles s'insèrent assez bien dans la chronologie d'ensemble. Les remblais d'aménagement de la cour et le radier qui couvre ces importants travaux de terrassement peuvent, ainsi, être situés au cours des années 140 à 160 .

Les sigillées (neuf individus) du remblai sous le radier de circulation de la cour, dans le secteur nord, comprennent des vases de la période flavienne, mais aussi éventuellement du début du II $^{\circ}$ s. : quatre coupes moulées dont deux carénées Drag. 29 (60-90) et deux hémisphériques Drag. 37 (70-120), une assiette du service Ve. A et une coupelle du service Ve. C, ces différents vases sont issus des ateliers de La Graufesenque. Les pièces du II" s. sont représentées par une coupe et une coupelle du service Drag. 35-36 (Ve. A) provenant du centreouest et de plusieurs pièces du centre de la Gaule, à savoir deux Drag. 37 des premières décennies de ce siècle, dont l'un possède un décor dans le style de P-10, une assictte Lez. 15 (Ve. A2) de la première moitié du II" s., un Drag. 37 probablement dans le style de SECVNDINVS I des années 120-140 et une pièce de morphologie indéterminée de la première moitié du II $^{*}$ s. Une coupelle Drag. 33 du milieu et du troisième quart du II" $^{\circ}$. et un vase moulé dépourvu de décor identifiable, mais que l'on peut dater également du milieu du II" s., constituent les vases les plus récents de ce lot.

\section{Le radier de la cour}

Un radier de pierres recouvre la cour et forme le niveau de circulation de celle-ci, légèrement plus bas que le sol des portiques, sauf à l'est où l'on observe une différence plus importante. Les faibles portions de radier sont conservées autour du temple à l'est, au sud et au nord (fig. 22). Aucune trace ne subsiste d'un probable pavement de dalles. La céramique sigillée situe cette étape entre 140 et 160 apr. J.-C.

Les quelques fragments de céramique sigillée proviennent tous des ateliers du centre de la Gaule. Deux de ces pièces peuvent être datées de la première moitié du II $^{\mathrm{c}} \mathrm{s}$. Il s'agit pour l'une, vraisemblablement, d'un vase cylindrique guilloché (Lez. 84) et pour l'autre d'une coupelle Lez. 14 (Ve. Al). Les autres sigillées sont représentées par deux coupes hémisphériques moulées (Drag. 37) dépourvues de leur décor, datées du deuxième quart du $\|^{\circ} \mathrm{s}$. dans un cas et du milieu ou du troisième quart du $\mathrm{II}^{\circ} \mathrm{s}$. dans le second. Une forme fermée, sans 

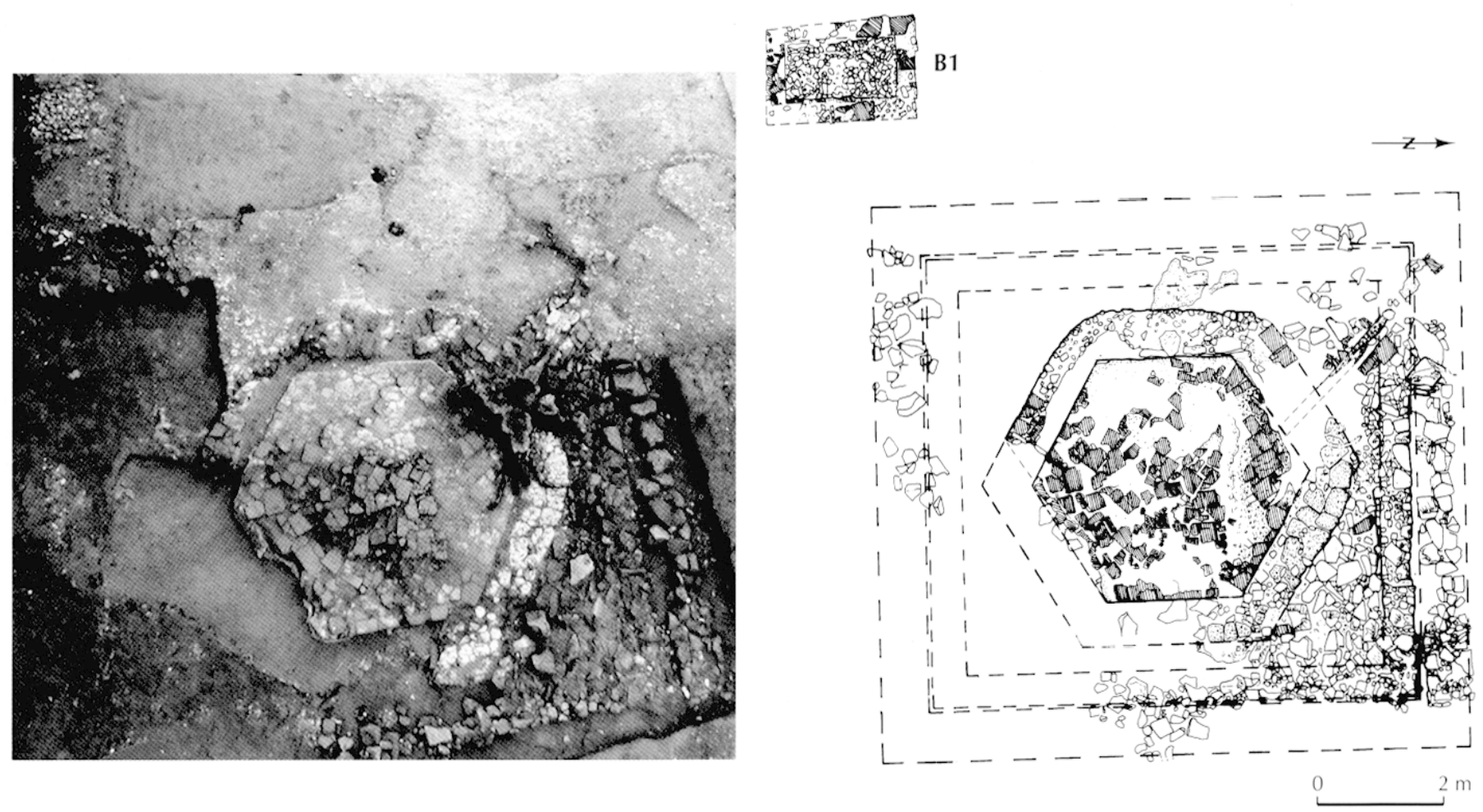

Fig. 52 - Vue et plan de la fontaine (édifice 9), et de la base B1 (horizon 5e).

attribution typologique, probablement du milieu du $\mathrm{II}^{\mathrm{r}} \mathrm{s}$, complète cet ensemble. Bien que ce lot de cinq individus reste des plus modestes, il se caractérise par une grande homogénéité, rendant ainsi fortement probable l'installation du radier au milieu du $\mathrm{II}^{\mathrm{e}}$ s., période qui voit également l'édification des portiques du sanctuaire.

\section{Les installations cultuelles de la cour}

Devant le temple, se trouvent une base rectangulaire d'offrande (B1) à encadrement de tuiles, légèrement décalée vers le sud, et une fontaine hexagonale, axiale (édifice 9) (fig. 22 et 52). Aucune trace d'un autel n'a été identifiée ${ }^{39}$. Plus vers l'est, une base de statue (B2) est placée plus ou moins sur l'axe est-ouest. Devant les entrées monumentales, à l'est (B3-B4) et au nord (B5-B6) et vraisemblablement par symétrie au sud devant l'exèdre A (B7-B8), les escaliers d'accès aux galeries étaient flanqués de deux bases quadrangulaires de $2,50 \mathrm{~m}$ de côté qui servaient de socles à un autel ou à une statue.

\section{La fontaine hexagonale (édifice 9)}

Dans la cour et dans l'axe du temple, à $13 \mathrm{~m}$ à l'est de l'extrémité des murs d'échiffre, est situéc une construction $(3,50 \mathrm{~m}$ nord-sud sur $4,30 \mathrm{~m})$, de forme hexagonale, de $2,15 \mathrm{~m}$ de côté environ (fig. 52). Cette structure centrale comprend un radier de deux assises de blocs en grès, d'une hauteur totale de $0,74 \mathrm{~m}$, surmonté de quatre lits de tuiles, sans rebords, liées au mortier de tuileau. Elle est entourée par une maçonnerie, de

39. L'autel du temple de Saint-Bertrand-de-Comminges, dans la HauteGaronne (Badie et al., 1994), est exceptionnellement bien conservé. La trace d'un autel a été identifiée à Ribemont-sur-Ancre (Brunaux dir., 1999).
$0,70 \mathrm{~m}$ de large, en grès roussard, peu fondée et plus basse de $0,20 \mathrm{~m}$, recouverte partiellement de mortier de tuileau et de tegulae; elle épouse la forme hexagonale de la structure en tuiles.

À $30 \mathrm{~cm}$ de la maçonnerie périphérique, un double aménagement quadrangulaire, plus ou moins parementé, large de $0,50 \mathrm{~m}$ à $0,70 \mathrm{~m}$ et construit en blocs en grès éocène, est bien conservé au nord. Un radier avec les mêmes matériaux s'étend dans les angles. Quelques traces subsistaient sur les autres côtés.

Une canalisation, de mortier de tuileau et à parois de tuile, apparaît sur 2,50 m de longueur au nord-ouest ; elle devait se prolonger jusqu'au bassin. Quelques fragments de frettes en fer ont été retrouvés à proximité de l'entourage externe. Cette canalisation, large de $0,15 \mathrm{~m}$ à $0,25 \mathrm{~m}$, s'écoule vers la pente nord du sanctuaire en direction du drain repéré à l'est de l'escalier 6 du portique nord. Aucune relation directe avec le caniveau du temple n'a été repérée. Aucune trace d'adduction d'eau n'a été découverte. La présence de blocs d'entablement à proximité indique que celui-ci était sans doute couvert.

D'après le plan et le profil d'une plaque (L.: $1,58 \mathrm{~m}$, h. : 0,69 m, ép. : 0,11 m ; cf. Gruel, Brouquier-Reddé dir., 2003, p. $107 n^{\circ} 157$ ), le parapet de ce bassin devait être composé de six plaques posées de chant. Leur longueur permet de restituer un bassin de $3,40 \mathrm{~m}$ sur 2,90 $\mathrm{m}$. Ce type de plan hexagonal est connu à Djemila et à Dougga ${ }^{40}$. D'après ces exemples, on pourrait restituer un bassin à vasque centrale hexagonale, mais

40. Fontaine du marché de Cosinius à Djemila (Algéric) ; fontaine de carrefour au nord du forum à Dougga (Tunisie). À Timgad (Algérie), la fontaine de Liberalis est de plan octogonal (Gros, 1996, fig. 492), la vasque centrale serait hexagonale d'après les blocs posés sur le dallage extéricur. 
aucun fragment de cette dernière n'a été retrouvé (BrouquierReddé et al., sous presse b). Des blocs d'entablement lisse (h. $>0,53 \mathrm{~m}$ ), taillés dans des marbres roses violacés (marbre de Normandie ou marbre rose de Mayenne, cf. Gruel, BrouquierReddé dir., 2003, p. $107 \mathrm{n}^{\circ} 156$ ), indiqueraient que la fontaine était couverte, le toit étant supporté par des pilastres à chaque angle. Les matériaux utilisés pour l'entablement sont différents de ceux employés dans l'architecture monumentale du sanctuaire.

\section{Les bases et offrandes de la cour}

À $10 \mathrm{~m}$ à l'est du mur d'échiffre sud de l'escalier du temple, la base d'une structure rectangulaire Bl $(1,20 \mathrm{~m} \times 2,40 \mathrm{~m})$ est constituée d'un radier de pierres entouré d'un cadre en tuiles. C'est vraisemblablement le soubassement d'une offrande (autel, statue, colonne ciselée...) dont le sommet des fondations correspond au niveau de circulation de la cour. Elle devait être aussi recouverte de plaques en marbre rose de Normandie ou mayennais, d'après les découvertes de plusieurs plaques à proximité (fig. 22).

Une base (B2) en calcaire coquillier d'une grande statue (L. : 1,30 m, l. : 0,77 m, h. : 0,65 m) est en place dans le secteur oriental de la cour. Sur le lit d'attente, trois cavités alignées et deux attaches métalliques sont des points d'ancrage nécessaires au maintien d'un élément supérieur important.

\section{LE QUADRIPORTIQUE}

Le quadriportique, de plan rectangulaire $(115 \mathrm{~m}$ est-ouest sur $94 \mathrm{~m}$ nord-sud), rythmé par des exèdres périphériques (voir infra), s'incurve à l'ouest, formant une abside encadrant le temple.

Du côtë est, une entrëe axiale monumentale est précëdëe d'un portique de façade de $4,40 \mathrm{~m}$ de largeur, s'appuyant contre l'aile orientale du péribole. Ce portique externe, vraisemblablement fermé sur les côtés, se retrouve à Périgueux, Mazamas à Saint-Léonard-de-Noblat (Haute-Vienne), Jublains (Mayenne) et à La Motte du Ciar (Nièvre) ${ }^{41}$. Les pavillons d'angle du portique oriental sont connus à Corseul et à Périgueux ${ }^{42}$. L'hypothèse probable de deux entrées latérales dans l'axe des portiques sud et nord comme à Corseul n'a pas été confirmée en raison de la récupération totale des murs (fig. 22). La galerie interne orientale plus large $(10,20 \mathrm{~m})$, flanquée de pavillons d'angle ( $\mathrm{D}$ et $\mathrm{E}$ ), pouvait éventuellement supporter un étage ; elle est artificiellement surélevée comme à Périgueux. Un escalier (escalier 7) permettait de descendre dans la galerie nord. Une deuxième entrée monumentale, précédée d'un escalier (escalier 6), ouvre au centre du péribole nord (voir infra). Les portiques nord et sud ont un tracé rectiligne de 6,60 m de largeur. Le portique ouest présente, dans sa partie centrale, une galerie en arc de cercle plus étroite, flanquée de deux galeries rectilignes. Un dénivelé de 1,42 m entre le sol des portiques sud et nord est compensé, à l'ouest, par deux volées de marches, l'une située au sud de l'abside

41. Lauffray, 1990 ; Vezeaux de Lavergne, 1999; Naveau dir., 1997 ; Pinon, Adam, 1994 ; Brouquier-Reddé, Gruel, à paraitre.

42. Formigé, 1944 et Provost, 1999 ; Lauffray, 1990.

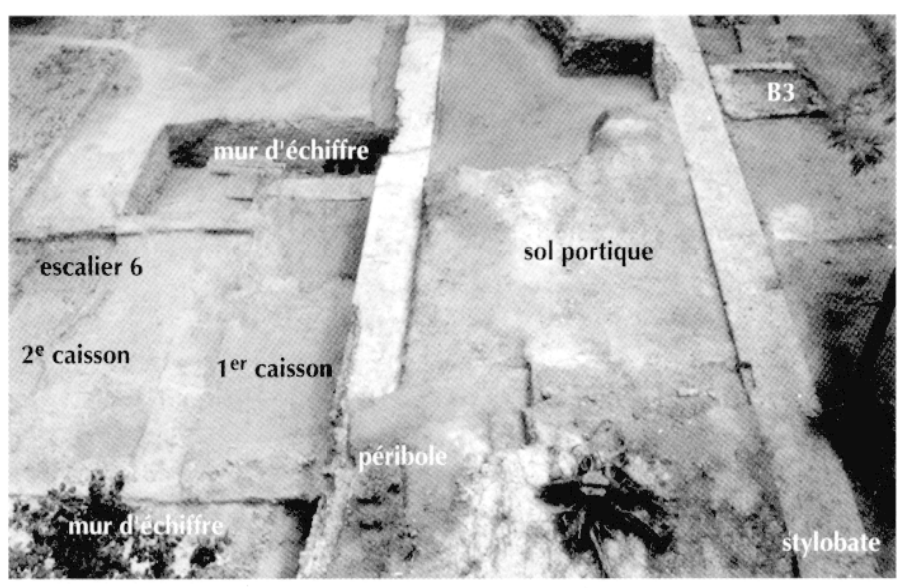

Fig. 53 - Le portique nord et les vestiges de l'escalier 6.

ouest (escalier 2), l'autre restituée au nord de celle-ci (escalier 3).

Les portiques ne conservent qu'un seul béton de sol composé d'un mélange de chaux, de sable siliceux, de graviers et cailloux de calcaire. La qualification de béton découle donc directement de la présence des éléments calcaires. Ce béton de sol, épais de $14 \mathrm{~cm}$, repose sur un radier de pierres posées de chant, haut de $20 \mathrm{~cm}$. Ce sol couvre l'espace interne des portiques du péribole jusqu'au bord interne du stylobate qui était probablement dallé.

\section{La construction des portiques (horizon 5e, après 130-140)}

L'essentiel des informations de cette étape provient des fouilles menées à l'extérieur des portiques. La construction du quadriportique a suivi celle du temple, tant au sud qu'au nord. Les èléments de datation orientent vers des travaux ëchelonnès après 130 et 140 apr. J.-C. Les niveaux de construction ont été observés au portique nord, à hauteur de l'escalier monumental (escalier 6) et de l'angle nord-ouest, et au portique sud autour de l'exèdre A. Aire de gâchage, trous de poteau d'échafaudage et pendage des remblais permettent de reconstituer les différentes étapes de la construction (fig. 53).

Le quadriportique est construit en opus mixtum, avec le matériau local, le grès roussard, associé à des cordons de trois lits de briques tous les onze rangs. Les joints des moellons sont soulignés au fer. Le blocage interne est constitué de lits de pierres liées au mortier jaune orangé, organisés en assises régulières. Le grand appareil n'était utilisé que pour l'ordre des colonnades. Au portique nord, la section dégagée a été édifiée d'un seul tenant par banchées successives de 1,35 $\mathrm{m}$ : deux d'entre elles sont séparées par un alignement de trous de boulin (fig. 54). La semelle de fondation, atteinte à l'ouest de l'escalier nord, est constituée de blocs de grès éocène non équarris liés par du mortier jaune orangé. La qualité de la construction est la même pour l'ensemble du quadriportique, à l'exception de la fondation arrondie de l'abside ouest beaucoup moins soignée et plus étroite dans sa partie centrale. Les sols de construction ont été identifiés, à l'extérieur, au nord du péribole et plusieurs trous de poteau d'échafaudage ont été repérés parallèlement à celui-ci et en face des trous de boulin, mais aussi à l'aplomb des murs d'échiffre. 


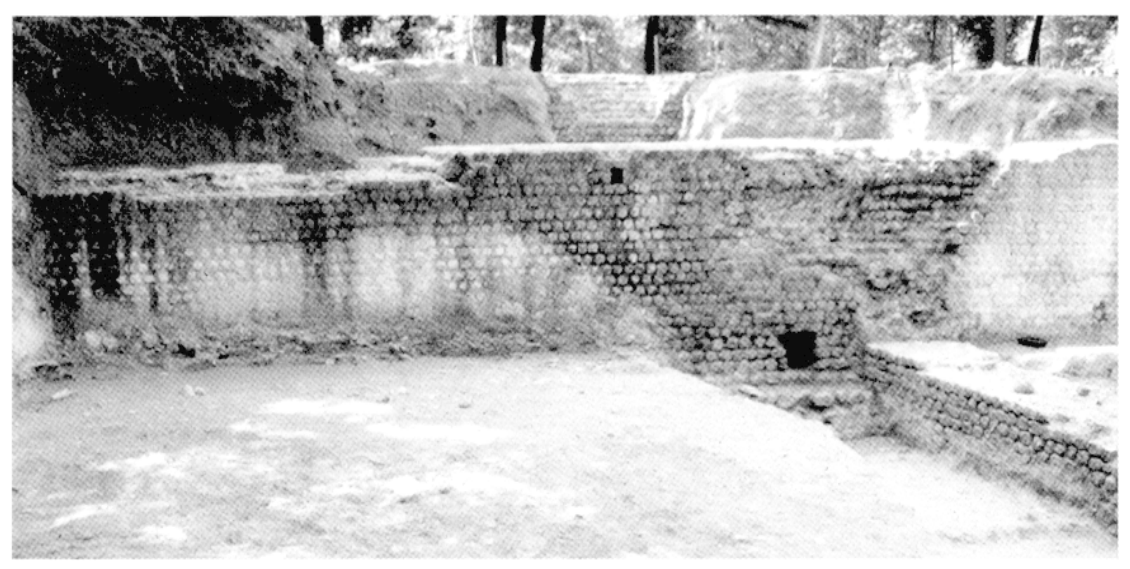

Fig. 54 - Péribole nord, drain à l'est de l'escalier 6.

Les travaux du portique nord ont été exécutés parallèlement à l'aménagement de la cour sur une terrasse artificielle mesurant environ $120 \mathrm{~m}$ de côté. Le péribole nord est un mur de soutènement : $5,64 \mathrm{~m}$ de différence entre le sol de circulation de la galerie sud et le sol antique au pied du péribole nord. Les murs du portique servent en effet de soutènement aux remblais qui couvrent le chantier de construction du temple. Le mur du stylobate a dû être construit le premier. Le mur du péribole et les deux murs d'échiffre de l'escalier de la porte nord furent montés ensemble puisque leurs maçonneries sont liées (fig. 53). Le vide entre ces deux derniers fut comblé à partir du sud, de l'intérieur, au fur et à mesure de l'élévation. Lorsque les murs curent atteint le niveau de la cour intérieure, l'espace du caisson sud de l'escalier fut rempli depuis le portique. Ce nouvel espace ainsi nivelé permit le remplissage du caisson nord. À l'angle nord-ouest, les fondations du portique nord épousent le dénivelé naturel de la colline, car péribole et stylobate sont fondés moins profondément que dans la section plus à l'est. Les murs de l'exèdre $G$ ont été entièrement récupérés et ne sont plus visibles qu'à l'état de négatif. Cependant l'observation des traces d'arrachement sur le mur du péribole montre que les murs latéraux de l'exèdre sont collés contre les fondations du péribole mais liés en élévation. Les assises de fondations du péribole ont donc été construites avant celles de l'exèdre. On constate le même mode de construction entre le mur ouest de l'exèdre A et le péribole sud, où les deux murs sont accolés en fondation. L'angle ouest du portique nord est renforcé, en fondation, par un mur de refend de 1,70 $\mathrm{m}$ de large, joignant le péribole et le stylobate nord, sans doute pour empêcher la pression depuis l'est des terres de remblais remplissant le sous-sol du portique.

\section{L'entrée axiale nord}

Sur la façade nord s'ouvre une deuxième entrée monumentale, précédée d'un escalier et presque centrée, entre l'angle interne du pavillon d'angle nord-est $(40,40 \mathrm{~m})$ et l'angle nordouest $(39 \mathrm{~m})$. L'accès est aligné sur la base de l'escalier du temple et sur l'exèdre A du portique sud (fig. 53, 54 et 56). Il met en relation le sanctuaire et la ville par la voie est-ouest qui passait en contrebas au nord, venant du gué de Chaoué. Ce type d'accès latéral par un escalier a été adopté à Corseul, mais placé aux extrémités du portique ouest (Formigé, 1944 ; Provost,
1999). À cet endroit, le sol de la galerie nord est surbaissé de $32 \mathrm{~cm}$ (escaliers 4 et 5 ).

Deux murs fantômes parallèles, larges de $1,05 \mathrm{~m}$, liés au péribole nord, correspondent aux murs d'échiffre d'un escalier externe (esc. 6). On voit les traces d'arrachement sur le parement du péribole. Deux murs de soutènement, conservés en négatif, perpendiculaires aux précédents, limitent un caisson sud de $3,75 \mathrm{~m}$ et un caisson nord de 3,10 $\mathrm{m}$ de profondeur. Ces caissons sont remblayés de couches argilo-sableuses très compactes et donc particulièrement stables. Leur fouille montre un remplissage par le sud depuis les angles (fig. 25).

Le sol de circulation au pied de l'escalier indique sa hauteur par rapport au sol de la galerie $(4 \mathrm{~m})$. D'après l'emprise des structures conservées en négatif, on peut reconstituer un escalier de 24 marches sur $9 \mathrm{~m}$ de large, en ménageant devant l'entrée un palier qui reposerait sur le mur de refend sud (fig. 25). L'examen des revers d'un enduit peint montre à la fois le biseau supérieur d'une rampe et l'orientation des assises de moellons du mur d'échiffre, les axes ainsi définis forment un angle de $30^{\circ}$ (Gruel, Brouquier-Reddé dir., 2003, p. 100 n $^{\circ} 144$ ). Les murs d'échiffre étaient surmontés d'un parapet maçonné et peint. La découverte, en contrebas du portique nord, d'un élément de buste en bas relief d'un géant ou barbare captif laisserait supposer que le porche, vraisemblablement tétrastyle, présenterait un fronton décoré, à moins qu'il ne provienne d'un groupe statuaire. Ce porche serait aligné sur les façades nord des deux exèdres ( $\mathrm{H}$ et $\mathrm{G}$ ) qui l'encadrent. L'ensemble porche et escalier a une profondeur de $11,50 \mathrm{~m}$, égale à celle des exèdres $\mathrm{A}$ et $\mathrm{C}$, et à celle des pavillons d'angle, $\mathrm{D}$ et $\mathrm{E}$, et respecte la symétrie du monument.

\section{Les exèdres}

Six exèdres sont disposées symétriquement le long des galeries, sauf à l'ouest. Les trois salles du portique sud s'ouvrent face à l'entrée nord et aux deux exèdres latérales du portique nord. L'exèdre $G$, fouillée, mesure $4,90 \mathrm{~m}$ de large et $11 \mathrm{~m}$ de long. De l'exèdre $\mathrm{H}$, de même taille, partiellement vue par P. Térouanne, il ne reste que les traces d'arrachement sur le péribole nord. Les exèdres médianes sont monumentalisées. Au sud, l'exèdre A présente une profondeur double (9 $\mathrm{m}$ de large sur $11 \mathrm{~m}$ ) de ses deux exèdres latérales $(5 \mathrm{~m}$ sur $10,70 \mathrm{~m})$. Au nord, elle se transforme en une entrée précédée par un escalier. 


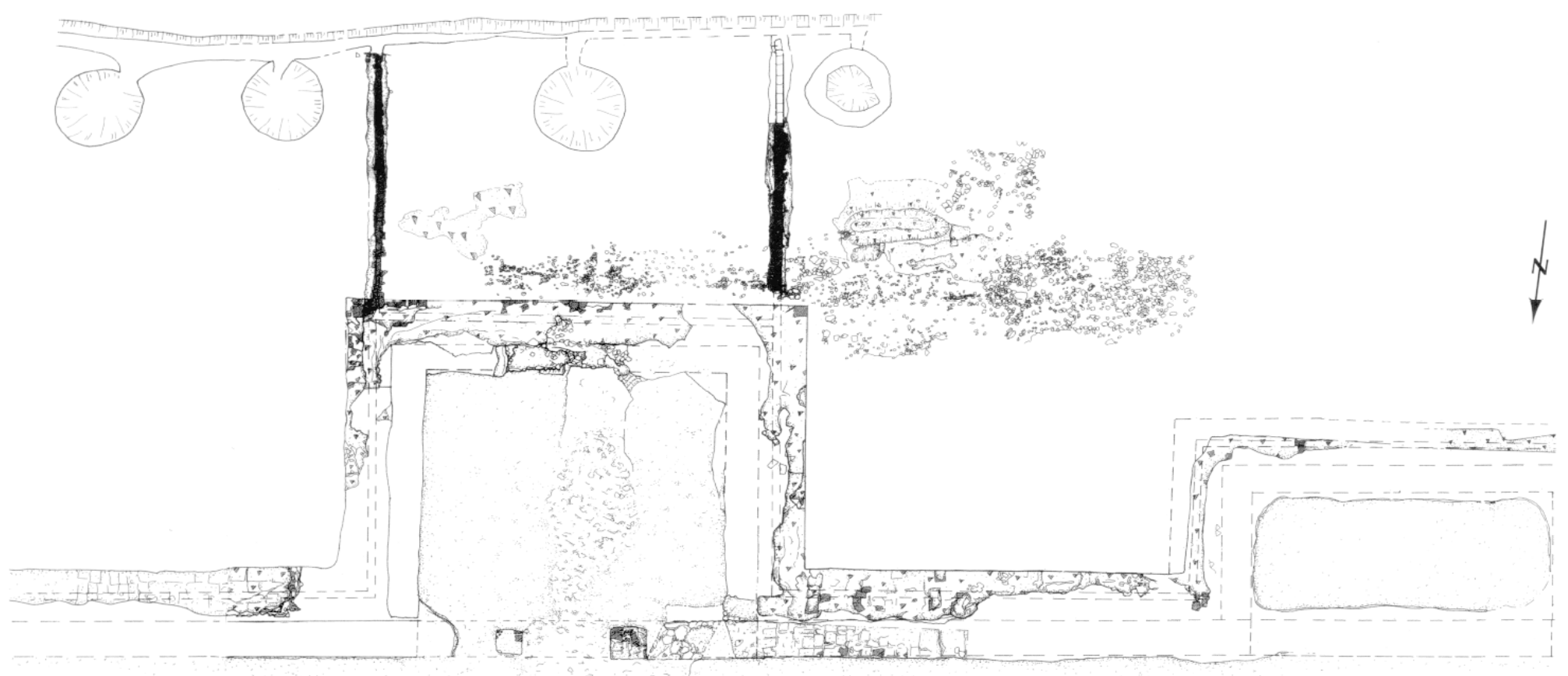

Fig. 55 - Plan de l'exèdre A du portique sud. 


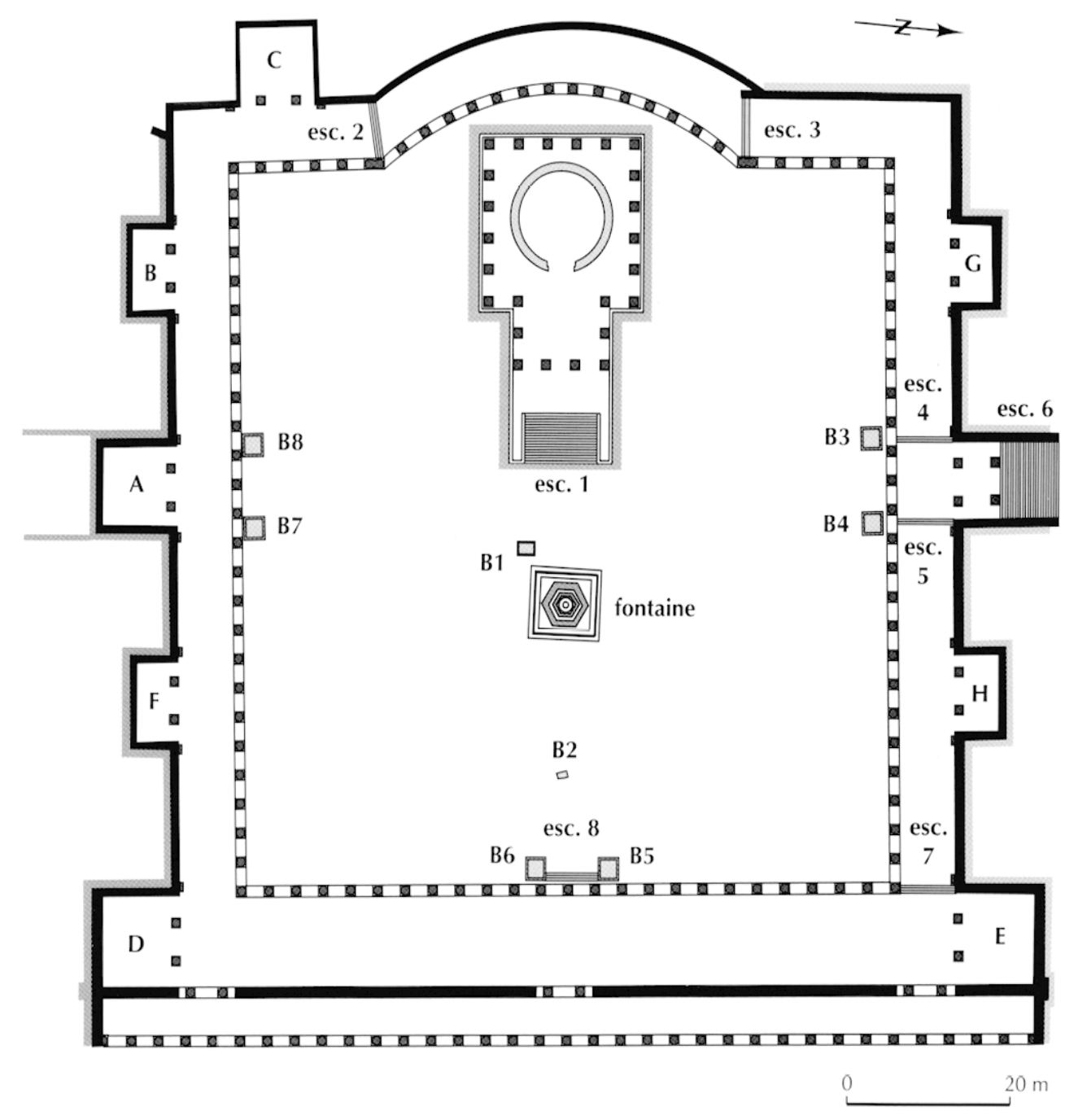

Fig. 56 - Plan restitué du sanctuaire de Mars Mullo (horizon 5; hypothèse 2003) : A-C et F-H, exèdres ; $B 1-B 6$, bases d'offrande ou de statue; D-E, parillons d'angle; trames grises, aménagements hydrauliques.

L'abside semi-circulaire ouest est flanquée au sud d'une exèdre $(C)$ de mêmes dimensions que l'exèdre $A$. Son pendant au nord-ouest n'a jamais été construit, créant une curieuse asymétrie. La façade de l'exèdre A est divisée en trois baies par deux colonnes dont il ne reste que la plinthe en brique ${ }^{4: 3}$ (fig. 55 et 61 ). Le sol couvre le péribole en cet endroit, mais l'usure du béton de sol laisse apparaître, au centre, le radier de pierre sous-jacent. Le sol s'épaissit à l'arrière des plinthes des colonnes jusqu'à l'aplomb des murs latéraux de l'exèdre.

\section{La restitution des portiques}

Les fouilles rendent parfaitement compte du plan général du sanctuaire; en revanche, les données qui permettent de restituer les élévations sont très fragmentaires et dispersées. La restitution se base donc sur une analyse de la répartition des fragments retrouvés, des matériaux et de leur localisation, puis sur la confrontation de ces hypothèses avec celles qui sont avancées pour d'autres monuments.

43. Cet indice archéologique est rarement conservé en Caule.
Le stylobate est partout conservé sous le niveau du sol du portique et seules deux traces de l'emplacement des colonnes y ont été repérées : à l'angle sud-ouest, le lit de briques s'interrompt et un logement de 1,30 m sur 1,40 m est ainsi ménagé. Un espace identique de $1,20 \mathrm{~m}$ x 1,20 m se situe sur le stylobate, dans l'axe du mur latéral ouest de l'exèdre A. Aucune base de colonne en place n'a été mise au jour à l'exception des deux plinthes de colonnes de l'exèdre A: deux socles carrés en brique de $0,80 \mathrm{~m}$ sur $1,10 \mathrm{~m}$, distants de $2,50 \mathrm{~m}$, sont placés sur la fondation du péribole. En se basant sur ces rares éléments et sur la longueur des portiques, le rythme des colonnes semble régulier. On peut restituer (fig. 56), d'après un entraxe moyen de $3,36 \mathrm{~m}, 26$ colonnes pour les portiques nord et sud, 25 pour le portique oriental et 28 sur celui de l'ouest 6 colonnes sur chaque section rectiligne et 16 colonnes sur le stylobate de l'abside). L'entrée de chaque exèdre et, éventuellement, celle des pavillons d'angle à l'est seraient ouvertes par deux colonnes selon les vestiges de l'exèdre $A$. On peut aussi supposer que le passage à l'arrondi de l'abside, marqué par quatre marches, est habillé de deux colonnes jumelées. 


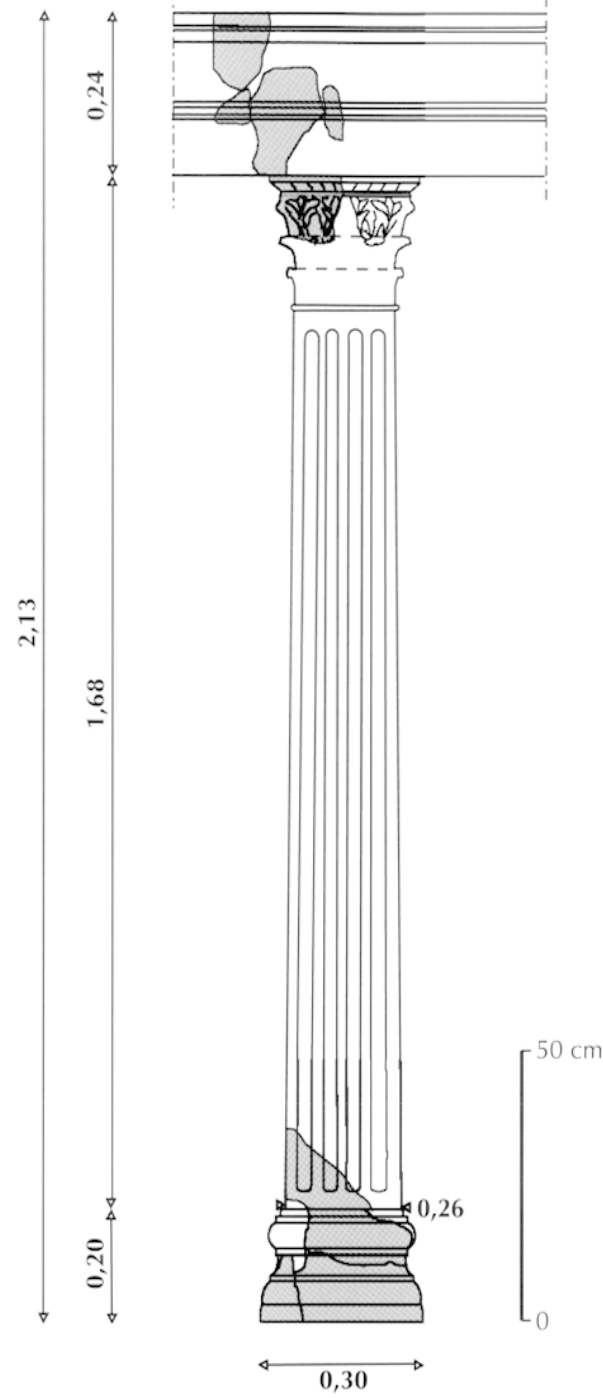

Fig. 57 - Restitution d'un pilastre d'applique décorant le quadriportique.

\section{La décoration du quadriportique}

À l'intersection des galeries orientale et sud, le sol inclut, contre l'aile sud du péribole et le mur occidental du pavillon d'angle sud-est (pavillon d'angle D), une structure rectangulaire de 1,20 m sur $0,75 \mathrm{~m}$, composée de trois lits de briques liés au mortier. Ces lits reposent sur une fondation de deux assises de pierres posées en hérisson sur $30 \mathrm{~cm}$ de profondeur ; il s'agit vraisemblablement de la fondation d'une ante décorant le mur latéral du pavillon D. Une structure rectangulaire similaire, en mortier de tuileau recouvert par des briques, est placée, dans l'axe du stylobate sud, contre le mur sud de l'exèdre sudouest (C). L'emplacement de ces deux socles, marquant l'entrée de l'exèdre $C$ (côté sud) et du pavillon D (côté ouest), permet de proposer un ordre de pilastres plaqués dont plusieurs éléments sont conservés (fig. 57). Ceux-ci flanqueraient les entrées des exèdres en zone médiane. Ils reposent sur un dé en applique, décoré d'une base et d'un couronnement, placé en zone basse. Ils reprennent l'ordre corinthien monumental du temple et des portiques. Ils sont taillés principalement dans deux matériaux aux couleurs et caractéristiques géologiques différentes: un calcaire cristallin gris clair (roche métamorphique du synclinal de Sablé-sur-Sarthe) est employé pour la réalisation des bases, des chapiteaux et de l'entablement plaqués, les psammites (grès) de Sillé-le-Guillaume (Sarthe) servent uniquement aux fûts. L a base, à double tore sur plinthe, de $30,5 \mathrm{~cm}$ sur $20,5 \mathrm{~cm}$, serait une réplique de la base monumentale ; le lit d'attente, destiné à recevoir le fût, porte très souvent des trous de fixation pour les goujons métalliques reliant la base au fût. Le fût comporterait quatre rudentures et cinq listels. Le chapiteau d'ordre corinthien présente toutefois une grande variété dans le traitement de l'acanthe. L'abaque, décoré de feuilles inclinées, comme dans l'ordre monumental, ou lisse, est encadré de perles et pirouettes. Un fragment en calcaire cristallin gris, figurant un oiseau, se distingue de l'ornement classique végétal (Gruel, Brouquier-Reddé dir., 2003, p. 102-103 $\mathrm{n}^{\text {os }}$ 149-154). L'entablement monolithique (architrave et frise séparées par une moulure) est lisse et le bandeau de la corniche est suivi d'une doucine (fig. 57).

À ces pilastres, on associe un décor mural composé d'un soubassement en placage de marbre (peut-être remplacé en certains endroits par un faux marbre peint, en opus sectile de peltes et de scutum), d'un décor en panneaux alternés peints dans la partie médiane et d'une couverte rouge pour le registre supérieur (fig. $58 \mathrm{cf}$. pl. X hors texte).

La partie basse des murs était probablement décorée audessus d'une plinthe en marbre local, de placages de marbre choisis pour leur couleur. Bien qu'aucune d'entre elles n'ait été retrouvée en place, le nombre de plaques recensées, en grès, calcaires, calcite et marbre, est particulièrement important sur les portiques nord et sud. On recense en particulier une forte proportion de marbre vert de Grèce ( $44 \%$ ). Une moulure de transition courait entre le soubassement et les panneaux de peinture murale de la partie médiane.

Sur le sol de l'angle sud-ouest du quadriportique reposaient des plaques d'enduits peints tombées du mur même de la galerie ${ }^{44}$. Des connexions entre fragments montrent bien qu'il s'agit d'un unique remblai de destruction. C'est le décor mural du dernier état du péribole. Le support des enduits peints comporte parfois, au revers, des empreintes de moellons dont la hauteur moyenne est de $8 \mathrm{~cm}$. Les deux couches de mortier (une de préparation, irrégulière ; une de transition, de $2,5 \mathrm{~cm}$ à 2,7 cm) sont beiges, chargées d'un fin gravier. La couche d'épiderme, de $0,2 \mathrm{~cm}$, présente la caractéristique d'être teintée, ce qui fait qu'une sous-couche rose apparaît sous toutes les teintes du décor.

Sur la partie médiane, une colonnette à fût lisse, large de $4 \mathrm{~cm}$, sépare les deux champs : un champ noir à gauche, un champ rouge à droite (fig. 59a cf. pl. X hors texte). Elle est traitée en jaune, rehaussée de vert sur sa partie droite, de blanc sur la partie gauche. La bande brune qui lui est parallèle, sur le fond noir, doit correspondre à l'ombre portée par le fût et donne par conséquent l'illusion d'un relief. Le chapiteau de type corinthien simplifié, est finement traité (fig. 59b cf. pl. X hors texte) : deux annelets enserrent la base de l'échine,

44. Étude de C. Allag, avec la collaboration de F. Miane et D. Neige, stagiaires au Centre d'études des peintures murales romaines de Soissons (LMR 8546 du CNRS). 
surmontés d'une couronne de feuilles (anthémion) marquée d'une fleurette centrale. L'abaque est légèrement infléchi. À droite, sur le fond rouge, la coque et les pans d'un nœud de ruban bleu annoncent un motif ornemental, proche de feuillages. On peut envisager des guirlandes légères attachées par des rubans, motif de remplissage extrêmement fréquent. La double bande verte qui surmonte cette zone mesure au total $17,5 \mathrm{~cm}$ de hauteur. La bande inférieure est vert foncé ; un trait vert très pâle, blanc à l'origine, la sépare de la bande supérieure, d'un vert asse\% clair qui fonce progressivement vers le haut. Il s'agit d'une transition entre les parties basse et médiane de la paroi, schématisant l'assise supérieure des soubassements architecturaux parfois représentés de façon plus réaliste. Un motif indéterminé, peut-être végétal, partait de sa limite inférieure et constituait probablement un ornement axé des panneaux noirs. Au-dessus, s'étend à nouveau un champ noir sur lequel devaient se détacher de grands panneaux rouges, superposés aux compartiments noirs de la partie inférieure. Ces panneaux étaient encadrés d'une bande jaune tirant souvent sur le rose, peut-être à cause d'une couleur de fond qui réapparaît. Il s'agit d'une bordure horizontale ou verticale : en effet, les coups de pinceau horizontaux du passage d'un fond uni imposent un sens de lecture incontestable (fig. 58).

Bien entendu, il est impossible d'avoir une quelconque idée des dimensions de ces panncaux. On aura noté toutefois l'aspect imposant qu'ils présentent, avec le caractère architectural marqué que donne la scansion par des colonnettes assez. élaborées. Les panneaux surmontés d'une double bande verte de transition et d'une zone colorée importante, leurs dimensions, celles des colonnettes, les motifs annexes, sont décidément conformes à ce que l'on s'attend à trouver en zone médiane. La galerie, scandée par les pilastres de marbre gris, portait sa succession de panneaux réguliers où le rouge contrastait avec le noir ; la finesse des encadrements, des colonnettes peintes, des guirlandes végétales nouées de rubans, témoigne d'un effort certain de raffinement.

\section{Les protections contre l'humidité}

Construire un sanctuaire de modèle romain dans la Sarthe implique quelques adaptations en particulier pour drainer les eaux pluviales sur un terrain au sous-sol très argileux. Des toits à double pente permettent de mieux collecter les eaux de pluie et d'en évacuer une partie directement à l'extérieur du sanctuaire.

La façade extéricure des portiques est enduite d'un revêtement dont le côté fonctionnel de protection contre l'humidité a été particulièrement soigné, au détriment de toute recherche décorative. Ce mortier, d'une épaisseur de 2 à $4 \mathrm{~cm}$, comprend généralement quatre couches successives: une couche de préparation d'épaisseur variable destinée à compenser les irrégularités du mur, deux couches de transition et une de finition. Toutes sont en mortier très compact de chaux et de sable, avec quelques brindilles et charbon de bois. Ce mortier est d'un rose foncé, couleur qui lui est donnée par une forte tencur en tuileau; la surface est simplement badigeonnée d'une couleur rouge épaisse et foncée. Sur certains, on reconnaît le fruit marquant la base du mur. Un voile de calcite trahit l'abondance des remontées humides par capillarité. Ces enduits, toujours en place sur la face extérieure des périboles ouest et nord, assuraient une imperméabilisation de tous les murs extérieurs ${ }^{45}$. Des joints d'étanchéité, également peints en rouge, couvraient la liaison avec le caniveau extérieur.

Au nord, un caniveau en mortier de tuileau de $0,70 \mathrm{~m}$ de large longe le péribole; il s'adapte aux dénivelés du terrain : dans l'angle nord-ouest, il se situe près de $1 \mathrm{~m}$ au-dessus de la section à l'est de l'escalier, là où la pente naturelle du terrain est plus accentuée. Il recueille aussi les eaux des drains qui passent sous le portique (fig. 54).

Les aménagements sont beaucoup plus importants au sud car cette façade, placée en contrebas de la colline, reçoit, en plus, toutes les caux de ruissellement. Tout le péribole sud est doublé à sa base par une canalisation partiellement conservée qui repose sur une fondation en pierre et en brique recouverte d'un mortier sableux jaune (MS 2) et d'un mortier hydraulique rose (MTS 1), riche en tuileau fin. Les parois de la canalisation sont composées d'au moins trois assises de brique. Le chenal central de $0,25 \mathrm{~m}$ à $0,50 \mathrm{~m}$ de large avait la fonction de récupérer les eaux des toitures (fig. 60). Cette installation, large de $1,50 \mathrm{~m}$, servait à limiter les infiltrations d'eau dans le mur du péribole. Une couche d'argile verte, très plastique et très étroite $(10 \mathrm{~cm}$ maximum), sépare cet aménagement du péribole sud ; elle résulte visiblement de l'infiltration d'une argile apportée par l'eau et correspondant aux particules les plus solubles de la couche géologique présente plus au sud. Les briques des deux canalisations perpendiculaires, placées au sud de l'exèdre A et orientées nord-sud, reposaient sur un béton de tuileau et de sable (BTS 1) qui assurait aussi la cohésion de la maçonnerie (fig. 61). Ces deux canalisations, de 4,50 $\mathrm{m}$ de long, au pendage nord-sud, couvertes de tuiles, évacuaient le trop-plein du système précédent vers un petit fossé ouest-est, parallèle au talus sud et flanqué d'une série de puisards dont six ont été identifiés au sud de l'exèdre A. Ces puisards, non maçonnés, traversent toutes les couches d'argile et de cénomanien pour atteindre les niveaux géologiques de sable à plus de $10 \mathrm{~m}$ de profondeur ${ }^{46}$. Ils devaient être régulièrement curés pour rester fonctionnels (fig. 55 et 62).

De même, les eaux sont collectées dans la cour par des canalisations en bois enterrées et dirigées vers les drains qui courent sous le portique nord ${ }^{47}$. Le dénivelé de $1,42 \mathrm{~m}$ entre le nord et le sud de la cour, soit $1,8 \mathrm{~cm}$ par mètre, devait favoriser l'écoulement des eaux vers le nord. De la fontaine axiale part une conduite en brique destinée à en évacuer le trop-plein. Aucun collecteur des eaux du temple drainées vers l'est par le caniveau

45. Cet enduit protecteur est utilisé dans tous les sanctuaires (Brouquier-Reddé et al., sous pressc, p. 5 n. 24).

46. Profondeur estimée à partir de la carte géologique et des coupes de terrain qui montrent les niveaux sableux à partir de $58 \mathrm{~m}$ environ. I.'un des puisards a été ouvert à la pelleteuse sur quelques mètres et s'enfonce daus l'argile.

47. Deux d'entre eux ont été identifiés. Un drain parfaitement conservé de section carrée se situe à l'est du mur d'échiffre de l'escalier 6 de la porte nord; il traverse les fondations du portique. Un deuxième drain est placé dans l'angle nord-ouest, à hauteur du mur de refend, à l'ouest de l'exèdre (;. I.es canalisations en bois sont identifiées par les alignements de frettes en fer trouvees de place en place. 


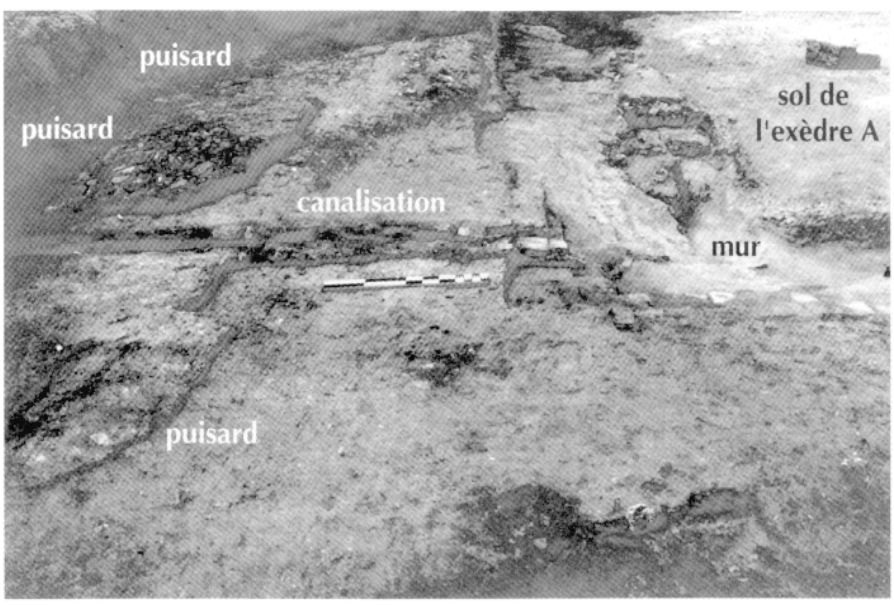

Fig. 60 - Extérieur de l'exèdre A : puisards, canalisation.

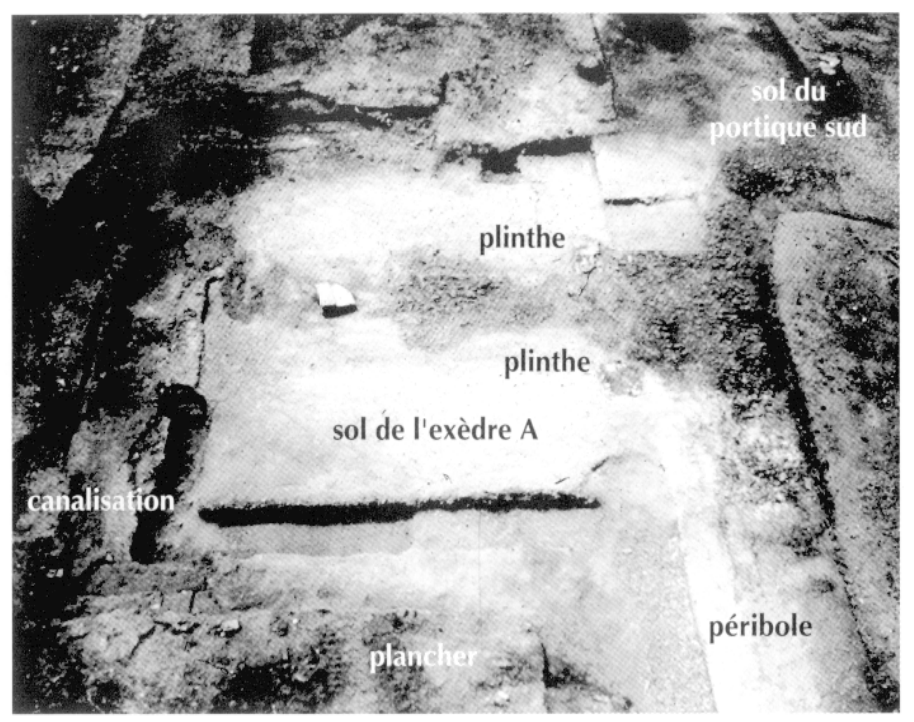

Fig. 61 - Exèdre A.
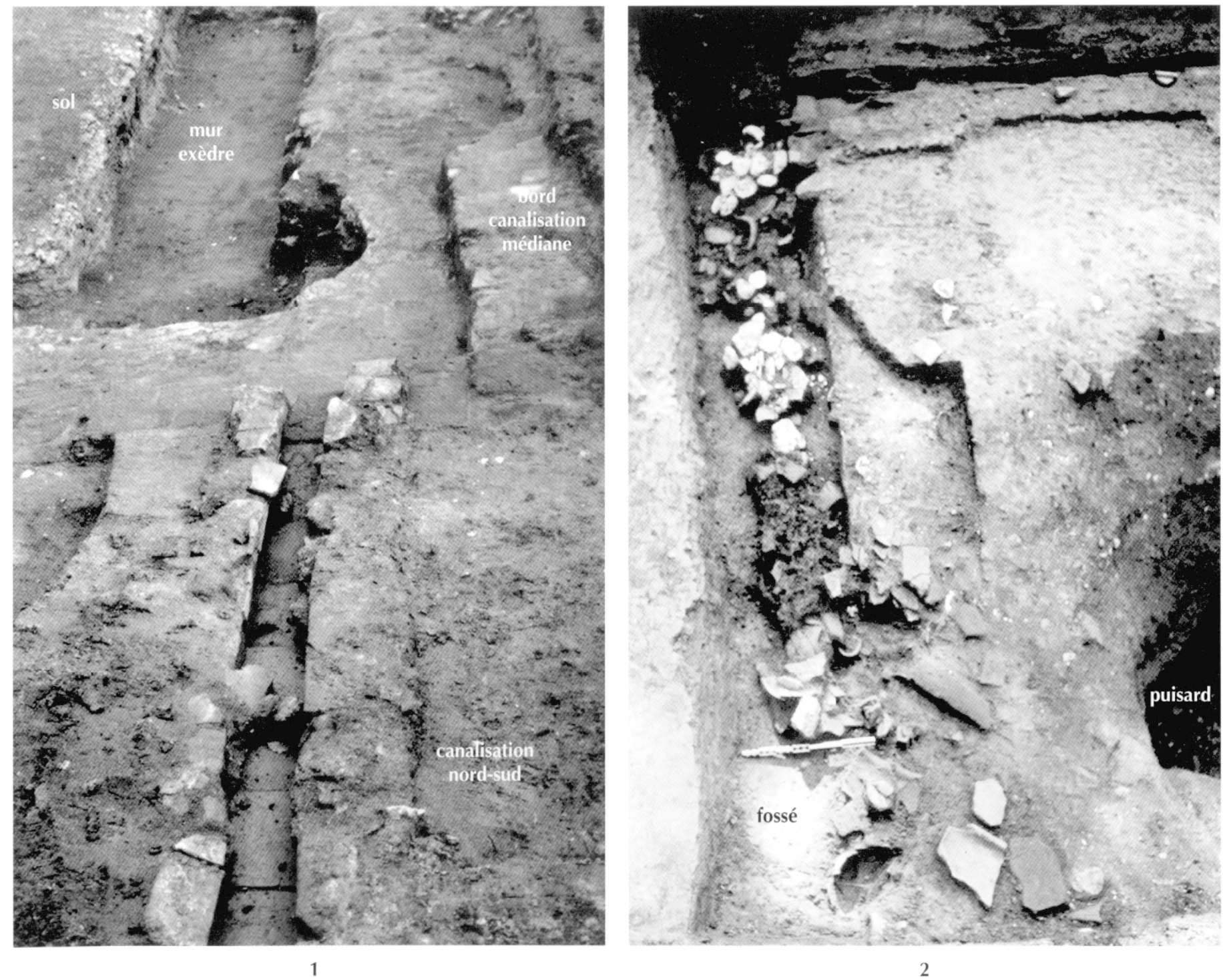

Fig. 62 - Exèdre A : 1, angle extérieur sud-est, vu du sud; 2, canalisation, fossé et puisard, vus de l'est. 

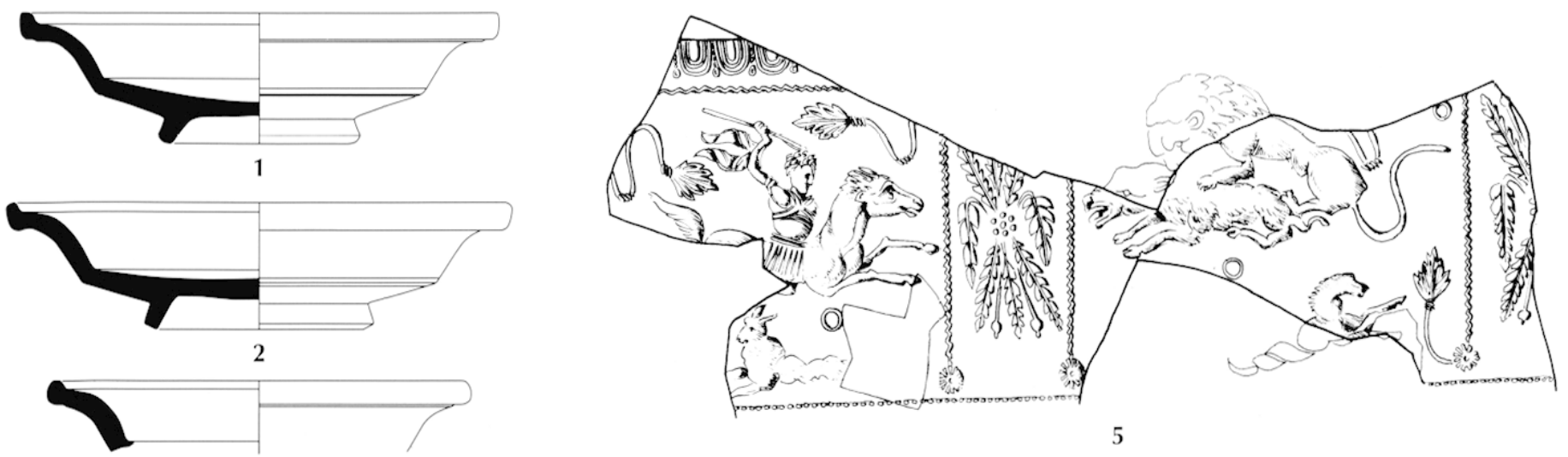

3
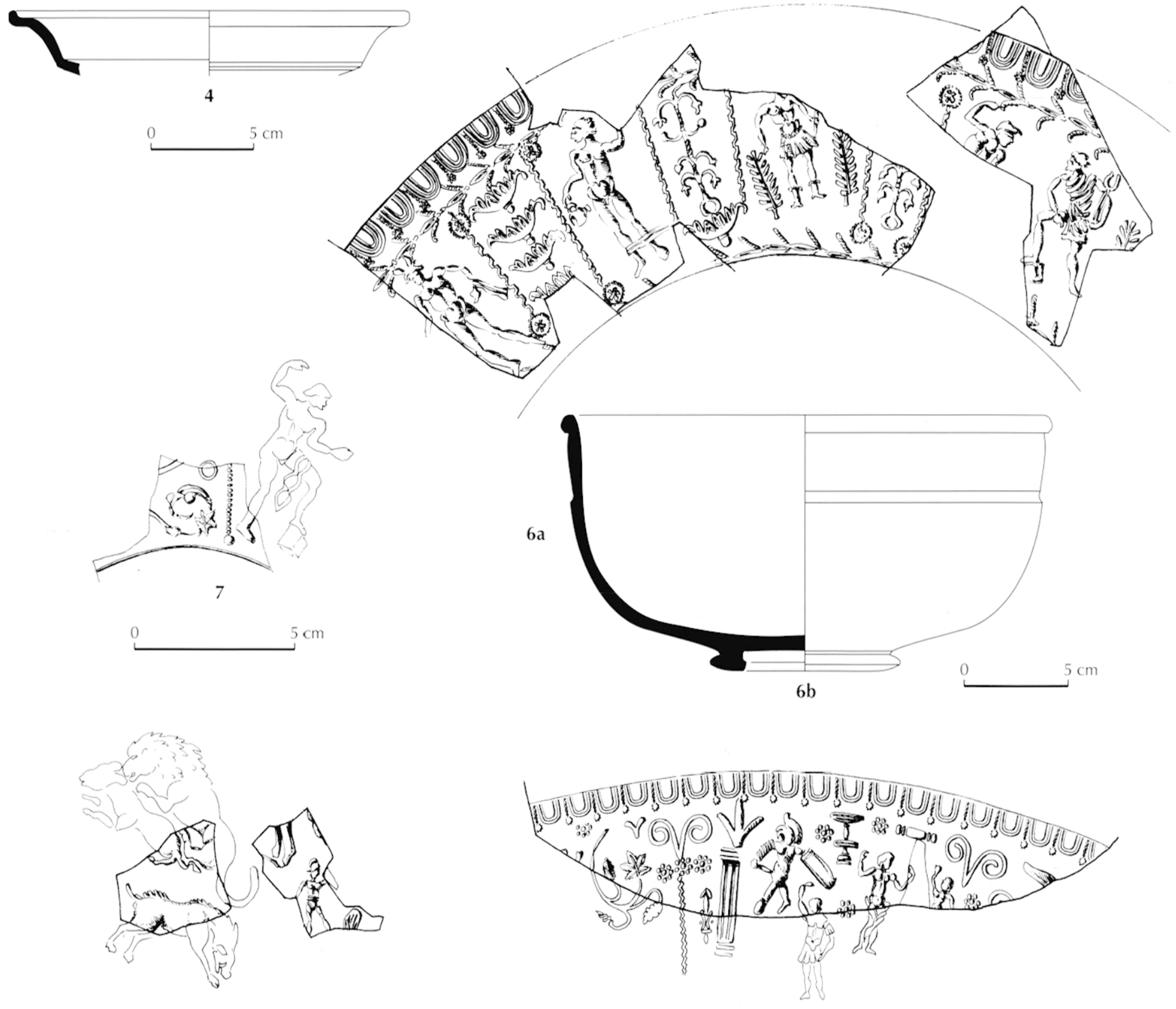

8

9

Fig. 63 - Phase de construction des portiques (horizon $5 d$ ), mobilier céramique :

$1-4$, sigillée lisse ; $5-9$, sigillée moulée. 
en picrre n'a été identifié ; on peut supposer l'existence d'un drain collecteur, passant à l'est du temple, qui acheminerait l'eau vers le nord, la conduirait à l'extérieur par le drain cncore visible qui traverse les murs du portique à l'est de l'escalier 6 de la porte nord.

\section{La datation des travaux de construction du quadriportique}

La datation des travaux de construction du quadriportique, à partir essentiellement de la céramique, en particulier de la sigillée, et des monnaies est décalée par rapport à celle du temple. La construction des portiques n'a pas pu commencer avant l'aménagement de la cour, c'est-à-dire entre les années 140 et 160. Les monnaies qui correspondent à des émissions de Nerva à Hadrien confirment ces datations. La caractérisation chronologique de la phase de construction des portiques n'est guère difficile à établir sur la base de la céramique sigillée, tant les niveaux stratigraphiques (construction, aménagement des puisards, plancher de circulation en bois...) sont riches en mobilier et parfaitement homogènes (fig. 63).

\section{Le portique nord}

L'essentiel de la vaisselle la mieux datée (souvent les sigillées moulées) est issu des officines du centre de la Gaule, actives au milieu du II $^{\mathrm{e}} \mathrm{s}$. $\mathrm{Si}$, pour un certain nombre de vases, les fourchettes chronologiques débutent dès les premières années du II $^{\mathrm{e}} \mathrm{s}$., la majorité d'entre eux ne peut avoir été produite avant les années 130-140 apr. J.-C. Par ailleurs, aucune pièce, lisse ou moulée, ne présente de caractéristiques techniques ou stylistiques que l'on peut considérer avec certitude comme postérieure à 160-170 apr. J.-C. Il s'agit là, non pas d'une preuve certaine, mais plutôt d'un argument fortement probable pour situer les niveaux liés à la construction des portiques après 130-140 apr. J.-C.

À l'extérieur du portique nord, les sigillées du centre de la Gaule représentent le lot principal. Les vases moulés sont nombreux et constituent souvent des pièces relativement bien datées par la confrontation des données stylistiques et techniques. Six des décors de cet ensemble peuvent être attribués, à part égale, à deux groupes stylistiques majeurs des années 130-160 : X-6 et CINNAMVS précoce (association CINNAMVS । PAVLLVS notamment).

Ce décor de X-6 figure sur deux vases originaires des ateliers de Lezoux, l'un fabriqué entre 130 et 140 (le vernis est orangé mat) et le second entre 130-160 (le vernis est rouge orangé, brillant, la pâte est de couleur saumon). Il orne aussi un vase probablement originaire des ateliers de Lezoux. Le vernis est rouge complètement mat, la pâte est calcaire, également de couleur rouge, avec des points de chaux visibles. Bien que de telles caractéristiques correspondent plus à des productions de la seconde moitié du $\mathrm{II}^{\mathrm{c}} \mathrm{s}$. qu'à celles du milieu du $\mathrm{II}^{\mathrm{e}} \mathrm{s}$., certains aspects "subtils" dans la réalisation du vase et la couleur du vernis diffèrent des productions plus tardives. Par ailleurs, comme pour les pièces moulées précoces de PVGNVS I SECVNDVS, la panse comporte de nombreuses stries de tournage, parallèles les unes aux autres, qui sont encore visibles malgré l'épaisseur du vernis. Le pied possède un profil élancé, nettement détaché de la paroi, ce qui constitue un critère relativement fiable de production antérieurement aux années 160-170 environ. La réalisation du vase peut donc être située vers $140-160$ (fig. $63, \mathrm{n}^{\circ} 6$ ).

Les supports des décors du groupe CINNAMVS correspondent soit à des productions du centre de la Gaule (le vernis est marron mat, la pâte est saumon, calcaire avec des points de chaux visibles ; le style décoratif peut être daté des années $130-160$, voir fig. $63, n^{\circ} 7$ ), soit à deux vases originaires des ateliers de Lezoux (le vernis est rouge orangé, brillant, la pâte est de couleur saumon; la datation proposée est de 130-150).

Les autres vases moulés présentent des décors que l'on peut rattacher à diverses officines de production des années 120 à 160 .

Les caractéristiques techniques du vase de IVLLICVS II sont celles du centre de la Gaule, sans qu'il soit possible de définir l'atelier producteur. Précisons que ce style est daté des années 150-180 par G. B. Rogers (1999), ce qui semble trop tardif si l'on tient compte, d'une part des affinités existant entre IVLLICVS II et CARANTINVS I ou bien encore PRISCIANVS pour n'en citer que quelques-uns, et, d'autre part, de l'absence totale de preuve quant à la présence dans le centre de la Gaule d'un seul individu ayant signé aussi bien des vases moulés que des mortiers Drag. 45 (postérieurs à 180). Ce style décoratif appartient plutôt à l'activité potière des années 130-160. Les vases de CATVSSA I et de PRISCIANVS présentent un vernis rouge orangé, pâte saumon, et sont datés des années 130-150. Les données techniques sont conformes à la datation stylistique. Les vases de BVTRIO sont fabriqués à Lezoux (vernis orangé) en 120-140, selon les datations technique et stylistique combinées (fig. 64, $\mathrm{n}^{\circ} 4$ ). Les vases d'AVITVS I VEGETVS, originaire de Lezoux, présentent un vernis orangé mat. Là encore, les datations technique et stylistique combinées donnent une fourchette entre 110 et 140 (fig. $64, n^{\circ} 2$ ). Un fragment de vase moulé possède un décor probablement contemporain de ceux d'ACAVNISSA (130-150) ou du groupe CINNAMVS. Les qualités techniques du vase sont toutefois bien différentes des productions habituelles de cette période puisque la pâte est beige-marron siliceuse et le vernis orangé poreux. Ces caractéristiques techniques sont, traditionnellement, celles en vigueur dans les ateliers lézoviens à la fin du $\mathrm{I}^{\mathrm{er}}$ s. et, pour certains d'entre eux, jusque vers les années 110. Toutefois, aussi bien dans le site de production que dans les sites de consommation (par exemple dans l'ouest à Mazières-en-Mauges dans le Maineet-Loire, cf. Delage, Simon, 2000), sont attestés des vases présentant de tels " archaïsmes ». Il s'agit donc bel et bien d'un vase moulé du deuxième quart du ${ }^{\mathrm{c}} \mathrm{s}$. Les sigillées, au vcrnis orangé mat, du groupe stylistique de QVINTILIANVS, proviennent de Lezoux. Les datations technique et stylistique combinées donnent 130-140 (fig. 64, n 1). Les caractéristiques techniques de ce vase de style de PATERNVS I I IANVARIS II I CARANTINVS II peuvent être celles d'une production lézovienne atypique ou bien encore d'un autre atelier de production du centre de la Gaule. Le vernis est marron-rouge, mat, la pâte est beige clair, calcaire. Il s'agit assurément d'une production antérieure aux années 150. La confrontation de cette hypothèse avec la datation stylistique traditionnellement allouée aux vases de PATERNVS I permet de proposer une datation au cours des années 140. Il possède un graffite infra décoratif 
in forma probablement incomplet, de graphie "PP " (cette marque a été apposée par l'utilisateur du moule et non le créateur de celui-ci).

Le répertoire des formes lisses du centre de la Gaule est tout aussi riche que celui des vases moulés, puisqu'il compte une dizaine d'individus, provenant de deux origines différentes. Deux vases sont issus des ateliers des Martres-de-Veyre : une assiette Lez. 55 (Drag. 18/31) et une assiette Lez. 45 (Curle 15) possédant une anse peuvent être datées de la première moitié du II $^{\mathrm{c}} \mathbf{s}$. sans plus de précision. Les autres possèdent les caractéristiques techniques des ateliers lézoviens ou d'autres centres de production appartenant à la même mouvance. Quelques pièces sont susceptibles d'avoir été produites dès le début du II ${ }^{\text {` }}$ s. : une coupe Lez. 88 (Drag. 38), une coupelle et une assiette du service Lez. 44-45 (Curle 15), ainsi qu'une coupelle Lez. 14 (Drag. 35, Ve. Al). D'autres formes présentent des pâtes et des vernis montrant qu'elles n'ont pas été conçues avant les années 130-140: deux assiettes Lez. 43 (Curle 23), dont une possède une pâte beige fortement calcaire et un vernis marron très brillant, deux assiettes Lez. 45 (Curle 15) (fig. 63, no 1), une assiette Lez. 17 (Ve. D2), une coupelle très certainement Lez. 24 (Ve. E2) possédant une estampille de graphie IVNIVS (milieu du II $^{\mathrm{e}}$ s.) ${ }^{48}$ et un fragment d'un gobelet ovoïde précoce de forme Lez. 102 (Déch. 72), aux parois minces et au profil élégant.

\section{Le portique sud}

Le colluvionnement assez fort à l'extérieur du portique sud, dominé par un talus argileux, entraîne une stratigraphie fine des couches donnant une bonne image de la séquence: construction, fréquentation, destruction, récupération. Quatre vases des ateliers du sud de la Gaule appartiennent tous aux productions de la fin du $\mathrm{I}^{\mathrm{cr}} \mathrm{s}$. et des premières décennies du II $^{c}$ s. : deux assiettes du service Ve. D non antérieures aux années 90, une assiette du service Ve. A et un Drag. 37. Les sigillées du centre-ouest de la Gaule, particulièrement marginales dans ces niveaux, sont représentées par une assiette Curle 23 et un vase hémisphérique Drag. 37 moulé.

Le corpus des vases moulés du centre de la Gaule se compose de douze exemplaires, présentant presque tous un décor que l'on peut associer à un ensemble stylistique défini. De ce fait, les datations proposées reposent sur la confrontation des données stylistiques et techniques, ce qui favorise l'attribution de fourchettes chronologiques relativement précises.

Les décors issus de l'officine de BVTRIO constituent le lot majoritaire (fig. 63, $\mathrm{n}^{\circ} 5$ ). Les quatre pièces comportent un vernis rouge clair ou rouge orangé, ainsi qu'une pâte de couleur claire, témoignant ainsi d'une conception au cours du deuxième quart du $\mathrm{II}^{\circ} \mathrm{s}$. Les groupes CINNAMVS (fig. 63, n8)

48. Ce nom de potier est peu comnu. F. Oswald le mentionne dans les productions du centre de la Gaule, à la période flavienne, datation qui, dans le cas présent, ne peut être validée (Oswald, 1931, p. 154). Ce nom ne figure pas dans le corpus de B. Hofmann (1985) et P. Bet (1988, inv. 466.1) n'a pu recenser, à partir des pièces issues des foulles lézoviennes, qu'unc estampille incomplète dont la graphie peut toutefois correspondre à ce nom : IVN [- - - Elle est présente sur unc assiette vraisemblablement L.ez. 55 et de ce fait postérieure aux années 120-130. et QVINTILIANVS (fig. 63, $\mathrm{n}^{\circ} 9$ ) sont représentés par deux décors chacun, dont les caractéristiques techniques des vases sont identiques aux précédents. Les datations stylistiques (phase de création des moules) généralement admises étant dans l'ensemble identiques à celle de BVTRIO, il paraît justifié de les considérer comme contemporains ou presque (une datation jusqu'en 160 est envisageable). Cet ensemble de vases moulés est également complété par une pièce de X-6 (fig. 64, n³) (famille "A " de Rogers, 1999) des années 120-140 (vernis orangé, pâte saumon), ainsi qu'un décor, sans attribution stylistique, de la période de transition entre les $\mathrm{I}^{\mathrm{er}}$ et II ${ }^{\mathrm{c}} \mathrm{s}$. Le seul vase moulé identifiable dont la production est postérieure à 150 appartient à une des familles "précoces " de PATERNVS II (fig. 64, $\mathrm{n}^{\circ}$ 5), dont la datation stylistique peut être envisagée jusqu'à la fin du troisième quart du $\mathrm{II}^{\mathrm{\prime}} \mathrm{s}$.

Le corpus des vases lisses du centre de la Gaule comporte également de nombreuses pièces. Sur les vingt-huit exemplaires recensés, dix appartiennent aux productions de la première moitié $\mathrm{du} \mathrm{II}^{\mathrm{e}}$ s., certains présentant des caractéristiques tout à fait conformes aux productions les plus "classiques " de la phase technique 5 (Bet, 1988). Ils ne peuvent, de ce fait, être datés au-delà de 140 apr. J.-C. On compte deux assiettes Lez. 15 (Ve. A2), deux assiettes et coupelles des services Lez. 42-43 (Curle 23) et Lez. 44-45 (Curle 15) (fig. 64, nos 2 et 4), une des assiettes de ce dernier appartenant vraisemblablement aux productions des Martres-de-Veyre. On a également des formes Lez. 84 (le « Drag. 30 » guilloché) et Lez. 36 (Drag. 33).

Le reste du répertoire se compose de pièces attestées essentiellement à partir des années 130-140 apr. J.-C. Elles ont le plus souvent un vernis rouge brillant et une pâte désormais systématiquement pourvue de points de chaux visibles à l'œil nu. Les assiettes et coupelles du service Lez. 44-45 (Curle 15) (fig. 64, $\mathrm{n}^{\circ} 3$ ) sont les plus nombreuses: quatre pièces attestées pour chacune des formes. Sont également bien représentées les assiettes et coupelles du service Lez. 42-43 (Curle 23) avec un total de six pièces. On recense enfin deux coupes hémisphériques guillochées Lez. 8, trois assiettes Lez. 15 (Ve. A2), ainsi que des assiettes Lez. 25 (Ve. E2) et Lez. 56 ("Drag. 31R»). La probabilité de production de ces formes au-delà du troisième quart du II $\mathrm{s}$. doit être considérée pour la plupart d'entre elles comme très faible.

Ces contextes comprennent aussi des céramiques communes et fines quelque peu différentes de celles des ensembles précédents avec, notamment, l'apparition de nouvelles formes de pots et de cruches. Les céramiques à parois fines engobées sont pour l'essentiel des gobelets à décors d'épingle à cheveux et à décors guillochés. Les pâtes sont le plus souvent proches de celles reconnues dans les ateliers de fabrication de la céramique sigillée du centre de la Gaule (fig. 64, $\mathrm{n}^{\mathrm{os}} 6$ et 7). Pour la céramique commune claire tournée, la cruche à lèvre en capuchon est en forte régression. À l'inverse, deux nouvelles formes semblent fabriquées à cette période. Il s'agit de cruches à panse globulaire et lève en bec d'aigle ${ }^{49}$

49. Des formes identiques proviennent du Mans, de la résidence Beauregard (Gondard et al., 1993, p. 42, $\mathrm{n}^{\text {os }} 12$ et 13), de l.'́́toile/Jacobin (Guillier, Pouli, 1991, p. 44, n"4), et de l'îlot 7 F1 (Delage, Guillier, 1997, p. 265, $\mathrm{n}^{\circ}$ 1). 


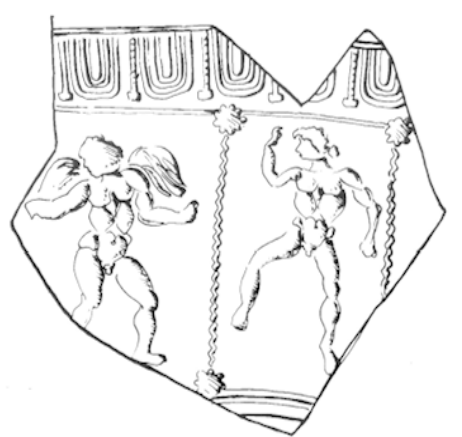

1
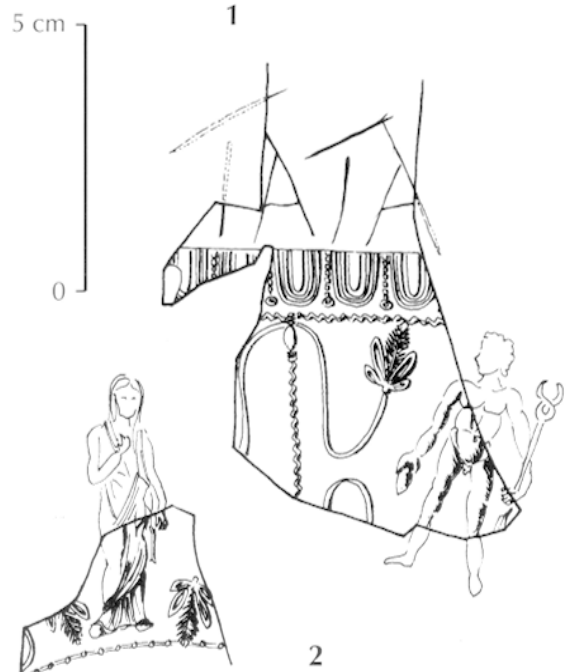

2
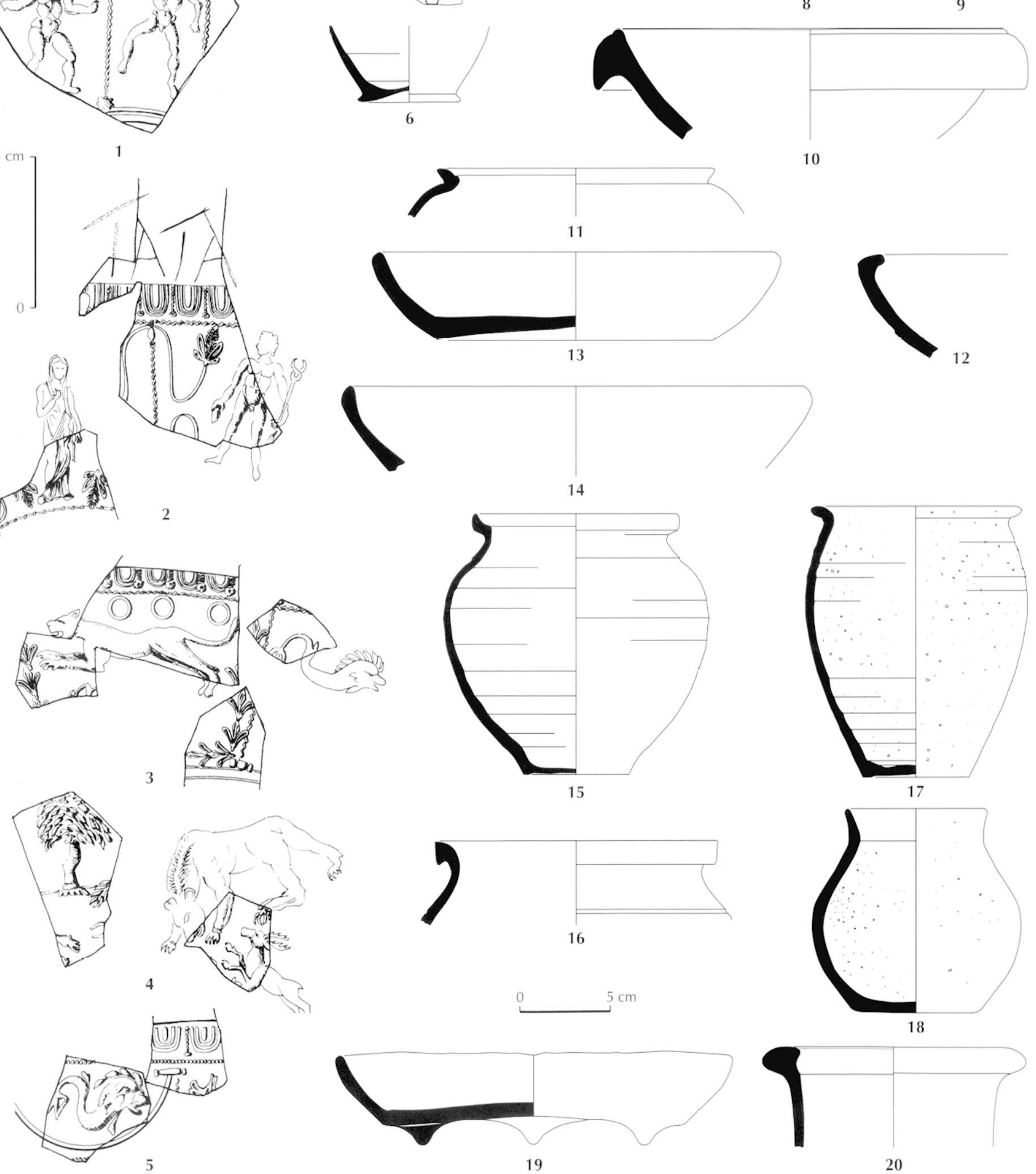

10

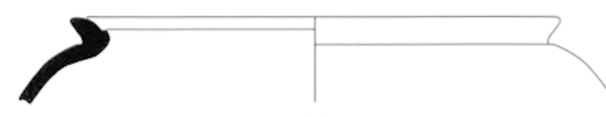

11
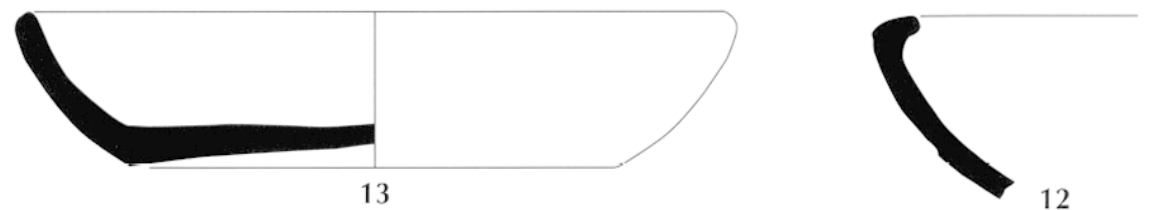

12

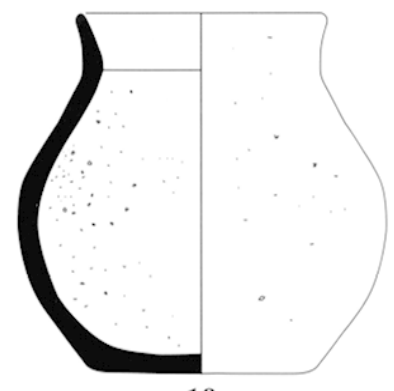

18

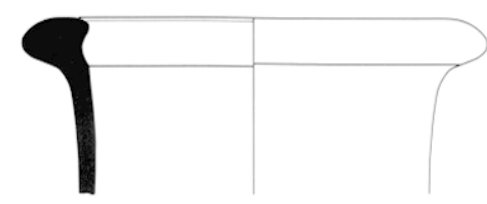

20

Fig. 64 - Phase de construction des portiques (horizon 5d), mobilier céramique : 1-5, sigillée moulée ; 6-7, paroi fine engobée; 8-10, commune claire tournée ; 11-12, commune à engobe orange micacé; 13-16, commune grise tournée ; 17, commune grise granuleuse tournée ; 18-19, modelée; 20, amphore. 
(fig. 64, $\mathrm{n}^{\circ} 8$ ) et de cruches à lèvre en poulie ${ }^{50}$ (fig. 64, $\mathrm{n}^{\circ} 9$ ). Il faut aussi noter la présence des cruches à col fin et lèvre droite anguleuse. Les pots à lèvre moulurée, déjà observés dans le contexte antérieur, restent encore nombreux. Le pot à lèvre moulurée en amande semble même avoir fait l'objet d'un commerce plus important à cette période (fig. 64, $\mathrm{n}^{\circ} 11$ ). Les écuelles en céramique commune à engobe orange micacé sont moins fréquentes. La forme à lèvre rentrante à bourrelet laisse la place à l'écuelle à lèvre rentrante anguleuse (fig. 64, nº 12). Les assiettes (ou plats) en céramique commune grise tournée sont identiques à celles des contextes antérieurs avec toutefois deux nouvelles formes : il s'agit d'une assiette à fond plat et à lèvre légèrement rentrante, formant une arête sur le haut de la paroi externe (fig. 64, $\mathrm{n}^{\circ} 14$ ), et d'une autre à fond plat et à lèvre épaisse et carrée (fig. $64, n^{\circ} 13$ ). Les pots à lèvre rectangulaire sont encore présents mais de manière résiduelle. Les pots à lèvre en amande, déjà observés dans les contextes 100-130 et 120-140 apr. J.-C., restent encore fréquents au milieu du ${ }^{\mathrm{e}}{ }^{\mathrm{s}} \mathrm{s}$. apr. J.-C., mais leur pâte semble plus affinée et plus dure. Les pots à lèvre en gouttière, absents des ensembles antérieurs, sont à pâte grise et sableuse (fig. 64, $\mathrm{n}^{\circ} 15$ ) ; les surfaces sont grises et granuleuses, le haut de la panse est marqué par une cannelure ou une moulure. Les lèvres éversées en gouttière sont trapézoïdales. À ces nouveaux vases sont associés des pots à lèvre éversée en corniche. Tous servent à cuire comme le prouvent les coups de feu sur les panses. Toujours en céramique commune grise tournée, cette période voit se développer un autre type de pots en pâte fine et surface grisée (fig. 64, n*16). La panse de ces derniers est globulaire et possède une cannelure sur le haut ; la lèvre est éversée en bec d'aigle. Cette nouvelle forme, comme la précédente, constituent probablement les premières ébauches de certains pots, qualifiés de type La Bosse, qui apparaissent à la période suivante.

En céramique commune sombre grossière tournée, les pots à lèvre éversée globulaire ou en amande, déjà observés, sont de modules différents. Des pots à lèvre éversée globulaire et à panse ovoïde sont fabriqués en céramique commune grise granuleuse tournée avec une pâte de couleur blanche à grise (fig. 64, no 17). Celle-ci contient beaucoup de grains de quartz (parfois grossiers) qui transparaissent en surface ${ }^{51}$.

Le milieu du $\mathrm{II}^{\mathrm{I}} \mathrm{s}$. voit également apparaître des céramiques modelées aux formes diverses : pot ou gobelet à panse ovoïde et globulaire et à lèvre triangulaire, assiette tripode (fig. 64, $\mathrm{n}^{\mathrm{os}} 18$ et 19). Les surfaces extérieures sont souvent lustrées. Les pâtes noires à marron sont de deux types : l'une est fine et sableuse, l'autre contient des particules blanchâtres ${ }^{52}$. Les amphores,

50. Des cruches à col en poulie ont été découvertes au Mans (Humbert, 1987 , p. 30, n"6 ; Guillier et al., 1993, p. 121, n"1 ; Guillier, 1995, p. 225, n"69; Delage, Guillier, 1997, p. 270, tig. 13, n"16).

51. Le répertoire de cette production est certainement plus important puisqu'un fragment d'assiette ou d'écuelle a été découvert dans le contexte suivant. Une jatte, une cruche, divers pots à lèvre ronde ou rectangulaire ainsi qu'un gobelet sont recensés au Mans (Îlot 7 Fl, cf. Delage, Guillier, 1997 , p. 264 , fig. 8 , n" 12 ; p. 265 , fig. 9 , n” 7 ; p. 266 , fig. $10, n^{\circ 1} 11-17$, et p. 267, fig. $11, n^{\circ} 8$ ).

52. Des formes sont signalées au Mans dans des contextes allant de la première moitié du II"s. au III"s. apr. J.-C. encore peu nombreuses, se répartissent en un fragment de panse de Gauloise 3/5 de Narbonnaise, un col de Gauloise 5 (fig. 64, n²0) avec une pâte brune à cœur gris associé à une anse, ainsi qu'un fragment de panse de Dressel 20 de Bétique.

\section{LA FRÉQUENTATION (HORIZON 6) ET LA DESTRUCTION DU SANCTUAIRE À QUADRIPORTIQUE (HORIZON 7)}

\section{LA FRÉQUENTATION (HORIZON 6)}

La période de fonctionnement du sanctuaire est surtout connue par le matériel recueilli dans certaines zones extérieures comme celle qui côtoie l'exèdre axiale $A$, au sud, et comme aux abords de la porte nord.

Dans la zone extérieure attenante à l'exèdre axiale $\mathrm{A}$, un plancher de chêne (analyse de D. Marguerie), identifié grâce aux bois recueillis et aux nombreux clous plus ou moins alignés, autour des puisards, est associé à une quantité de mobilier très supérieure à celle prélevée en d'autres points périphériques du quadriportique qui montre une occupation intense de ce secteur (fig. 62). On y trouve en abondance de la céramique commune ou sigillée, parfois des assiettes, des plats presque entiers, des coquillages (huîtres, moules, coques...), des ossements animaux. La fonction de ces vestiges et la nature de ces dépôts nous échappent : campement de pèlerins, boutiques associées au sanctuaire, évacuation des restes d'offrandes ou de festins rituels se tenant dans la salle adjacente. Rien dans la nature du mobilier ne permet de trancher entre ces différentes hypothèses.

La fréquentation du sanctuaire entre 150 apr. J.-C. et le milieu du $\mathrm{r}^{\mathrm{e}}$ s. apr. J.-C. est attestée par plusieurs types de mobiliers, céramiques et monnaies qui fournissent quelques données spécifiques sur ce lieu de culte. On remarque cependant une abondance particulière du mobilier de la fin du $\mathrm{II}^{\mathrm{e}} \mathrm{s}$. et du $\mathrm{III}^{\mathrm{e}} \mathrm{s}$., puis une baisse progressive des pièces céramiques aisément datables dénotant soit un usage plus important de céramiques locales, soit une diminution réelle des dépôts céramiques dans le sanctuaire qui n'est pas conforté par le matériel monétaire. Il est possible que ce début du $\mathrm{IV}^{\mathrm{c}} \mathrm{s}$. soit marqué par un appauvrissement du sanctuaire ou du moins par des modifications des pratiques religieuses, prélude à sa fermeture.

\section{LES MONNAIES ROMAINES}

La phase de reconstruction du sanctuaire s'accompagne d'une chute progressive du rapport annuel des monnaies antonines, observée à partir de Nerva (fig. 65). Cette baisse va à l'encontre des volumes de frappe de l'atelier de Rome, les monnaies d'Hadrien (117-138 apr.J.-C.) étant à peine plus nombreuses que celles de Trajan entre 96 et 98 apr. J.-C. (15 contre 14), alors que le premier fit frapper une fois et demie plus de monnaies que son prédécesseur (Besombes, 2001, p. 215). Cette diminution, plus curieusement, se poursuit sous Antonin le Picux, Marc Aurèle et Commode (respectivement 12, 8 et 3 monnaies), alors que la reconstruction du sanctuaire s'achève 


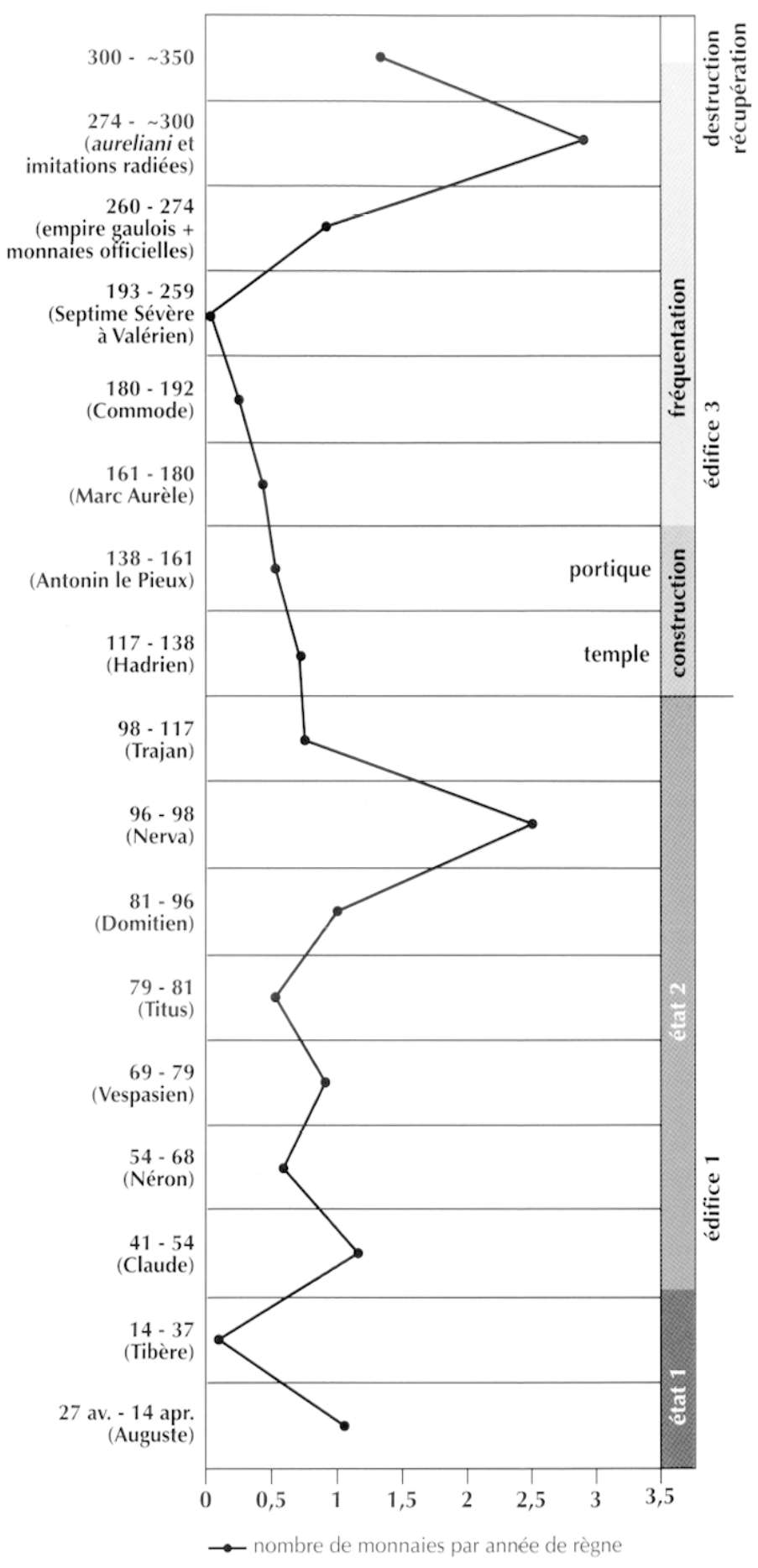

Fig. 65 - Rutio annuel des montnaies romaines du sanctuaire de Mars Mullo par rapport aux phases d'occupation du site à l'époque romaine.

et que celui-ci est en pleine activité. Ces chiffres doivent cependant êtres observés arec prudence en fonction de la durée de circulation prolongée des monnaies antonines qui ont pu circuler durant la phase de fréquentation. Néanmoins, seule une minorité de ces monnaies antonines correspond aux niveaux de fréquentation. Cette constatation peut être faussée par le fait que les sols de fréquentation étaient régulièrement nettoyés, les monnaies égarées ou offertes étant alors récupérées.

Outre cette difficulté de pénétration du numéraire sous les Antonins, la répartition par dénomination des monnaies du
II $\mathrm{e}$ s. pourrait faire penser à une faible croissance du sanctuaire puisque les monnaies à fort pouvoir d'achat sont minoritaires avec trois deniers alors que les sesterces ne représentent que $32 \%$ des espèces (contre $76 \%$ à Rennes) ${ }^{53}$.

La phase creuse caractérisant le monnayage de la fin des Antonins est suivie d'un hiatus monétaire de plus d'un demisiècle (de 190 à 244). Ce vide est l'illustration de la pénurie de bronze généralisée en Gaule s'amorçant à la fin du règne de Commode (Callu, 1969, p. 125). Cette pénurie est sensible dans de nombreux sites armoricains comme Rennes, Corseul ou encore Jublains, où l'on ne compte que deux monnaies pour la période 180 à 260 , période correspondant pourtant là encore à de grands travaux du sanctuaire (Aubin, 1997, p. 216). Le hiatus observé au sanctuaire de Mars Mullo ne saurait donc être interprété comme une diminution de son activité, même si la pénurie monétaire dut y être importante puisque les monnaies antonines ne semblent pas avoir, dans leur majorité, contribué à pallier le déficit de bronze, et encore moins celui des deniers de la première moitié du III's., totalement absents.

Le renouvellement du numéraire ne se fait qu'avec l'arrivée tardive et marginale de l'antoninie dans le sanctuaire comme dans l'ensemble des sites: deux antoniniens de Philippe $I^{\text {"r }}$ (244-249) pour la période 238 à 260. Ces monnaies circulaient tout de même jusqu'à Allonnes, comme le montre le trésor d'Allonnes I (Giard, 1962, p. 218), clos vers 266, où l'on retrouve 733 antoniniens frappés entre 238 et $260(72 \%$ de l'ensemble). Enfoui une décennie plus tard, le trésor d'Allonnes II (Estiot et al., 1986, p. 53) ne contient plus que $1,8 \%$ de ces monnaies. La thésaurisation rapide de ces espèces de bon aloi explique leur absence dans le complexe cultuel.

Après 260, le numéraire officiel reste rare, malgré les importantes frappes inflationnistes d'antoniniens à partir de 266. Ainsi, pour la période de l'Empire gaulois (260-274), seules dix monnaies officielles (six au nom des empereurs officiels contre quatre pour les usurpateurs gaulois) parviennent dans le sanctuaire de Mars Mullo. Ces antoniniens officiels étaient généralement véhiculés par l'armée, comme c'est le cas des frappes d'argent de Postume (un exemplaire recensé). Néanmoins, la quasi-absence d'antoniniens de Postume s'explique par le fait que ces monnaies fortement argentées étaient rapidement thésaurisées, comme l'illustrent les trésors d'Allonnes I et II : le premier se compose de 286 monnaies terminales de Postume (Giard, 1962, p. 218), tandis que le second comprend 165 de ces monnaies auxquelles il faut ajouter un grand nombre de monnaies de Victorin (Estiot et al., 1986, p. 55). La présence de celles-ci, issues pour la plupart de l'atelier de Cologne, pourrait être à mettre en relation avec le passage de troupes rhénanes, même si le monnayage des usurpateurs circulait abondamment au nord de la Gaule, ces derniers ayant retiré les espèces romaines pour frapper leur propre monnaie (Estiot et al., 1986, p. 65).

Tandis que les antoniniens officiels sont rapidement thésaurisés, la circulation monétaire est envahie par les imitations radiées, produites à partir de 274, destinées à pallier

53. Selon A. Audra et P. Mathey, la prolifération des grands bronzes pourrait être un signe de vitalité économique (Audra, Mathey, 1992, p. 50$)$. 
le manque de monnaies officielles. Ainsi, soixante-trois imitations gauloises ( $17 \%$ du total) ont été retrouvées dans le sanctuaire de Mars Mullo. Une importante quantité de ces monnaies est caractéristique de sites occupés sans discontinuité à la charnière des III $^{*}$ et IV* s., ce qui est confirmé par la majorité de minimi (imitations de module inférieur à $14 \mathrm{~mm}$, frappées à la toute fin du III $^{\circ} \mathrm{s}$.) constituant le lot des imitations. Ia proportion d'imitations n'y est néanmoins pas écrasante, comparée à des sites comme Corseul (28\%), Alet (30 à $40 \%$ ) ou encore Jublains ( $55 \%$ ) (Aubin, 1997, p. 216 ; Besombes, 2001, p. 215-216).

Face à ce flot d'imitations barbares, les monnaies issues de la réforme d'Aurélien (274) ont des difficultés à s'imposer et ne pénètrent que tardivement en Gaule, comme l'illustre le trésor d'Allonnes II, enfoui sous Aurélien, qui ne contient que $0,1 \%$ de ces aureliani. Trois exemplaires de cette espèce, présents dans le sanctuaire de Mars Mullo, semblent confirmer l'occupation ininterrompue du monument entre la fin du III" $^{\circ}$ s. et le début du siècle suivant ${ }^{54}$ (fig. 66).

\section{LA CÉRAMIQUE}

Les couches archéologiques de cet horizon comportent des mobiliers dont la date de production couvre en grande partie

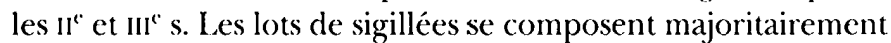
de pièces du centre de la Gaule de la seconde moitié du II" $s$. et des premières décennies du $\mathrm{III}^{*} \mathrm{~s}$. Le répertoire comporte ainsi la plupart des formes en usage à cette période : services Lez. 42-43 (fig. 67, n"1) et Lez. 44-45 (fig. 67, n³ et 4), assiettes I.e\% 56 et I.$e .54$ dont l'unc porte une estampille de graphie L.UPIN [- - ] (fig. 67, n"7), ainsi que des coupelles Lez. 36 (Drag. 33) associées dans un cas à une estampille ALBILLI. $\overline{\mathrm{MA}}$ (fig. $67, n^{\circ} 8$ ). À ceux-ci, il faut ajouter la présence de vases globulaires Déch. 72 de la seconde moitié du $\mathrm{II}^{\circ} \mathrm{s}$. (fig. $67, \mathrm{n}^{\circ} 6$ ),

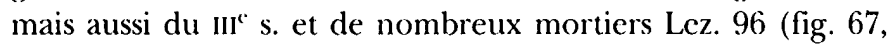
$n^{\circ} 4$ ), Lez. 97 (Curle 21) (fig. 67, n5) et Lez. 100 (Drag. 45) créés à la fin du $\mathrm{II}^{\circ}$ s. et au cours du $\mathrm{III}^{\circ} \mathrm{s}$. au sein des ateliers de Lezoux, mais aussi très certainement de Terre-Franche. Les vases moulés sont pourvus de décors des groupes stylistiques de PATERNVS (fig. $67, \mathrm{n}^{\circ} 10$ ) et de CINNAMVS.

Les céramiques fines autres que sigillées comportent de petits fragments de parois fines engobées ou métallescentes de première génération (fig. $67, n^{\circ} 12$ ), ainsi que des vases en céramique métallescente " classique " du centre de la Gaule (fin du II" s.-début du III" s.), dont une coupelle Lez. 303 (fig. 67, n'11).

Les céramiques communes cuites en mode A comportent, à l'image des autres horizons, essentiellement des cruches (fig. 67, $n^{\circ} 15-17$ ) ainsi que des mortiers (fig. 67, n\%18). L.es premières possèdent majoritairement des lèvres en bec d'aigle (fig. 67, n"15) et en poulic (fig. 67, n"16). Les cruches à lève en capuchon (fig. $67, n^{\prime \prime} 17$ ) sont toujours attestées, mais elles présentent fréquemment un volume plus important. Quant au

54. R. Reece a établi les faciès de circulation du monnayage romain pour la partic oucst de l'Kmpire romain. Il est intéressant d'y intégrer le faciès monétaire d'Allonnes (Reece, 1967, 1972, 1973).

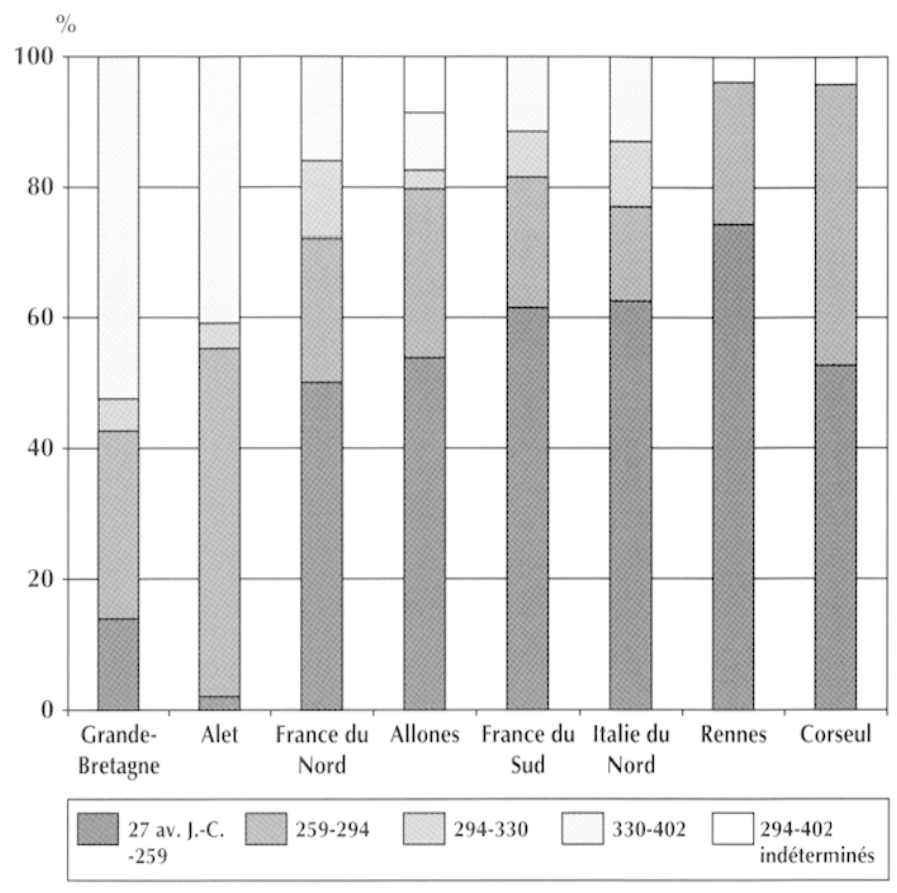

Fig. 66 - Comparaison du faciès du sanctuaire avec les différents faciès régionaux.

répertoire des mortiers, il n'évolue guère par rapport à celui de l'horizon précédent (fig. 67, n'18).

Deux plats à engobe interne rouge pompéien (fig. 67, $n^{\circ} 14$ ), ainsi qu'un couvercle (fig. 67, n\%13), figurent au sein de ces niveaux.

I.es céramiques communes cuites en mode B comportent, en plus des pots en céramique commune grise granuleuse déjà présents dans l'horizon précédent (fig. 69, n6), deux nouvelles catégories. La première, définie sous le terme de " commune sombre gris blcuté tournée " possède une pâte fine kaolinique de couleur blanche à rose, ses surfaces rugueuses varient du bleu marine au bleu clair avec parfois des tonalités plus proches du gris bleuté. Il s'agit, en grande majorité, d'un ensemble issu probablement des ateliers sarthois de La Bosse, à $40 \mathrm{~km}$ au nordest du Mans 5 . Le répertoire est particulièrement diversifić puisqu'il comporte des assiettes ou plats à lèvre simple et à lèvre rentrante (fig. $68, \mathrm{n}^{\circ} 1$ ), des bols et jattes (fig. $68, \mathrm{n}^{\circ \times}$ 2-7) avec ou sans collerette, tripodes ou à fond annulaire dont certains imitent des formes de sigillée : Drag. 38 (fig. 68, n"4), Drag. 37 avec décors de guillochis (fig. 68, n6) et Curle 21 (fig. 68, n5).

55. L'implantation des ateliers s'est faite sur les hauteurs d'une colline. l.es prospections ont montré de fortes concentrations de tessons. En totalité, sept secteurs, matérialisés aut sol par des taches grises, ont été identifiés. I.es découvertes, dans les sites de consommation, de ceramiques de tvpe La Bosse sont nombreuses. Ainsi. au Mans, cette production représente plus de $50 \%$ des céramiques communes (Les Halles, cf. Delage, Guillier, 1997). Toutefois, il faut rester prudent quant à l'aturibution des vases de pâte identique à l'atelier de la Bosse. En effet, des formes d'aspect semblable, non identifiées dans cet atelier, tendent à démontrer l'existence d'autres ateliers réalisant des céramiques aux caractéristiques techniques très proches mais aux formes différentes. 


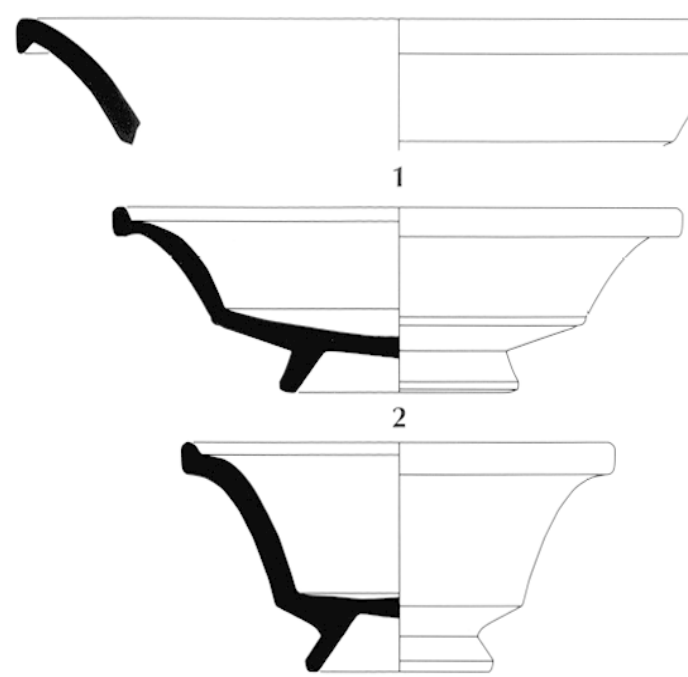

3
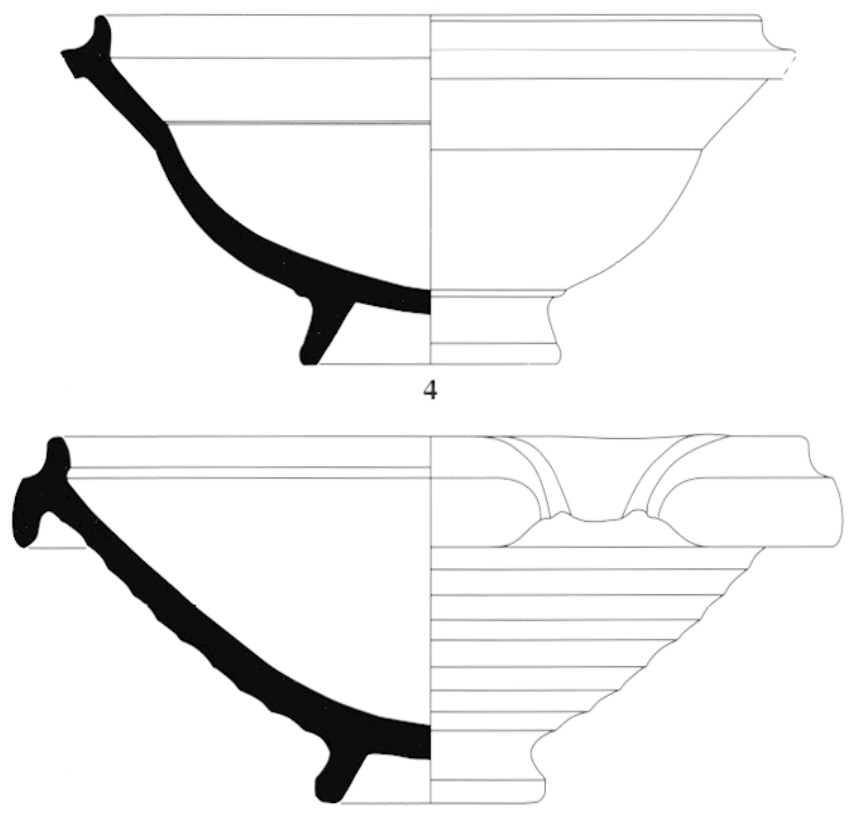

5
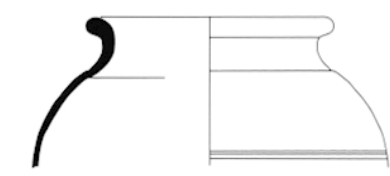

6

TVPIS ARBIILIEA

7

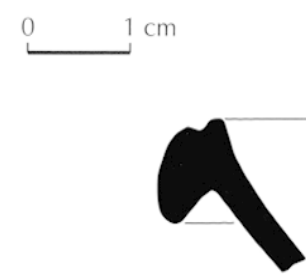

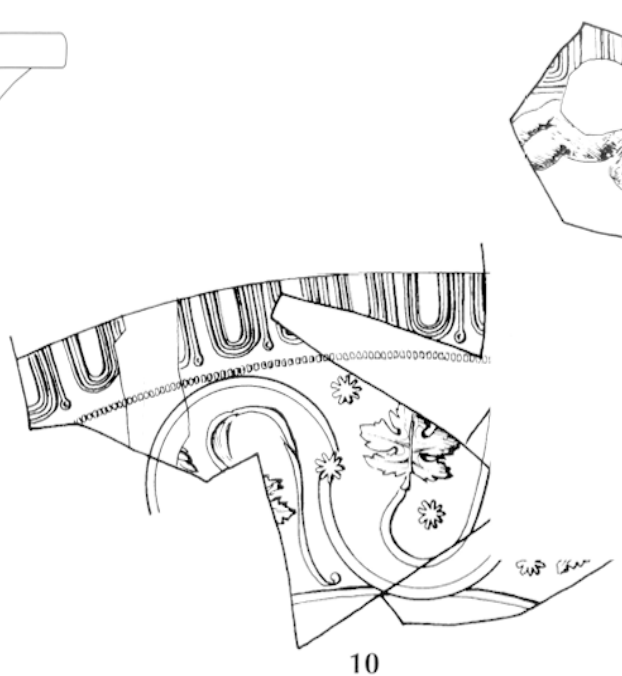

(0)

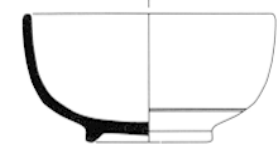

11

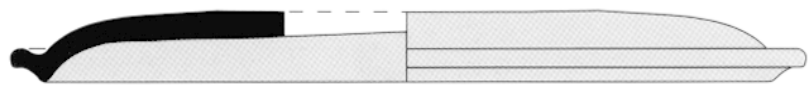

13
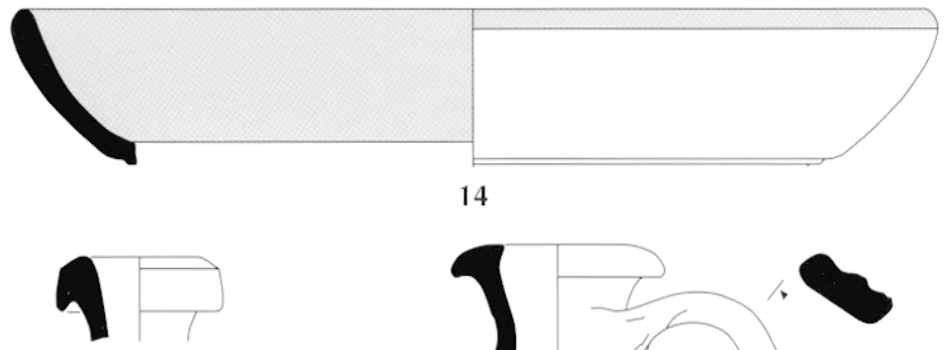

15

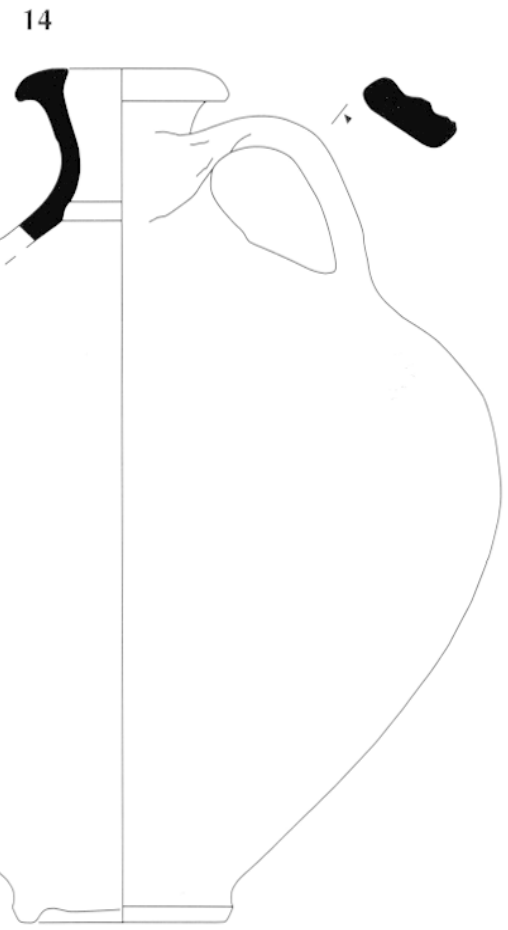

17

Fig. 67 - Phase de fréquentation du sanctuaire (horizon 6), mobilier céramique : 1-6, sigillée lisse ; 7-8, estampilles ; 9-10, sigillée moulée; 11-12, paroi fine engobée et métallescente ; 13-14, engobe interne rouge; 15-18, commune claire tournée. 

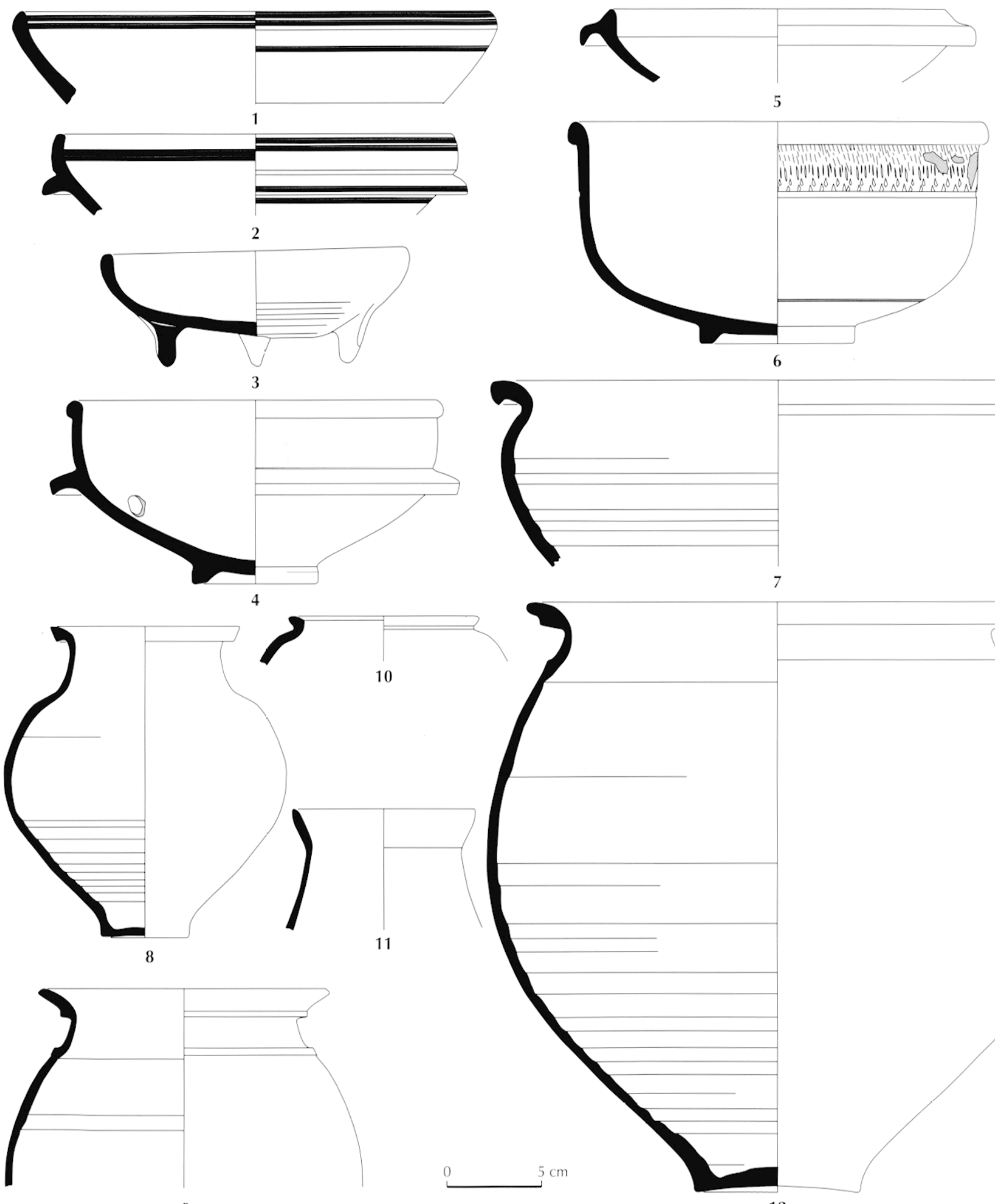

11

9

$$
12
$$

Fig. 68 - Phase de fréquentation du sanctuaire (horizon 6), mobilier céramique : 1-12, type La Bosse, commune sombre gris bleuté tournée.

Les pots à cuire (fig. $68, \mathrm{n}^{\circ} 8$ ) et pots aux fonctions diversifiées sont également attestés. Ces derniers, nettement majoritaires, comptent deux formes globulaires, l'une à lèvre simple à ressaut (fig. 68, $\mathrm{n}^{\circ}$ 12), l'autre à lèvre éversée à baguette (fig. $68, \mathrm{n}^{\circ} 9$ ), et une forme biconique à lèvre éversée simple et allongée (fig. $68, n^{\circ} 11$ ). On note également la présence de cruches aux variantes de lèvre et de forme (fig. $69, \mathrm{n}^{\circ} \mathrm{l}$ ).

La seconde catégoric présente un ensemble de vases à pâte fine micacée, issus vraisemblablement d'un atelier local. I.c

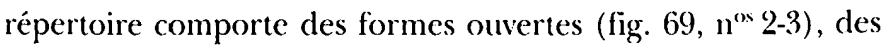


pots globulaires et biconiques (fig. $69, \mathrm{n}^{\circ} 5$ j et, plus rarement, des cruches (fig. 69, $\mathrm{n}^{\circ} 4$ ).

Quant aux céramiques communes modelées, apparues dans l'horizon précédent, elles se caractérisent à cette période par un bol globulaire (fig. $69, \mathrm{n}^{\circ} 8$ ) et des pots à lèvre rectangulaire épaisse (fig. 69, $\mathrm{n}^{\circ} 7$ ).

Les amphores sont représentées par deux panses de Dressel 20 de Bétique, une anse d'amphore à pâte brune et coeur gris et un fragment de Gauloise 12 (fig. 69, no9). Une forme locale à lèvre horizontale et anse plate, proche des types aquitains, complète cet ensemble modeste.

Ces contextes homogènes et bien stratifiés du sanctuaire de Mars Mullo à Allonnes apportent de nouvelles informations sur les productions de céramiques communes découvertes en Sarthe. L'association des données issues de l'analyse du mobilier métallique, des monnaies et de la sigillée, avec celles des amphores et des céramiques fines et communes, permet d'affiner les datations pour ces dernières, mais aussi de micux comprendre l'évolution de ces céramiques et de certains courants culturels et commerciaux en région sarthoise. Au II" $s$. apr. J.-C., par exemple, les importations ainsi que les influences provenant du centre de la Gaule (cruches, amphores, pots,

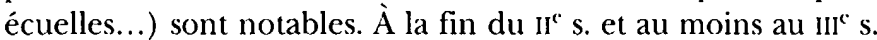
apr. J.-C., elles s'estompent et l'on voit se développer un courant d'influence plus orienté est-ouest. La diffusion des céramiques locales de type La Bosse suit d'ailleurs ce mouvement puisqu'on en retrouve ${ }^{56}$ au sud de l'Orne dans la plaine de Caen (Sées, Alençon) ${ }^{57}$ et au moins jusqu'à Jublains en Mayenne. Au-delà, les courants culturels et de diffusion de la Bretagne, avec les influences du Sud-Ouest, prédominent. Certains contextes restent encore mal connus en Sarthe comme ceux du $\mathrm{I}^{\mathrm{rr}} \mathrm{s}$. apr. J.-C. ou du IN" s. apr. J.-C. Ceux des II" et III" s. apr. J.-C. commencent à être mieux perçus.

\section{LA DESTRUCTION DU SANCTUAIRE (HORIZONS 6B ET 7, FIN III' ${ }^{\mathrm{e}}$. OU IV $^{\text {re }}$ S.)}

À l'intérieur de l'exèdre A tout comme dans la galerie sud, le sol est entièrement conservé au niveau du radier ou du béton supérieur. Une couche cendreuse très épaisse à hauteur des plinthes des colonnes $(15 \mathrm{~cm})$ s'amincit rapidement plus au sud pour n'être plus constituée que d'un mince lit de cendres. Elle atteste un feu dans la galerie qui se situerait dans les années 330 d'après le témoignage d'une monnaie romaine datée de 321-32. ${ }^{58}$ (horizon 6b). Elle est immédiatement recouverte par les couches de démolition (horizon 7). Les tuiles restent tiès

56. Il faut bien sûr nuancer cette donnée puisque certaines formes, comme le pot biconique, sont encore communes à différentes régions, notamment celle du Centre. Il s'agit peut-être ici d'une bonne adaptation de la forme à un besoin précis.

57. Quelques fragments à pâte blanche et surface bleutée sont signalés à Corneille près de Caen, mais en très faibles proportions et le plus souvent dans des contextes datés du $\mathrm{N}^{\mathrm{N}} \mathrm{s}$. apr. J.C. (Navarre, 1997).

58. Cette monnaie (inx: AL.05.94-163) a très peu circulé car elle correspond à une émission courte et peu abondante, qui a été rapidement démonétisée, d'où l'intérêt de sa découverte sur le sol même de l'exèdre $A$. C'est un bronze frappé à Lyon en 321-323, présentant au fragmentaires et ont dû, pour une bonne part, être récupérées comme les pierres des murs. Cette même séquence stratigraphique est plus ou moins bien conservée dans tous les secteurs du quadriportique. Des points de feu se retrouvent de place en place. La destruction systématique du sanctuaire apparaît plutôt comme une fermeture avec récupération immédiate d'une partie des matériaux. L'importante couche de démolition au nord et au sud du temple, dans la cour, confirme les observations faites sur le portique. Les derniers témoins numismatiques, datant des années 350, confirment que le sanctuaire de Mars Mullo était toujours fréquenté en ce milieu de siècle et correspondraient aux phases de destruction et de premières récupérations de matériaux. En outre, l'absence des abondantes frappes valentiniennes (364-378) paraît confirmer l'abandon complet du monument dans la seconde moitié du $\mathrm{IV}^{\mathrm{N}} \mathrm{s}$.

\section{LES MONNAIES}

Le $\mathrm{IV}^{\mathrm{c}}$ s. est représenté par soixante-neuf monnaies (18,3\% de l'ensemble), proportion correcte mais pas exceptionnelle pour un sanctuaire fréquenté durant toute la première moitié du $\mathrm{IV}^{\mathrm{re}} \mathrm{s}$. La première manifestation du nummus apparaît avec deux monnaies frappées dans la première décennie du siècle. Ces monnaies de grand module restent rares sur les sites, alors que les imitations radiées circulent toujours. Le numéraire frappé durant le deuxième quart du $\mathrm{IV}^{\mathrm{C}} \mathrm{s}$. est assez bien représenté ( 11 exemplaires), mais ce sont les minimi au type GLORIA EXERCITVS (27 exemplaires, dont 7 imitations), frappés entre 330 et 341 , qui prédominent logiquement. Le numéraire précédant la réforme de 348 parvient toujours de façon régulière dans le site ( 7 monnaies frappées entre 341 et 346 ), tandis que seules deux monnaies sont postérieures à cette réforme. Ce faible nombre est probablement dû à la réduction du volume de frappe de l'atelier de Trèves à partir de 336 (Depeyrot, 1982, p. 172-174), d'autant plus que cet atelier fournissait un apport déterminant sur le sanctuaire (plus de la moitié des exemplaires du $\mathrm{IV}^{\mathrm{c}} \mathrm{s}$. identifiés). Les monnaies montrent un approvisionnement en numéraire du sanctuaire jusqu'au milieu du IV s., et l'on peut probablement associer les monnaies du IV $v^{\prime \prime} s$. avec sa destruction : plusieurs pièces émises dans les années 330-340 ont été trouvées sur les sols des portiques, dans la couche d'incendie.

\section{LA CÉRAMIQUE}

L'analyse de la céramique sigilléc des niveaux d'abandon des portiques et du temple met en évidence la présence de nombreux vases liés à l'occupation du sanctuaire monumental, depuis le milieu du II"s. jusqu'à la fin du Haut-Empire, voire un peu plus tard si l'on tient compte de la présence de céramiques susceptibles d'avoir été produites au début du Bas-Empire.

Les sigillées du centre de la Gaule constituent, pour le HautEmpire, l'essentiel du répertoire ; les plus récentes pouvant être datées du III" s. Ce sont plus particulièrement des vases globu-

droit un buste lauré, CRISPYS NOB CAES et, au revers, la légende BEATA TRANQVILLITAS VOT / IS / XX CR PLG, type RIC 168 $2,71 \mathrm{~g}, 20 \mathrm{~mm}$ 


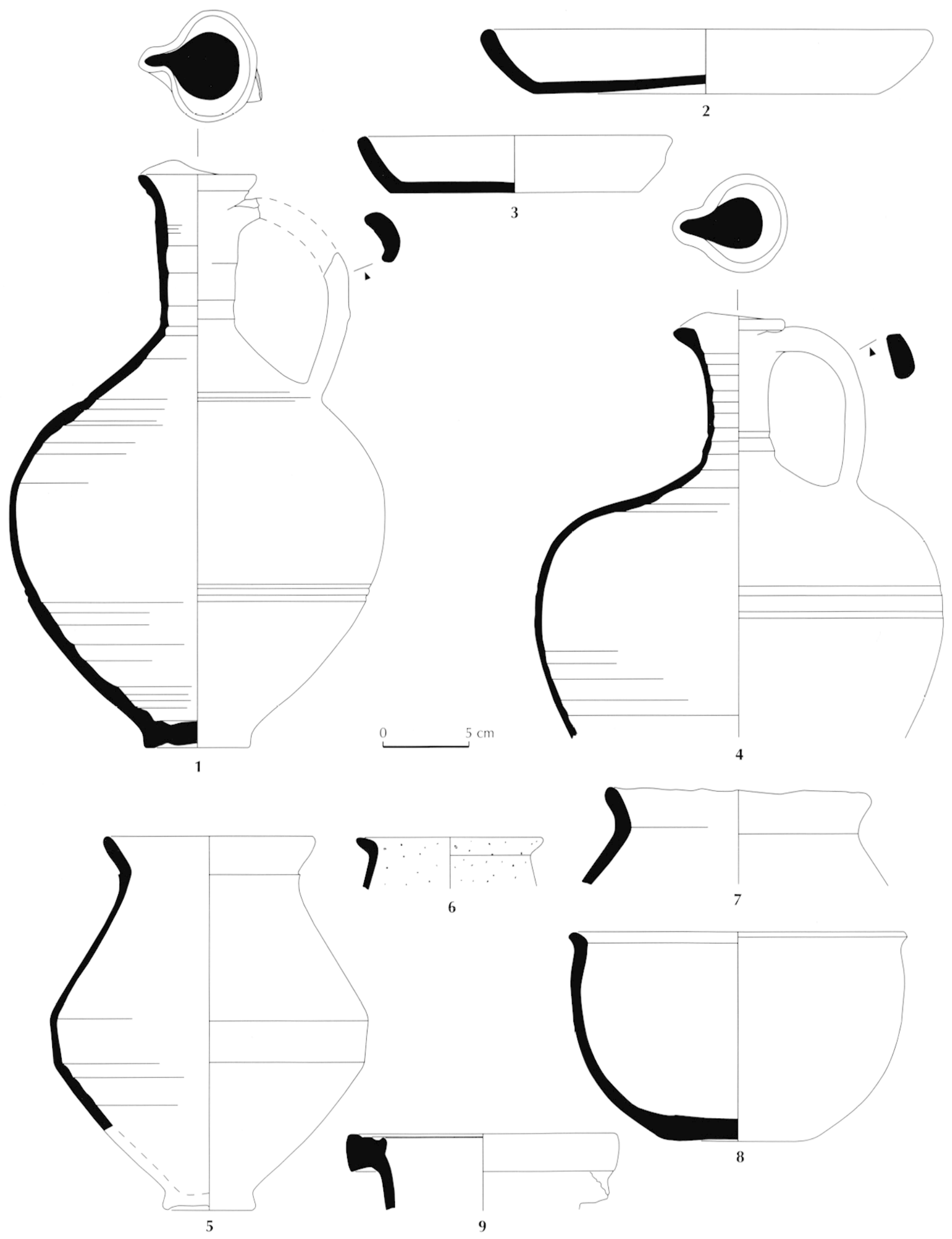

Fig. 69 - Phase de fréquentation du sanctuaire (horizon 6), mobilier céramique :

1-5, commune fine grise tournée; 6, commune grise granuleuse tournée; 7-8, modelée; 9, amphore. 
।

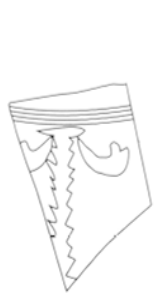

1

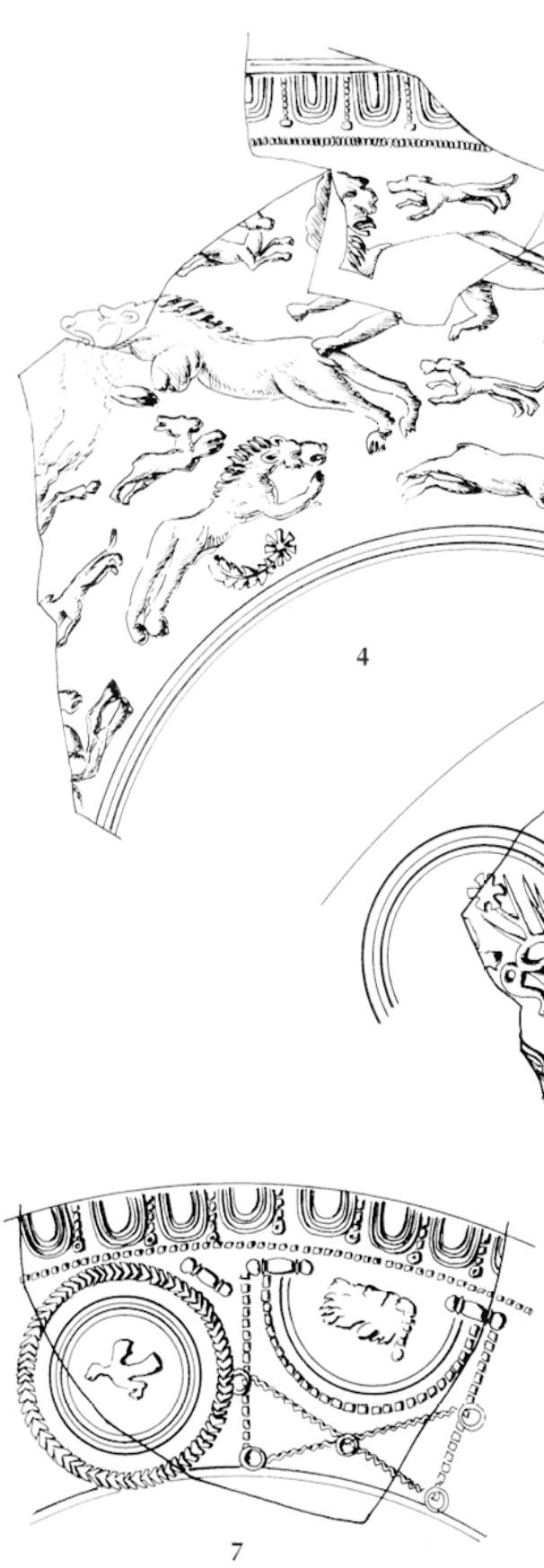

laires Déch. 72 (fig. 70, $\mathrm{n}^{\circ} 1$ ) et des mortiers Drag. 45 (fig. 70, $n^{\circ} 2$ ) présents dans tous les contextes, parfois en grand nombre. L'un des vases se compose d'une assise de $9 \mathrm{~cm}$ de diamètre, induisant ainsi une hauteur totale d'au moins $25 \mathrm{~cm}$. Des pièces de cette dimension sont fréquentes en Gaule dans les contextes du milieu et de la seconde moitié de ce siècle, sans qu'elles soient en situation de résidualité. Un autre vase possède une

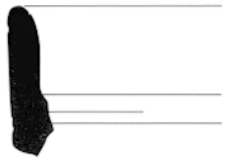

3

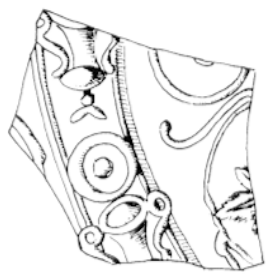

5 and

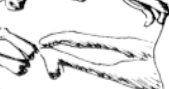

6 $5 \mathrm{~cm}$

Fig. 70 - Phase de destruction du sanctuaire (horizon 7), mobilier céramique : 1-3, sigillée lisse; 4-7, sigillée moulée. 
milieu du III" s., présentant un décor de l'officine de MARCVS (fig. 70, n⿳6). Certaines compositions décoratives du II ${ }^{\circ}$ s. apparaissent sur des vases moulés présentant des caractéristiques techniques " tardives ". Dans de tels cas, les moules ont été utilisés par des potiers tourneurs bien après que l'officine créatrice eut cessé ses activités. Ainsi l'un des vases moulés porte un décor de PATERNVS II (fig. 70, n4).

Dans cet horizon tardif apparaissent des céramiques sigillées d'Argonne, en l'occurrence des mortiers, correspondant vraisemblablement à des productions de la fin du Haut-Empire ou du début du Bas-Empire: Chenet 328-330 ou Drag. 45 (fig. 70, n*3).

\section{LES ÉLÉMENTS D'HISTOIRE RELIGIEUSE}

Les thèmes iconographiques et les dédicaces apportent quelques données sur les rites et les attributions des dieux honorés. Les offrandes d'ossements animaux complètent cette connaissance.

\section{L'ICONOGRAPHIE RELIGIEUSE}

Le sanctuaire de Mars Mullo a livré très peu de pièces d'une certaine extension et encore moins de scènes organisées : les quelques fragments de chapiteaux historiés et morceaux de colonnes ornées font figure d'exception. Pour l'essentiel il s'agit de têtes et d'éléments anatomiques peu significatifs. On demeure trop souvent indécis dès qu'il s'agit de préciser l'appartenance d'un fragment considéré à une statue (statuette), ou à un fragment de bas-relief, ou à un élément en ronde bosse provenant d'un relief ou, inversement, à un élément en relicf détaché d'une ronde-bosse.

Même s'il est impossible de regrouper les fragments à l'intérieur de scènes constituées autour d'un thème (mythologique, religieux, historique) pour les réintégrer au sein de l'organisation architecturale du sanctuaire, l'observation de certaines pièces laisse entrevoir la nature des choix iconographiques retenus. En nous éclairant sur l'ambiance thématique du décor du sanctuaire, elle contribue dans une certaine mesure à la connaissance de la personnalité du dieu d'Allonnes.

Deux têtes juvéniles casquées un peu plus petites que nature ne sont pas, semble-t-il, des têtes de statues. Elles sont réalisées en très haut relief et des traces d'arrachement sont perceptibles. Elles n'appartenaient certaincment pas à la même scène. Flles sont à l'évidence de deux mains différentes et chacune d'un style bien individualisé. En dépit de traits plutôt fins qui pourraient faire hésiter sur le sexe du personnage, la tête $n^{\circ} 1$ (inv. AL.05.96.1555) est indiscutablement masculine puisqu'elle porte des favoris visibles du côté droit tourné vers le spectateur et qui, pour cette raison, est légèrement plus soigné et plus volumineux que l'autre (fig. $71, n^{\circ} 1$ ). Il s'agit du dieu Mars. La coupe du visage plein, plutôt large, presque poupin, évoque de nombreuses représentations du dieu juvénilc inspirćes par les types de l’Arès Borghèse ${ }^{59}$,

59. Bruncau, 1984, p. 481 n" 23 et fig. ; p. 489 (cf. Simon, 1984, p. 512 $n^{\circ} 21$ [nombreuses répliques de cette création d'Alcamène pour le temple d'Arès de l'agora d'Athènes]). de l'Arès de Krésilas (Simon, 1984, p. 513 n²2 et fig.) et de l'Arès Ludovisi ${ }^{60}$. Les arcades sourcilières marquées surplombant des orbites creusées de manière à souligner la saillie des globes oculaires, les iris incisés et les pupilles indiquées au trépan, confèrent au regard levé cette expression pathétique, sévère et un peu rêveuse, propre aux représentations du dieu. La bouche petite, charnue, légèrement entrouverte ainsi que les mèches désordonnées, échappées du casque ${ }^{61}$ en grosses boucles qui encadrent le visage et recouvrent en partie les favoris frisés, sont également caractéristiques ${ }^{62}$. Bien que la chevelure épaisse bouclée couvrant la nuque appartienne plus spécifiquement au type du Mars barbu et cuirassé ${ }^{63}$, elle se combine aussi parfois à ses représentations nues et imberbes ${ }^{64}$. Dans les provinces du NordOuest, elle est même presque systématiquement associée au dieu, que celui-ci soit imberbe ou barbu, nu ou cuirassé ${ }^{65}$. La coiffure du dieu d'Allonnes qui prend place dans une série homogène appartient au faciès provincial de Mars en Gaule romaine.

La structure du visage de la tête casquée $\mathrm{n}^{\circ} 2$ (inv. AL.05. 54-79.71) ${ }^{65}$ trouvée au nord de la cella, la sévérité de son expression, sa coiffure comparable à celle de la tête $n^{\circ} \mathrm{l}$, le port d'un casque d'un modèle qui semble voisin du sien ${ }^{67}$ inviteraient plutôt à reconnaître une fois encore le dieu Mars (fig. 71, n²). Cette identification, toutefois, n'emporte pas totalement notre conviction. Cette tête pourrait bien être féminine comme le pensait L. Harmand ${ }^{68}$. D'une part, à la place des favoris, elle porte des guiches. Ces ornements de cheveux en forme de virgule paraissent plus fréquents chez les femmes, bien que des personnages masculins puissent, il est vrai, en être également

60. Bruneau, 1984, p. 481 n” 24 et fig. ; p. 489 (cf. Simon, 1984, p. 514 n" 23 [nombreuses répliques de cette création de Scopas]).

61. Simon, 1984, p. 513 n 220 e fig. (variante du type Arès de Krésilas, Vatican, museo Gregoriano Profano, inv. 9981 : époque des Antonins); voir aussi en Gaule la tête de Mars du temple de Montmarte dont un moulage est conservé au musée d'Avallon : Rolley, 1979, p. 206, fig. 23 et 24; voir aussi, sans casque, le Mars de Coligny: Boucher, 1976, p. 132-133, fig. 41 ; Boucher, Tassinari, 1976, p. 53-57, n" 43 et fig.; Hatt, $1979,3-4$, p. 186 , p. 190 , fig. $1-2$; également sans casque, celui d'Avallon : Hatt, 1979, 3-4, p. 186 et p. 191, fig. 3.

62. Quelques exemples de Mars avec des favoris frisés: Simon. 1984, p. $509 \mathrm{n}^{\circ} 1$ et fig. (Mars de Todi, Vatican, museo Gregoriano Etrusco inv. 13886 : vers 400 av. J.-C.) ; p. 513 n"2ld et fig. (type Borghèse avec un casque comparable à celui d'Allonnes; de Rome, du temple anonyme B circulaire du Largo Argentina; de Rome, Palazzo dei Conservatori, museo Nuovo 795 : fin de l'époque des Antonins) ; p. 513 n" 21 h et fig. (type Borghèse, Munich, glyptothèque 212 : époque des Antonins) ; p. 547 n"376 et fig. (peinture de Pompei, VII, 9, 47).

63. Simon, 1984, n"24a et fig. ; n"37 et fig. ; n"37a et fig. ; n" 77 et fig. ; n" 87 et fig.

64. Simon, 1984, n"121 et fig. ; n" 124 et fig. ; n" 126 et fig. ; n" 130 et fig. ; $\mathrm{n}^{\circ} 169 \mathrm{et}$ fig.

65. Bauchhenss, 1984 , p. 559-580 n" 421 et fig. : $n^{\circ} 425$ et fig. ; n" 441 et fig. ; n" 442 et fig. ; n" 467 et fig. ; n" 477 i et fig. ; n" 477 e et fig. ; n" $478 \mathrm{c}$ et fig. ; n" 478 e et fig. ; $n^{\circ} 478$ h et fig. ; $n^{\prime \prime} 480$ o ce fig.

66. Espérandieu, XV, p. 121 n"9170, pl. XCI (R. Lantier daaprès les renseignements fournis par $P$. Térouanne).

67. Les deux casques présentent le même ornement latéral en forme de: spirale.

68. Harmand, 1962, p. 774 ; voir aussi Espérandicu, XV, p. 121 n"9170. 
parés. Sur un sarcophage romain au Vatican ${ }^{69}$, par exemple, Adonis, un chasscur, Aphrodite et une suivante en portent tous, indifféremment. Quant à Mars lui-même, il peut en être doté comme le montre la tête provenant du temple de Montmarte à Vault-de-Lugny (Yonne) ${ }^{70}$. La coiffure de la tête $\mathbf{n}^{\circ} 2$, qui combine une épaisse chevelure massée sur la nuque à de grosses boucles ovoïdes, évoque plutôt une disposition capillaire masculine, même si elle est également adoptée, bien que plus rarement, sur des représentations féminines, en Gaule notamment: signalons par exemple une petite Minerve de bronze $^{71}$ ou encore la Roma de la colonne de Jupiter de Mayence ${ }^{72}$. À bien la considérer, cette coiffure offre quelque chose d'apprêté, de calamistré, qui ne nous paraît guère dans l'esprit de celle que Mars porte d'ordinaire, laquelle est toujours un peu négligée et décoiffée. Le caractère féminin de la coiffure de la tête $n^{\circ} 2$ pourrait se confirmer par le fait qu'à la surface de l'amas de cheveux qui couvre la nuque, sous une certaine lumière, on discerne les traces d'un filet au maillage assez gros ${ }^{73}$. Ce maillage fait penser à un reticulum, cette sorte de résille que les femmes, au moins chez les Romains, utilisaient pour contenir leurs cheveux et qui faisait office du cécryphale grec, sans se confondre avec lui ${ }^{7.4}$. La présence d'un reticulum serait alors l'indice que le personnage casqué est bien une femme, et même une femme d'action dont les ébats ne sauraient être gênés par une chevelure indisciplinée. Si tel est bien le cas, quelle serait l'identité de la virago casquée ? Quatre candidates s'offrent à l'esprit : Minerva, Bellona, Virtus et Roma. Divinité poliade, sinon guerrière, du moins armée, la présence de Minerva dans le sanctuaire de Mars se comprendrait par le fait qu'elle semble avoir assumé l'une des fonctions protectrices du dieu : celle de la santé. Néanmoins, l'air farouche, et qui en impose, lui convient moins bien qu'aux trois autres. Bellona, Virtus et Roma sont, du point de vue iconographique, très proches, souvent impossible à distinguer. Elles entretiennent d'ailleurs sur le plan idéologique des relations de proximité. Bellona est la déesse de la guerre et l'épouse de Mars (Blazquez, 1986). Elle est peut-être la moins plausible des trois : le corpus de ses représentations est mince; en Gaule, elle ne semble pas avoir joui de beaucoup de popularité. On peut mentionner tout de même le couple qu'elle forme avec Mars Cicolluis ${ }^{75}$ et l'existence d'une chapelle qui lui est dédiée dans le complexe cultuel du lac d'Antre et de Villards-d'Héria

69. Sichtermann, Koch, 1975 , p. 19-20 n" 7 pl. 12A (Adonis, Aphrodite et suivante) et pl. 12B (chasseur) (museo Gregoriano Profano, inv: 10409 : vers 220 apr. J-C.).

70. Espérandicu, III, n" 2236 ; Nerzic, 1989, p. 157 et fig.

71. Musée d'Arles, inv. P. 1907, cf. Oggiano-Bitar, 1984, p. 102 n” 204 et fig.

72. Espérandieu, VII, p. $377-389$ n 5887 et plus spécialement p. 384 (deuxième tambour) avec fig.; Di Filippo Balestrazzi, 1997, p. 1051 n" 34 et fig. (époque de Néron).

73. Au vu de la photographie de l'objet, $M^{\text {"w1 }}$ G. Di Vita-Evrard a attiré notre attention sur ce détail.

74. Saglio, DA, IV, 2, p. 855, s. v. " Reticulum ", " Retiolum ".

75. P.-M. Duval, 1976, p. 89. En ce qui concerne l'association de Mars et de Bellone en Gaule, attestée par des inscriptions (CII., XIII, 53.51, $5352,3657,6660)$, voir Lerat, 1965 , p. 36-37, n. 2.
(Jura) ${ }^{76}$. Virtus ou Roma nous semblent davantage convenir. Leur iconographie est abondante, riche et variée aussi bien sur des reliefs historiques qu'au sein de scènes mythologiques. En règle générale, Virlus a les cheveux longs dans le cou, flottant parfois assez librement (Ganschow, 1997, n 38 et fig., n 48 et fig., $n^{\circ} 49$ et fig., $n^{\circ} 64$ et fig.), ou bien une chevelure à grosses mèches ondulées, coiffée en bandeaux et ramassée en chignon (Ganschow, 1997, $\mathrm{n}^{\circ} 32$ et fig.). Elle peut cependant, exceptionnellement, comme la Virtus de la colonne de Mayence, avoir le visage encadré d'un rang de bouclettes sur le front et de touffes de bouclettes et d'ondulations sortant de chaque côté du casque (Ganschow, 1997, n'19 et fig.), coiffure qui rappelle celle de la tête $\mathrm{n}^{\circ} 2$. Comme elle, sur un sarcophage du Campo Santo de Pise de la seconde moitié du II $^{\mathbf{e}}$ s., Virtus porte des guiches devant l'oreille ${ }^{i}$. Le type iconographique de la Roma en armes et casquée est si proche de celui de Virtus que le contexte seul permet de les distinguer. Sur la colonne de Mayence qui les présente toutes les deux, de menus détails peu significatifs de leur personnalité respective les différencient : tandis que Virtus a des touffes bouclées qui bouffent sur les côtés, Roma (Di Filippo Balestrazzi, 1997, p. 1051 n³ 34 et fig.), plus sobre, a les cheveux disposés en boucles qui cernent le visage comme à Allonnes. À qui appartient la tête casquée : s'agit-il de Mars ou s'agit-il de Roma, de Virtus ou même éventuellement de Bellona? Le débat reste ouvert.

Une tête de femme âgée ${ }^{78}$ (inv. AL.05.54-79.70), en très haut relief, a été trouvée en 1957 dans la zone du péribole du portique ouest, à côté de deux têtes, l'une de jeune fille, l'autre d'enfant, sans que nous puissions savoir si ces trois têtes étaient à l'origine en rapport les unes avec les autres. Cette tête, presque de taille naturelle $(\mathrm{h} .: 25 \mathrm{~cm})$, offre une structure cubique (fig. $71, n^{\circ} 3$ ). Les lèvres plates et rectilignes, le pli nasogènien accusé, les trois plis d'affaissement sur les côtés du visage, le front barré de deux rides horizontales, les yeux enfoncés sous les arcades sourcilières, indiquent la sénescence. Une sorte de turban, de foulard replié, masque la chevelure de cette femme marquée par l'âge et la tension psychologique. Vue de près, la tête paraît d'une exécution grossière mais elle devait, à quelque distance, frapper le spectateur par son rendu puissant et expressionniste. Cette qualité expressive est caractéristique de l'art des sculpteurs qui ont travaillé à Allonnes. En Gaule romaine, ces représentations sont plutôt rares. Une tête de vieille femme trouvée à Grand dans les Vosges (Espérandieu, VI, p. 209 n 4909, musée d'Épinal) n'est certainement pas un portrait. La tête de Neumagen (Espérandieu, VI, p. 396 n5212, musée de Trèves) est assez comparable à celle d'Allonnes.

Privées des éléments qui permettent d'ordinaire d'interpréter une figure (sexe, vêtements, accessoires, attributs spécifiques, contexte narratif, position sur le monument), la plupart

76. J.-J. Hatt (1979, p. 183-184) y signale une chapelle circulaire avec une dédicace à Mars (CIL, XIII, 5344) et une base de statuctte de bronze avec une dédicace à Bellone (CIL, XIII, 5351).

77. Sichtermann, Koch, 1975 , p. 33-34 n²6 et pl. 57, 3 (sarcophage de Phèdre et Hippolyte).

78. Van Effenterre, 1959, p. 335 et fig. 9; Espérandieu, XV, p. 121 n"9171, pl. XCI. 


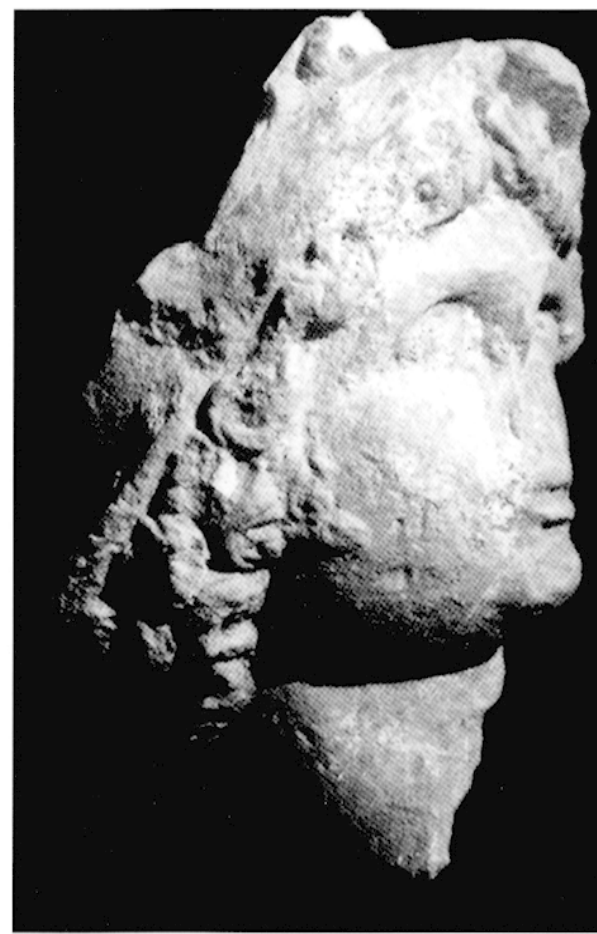

1

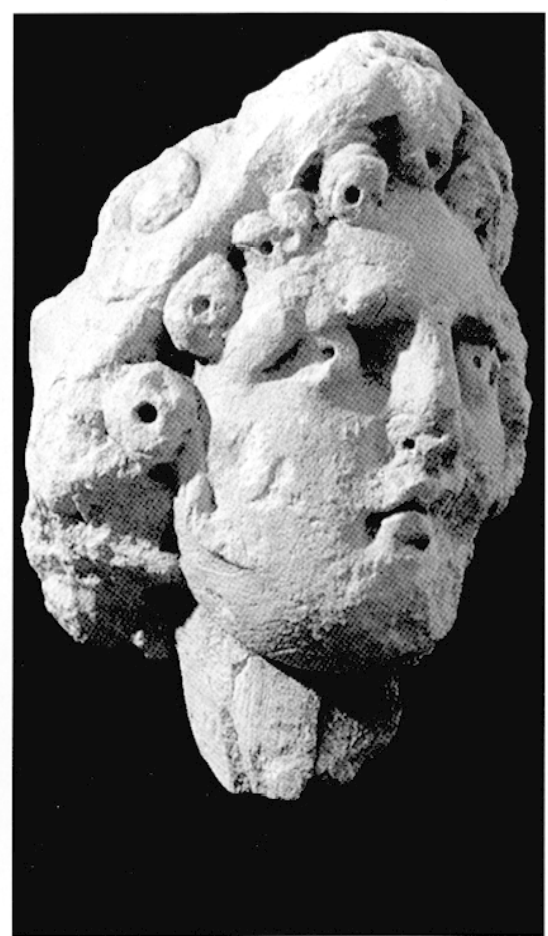

2

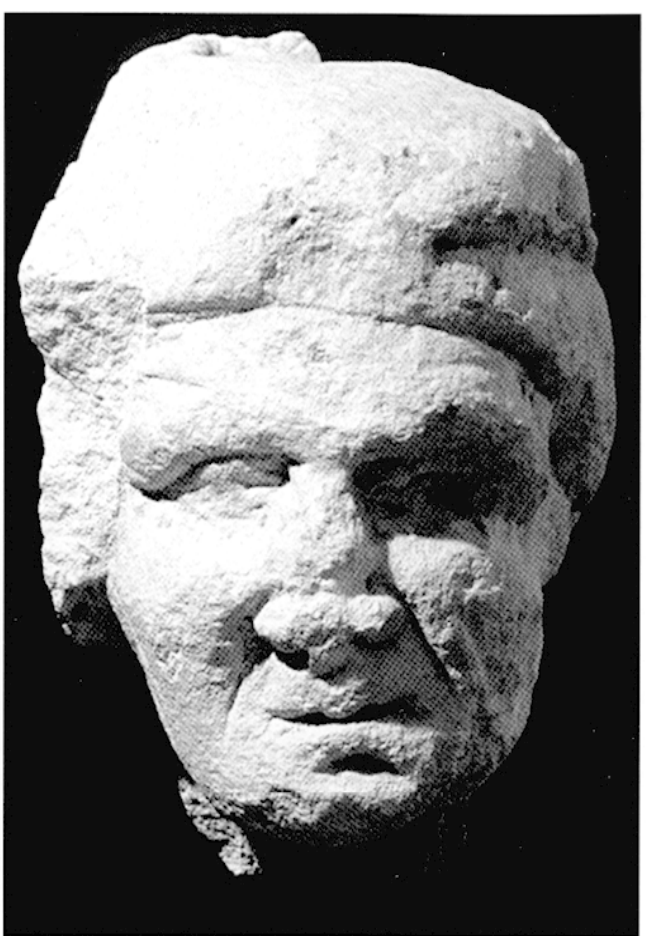

3

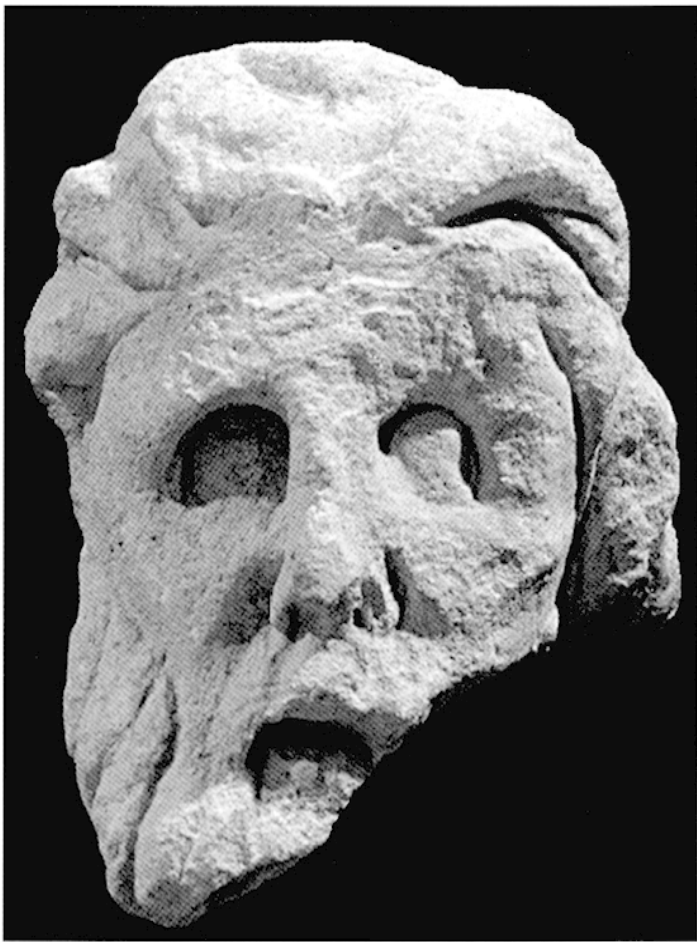

4

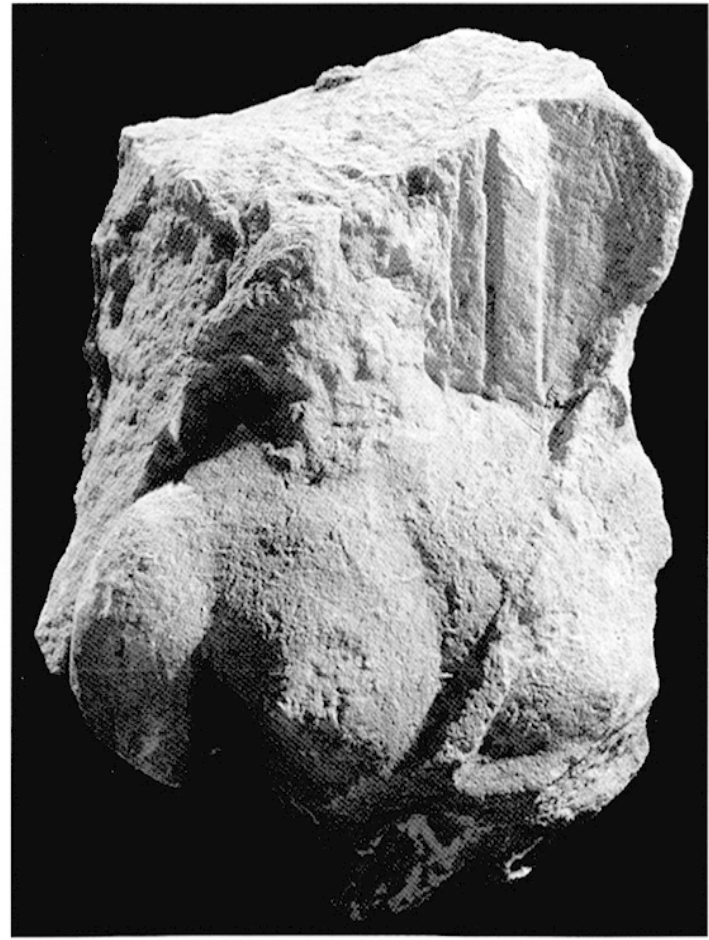

Fig. $71-1$, tête de Mars $n^{\prime \prime} 1 ; 2$, tête de Mars ou tête féminine $n^{0} 2$;

3, tête de vieille nourrice; 4, tête de vieillard barbu; 5, buste.

des têtes posent de réels problèmes d'identification. La tête de vieille femme fait donc exception. Le sexe, indiscutablement féminin, l'âge, la sorte de turban, l'expression tendue, tragique, rattachent notre figure à un type iconographique bien répertorié : celui de la vieille servante, et plus précisément celui de la vieille nourrice. Création de l'art grec, ce type est omniprésent à Rome dans les scènes mythologiques qu'inspire la geste de héros malheureux. La vieille nourrice est alors une figure touchante qui incarne la fidélité sans condition. Elle assiste le héros, le conseille, reçoit ses confidences, s'entremet pour lui, 
s'intéresse à l'action, s'alarme, se désole et pleure sur son sort. Elle souligne le pathétique du destin qui l'accable. Elle nous invite à compatir. Le personnage est très abondamment illustré sur les sarcophages d'époque impériale ${ }^{79}$, lesquels, tout en s'inspirant de légendes différentes, recourent toujours à un stéréotype identique afin de faciliter l'identification du personnage.

Le rapprochement de la vieille femme d'Allonnes avec ses homologues figurées dans l'art funéraire permet d'écarter l'interprétation proposée par L. Harmand (1962) qui voyait dans " cet admirable masque de vieille femme, indiciblement douloureux, celui d'une aveugle ", car disait-il « on cherche en vain le regard sous les orbites profondément creusées, derrière les paupières sans vie ". Cette interprétation de la vieille femme en ex-voto médical procédait, en premier lieu, de l'idée selon laquelle le sanctuaire de Mars Mullo aurait été celui d'un dieu guérisseur. Cette idée d'un Mars guérisseur, agissant par la puissance des eaux, plus spécialement invoqué dans les maladies des yeux, est empruntée à É. Thévenot (1955; Hatt, 1979 , p. 123). Une fois admise, cette idée était étayée par l'appréciation subjective de maladresses relevées dans le rendu anatomique des figures et par celle de traits stylistiques liés notamment au traitement des yeux : absence de l'iris, paupière supérieure renflée, paupière inférieure parfois absente, globe oculaire saillant, orbite creusée, arcade sourcilière très marquée. Ces caractéristiques, qui appartiennent seules ou réunies à de nombreuses figures, conduisaient L. Harmand à considérer plusieurs sculptures du sanctuaire comme des ex-voto de malades atteints d'affections diverses, oculaires et autres. Cette interprétation ne résiste pas à l'examen. D'une part Mars Mullo ne semble pas avoir été un dieu guérisseur. Les ex-voto sont très rares dans son sanctuaire d'Allonnes ${ }^{80}$ et les quelques exemplaires de statuettes de Vénus, de déesses-mères, d'enfants souriants, de Silène ou d'animal proviennent de la cour devant les bases B5 et B6 de l'entrée axiale orientale, ou des galeries nord, ouest ou sud, mais aussi de l'extérieur du sanctuaire, derrière le portique sud. Des boutiques ont pu exister à la péri-

79. Voir par exemple au musée du Louvre : sur la face principale d'une cuve de sarcophage romain des années 140 apr. J.-C. (Ma 283), Créüse en présence de Jason reçoit des enfants de Médée les cadeaux empoisonnés que celle-ci lui adresse. La nourrice semble mettre Créüse en garde contre la malignité de sa rivale (Baratte, Metzger dir., 1985, p. 9295 n" 34 : Médée à Corinthe) ; sur un fragment de petit côté de sarcophage attique (Ma 1663), attribué au premier quart du III' $^{\circ}$ s. apr. J-C., la nourrice de Phèdre lisait vraisemblablement derrière l'épaule d'Hippolyte le message d'amour de Phèdre contenu dans les tablettes aujourd'hui mutilées (Baratte, Metzger dir., 1985, p. 266-267 no 173 : sarcophage d'Hippolyte) ; le petit côté gauche d'une cuve de sarcophage attique (Ma 2120), vers 240 apr. J.-C., figure Achille au gynécée chez le roi Lycomède. La scène décrit le moment précis où se met en marche le Destin qui conduira le héros aux pieds des murs de Troie : tandis qu'un soldat sonne de la trompette dont les accents vont réveiller sa nature virile et belliqueuse, une vieille servante courbée par l'âge, coiffée du turban habituel, regarde intensément celui qu'elle a élevé avec Déidamie et ses sœurs (Baratte, Metzger dir., 1985, p. 252-256 $\left.\mathrm{n}^{\circ} 165\right)$.

80. Gruel, Brouquier-Reddé dir., 2003, p. 138-145 n" 194-208. En revanche, le sanctuaire voisin et contemporain des Perrières (Allonnes) a fourni des statuettes mais aussi des ex-roto en forme d'yeux. phérie du sanctuaire. Jusqu'à présent, aucun des lieux de culte de Mars Mullo n'a livré d'ex-voto et, dans l'état actuel de la documentation, le rôle de la divinité guérisseuse est tenu à Allonnes par Minerve au sanctuaire des Perrières ( $A E, 1983,697)$. La présence d'un gué important à proximité du complexe cultuel de La Forêterie n'implique pas le développement d'un culte des eaux salutaires sous la protection du dieu, même si nous pouvons admettre que Mars Mullo, comme tous les autres Mars indigènes, ait eu une certaine polyvalence protectrice (Hatt, 1979, p. 123). D'autre part, le prétendu réalisme des représentations de malades ne relève que de l'appréciation erronée des particularités du style des sculpteurs d'Allonnes, particularités dont nous trouverions des parallèles à Genainville (Val-d'Oise) par exemple, dans le traitement des yeux notamment (Mitard, 1993, p. 191 et 195-205). L'expression douloureuse, pathétique, de plusieurs têtes trahit un poncif scopasique. Elle n'exprime en aucune façon la tragédie personnelle de dédicants.

La présence parmi les vestiges d'Allonnes d'une figure de nourrice, dont la hauteur restituée à partir des dimensions de la tête se situerait autour de $150 \mathrm{~cm}$, permet de supposer qu'un élément du décor, de grande dimension (fronton, autel), illustrait un thème mythologique héroïque d'une certaine ampleur mettant en scène, comme sur les sarcophages, de nombreux personnages, car la nourrice joue les utilités mais n'est jamais l'un des protagonistes de l'action. Quel pouvait être l'épisode représenté ? Il serait aventureux de se prononcer. L'expression douloureuse de la nourrice conviendrait à un épisode particulièrement tragique ${ }^{81}$. Dans la mesure où Mars est la divinité honorée du sanctuaire où son culte devait être associé à celui des empereurs, nous sommes tentés de chercher du côté des légendes relatives au dieu lui-même ou à quelque autre divinité ayant avec lui des rapports directs. Nous pouvons songer à Minerve, honorée aux Perrières à Allonnes, ou à Vénus avec laquelle il forme couple, notamment en Gaule. Nous pouvons également penser à Diane et plus généralement à tout être mythologique exaltant la virtus d'un guerrier ou d'un chasseur légendaire comme par exemple Méléagre ${ }^{82}$. Pour les Anciens, la guerre et la chasse sont des activités équivalentes sur le plan symbolique et sont, par définition, celles où s'exerce la virtus et où s'éprouve la victoria. Les divinités qui y président - Mars, Roma, Mâ-Bellona, Nerio, Diana - ou les figures héroïques et légendaires qui s'y illustrent - Hercule, Bacchus, Persée, Bellérophon, Méléagre, Thésée, les Amazones, les Castores, Atalante (Boardman, Arrigoni, 1984) - possèdent une affinité naturelle avec ces notions de virtus et de victoria qui résident au cocur de l'idćologic impćrialc, ct particulic̀rcment dans ccllc dc la fin des Antonins et de l'époque des Sévères (Aymard, 1951). L'exemple des décors sculptés de Sens (Yonne), de Champlieu

81. Comme par exemple le massacre des Niobides. Pour veiller sur les enfants, Dionysos compris, les nourrices sont jeunes. L'âge de la nourrice d'Allonnes exclut, nous semble-t-il, une scène de naissance, ou une scène d'enfance, même inspirée par la légende d'un héros promis à un destin difficile.

82. L'épisode de la chasse de Calydon, tout spécialement apprécié à la fin du II" s. et dans la première moitié du III" s. apr. J.-C., pourrait assez bien convenir. Rappelons que Méléagre, fils du roi de Calydon, est aussi selon d'autres traditions fils d'Arès. 
à Orrouy (Oise) ou de Genainville pour ne mentionner qu'eux, prouve que les mythes grecs étaient connus et appréciés en Gaule romaine (Nerzic, 1989, p. 158-184 et fig.).

Une tête de vieillard barbu conforte l'hypothèse d'une ou plusieurs représentations légendaires héroïques et tragiques (inv. AL.05.54-79.80). Ce vieillard a des traits accusés et comme affaissés, des lèvres entrouvertes, des globes oculaires saillants, sans pupilles, sans paupières, profondément enfoncés sous l'arcade sourcilière (fig. $71, \mathrm{n}^{\circ} 4$ ). Il ne s'agit évidemment pas d'un aveugle comme L. Harmand le pensait. Ce vieillard douloureux peut être rapproché de deux types iconographiques. Le premier type est celui du roi tragique, le second celui de la divinité ou de la personnification topique (montagne, fleuve, lac) du lieu où l'action prend place. Dans le cas du vieillard d'Allonnes, il est impossible de choisir entre ces deux solutions. L'expression pathétique pourrait être celle d'un père frappé par le malheur mais le regard inspiré conviendrait aussi à un genius loci contemplant le Destin accompli.

D'autres fragments pourraient avoir appartenu eux aussi à des illustrations de thèmes héroïques compatibles avec une exaltation de la virtus. Un élément de relief (inv. AL.05. 54-79.635) conserve la jambe gauche comprise entre la cheville et le dessus du genou d'un personnage juvénile. Il était chaussé de bottines montant jusqu'à mi-mollet et vêtu d'une tunique courte dont l'extrémité inférieure ondule vers l'arrière sous l'effet de la marche. Quel que soit le sexe du personnage, sa tenue de chasseur ou de guerrier le rattache à la sphère des exploits virils, qu'ils soient ou non mythologiques. Un bloc en relief conserve un buste de face coupé sous la poitrine (inv. AL.05.54-79.52). La différence d'échelle entre cette pièce et la précédente exclut toute appartenance des deux pièces à la même composition. La tête et le cou sont arasés, les bras manquent à partir de l'attache de l'épaule. Les seins, discrètement renflés, appartiennent bien à un personnage féminin en dépit d'une carrure plutôt athlétique. Le vêtement ceinturé sous la poitrine dénude la partie droite du buste et dégage l'épaule et le bras de ce côté (fig. $71, \mathrm{n}^{\circ} 5$ ). Cette représentation de femme virile au buste à demi découvert se rattache au type iconographique de l'Amazone (Devambez, KauffmannSamaras, 1981) dont procèdent ceux de la Dea Roma, de Bellona (Blazquez, 1986, p. 92-93 nº et fig.), de Virtus et d'Atalante. Ce type est apparenté à certaines images d'Artémis, divinité en honneur chez les guerriers et les chasseurs. Une fois encore, malheureusement, l'absence d'attribut significatif interdit de préciser l'identité du personnage figuré.

Le décor architectural du sanctuaire puise lui aussi au répertoire qu'inspirent les notions complémentaires de virtus et de victoria. Deux éléments d'un entablement en tuffeau et en calcaire coquillier orné d'une frise d'armes conservent, l'un, l'extrémité d'une pelte (inv. Al.05.97.72), l'autre, l'amorce d'un bouclier rond et un casque à cimier (inv. Al.05.54-79.115, fig. 37, n"2) (Espćrandieu, XV, p. 122 n9177, pl. XCII) en forme de calotte hémisphérique équipée d'une visière, d'un couvre-nuque et de paragnathides. Un fragment de tambour de colonne ciselée (inv. AL.05.54-79.65) témoigne ćgalement de l'importance de la thématique triomphale dans le décor du sanctuaire : dans l'espace ménagé par le croisement de rubans réunis par une rosette quadrilobée, un bouclicr masque en partie un glaive (Gruel, Brouquier-Reddé dir., 2003, p. 131 $\left.n^{\circ} 177\right)$. Des jonchées d'armes et trophées dressés sont des motifs fréquents sur les monuments triomphaux de la Gaule romaine ${ }^{8.3}$. La frise d'armes et les ornements guerriers de la colonne ciselée confirment, s'il en était besoin, les attributions guerrières de Mars Mullo.

Le décor d'un fragment de tambour de colonne ciselée (inv. AL.05.54-79.22), trouvé au nord-ouest de la cella de l'édifice 3, compte parmi les plus intéressants du monument ${ }^{84}$ (fig. 72, $\mathrm{n}^{\prime}$ 1). La scène présente un caractère composite qui illustre les procédés mis en œuvre par les artistes provinciaux lorsqu'ils s'approprient les thèmes et les schémas gréco-romains. Une frise de feuilles de vigne stylisées sépare deux registres superposés inégalement conservés. Peu de chose subsiste du registre supérieur, mais au registre inférieur un personnage féminin dont le bas du corps est cassé au niveau du nombril s'appuie de sa main gauche sur une colonne. (?). La figure est nue, à l'exception d'une draperie qui couvre la tête et le dos. La main d'un personnage disparu soulève cette draperie et l'écarte de son visage. Sa coiffure formée de bandeaux ondulés évoque celle de Julia Domna. Elle est caractéristique de la fin du II ${ }^{\complement} \mathrm{s}$. et du début du III' s. apr. J.-C. Un Amour, sous l'aspect d'un putto aptère, brandit un fouet du bras droit. Sa chevelure ondulée est coquettement tressée sur le sommet du crâne ${ }^{8.5}$. Sa jambe gauche est masquée par le torse musculeux de Pan, sans tête, mais dont on distingue encore les cornes. Le bas de son corps, cassé à la taille, manque. Les bras du vaincu sont liés derrière le dos. À droite, une palme est dressée.

La scène illustre le combat d'Amour et de Pan avec la victoire du premier sur la force brutale incarnée par le second ${ }^{86}$. La palme triomphale symbolise cette victoire et récompense le vainqueur. Le thème n'est pas rare sur les peintures murales, les mosaïques ou les reliefs de sarcophages romains où il est associé à Vénus ou à un couple divin, le plus souvent celui de Bacchus et Ariane (Blanc, Gury, 1986, $n^{\circ 2} 240$ et 241). À Allonnes, il semble qu'un couple de spectateurs assistait également à la scène : Vénus, plutôt qu'Ariane, pourrait avoir été accompagnée par Mars. Le dieu devait écarter le voile de la déesse comme nous le voyons faire à Pompéi dans des scènes dites d'intimité ${ }^{87}$. Contrairement à la torche, à l'arc et

83. Sur les arcs de Glanum, de Carpentras, d'Orange, de Saintes, le Trophéc des Alpes à La Turbie, la Porte Noire de Besançon et la Porte de Mars à Reims pour ne signaler que les plus célèbres. Voir aussi les fragments de Rouen (Espérandieu, IV, n" 3079), Paris (ibid., IV, n" 3183), Langres (ibid., IV, n*3 3319-3321, 3324), Dijon (ibid., IV, n" 3524 et 3528), Arlon (ibid., V, n" 4058 et 4061), Bordeaux (ibid., IX, n"6938), Périgueux (ibid., IX, n"6956), Saint-Ambroix-sur-Arnon (ibid., IX, n"6995), Arles (ibid., IX, n6715), Nîmes (ibid., IX, n6 6812).

84. Van Effenterre, 1959, p. 333-335 et fig. 8; Espérandieu, XV, p. 122 n"9178, pl. XCIII.

85. Pottier, Albert, Saglio, DA, I, s. v. " Coma ", p. 1358 et fig. 1810; Blanc, Gury, 1986, p. 1044.

86. Voir le groupe de Délos où Pan est châtié directement par Aphrodite qui le menace de sa sandale (Bulard, 1906).

87. Simom, $1984, n^{\circ} 376 \mathrm{et}$ fig. (il cite de nombreuses variantes). Dans les scènes d'intimité entre Mars et Vénus. les Amours jouent arec les armes du dieu. 


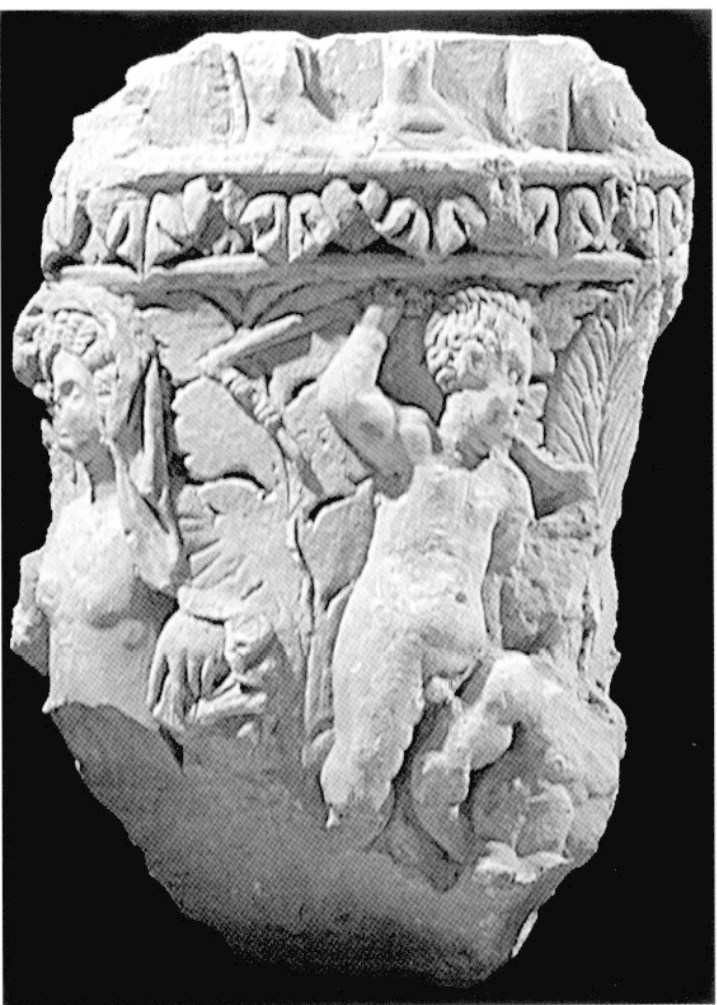

1

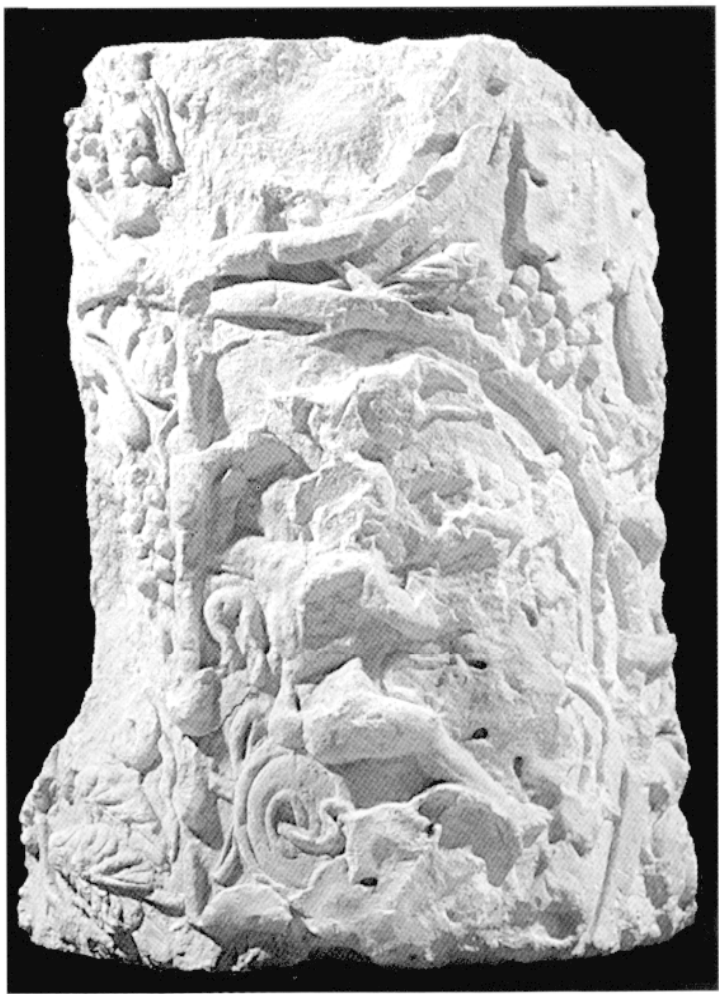

3

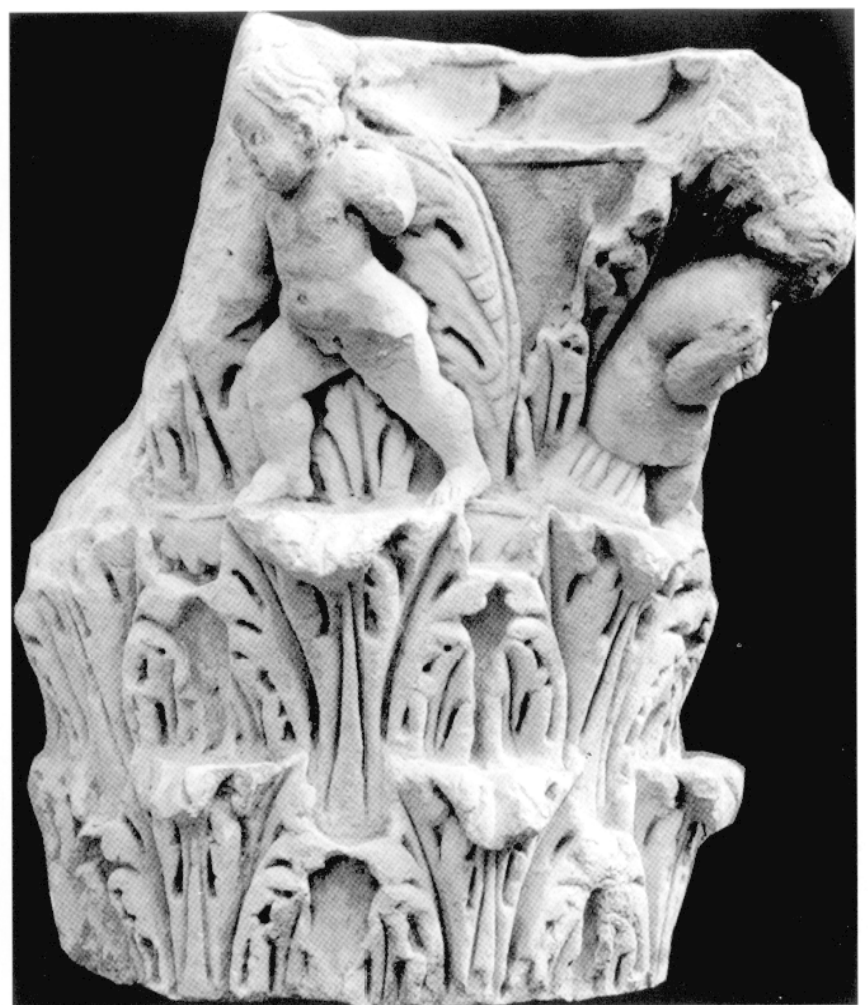

2

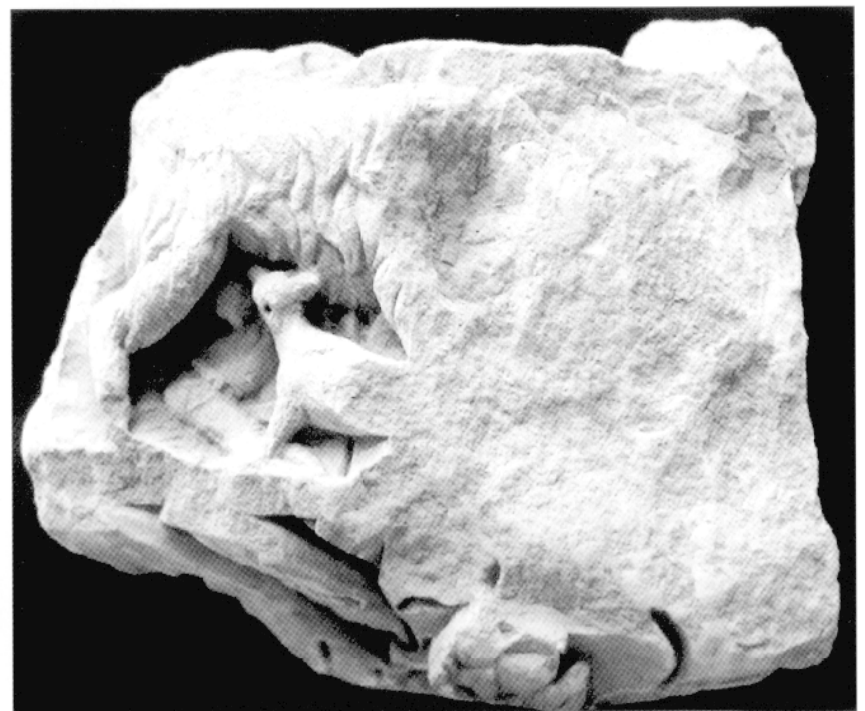

Fig. 72 - 1, tambour de colonne ciselée, combat d'Amour et de Pan;

2, chapiteau corinthien aux amours; 3, tambour au satyre vendangeur ; 4, tambour à la brebis allaitant. 
aux flèches, le fouet n'est pas considéré comme l'un des attributs ordinaires d'Amour. Cet instrument ${ }^{88}$ est cependant suffisamment fréquent entre ses mains, notamment lorsqu'il conduit un attelage ou chevauche un animal, pour accéder au statut d'accessoire privilégié du dieu. Cet instrument de torture et de domination symbolise la nature du pouvoir qu'exerce le fils de la Vénus Victrix. La position de Pan, les mains liées derrière le dos, évoque d'ailleurs celle d'un captif au pied d'un trophée. La flagellation de Pan n'est ici ni religieuse, ni initiatique, ni fécondante (Turcan, 1982). Elle n'appartient à aucun rituel dionysiaque ou métroaque ${ }^{89}$. Elle illustre simplement la nature victorieuse d'Amour, et la cruauté que celui-ci exprime dans les tourments qu'il inflige à ses victimes. La cruauté d'Amor, conjuguée à son aptitude au détournement de leur fonction des objets dont il s'empare ${ }^{90}$, appartient à sa nature démoniaque. Elle caractérise sa puissance agissante. C'est dans cette perspective triomphale qu'il faut comprendre la participation d'Amor au décor du sanctuaire : outre les nombreuses têtes d'enfant, dont la plupart appartenaient sans aucun doute à des Amores (forme démultipliée d'Amor), un chapiteau historié d'ordre corinthien conserve deux des quatre putti ${ }^{91}$ (inv. AL.05.54-79.113). Un grand fragment d'aile droite éployée (inv. AL.05.54-79.61) appartenait à un Amour ou à une Victoire (fig. 72, n⿳2) .

La thématique victorieuse d'Amor se situe au point de convergence de deux univers, celui de Mars et celui de Bacchus, qui sont l'un comme l'autre des dieux triomphants. À l'instar de très nombreux édifices publics gallo-romains, ce sanctuaire de Mars Mullo devait à l'inspiration dionysiaque une part non négligeable de son décor. La zone au nord de la cella a livré un autre morceau de tambour de colonne ciselée (inv. AL.05.54-79.21; Espérandieu, XV, p. 122 n 9179, pl. XCIII ; Harmand, 1962, pl. CLV fig. 1) figurant un Satyre vendangeur dans une treille peuplée de petits animaux (oiseaux, écureuil, lièvre, serpent) hôtes de la vigne et prédateurs du raisin (fig. 72, n³). Un autre fragment (inv. AL.05.54-79.60) montre une feuille de vigne et une grappe de raisins. Sur un autre fragment (inv. AL.05. 54-79.23), un Satyre danse avec animation en faisant virevolter la peau de bête nouée autour de son ventre (Gruel, BrouquierReddé dir., 2003, p. 132 n $^{\circ} 179$ ) et, à une tout autre échelle, puisqu'il s'agit d'un petit fragment, une femme étendue de dos

88. Fougères, $D A, \mathrm{II} / 2$, s. v. « Flagellum ", p. 1152-1156. Le fouet sert à frapper les animaux et certaines classes d'individus comme les esclaves et les enfants. Celui que tient Amor est plutôt un fouet de cocher (op. cil., p. 1153, fig. 3082-3081).

89. Voir parallèlement les critiques formulées par Tassignon (1996, p. 120 et p. $286 \mathrm{n}^{\circ} 295$, fig. 38 ), à l'encontre de l'interprétation donnéc à la scène figurée sur l'anse d'onochoé campanienne de Royers par Mariën (1972) et par Faider-Feytmans (1979, p. 163 n³22).

90. Dans un contexte agonistique comme celui de la lutte d'Amor et de Pan, le fouet évoque celui des assistants des agonothèques qui réprimaient les infractions aux règlements des jeux, empêchaient les lutteurs de s'engager trop à fond et peut-être aussi tenaient le public à distance.

91. Cordonnier-Détrie, 1957, p. 207-208, fig. 8 ; Espérandieu, XV, p. 122 $n^{\circ} 9181$, pl. XCIII ; Harmand, 1962, p. 775, pl. CI.X fig. 10 ; Mercklin, 1962 , p. $179 n^{\circ} 432$, fig. 840 . sur une draperie 92 : une Nymphe ou une Ménade (inv. AL.05.54-79.633). La brebis allaitant un agneau sur ce qui reste d'un chapiteau historié (inv. AL.05.54-79.63) participe à l'atmosphère pastorale qui entoure le dieu et son cortège (fig. 72, $\mathrm{n}^{\circ} 4$ ). Cette scène peut être considérée comme une évocation de la fécondité. La valeur symbolique d'un canthare à godrons bachique (inv. AL.05.54-79.000), d'un modèle assez proche de ceux de Mayence ${ }^{93}$, rejoint celle de la corne d'abondance dont l'extrémité supérieure est conservée (inv. AL.05.54-79.53).

Avec les réserves qu'imposent aussi bien l'état de conservation de vestiges très lacunaires que la nature aléatoire de l'échantillonnage parvenu jusqu'à nous, lequel peut n'être pas statistiquement représentatif de l'ensemble du décor, l'étude du matériel iconographique permet quelques remarques préliminaires. Nous sommes tout d'abord frappés par la qualité expressive et pittoresque de l'ensemble. Plusieurs mains ont travaillé à Allonnes, certaines, il est vrai, plus habiles que d'autres. Les différences relevées dans le traitement des figures peuvent correspondre à des campagnes successives d'embellissement du sanctuaire, aux étapes de son histoire ou aux différentes structures du sanctuaire (temple et quadriportique). Bien que certaines pièces puissent être plus anciennes, la plupart des fragments appartiennent selon toute vraisemblance plutôt à la seconde moitié du $\mathrm{II}^{\mathrm{c}} \mathrm{s}$. ou au début du siècle suivant. Peut-être serait-il possible de repérer plusieurs ateliers. Si quelques pièces sont à situer dans le prolongement de la tradition pergaménienne dont elles retiennent les leçons d'un romantisme tourmenté, d'autres paraissent affranchies de ses canons. Elles sont à la fois plus provinciales par le style de l'exécution et par la réinterprétation des schémas iconographiques qui se voient recombinés avec originalité et vivacité comme sur le tambour de colonne de l'Amour vainqueur. À l'évidence, le sanctuaire de Mars Mullo bénéficiait d'une parure soignée. La variété des modules des figures conservées atteste l'existence de compositions comportant des personnages presque grandeur nature, mais aussi toute une gamme de scènes de dimensions diverses et jusqu'à des ensembles dont les figures avaient au plus $25-30 \mathrm{~cm}$.

\section{LES DÉDICACES}

Plusieurs témoignages épigraphiques sur plaques en marbre appartiennent à la phase de fréquentation du sanctuaire à quadriportique (horizon 6). Leur étude apporte quelques précisions sur leur datation et sur le cursus d'un gouverneur de Lyonnaise, malheureusement anonyme ${ }^{94}$.

92. Ou sur un fond végétal sclon Espérandieu, XV, p. 121 n*9174, pl. XCiI.

93. Selzer et al., 1988, p. $210 \mathrm{n}^{\circ} 187$ et fig. (première moitié du III" s. apr. J.-C.), p. $211 \mathrm{n}^{\prime \prime} 190$ et fig. (II'-III" s. apr. J.-C.), p. $212 \mathrm{n}^{\circ} 192 \mathrm{et}$ fig. ( ${ }^{\mathrm{rt}}$ s. apr. J.-C.) .

94. Sauf mention contraire, toutes les inscriptions proviennent du sanctuaire de Mars Mullo et sont conservées à la mairie d'Allonnes (salle d'exposition). Le cursus sénatorial fait l'objet d'unc étude de F. Bérard à laquelle on se reportera pour le détail des hypothèses et de la bibliographie (Bérard, à paraître). 


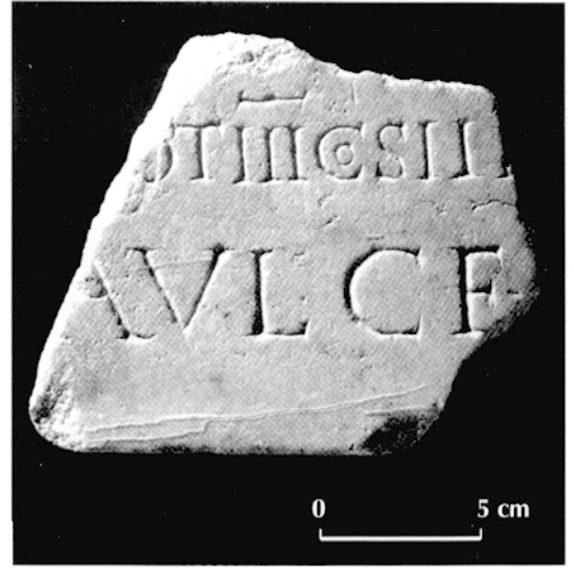

Fig. 73 - Dédicace impériale offerte par la cité des Cénomans.

\section{LES DÉDICACES IMPÉRIALES}

Inscription $\mathrm{n}^{0} 4=I L T G, 346^{95}$ (inv. AL.05.54-79.105). Découverte en 1961, secteur $9 \mathrm{~F} 2$, au nord de l'édifice 3. Fragment de plaque en marbre blanc, brisée en haut, à droite et à gauche, mais dont est conservé le bord inférieur (fig. 73). L'angle inférieur gauche est également en partie visible, ce qui assure que les deux dernières lignes de l'inscription, qui seules ont été conservées, sont complètes ou à peu près complètes à gauche. Des traces sont visibles au centre du fragment, audessus du chiffre III, mais cette $3^{*}$ ligne est trop endommagée pour être lisible. Dimensions : haut. : 12 ; larg. : 13 ; ép. : 2,8 ; haut.d.l. 1. $2: 1,5$ et $1.3: 2,3$. Très belles lettres, larges et très soigneusement gravées, avec empattements. Petit $\mathrm{O}$ inscrit dans le Cà la l. 2 ; barre d'abréviation sur le chiffre III, mais apparemment pas sur II. Pas de ponctuation visible.

$$
\begin{aligned}
& {[--]+[--]} \\
& {[p] \text { ot(estate) III, co(n)s(uli) II, I[-- ] }} \\
& \text { Aul(erci) Ce[nomani ? - - ]. }
\end{aligned}
$$

L. 1: traces d'une ou deux lettres, non notées par Wuilleumier; base d'une haste verticale suivie, peut-être, d'un V (IV ?).

L. 2 : trace de lettre dans la cassure, après le chiffre II. L'espace un peu plus grand $(1,3$ contre $1,2 \mathrm{~cm})$ invite à lire non pas le chiffre III, mais plutôt la première lettre du mot suivant, avec une haste verticale dont on voit l'empattement inférieur ; peut-être i mp(eratori) - - - J (Wuilleumier), mais d'autres solutions sont possibles (voir infra).

" [À l'empereur...], dans sa troisième puissance tribunicienne, deux fois consul, ..., les Aulerques Cénomans... "

Il s'agit d'une dédicace impériale offerte par la cité des Cénomans, dont le nom doit peut-être également être restitué dans un autre fragment (ILTG, 348bis d, voir infra $\mathrm{n}^{\circ} 11$, p. 372-373), ainsi sans doute que dans deux des nouvelles plaques ( ${ }^{\circ} 6$ et 12, infra, p. 363-370 et 373 ) où elle apparaîtrait également en position de dédicant.

95. Voir de Boüard, 1962, p. 427 et fig. 9 ; Aubin dir., $1980, n^{\circ} 3$.
La titulature est datée de l'époque julio-claudienne par P. Wuilleumier, qui préfère la troisième puissance tribunicienne de Néron (entre le $1^{\text {er }}$ janvier et le 12 octobre 57 ) à celle de Tibère, qui, exercée du vivant d'Auguste (26 juin 4 au 25 juin 3 av. J.-C.), paraît nettement trop ancienne. On aurait pu songer aussi à Caligula, entre le 18 mars et le 31 décembre 39. Mais il faut surtout s'interroger sur les raisons d'une datation aussi ancienne, qui est donnée sans aucune justification dans la notice des ILTG. La principale est vraisemblablement la découverte à peu près contemporaine des deux bases à Mars Mullo (ILTG, 343 et 345 , voir supra inscriptions $n^{\text {os }} 1-2$, p. 354-355), que $P$. Wuilleumier datait également de l'époque julio-claudienne et même, pour la première, du règne d'Auguste. La paléographie n'offre pas de critère décisif, mais la forme des $\mathrm{E}$ (avec une barre centrale courte), des $\mathrm{S}$ et des $\mathrm{T}$ et le soin apporté aux empattements ne plaident pas en faveur d'une date haute. Un martelage aurait pu constituer un indice en faveur de Néron (ou de Caligula), mais les très faibles restes qui subsistent de la 1.1 ne suffisent pas à justifier une telle hypothèse. Un argument plus sérieux pourrait venir de la place des salutations impériales, que $P$. Wuilleumier plaçait après les consulats en restituant $i$ mp(eratori)---] à la fin de la l. 2. Cette place est en effet asse $z$ courante au $\mathrm{I}^{\mathrm{er}} \mathrm{s} .{ }^{96}$, et en revanche très rare à partir de l'époque flavienne, quand s'est fixé l'ordre canonique : puissances tribuniciennes - salutations impériales - consulats. L'argument est incontestablement plus solide que le précédent, mais n'est pas non plus décisif dans la mesure où la restitution i[mp(eratori)---], qui ne repose que sur une haste verticale, est hypothétique.

Il est donc nécessaire de s'interroger d'abord sur les restitutions possibles à la fin de la l. 2, avant d'envisager une datation éventuelle de la titulature. Il faut d'abord observer que la restitution obligée de Ce/noman( $i$ ?)] à la l. 3 oblige à supposer une lacune d'au moins 5 lettres, soit une longueur à peu près équivalente à celle du fragment conservé et donc une douzaine de lettres à la 1.2 , voire un peu plus si la 1.3 était centrée. On pourrait éventuellement y placer le mot ciuitas, mais ce n'est pas la solution la plus probable, l'indication du dédicant étant probablement contenue tout entière dans la dernière ligne. Après le chiffre II qui suit l'indication du consulat, on ne voit plus qu'une haste verticale qui disparaît en haut dans la cassure, mais dont l'empattement inférieur est bien visible. Il est peu probable qu'il s'agisse encore du chiffre des consulats, car l'espace qui la précède est un peu plus grand que celui qui sépare les deux hastes précédentes $(1,3$ contre $1,2 \mathrm{~cm})$ et invite donc à lire non pas le chiffre III (ou IIII), mais plutôt la première lettre du mot suivant; on remarquera que le chiffre des consulats n'est pas surmonté d'une barre d'abréviation, contrairement à celui des puissances tribuniciennes. Avec une haste verticale, dont manque la partie supérieure, on peut certes restituer i[mp(eratori)---], qui figure souvent après le consulat à l'époque julio-claudienne, mais aussi bien $p$ (atri) $[p(a t r i a e)]$, qui se fixe après le consulat à partir du règne de

96. Voir par exemple CIL, VI, 915, 916, $920=40416$, sous Claude ; CIL, III, 6741 = ILS, 232 sous Néron, dont la plupart des inscriptions placent cependant les salutations impériales entre les puissances tribuniciennes et le consulat. 
Tabl. IV - Association de la $3^{4}$ puissance tribunicienne et du 2 consulat (en gras les cas où l'empereur a été consul III pendant sa $3^{\circ}$ puissance tribunicienne).

\begin{tabular}{|l|l|c|c|}
\hline \multicolumn{1}{|c|}{ Empereur } & \multicolumn{1}{|c|}{$\begin{array}{c}3^{\mathrm{e}} \text { puissance } \\
\text { tribunicienne }\end{array}$} & $\begin{array}{c}\mathbf{2}^{\mathrm{e}} \\
\text { consulat }\end{array}$ & $\begin{array}{c}\mathbf{3}^{\mathrm{e}} \\
\text { consulat }\end{array}$ \\
\hline Tibère & $26.06 .-4 / 25.06 .-3$ av. J.-C. & -7 & 18 \\
\hline Caligula & $18.03 .39 / 17.03 .40$ & 39 & $\mathbf{4 0}$ \\
\hline Claude & $25.01 .43 / 24.01 .44$ & - & $\mathbf{4 3}$ \\
\hline Néron & oct.-déc. 56/ oct.-déc. 57 & 57 & 58 \\
\hline Vespasien & $01.07 .71 / 30.06 .72$ & - & 71 \\
\hline Titus & $01.07 .73 / 30.06 .74$ & 72 & $\mathbf{7 4}$ \\
\hline Nerva & $10.12 .97 / 27.01 .98$ & - & 97 \\
\hline Trajan & $10.12 .98 / 09.12 .99$ & 98 & 100 \\
\hline Hadrien & $10.12 .118 / 09.12 .119$ & 118 & $\mathbf{1 1 9}$ \\
\hline Antonin & $10.12 .139 / 09.12 .140$ & 139 & $\mathbf{1 4 0}$ \\
\hline Marc Aurèle & $10.12 .148 / 09.12 .149$ & 145 & 161 \\
\hline Lucius Verus & $10.12 .162 / 09.12 .163$ & 161 & 167 \\
\hline Septime Sévère & $10.12 .194 / 09.12 .195$ & 194 & 202 \\
\hline Géta & $10.12 .210 / 09.12 .211$ & 208 & - \\
\hline Élagabal & $10.12 .219 / 09.12 .220$ & 219 & $\mathbf{2 2 0}$ \\
\hline
\end{tabular}

Domitien. Cependant, l'abréviation est trop courte pour combler la lacune, et il faut donc préférer un titre comme p[roco(n)s(uli)], qui apparaît à partir de Trajan, ou peut-être plutôt dlesignato III], qui est plus fréquent et comblerait parfaitement la lacune. Une dernière possibilité serait un titre comme propagator imperii, qui nous reporterait dans la seconde moitié du III" s. et paraît donc moins probable.

L'association de la $3^{r}$ puissance tribunicienne et du 2 c consulat est assez fréquente en début de règne, comme le montre le tableau (tabl. IV). On y a fait figurer aussi le $3^{c}$ consulat, moins à cause de l'éventualité d'une lecture COS III, qui paraît peu probable, que parce qu'il permet de repérer les empereurs qui ont été consuls désignés pendant l'année de leur $2^{\circ}$ consulat.

On trouve tout au long du II" s. et encore sous les Sévères des empereurs qui ont été consul II pendant leur $3^{c}$ puissance tribunicienne, soit que le consulat tombe dans la $3^{c}$ puissance tribunicienne, soit qu'il soit antérieur. On en trouverait encore dans la seconde moitié du III" s. avec Dèce, Valérien, Gallien, Probus, Carin et Dioclétien. L'absence des salutations impériales, qui ne poserait guère de problème dans la seconde moitié du III" s., est plus difficile à expliquer dans les titulatures du II"s. et de l'époque sévérienne, qui sont beaucoup plus régulières. Mais elle peut s'expliquer en début de règne, où l'indication est fréquemment omise tant que l'empereur n'a pas pris de $2^{c}$ salutation après celle qui eut lieu au moment même de l'avènement : c'est ce que montrent en particulier les diplômes militaires, notamment pour Trajan, avant la $2^{c}$ salutation prise en 102 dans la première guerre dacique (CIL, XVI, 42, 44, 45; $R M D, 142)$, pour Hadrien, dont la $2^{\circ}$ salutation ne tombe qu'en 135 (CII, XVI, 67, 69, 70, 72, 74, 78, 79), pour Antonin, avant 142 (CIL, XVI, 87 et $177 ; R M I$ ), 38 et 39) et encore pour Marc
Aurèle et Lucius Verus avant la guerre parthique (CIL, XVI, 118 en 162). On pourrait avoir donc affaire ici à un empereur du $\mathrm{II}^{\circ} \mathrm{s}$. avant sa $2^{\circ}$ salutation impériale aussi bien qu'à un prince julio-claudien, qui placerait cette indication après les consulats. Si Hadrien et Antonin offrent peu de possibilités, la coinncidence entre $2^{r}$ consulat et $3^{r}$ puissance tribunicienne se limitant aux derniers jours de décembre (118 ou 139), il y en a plus pour ceux pour lesquels elle couvre presque toute l'année (avant le 10 décembre), comme Trajan en 99, Marc Aurèle en 149, Lucius Verus en 162, ou encore Septime Sévère en 194. Dans ces quatre exemples, seul Trajan a exercé un $3^{\mathrm{e}}$ consulat l'année suivante, en l'occurrence le fameux consulat de 100 . Ce pourrait être un argument en sa faveur, si on voulait restituer designatus à la fin de la 1. 2. Mais il est naturellement aussi fragile que la restitution elle-même, et il ne faudrait pas négliger à ce compte Hadrien et Antonin, eux aussi désignés pour un $3^{\mathrm{c}}$ consulat en décembre 118 et en décembre 139, comme aussi Élagabal en décembre 219 , voire certains empereurs de la seconde moitié du I ${ }^{\mathrm{er}}$ s., comme Néron, consul II en 57 et III en 58 ou Titus, consul II en 73 et III en 74 .

Il est, on le voit, difficile d'avancer une restitution précise pour un texte aussi fragmentaire. Mais on espère au moins avoir montré que la datation doit englober tout le II $^{\text {c }}$ s. et même le début du III's. C'est aussi ce que confirme un fragment d'une plaque dédiée à Septime Sévère (voir infra, inscription $n^{\circ} 5$ ), qui, notamment du point de vue paléographique, fournit un parallèle nettement plus satisfaisant pour ce texte que les bases de Mars Mullo.

Inscription $\mathbf{n}^{0} 5$ (inv. AL.05.94.1554). En surface dans l'abside du portique ouest. Fragment de plaque en marbre blanc, brisée de tous côtés (fig. 74). Dimensions: haut. : 8 ; larg. : 7 ; ép. : 1,2 ; haut.d.l. : 1,5 ; interligne : 1,3. Lettres asse\%. irrégulières, dans leur taille (de 1,7 à 1,4 à la l. 1) comme dans leur dessin (par exemple le A, 1. 1), mais profondément gravées, avec des empattements.
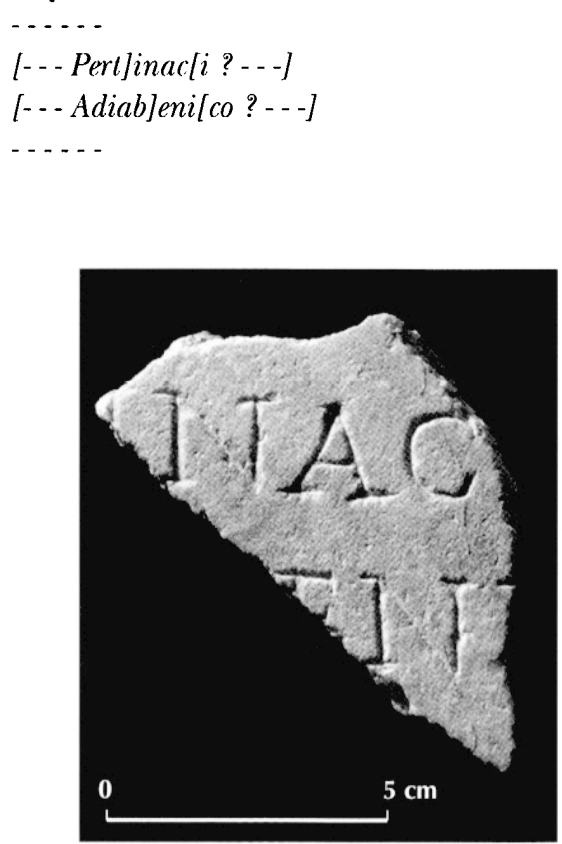

Fig. 74 - Dédicace impériale à Septime Sévère. 
L. 2 : au début du fragment peut-être un E, dont on voit encore les deux barres supérieures, la seconde plus courte que la première; trace d'une haste verticale, dans la cassure, et de son empattement supérieur.

Les quelques lettres restantes suggèrent une titulature de Septime Sévère, qui portait le nom de Pertinax depuis son accession au pouvoir en 193 et les surnoms d'Arabicus et d'Adiabenicus depuis ses victoires de 195 : peut-être [Pert]inacli Aug(usto) Arabico/Adiab]eni[co---] (voir par exemple CIL, XIV, 112, à Ostie, en 196), mais l'ampleur des lacunes empêche toute restitution précise. Il semble donc s'agir plutôt d'une dédicace impériale, bien qu'on ne puisse exclure une dédicace religieuse (pro salute Imperatoris- - -) ni une inscription honorifique où le nom de l'empereur apparaîtrait dans un cursus, à propos d'une fonction ou encore de décorations militaires.

\section{LES DÉDICACES AUX SÉNATEURS OU CHEVALIERS ROMAINS}

Inscription $\mathbf{n}^{\circ} 6$. Dix petits fragments appartenant à une même plaque en marbre inscrite (fig. 75 et 76 ), découverts l'un en 1957, et les autres entre 1994 et 1998, au voisinage du temple (Bérard, à paraître).

Fragments $\boldsymbol{A}-\boldsymbol{B}$ (inv. AL.05.97.451). Le $1^{\mathrm{cr}}$ avril 1997, dans la cour au sud du podium du temple (sondage 39). Deux fragments de plaque en marbre blanc jointifs conservant, le premier le bord gauche d'une inscription avec les restes de six lignes, le second le bord inférieur, avec cinq lignes dont la dernière en lettres plus grandes. Dimensions : haut. : 24 ; larg. : 21,5 ; ép. : 3,7 ; haut.d.l. : 1 . $1: 3 ; 1$. $2-4: 1,5$ à 1,$6 ; 1.5-7: 1,45$ à 1,5 ; interligne: 1 à 1,2 ; entre la 1 . 1 et le bord inférieur : 3,5 .

Fragment $C$ (inv. AL.05.97.3310). Le 7 juillet 1997, dans la couche de destruction (sondage 39 ). Fragment de plaque en marbre blanc avec l'angle inférieur gauche de la plaque et les restes de deux lignes, dont la dernière en lettres plus grandes ; jointif avec $\mathrm{A}$ et $\mathrm{B}$, dont il comble la lacune. Dimensions : haut. : 11 ; larg. : 10 ; ép. : 3,7 à 4 ; haut.d.l. : $1.1: 3 ; 1.2: 1,5$ à 1,6 ; interligne : 1,2 ; entre la 1.1 et le bord inférieur : 3,2 .

Fragment $D$ (inv. AL.05.97.455). Le 16 mai 1997, dans la cour au sud du pronaos du temple, dans la couche de destruction (sondage 34, us 484). Fragment de plaque en marbre blanc veiné de rose, avec les restes de cinq lignes; jointif avec $A$ et $B$. Dimensions : haut. : 14,5 ; larg. : 11,5 ; ép. : 3,7 ; haut.d.1. : 1,4 à 1,5 ; interligne : 0,9 à 1,2 .

Texte de A, B, C et D :

$$
\begin{aligned}
& \text { - . . . - } \\
& \text { - - - ]+++ICA[- - } \\
& \text { - - Janis Daclisque? - - } \\
& \text { - - - ] +s ob sec [- - . } \\
& \text {---1+MESENETT--donis } \\
& \text { mi]litaribus c coronis- - - item- } \\
& \text { que uexillis }+ \text { [- - - } \\
& \text { ri Augusti, trl- - tri- } \\
& \text { buno leg(ionis) sext [ae- - - leg(ionis) } \\
& \text { XXII Primigen liale- - - } \\
& \text { ciuit [as Aulercorum Cenomanorum? }
\end{aligned}
$$

L. e : à droite, après le $S$, en bas, extrémité gauche d'un empattement triangulaire, qui peut convenir à de nombreuses lettres, en particulier T, A ou I.
L. g : à gauche, avant le M, extrémité inférieure d'une lettre, qui ne semble pas pouvoir appartenir à une haste verticale, mais plutôt à l'empattement d'une lettre comme E, L ou, moins probablement, $\mathrm{C}$.

L. h : à gauche, avant $S$, on distingue en haut une petite barre horizontale qui pourrait être le sommet d'un I.

L. $\mathrm{j}$ : de droite à gauche $\mathrm{A}$ et $\mathrm{C}$ certains, I probable, étant donné la proximité de C. Avant, il ne reste que l'extrémité inférieure de trois ou quatre lettres difficiles à identifier : sous le I, plus court, trace courbe que l'on pourrait attribuer à un $R$ (cf. les séquences RI lignes b, d, f), mais qui doit être plutôt une veine de la pierre, car il n'y a pas assez de place pour la boucle avant la haste verticale qui précède : plutôt une lettre comme $F$, $\mathrm{P}$ ou T, L paraissant exclu par l'absence de barre horizontale au bas de la lettre. Au-dessus du I de la ligne i, courbe terminée par un empattement qui pourrait être la partie inférieure d'un $S$ ou d'un B, ou aussi l'extrémité droite d'un A qui serait liée à la lettre suivante (cf. AR ligne f) ; à droite espace un peu large, mais qui ne permet de mettre qu'une lettre étroite avant celle qui précède le I. À gauche, au-dessus du N, trace d'un empattement, qui pourrait être aussi l'extrémité gauche d'un éventuel A.

Fragment $E=I L T G, 347^{97}$ (inv. AL.05.54-79.109). Lc $\mathrm{l}^{\text {er }}$ janvier 1957, secteur $16 \mathrm{G} 4$. Conservé dans une collection privée. Fragment de plaque en marbre blanc, veiné de rouge et de noir, avec des cristaux. Brisé de tous côtés, il a conservé huit lignes, dont la longueur varie d'une à sept lettres. Dimensions : haut. : 20 ; larg. : 12 ; ép. : 3,6 ; haut.d.1. : 1.1 : 1,7 ; 1. 2-7 : 1,45 ; interligne : 0,7 à 1 .

Fragment $\boldsymbol{F}$ (inv. AL.05.98.6820). Le 10 septembre 1998, dans la couche de destruction (sondage 39). Fragment de plaque en marbre blanc, jauni en surface par un long séjour dans la terre. Brisé de tous côtés, mais jointif avec le fragment $\mathrm{E}$ à gauche. Trois lignes (de six lettres maximum) conservées, ainsi que le sommet d'une quatrième. Dimensions : haut. : 10 ; larg. : 12 ; ép. : 3,6 ; haut.d.1. : $1.1: 1,7 ; 1.2: 1,5 ; 1.3: 1,4$; interligne : 0,7 à 1 . Lettres larges et dans l'ensemble régulières, avec des empattements longs et fins, un peu plus hautes 1.2 et un peu moins 1. 4. Pas de ponctuation 1. 1 ; barre d'abréviation sur XV, 1. 2.

Texte global de $\mathrm{E}$ et $\mathrm{F}$ :

$$
\begin{aligned}
& \text {-....- } \\
& \text { - - Jleg(ato) Aug[usti? - - } \\
& \text { - - -]sis, XVuiro [sacris faciundis -.. } \\
& \text { leg(ato) Augusti ? proJ praetore S[-- - leg(ato) Augusti? } \\
& \text { leg(ionis) XIIII G]eminae Mar[tiae Victricis -..- } \\
& \text { praeposito ? uexi]llation [ibus- - - } \\
& \text { G]allica[-.. - } \\
& \text { - - - JE CLAL- - - } \\
& ---] A E[--- \\
& ---]++[-\cdot \\
& \text {-..... }
\end{aligned}
$$

L. 5 : dans le bas du fragment $F$, traces d'une quatrième ligne, avec le sommet d'un $A$ et celui d'une haste verticale qui pourrait être celle d'un $\mathrm{R}$ : certainement Mar[tiae].

97. Grenier, 1957 , p. 145 -1 146 et fig. $1(A E, 1958,55)$; Dural P.-M., 1958 ; G. Alföldy, BJ, 166, 1966, p. 638 (compte rendu des IITG) ; Aubin dir., 1980 , n"4. Voir Saxer, 1967, p. 61, n"120 ; Dobson, 1967, p. XXV-XXVI ; Burnand, 1995. 


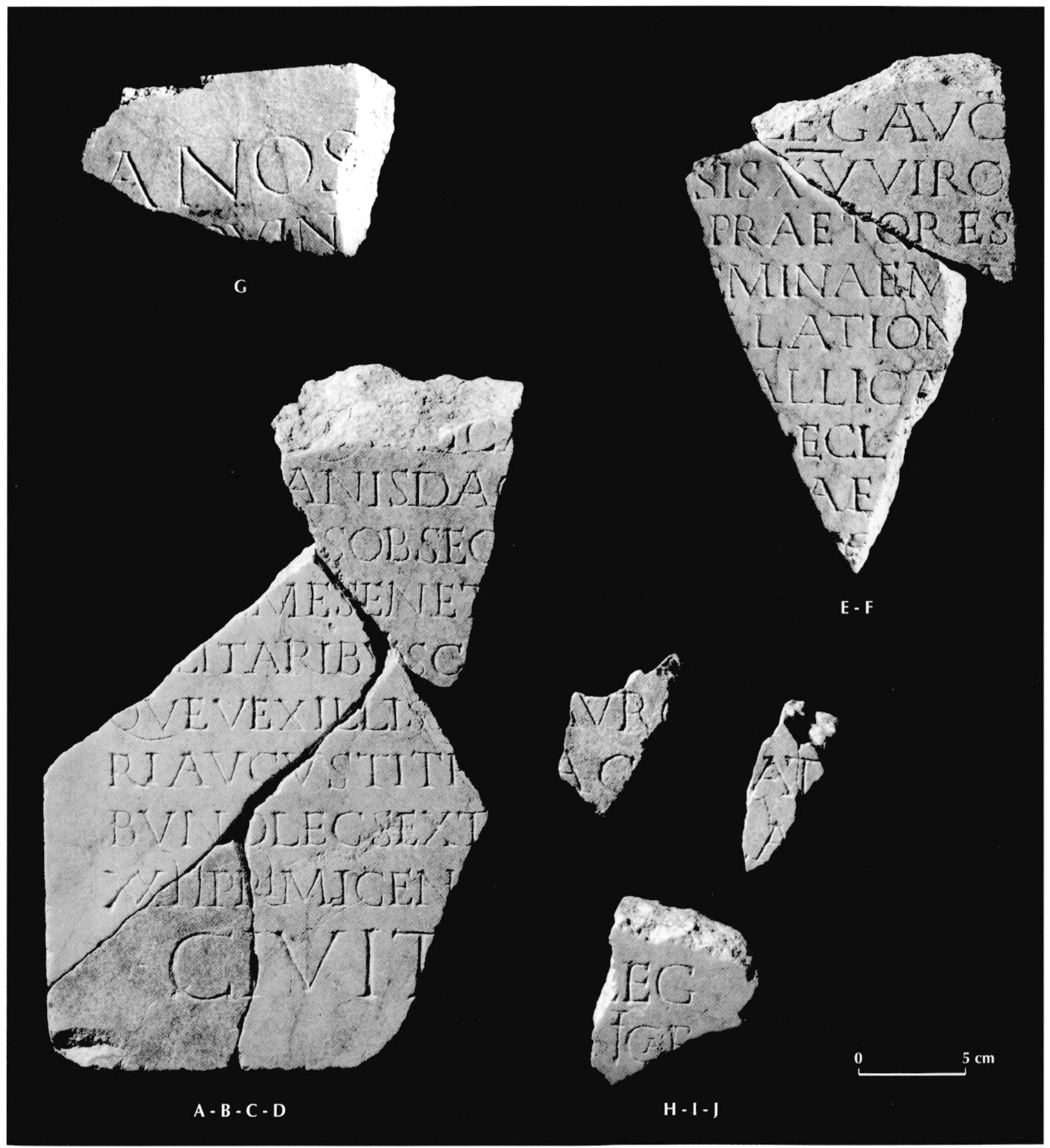

Fig. 75 - Dédicace à un sénateur romain.

L. 6: à gauche, avant le L, on distingue l'extrémité et le sommet d'un premier L: [uexi]llation[ibus].

L. 7 : [G]allica[e], Grenier, Wuilleumier; [G]allic[ae], Burnand; mais une moitié de A est bien visible à droite.

L. 8: [undecima]e Cl[audiae], Grenier, Wuilleumier; [septima]e Cl[audiae], Burnand ; mais on distingue encore après le L l'empattement et la partie inférieure d'un A.

L. 10 : C ou O, Grenier ; $\mathrm{C}$, Wuilleumier ; après une trace de lettre illisible dans la cassure et sous le $\mathrm{A}$, on distingue le sommet d'une lettre ronde sous le E.

Fragment $G$ (inv. AL.05.97.459). Le 16 mai 1997, dans la cour au nord du pronaos du temple, dans la couche supérieure de destruction (sondage 34, us 484). Fragment de plaque en marbre blanc, brisé en bas, à gauche et à droite, mais ayant conservé le bord supérieur de l'inscription, ainsi que deux lignes de quatre lettres chacune, la première en lettres 

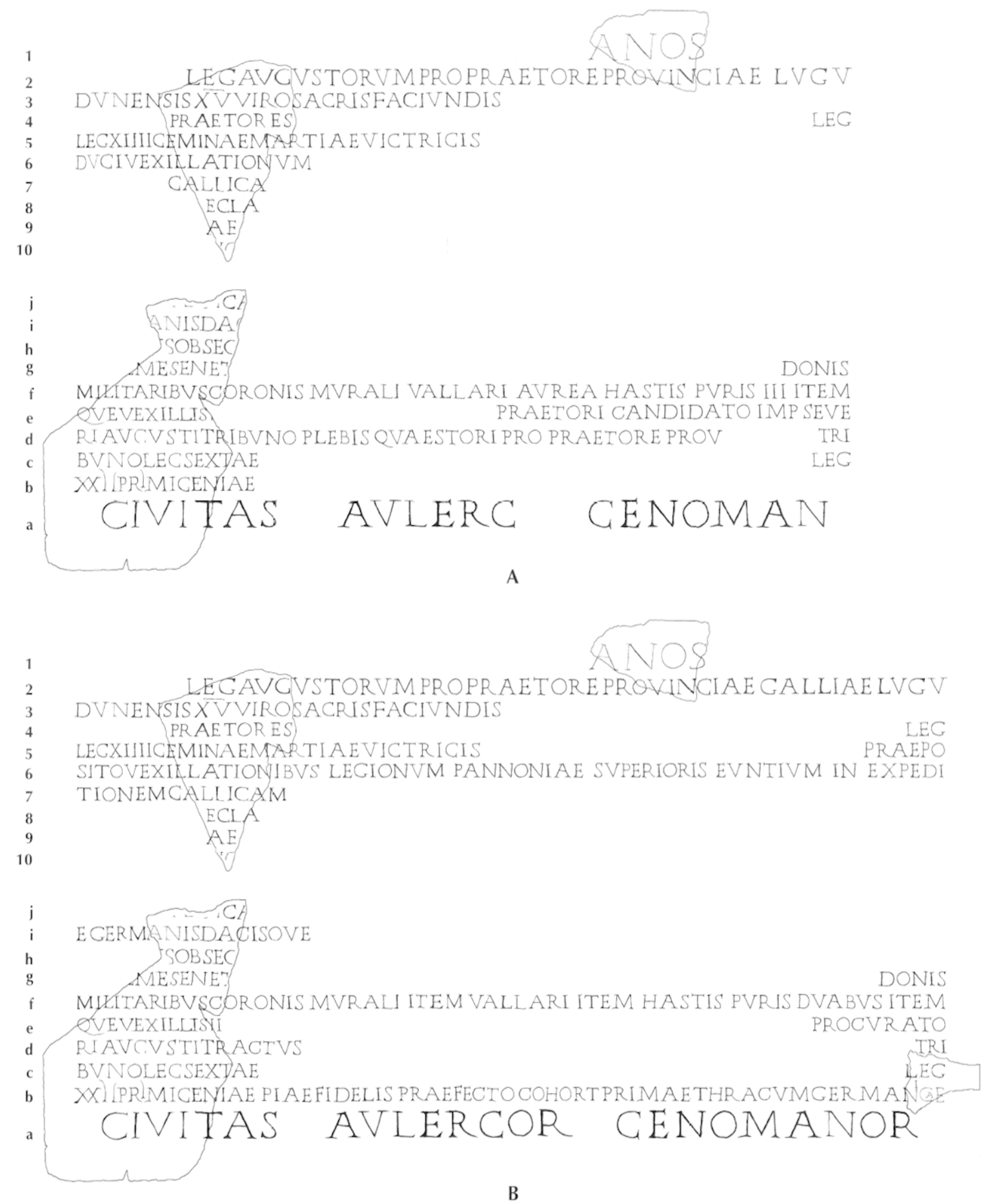

Fig. 76 - Dédicace à un sénateur romain: deux hypothèses de restitution, brève et longue (A et B).

nettement plus grandes que la deuxième. Dimensions : haut. : 9,5 ; larg. : 16,5 ; ép. : 3,7 ; haut.d.l. : $1.1: 2,8 ; 1.2$ : 1,6 (conservés) ; interligne: 1 à 1,1 ; entre la 1 . 1 et le bord supérieur: 3,3 .

$$
\text { - - - Jano S5- . - }
$$

L. 2 : O ou Q, C étant exclu.
Fragment $\boldsymbol{H}$ (inv. AL.05.98.6838). Le 13 novembre 1998, dans la couche de destruction (sondage 39). Fragment de plaque en marbre blanc, brisé de tous côtés, sauf à droite où le bord droit de la plaque est conservé sur 2 ou $3 \mathrm{~cm}$. Il reste la fin de deux lignes, séparées du bord par un vacat de $2,8 \mathrm{~cm}$, ainsi que dans la partic supérieure le bas de deux lettres non identifiables appartenant à une ligne supérieure. À la dernière ligne, ligatures NI et CA, comme si le lapicide avait manqué de place. Dimensions : haut. : 6,8 ; larg. : 6,3 ; ép. : 3,6 ; haut.d.l. : 1,5 ; interligne : 0,9 à 1 . 


$$
\begin{aligned}
& \cdots \\
& -.-1+[.]+ \\
& \text { - - -lleg(ionis ?) } \\
& \text {-.-Jnicae } \\
& \text { - . - . . }
\end{aligned}
$$

L. 1 : peut-être une lettre ronde (C ou $\mathrm{O}$ ) au-dessus du $\mathrm{E}$, ce qui expliquerait l'absence de trace de gravure à gauche.

L. 2 : ou $\operatorname{leg}($ ato $)$, qui paraît cependant moins probable.

L. 3 : [Macedo]nicae, ou Germa]nicae, Panno]nicae, etc.

Fragment I (inv. AL.05.94.1338). Le $1^{\text {er }}$ juillet 1994, au voisinage du podium du temple, côté sud, dans la couche de destruction. Fragment de plaque en marbre blanc, brisé de tous côtés, portant les restes de deux lignes, de respectivement quatre et deux lettres. Dimensions : haut. : 6,5 ; larg. : 4,3 ; ép. : 3,9 ; haut.d.l. : 1,6 ; interligne : 0,9 à 1 .

$$
\text { - - - - JAVROL - . }
$$

L. 1 : O, C, G ou Q; peut-être [triumuiro] auro [aere argento flando feriundo] ou, encore, [aduersus? M]auro[s] ou [coh(ortis)? M]auro[rum].

\section{2 : $\mathrm{C}$ ou $\mathrm{G}$.}

Fragment J (inv. AL.05.97.747). Le 2 juin 1997, dans la cour au sud du podium du temple, dans la couche de destruction (sondage 39, us 84). Fragment de plaque en marbre blanc, brisée de tous côtés. Dimensions : haut. : 7,2 ; larg. : 3 ; ép. : 3,7 ; haut.d.l. : 1,5 ; interligne : $1.2-3: 1,1$.

$$
\begin{aligned}
& [--]+[--]] \\
& [v] A T[--]] \\
& {[---]+A[---]} \\
& -\cdots-.
\end{aligned}
$$

L. 1 : on distingue probablement au-dessus du A l'extrémité horizontale d'un empattement.

L. 3 : avant le $A$, extrémité d'un empattement.

Quatre de ces fragments (A, B, C, D) sont jointifs et forment l'angle inférieur gauche d'une plaque, avec le début d'une dizaine de lignes, dont la dernière (qu'on appellera la ligne a, en numérotant à partir du bas) porte, en lettres plus grandes ( $3 \mathrm{~cm}$, contre en moyenne 1,5 à $1,6 \mathrm{~cm}$ ) le nom du dédicant, la ciuitlas Aulercorum Cenomanorum]. Cette restitution, qui est, comme on le verra, très vraisemblable, indique l'ampleur de la lacune, qui, même si on peut envisager quelques abréviations, équivaut à quatre ou cinq fois le texte conservé. Dans les deux lignes qui précèdent (lignes b et $c$ ), on reconnaît la mention de plusieurs tribunats légionnaires et, plus haut, celle de décorations militaires, qui s'étendent sur plusieurs lignes (c et f et peut-être $\mathrm{g}$ à i). La ligne d permet de supposer un cursus sénatorial, si on restitue [--quaesto]/ri Augusti, mais une carrière équestre est également envisageable, avec par exemple [- - procurato]/ri Augusti.

Le petit fragment $F$ appartient incontestablement à un cursus sénatorial, avec le titre de leg(atus) Aug(usti) et le quindécemvirat sacris faciundis. Ce morceau, qu'il faut sans doute situer plus haut dans le texte, ne recolle pas avec les quatre précédents, mais, par chance, il vient compléter exactement à droitc le morceau découvert dans les années 1950 et qu'on attribuait à un primipile $(I L T G, 347=\mathrm{E})$. La légion [X Freten]sis est ainsi remplacée par une province comme la [Iugudunen]sis ou la [Tarraconen]sis et la X [Gemina] par le titre de XVuir [sacris faciundis], tandis que la troisième ligne permet de reconstituer entièrement le mot praetore, dont le $\mathrm{O}$ est partagé par moitié entre les deux fragments. Il reste certes de nombreux problèmes, notamment avec le $S$ qui suit immédiatement le mot praetore sur le fragment $\mathrm{F}$, mais il n'est pas douteux que nous ayons là une autre partic du cursus dont nous avions déjà le début.

Avec un peu plus de risques, on peut même tenter un nouveau rapprochement avec un autre fragment (G), qui conserve le bord supérieur de l'inscription et une première ligne portant les quatre lettres ANOS en grands caractères de $2,8 \mathrm{~cm}$. La seconde et dernière ligne de ce fragment présente en effet en lettres de $1,6 \mathrm{~cm}$ les lettres OVIN, qu'il faut sans doute lire [pr]ouin[ciae]. On pourrait donc chercher là la suite de la titulature commencée à la première ligne du fragment $\mathrm{F}$ et restituer en conséquence leg(atus) Aug(usti) (ou Aug[usti] ou Aug[ustorum]) [pro praetore pr]ouin [ciae---]; la titulature pourrait même se prolonger au début de la ligne suivante, avec une épithète comme [Lugudunen]sis ou [Tarraconen]sis, qui viendrait logiquement à la suite du substantif [pr]ouin[ciae] mentionné à la fin de la ligne précédente. C'est sur cette hypothèse qu'est fondée la reconstitution proposée pour le haut de l'inscription, et c'est la raison pour laquelle le fragment G' s'y trouve autant décalé vers la droite. Naturellement, cet assemblage reste hypothétique, entre autres parce que le mot prouincia pouvait figurer plusieurs fois dans un cursus aussi riche et qu'il n'est donc pas sûr que l'unique attestation que nous en avons conservée dans le fragment $\mathrm{G}$ soit justement à la fois celle qui venait après le leg(atus) Aug(usti) mentionné par le fragment $\mathrm{F}$ et celle qui venait avant le nom de la province dont il reste les trois dernières lettres au début du fragment E. Néanmoins, l'hypothèse semble précisément confortée par cette double liaison, qui fournit un contexte satisfaisant avant et après le mot prouincia, ainsi que par la taille des lettres, qui, avec $1,6 \mathrm{~cm}$, sont, dans le fragment $\mathrm{F}$ comme dans le fragment G, légèrement plus grandes que la moyenne des autres lignes. Cela conviendrait très bien s'il s'agit de la seconde ligne de l'inscription, et on peut observer que la troisième ligne, perdue dans le fragment $G$, mais qui, si on admet ce rapprochement, serait conservée dans les lettres SISXVVIR des deux fragments E et $\mathrm{F}$ réunis, a également des lettres de $1,6 \mathrm{~cm}$, alors qu'à la ligne suivante on retombe dans la moyenne et même un peu en dessous avec le mot PRAETORE, qui présente les lettres les plus petites de tous les fragments conservés (seulement $1,4 \mathrm{~cm}$ ). Ln troisième argument en faveur d'unc telle reconstitution vient de la longueur des lignes qui, avec environ 40 à 50 lettres pour la restitution des deuxième et troisième lignes, est assez proche de la quarantaine ou cinquantaine de lettres nécessaires dans le bas du texte pour compléter les décorations militaires, les différentes étapes d'un cursus sénatorial, ou bien des milices équestres.

Naturellement, on ne peut ni dans un cas ni dans l'autre estimer exactement la longucur des lignes, dans la mesure où les titulatures sont sujettes à variation et à abréviation : même si le texte est d'une manière générale très peu abrégé, au point 
que l'on écrit en entier à la ligne c le grade de tribuno et le numéro de la légion sexta ou à la ligne d le génitif Augusti, on y trouve cependant quelques abréviations habituelles, comme leg(ato) dans le fragment F (ligne 2) ou le numéro XXII de la légion Primigenia (ligne b). On se gardera donc de proposer des restitutions trop précises, qui risqueraient d'être démenties. Ainsi, on pourrait penser qu'à gauche la troisième ligne commençait par Lugudunensis, ce qui ferait une lacune de 9 à 14 lettres avant les fragments $\mathrm{E}$ et $\mathrm{F}$, permettant de restituer par exemple [praeposito uexi]llationum à la sixième et lexpeditione GJallica à la septième. Mais même ces calculs paraissent incertains, si on observe que le lapicide n'a pas hésité à couper les mots dans le bas du texte (ainsi [quaesto ?]/ri ou [tri]/buno), et quelques indices laissent penser que la lacune pourrait être plus courte à gauche, des mots comme Lugudunensis, praeposito ou expeditione devant alors être coupés entre les deux lignes. Quant à la lacune de droite, elle est encore plus difficile à estimer. Le rapprochement que nous avons proposé suppose une lacune relativement courte après le fragment $G$, puisqu'à la deuxième ligne, après les quatre lettres manquantes de [pr]ouin/ciae], il ne pourrait guère y avoir que le début du nom de la province, si celui-ci était coupé. Mais, inversement, la première ligne réclame plus de place, puisqu'après les lettres [---]ano, qu'il faut probablement interpréter comme la fin d'un cognomen, un nouveau mot commence avec la lettre $S$ : qu'il s'agisse d'une fonction, par exemple une prêtrise, ou d'un autre cognomen, ce qui paraît peut-être préférable, il est probable que le mot était écrit en entier à la fin de la première ligne et donc que la lacune était moins courte qu'on ne serait tenté de le supposer au vu de la seule deuxième ligne. Cette difficulté de mise en page pourrait nous amener à renoncer au rapprochement proposé entre les fragments E-F et $G$, mais il y a peut-être une conciliation possible s'il s'agissait d'un cognomen bref et si le nom de la province était long et commençait à la fin de la deuxième ligne ; la lacune à gauche des deux fragments E-F serait alors plus courte et limitée peut-être à quelques lettres.

Que l'on admette ou non le rapprochement proposé avec les fragments $\mathrm{E}$ et $\mathrm{F}$, il n'est pas douteux que le fragment $\mathrm{G}$ présente la première ligne du texte, avec le nom du personnage écrit en plus grosses lettres. Il est dommage que celui-ci se réduise à la fin d'un cognomen en -anus, qui ne permet guère d'identification ; il faut évidemment supposer auparavant un nom complet, avec au moins un prénom. un gentilice et un cognomen, et peut-être un gentilice ou un cognomen supplémentaire, si les noms étainet brefs et s'il n'y avait pas de tribu et de filiation : dans tous les cas, le morceau $G$ ne peut se situer que dans la seconde moitié de la ligne et même sans doute assez près de son extrémité droite, même si on renonce à la liaison suggérée avec les fragments jointifs $\mathrm{E}$ et $\mathrm{F}$.

En résumé, on a localisé dans le bas de l'inscription quatre fragments jointifs (A, B, C, D) formant l'angle inférieur gauche, avec au total dix lignes (de $\mathrm{j}$ à a), et dans le haut trois fragments dont deux sont jointifs ( $E$ et $F$ ) et un troisième pourrait se situer plus à droite et surtout plus haut, avec un morceau de la première ligne $(G)$ : au total au moins neuf et sans doute dix lignes, que nous numéroterons désormais de 1 à 10. Dans un premier temps, nous avions cru pouvoir réunir l'avant-dernière ligne de l'ensemble supérieur (soit la ligne 9, appartenant au fragment $\mathrm{E}$ ), dont la première lettre est un $\mathrm{A}$ auquel il manque le bas de la jambe gauche, et la première ligne de l'ensemble inférieur (soit la ligne $\mathrm{j}$, appartenant au fragment D), dont la dernière lettre est précisément le bas de la première jambe d'un A : cela aurait fait un bel ensemble de 18 lignes et permis d'estimer au moins approximativement la longueur totale du texte. Malheureusement, il faut renoncer à ce collage, tant à cause de la lettre A elle-même, dont la partie centrale, notamment le début de la barre horizontale médiane, serait conservée dans les deux fragments, que de la forme générale des fragments D et E, dont les tranches saillantes excluent un tel assemblage. Mais cette trop belle hypothèse ne devrait pas être très éloignée de la réalité, soit que le collage doive être placé quelques lettres plus loin ou une ligne plus bas, soit qu'il faille intercaler une ou plusieurs lignes entre les deux ensembles.

Il faut ajouter, pour terminer, trois fragments plus petits qui ne comptent chacun que deux lignes lisibles et quelques lettres. Le fragment $\mathrm{H}$ est le plus intéressant, car il est le seul à donner la fin de deux lignes et le bord droit de l'inscription, qui présente à la fin des lignes un vacat de $2,8 \mathrm{~cm}$. À la deuxième ligne, la présence de deux ligatures dans un texte qui en est par ailleurs dépourvu donne l'impression d'une fin de texte. À la première, le mot leg(ionis) conviendrait parfaitement avant le nom de la XXII Primigenia qui occupe le début de l'avantdernière ligne dans les fragments $\mathrm{A}, \mathrm{B}, \mathrm{C}$ (ligne $\mathrm{b}$ ). On pourrait donc avoir là la fin des deux dernières lignes du cursus descendant dont le début est conservé par le fragment $\mathrm{A}$, juste avant la dédicace en grosses lettres par la ciuitas Aulercorum Cenomanorum (ligne a), mais nous verrons que cette localisation pose aussi des problèmes. Les fragments I et J, brisés de tous côtés, ne se laissent pas facilement placer, même si le texte un peu plus long de I permet quelques supputations.

Les cadres généraux du puzzle ètant ainsi fixés, autant qu'il est possible en l'état fragmentaire de la documentation, il s'agit d'essayer de remplir quelques cases, en s'appuyant sur les formulaires bien connus des carrières de l'époque impériale pour combler l'ampleur considérable des lacunes. Le travail est facilité par la dimension très régulière des lettres, qui sont toujours comprises entre 1,45 et $1,6 \mathrm{~cm}$. Seules font exception les première et dernière lignes ( $1 \mathrm{et}$ a), avec de grandes lettres de respectivement 2,8 et $3 \mathrm{~cm}$, et, dans une moindre mesure, la deuxième et la troisième ( 2 et 3 ) qui, si notre hypothèse concernant les fragments $F$ et $G$ est juste, ont des lettres légèrement plus grandes $(1,6$ à $1,7 \mathrm{~cm})$ et surtout plus espacées que le reste du texte. Le cursus étant dans l'ordre descendant et la partie inférieure de l'inscription étant la moins mal conservée, nous tenterons de remonter la carrière en partant du bas, en nous aidant de deux propositions de restitution, plus ou moins longues, qu'il faut bien sûr considérer comme indicatives (fig. 76 A et B).

La ligne a devait ètre entièrement remplie par le nom du dédicant, qui était écrit en lettres deux fois plus grandes. C'était très vraisemblablement celui de la ciuitas Aulercorum Cenomanorum, comme dans les $\mathrm{n}^{\circ} 4,12$ et 13. L'omission du nom des Aulerques, sans être exclue, parait peu probable, mais on peut hésiter en revanche sur la longueur du texte, qui était soit écrit en entier (28 lettres et deux espaces difficiles à estimer), soit légèrement abrégé, par exemple sous la forme 
ciuit(as) Aulercor(um) Cenomanor(um) (22 lettres, fig. 76 B) ou ciuit(as) Aulerc(orum) Cenoman(orum) (18 lettres, fig. $76 \mathrm{~A}$ ). Si l'on connaît déjà une dédicace de la cité à un empereur $\left(n^{\circ} 4\right)$, c'est la première qui soit élevée à un sénateur ou à un chevalier, mais on notera qu'il y a parmi les fragments d'Allonnes au moins deux autres cursus sénatoriaux ou équestres, malheureusement. encore plus lacunaires ( $\mathrm{n}^{\circ} 7$ et 8 ).

Aux lignes b et c est conservée l'indication de deux tribunats militaires, l'un dans l'une des deux $\mathrm{VI}^{\mathrm{e}}$ légions, soit la sext [a Victrix] d'Eboracum en Bretagne, soit la sext[a Ferrata] de Judée, et l'autre dans la XXII Primigen[ia pia fidelis] de Mayence. Alors que le premier numéro est écrit en lettres, le deuxième est en chiffres, ce qui doit inciter à une certaine souplesse dans les restitutions. L'ampleur de la lacune (4 à 6 fois le texte conservé) invite à supposer au moins une légion supplémentaire entre les deux, dans la seconde moitié de la ligne c, et éventuellement une autre dans la seconde moitié de la ligne b. Cette dernière pourrait être la (VMacedo/nica, si on place le fragment $\mathrm{H}$ à la fin des lignes $\mathrm{c}$ et $\mathrm{b}$ : mais cette localisation pose divers problèmes et doit être considérée comme incertaine. De toute façon, quatre tribunats légionnaires constitueraient une sorte de record, pour un sénateur comme pour un chevalier. On peut réduire la difficulté en supposant que le tribun nommé ligne c avait été placé, comme il arrive, à la tête de vexillations fournies par d'autres légions. Mais l'abondance de tribunats nous invite à restituer plutôt une autre fonction à la fin de la ligne $b$ : par exemple, s'il s'agit d'un chevalier, une préfecture de cohorte auxiliaire (voir fig. $76 \mathrm{~B}$ ), s'il s'agit d'un sénateur, le vigintivirat, ou encore, dans un cas comme dans l'autre, une fonction municipale, un patronat voire quelques épithètes qui célébreraient les vertus du personnage honoré.

À la ligne d, la lecture [quaesto]/ri Augusti paraît naturelle s'il agit d'un cursus sénatorial, mais les deux lettres TR posent problème. Un tribunat légionnaire laticlave serait parfaitement à sa place dans un cursus descendant, mais augmenterait encore le nombre déjà élevé des légions. Le triumvirat monétaire, qui est fréquemment associé au poste de questeur de l'empereur, remplirait à peu près parfaitement la ligne et pourrait même avoir laissé quelques traces dans le fragment I, qu'il serait tentant de placer ici: triiumuir aere argento] auro [flando feriundo] ; mais sa place serait vraiment anormale, puisque tous les exemples que nous ayons de ces débuts de carrière priviligiés se font dans l'ordre triumvirat monétaire, tribunat laticlave, questure. Une troisième possibilité serait de restituer après [quaesto]/ri Augusti tr[ibuno plebris- - -], en supposant un cursus de type compartimenté, dans lequel les magistratures (questure de l'empereur, tribunat de la plèbe et sans doute ensuite préture) auraient été regroupées dans l'ordre ascendant à l'intérieur d'une carrière globalement descendante; mais ce type de cursus est très rare, même s'il pourrait en l'occurrence s'expliquer par les nombreux états de service militaires qui occupaient la place principale. En fait, la solution la moins mauvaise serait peut-ĉtre une formule plus complexe, avec le nom de Septime Sévère à la place de [quaesto]/ri, ce qui permettrait de garder l'ordre descendant des magistratures (voir fig. $76 \mathrm{~A}$ ). Mais c'est bien sûr hypothétique, et il faut donc envisager aussi unc carrière équestre, soit que l'anonyme ait été adlecté et nommé directement à la questure après un tribunat angusticlave, ce qui est peut-être un peu rapide, surtout pour un questeur de l'empereur, soit qu'il faille lire plutôt [procurato]/ri Augusti, suivi d'un nom propre désignant le ressort de la procuratèle ou d'un mot comme tr[actus], que l'on trouve dans certaines titulatures (voir fig. $76 \mathrm{~B}$ ). L'adlection se placerait alors plus tard, après une riche carrière militaire équestre, comme on en a de nombreux exemples dans les guerres de la seconde moitié du $\mathrm{II}^{\mathrm{C}} \mathrm{s}$. et du début du $\mathrm{III}^{\mathrm{c}} \mathrm{s}$.

Les lignes e-f mentionnent précisément des décorations militaires qui pourraient se rapporter aux événements obscurs mentionnés dans les lignes précédentes $(\mathrm{g}, \mathrm{h})$. Le pluriel uexillis (ligne e) permet de restituer plusieurs c[oronae] et sans doute aussi plusieurs hastae à la ligne $\mathrm{f}$, mais les chiffres, qui permettraient de déterminer le grade exact de l'anonyme, ont disparu. On pense surtout à un officier de rang sénatorial, comme un tribun laticlave, qui recevait d'ordinaire deux couronnes (muralis et uallaris), deux hastae et deux uexilla, ou plus vraisemblablement, étant donné la place dans le cursus, un prétorien, qui avait droit en général à trois décorations de chaque série. Il pourrait s'agir ainsi d'un poste de légat de légion ou d'un commandement extraordinaire qui trouverait place dans les lignes g-h ; les magistratures sénatoriales ou l'adlection au sénat devraient être placées alors à la ligne e (ou éventuellement d dans le cas d'un cursus sénatorial). Cependant, on ne peut exclure un officier de rang équestre, car si la grande majorité d'entre eux ne recevaient qu'une ou au plus deux couronnes, une hasta et un uexillum, quelques exemples semblent montrer qu'un préfet d'aile pouvait obtenir deux couronnes, deux hastae et deux uexilla. Cela pourrait convenir en particulier à quelqu'un qui se serait distingué dans un commandement extraordinaire, par exemple comme praepositus uexillationum, ou qui aurait rang de procurateur, les décorations des procurateurs étant particulièrement mal connues.

L'ampleur des lacunes ne permet malheureusement pas de trancher la question, ni de proposer une restitution précise, puisqu'on peut hésiter sur le montant des chiffres (duobus ou tribus), les abréviations (III ou tribus), le degré de précision (hastis ou hastis puris, uexillis ou uexillis argenteis), les éventuelles coordinations (itemque ?), etc. La seule certitude est que les décorations, qui débordaient sur les lignes g (avec peut-être donato et en tous cas donis en fin de ligne) et e, occupaient l'ensemble de la ligne $f$, avec une lacune d'environ 35 à 50 lettres. C'est, avec la dédicace finale et la reconstitution du titre de légat propréteur aux lignes 2 et 3 , un des seuls moyens que nous ayons d'estimer la largeur globale du texte : une ligne moyenne, où les lettres ne sont ni plus grandes, ni plus espacées, comme au début ou à la fin du texte, devait donc compter entre 47 et 62 lettres, dont seulement 12, soit un quart à un cinquième, sont conservées. C'est dans ce cadre que s'inscrivent les restitutions de la figure 76 , qui comptent de 42 à 48 lettres, mais ne sont évidemment proposées qu'à titre d'exemples.

À la ligne g, après un vacat initial de quatre à cinq lettres, on lit sans ambiguïté les lettres MESENET, qui, n'entrant dans la composition d'aucun mot latin, doivent appartenir à un nom propre, par exemple géographique. Une première solution serait Mesene, une région qui s'étendait dans la partie méridionale de la Mésopotamie (Pline, Histoire naturelle, VI, 129, 
$131,132)$ et dans laquelle auraient pu prendre place des opérations militaires, en particulier pendant la guerre parthique de Lucius Verus ou pendant celle de Septime Sévère, qui a pris Ctésiphon dans l'hiver 197-198. Mais on peut songer aussi à l'adjectif [He]mesen(us) et, plutôt qu'à la ville d'Émèse, difficile à placer dans ce contexte, à une unité d'Éméséniens, par exemple la cohors I milliaria Hemesenorum sagittaria, qui est bien connue depuis le règne de Marc Aurèle comme garnison d'Intercisa, en Pannonie inférieure. L'abréviation et surtout le et qui suit posent quelques difficultés, mais il pourrait s'agir d'un commandement sur plusieurs unités ou peut-être vexillations auxiliaires, comme on en a d'autres exemples, pour des chevaliers comme pour des sénateurs. Une telle mission s'accorderait, elle aussi, assez bien avec le contexte militaire de l'inscription, avec les décorations qui commencent à la fin de la même ligne $g$ et que l'officier aurait pu obtenir dans l'exercice même de son commandement, et également, comme nous le verrons, avec la ligne précédente ; mais, à la différence d'éventuelles opérations en Mésène, rien ne permet d'en préciser la localisation géographique.

À la ligne h, la restitution ob sec[undam expeditionem- - -] (ou ob sec(undum bellum---J) paraît assez naturelle, laissant le choix ouvert entre l'expeditio Germanica secunda de Marc Aurèle et Commode contre les Marcomans en $178-180$ et la seconde guerre parthique de Septime Sévère, en 198-199. La première s'accorderait mieux avec une mention de la cohorte I Hemesenorum, qui était cantonnée en Pannonie inférieure, et la seconde conviendrait mieux à des opérations en Mésène. Mais il y a d'autres solutions possibles, en particulier une formule plus vague comme ob sec[undas res gestas- - -], qui, sans faire référence à une campagne officielle, décrirait des succès plus ponctuels, éventuellement avec une certaine précision géographique, qui pourrait s'étendre, le cas échéant, jusqu'au mot Mesene à la ligne suivante.

Les sept lettres conservées de la ligne i semblent ne présenter qu'une lecture possible : [Germ]anis Dac[isque]. Mais plutôt que d'ennemis, dont l'association paraît peu probable après les guerres de Domitien et de Trajan, il pourrait s'agir plutôt des troupes romaines cantonnées dans les provinces de Germanie et de Dacie. À la place des adjectifs Germanicis et Dacicis, qui sont habituellement employés dans ce sens, on aurait une expression comme [praeposito uexillationibus? e GermJani(i)s Dac[i(i)s ou Dac[iaque missis], qui trouve des parallèles dans le vocabulaire des vexillations. L'association est en elle-même intéressante, car l'absence de la Pannonie, qui se trouvait géographiquement entre ces deux groupes de provinces, laisserait penser que la force ainsi composée était destinée à opérer dans cette province. Ce serait un argument pour choisir plutôt à la ligne h l'expeditio Germanica secunda de Marc Aurèle et à la ligne g la cohorte I Hemesenorum. Mais il est fragile, car l'importance des lacunes ne permet pas de garantir que les trois lignes se rapportent aux mêmes opérations.

Le texte, qui n'est plus conservé que par le fragment $\mathrm{D}$, devient très lacunaire, et il est de plus en plus difficile de reconstituer sa logique, ainsi que la carrière de l'officier décoré. L'articulation avec les fragments E-F et la partie supérieure du cursus étant également problématique, on renoncera provisoirement à proposer une interprétation pour la ligne j, dont il ne reste que le bas d'une demi-douzaine de lettres, ainsi que pour les lignes 8 à 10 de l'ensemble supérieur, qui se réduisent à deux ou trois lettres et sur lesquelles on reviendra ultérieurement.

À la ligne 7, qui est la première à présenter un mot identifiable, la lecture [G]allica ne fait guère de doute, puisqu'il manque seulement la première lettre et qu'il reste des traces suffisantes des deux $\mathrm{A}$ à gauche et à droite. Mais l'interprétation peut hésiter entre le nom d'une légion, la III Gallica, de Syrie, que proposaient les premiers éditeurs du fragment $\mathrm{E}$ (= ILTG, 347), et l'expeditio Gallica que Septime Sévère conduisit contre Albinus en 196-197 apr. J.-C. La première lecture a été récemment reprise par Y. Burnand, qui voit dans ces contingents des vexillations engagées dans la guerre parthique de Lucius Verus (légions [III G]allica, [septim]a Cl[audia] et [secund] [ [Adiutrix]), et elle reste séduisante, surtout si on pouvait la relier avec d'éventuelles opérations en Mésène à la ligne $\mathrm{g}$. Mais la seconde a l'avantage de réduire le nombre déjà considérable des légions mentionnées et de s'accorder au mieux, comme nous le verrons, avec les deux lignes précédentes, qui sont plus proches que la ligne g, séparée par un vacat difficile à évaluer.

Les lignes 5 et 6 offrent des lectures assez sûres, avec respectivement le nom de la légion [XIIII G]emina Mar[tia Victrix], dont le nouveau fragment $F$ donne le sommet de deux lettres supplémentaires (A et R) et le mot [uexi]llation [ibus], au datif ou au génitif, qui invite à restituer auparavant un titre comme praepositus ou dux. Nous avons donc vraisemblablement affaire à un légat de la XIIII Gemina Martia Victrix, la garnison de Carnuntum, en Pannonie supérieure, qui a été, comme c'est souvent le cas, chargé de conduire les vexillations fournies par d'autres unités, peut-être de la même province. Il est très tentant de supposer que cette force exceptionnelle a été formée pour l'expeditio Gallica de 196-197, si c'est bien elle qui est nommée à la ligne 7 . Si l'hypothèse est juste, le personnage pourrait être un fidèle de Septime Sévère, qui était légat de Pannonie supérieure quand il accéda à l'Empire en 193, et peut-être le successeur de T. Flauius Secundus Philippianus, qui était sans doute légat de la XIV légion en 193 avant d'être nommé rapidement à d'autres fonctions, puisqu'il était légat de Lyonnaise en 196-197 (CIL, XIII, 1673). La chronologie convient particulièrement bien, et l'anonyme d'Allonnes pourrait avoir commandé la XIIII Gemina et d'autres contingents, appartenant peut-être à l'armée de Pannonie, pendant la campagne contre Albinus. L'ampleur des lacunes rend toute reconstitution aléatoire, mais on pourrait par exemple restituer dans la seconde moitié de la ligne 5 le nom de l'empereur (let ab Imp. Caesare L. Septimio Seuero Pertinaci Aug. praepo/sito uexi]llation [ibus, etc.), ou à défaut un second commandement légionnaire, à la ligne 6 la définition du groupe de vexillations ([praepo/sito uexi]llation[ibus legionum Pannonicarum ? euntium in expedi/tionem (3)allicalm]) et éventuellement aux lignes 7 et 8 le nom des légions concernées, en particulier une légion [septim] a ou [undecim]a Cla[udia] à la ligne 8 . Nous sommes bien sûr là dans le domaine de l'hypothèse, et on pourrait supposer aussi d'autres légions, comme la $V$ Macedonica, si le fragment $\mathrm{H}$ devait être placé dans ces lignes, d'autres provinces ou groupes de provinces, comme la Dacie ou l'une des Mésies, qui pourraient être substituées ou ajoutées à la Pannonie, voire la présence d'auxiliaires, rien n'indiquant explicitement que les vexillations soient légionnaires. 
La ligne 4 est sans doute celle qui pose la plus grosse difficulté. Si le mot praetore, partagé entre les fragments $\mathrm{E}$ et $\mathrm{F}$, permet de restituer sans trop de risque le titre de legatus pro praetore, il est plus difficile de rendre compte de la lettre $\mathrm{S}$ qui suit. S'agit-il d'une province prétorienne, comme la SyriePhénicie, dont l'anonyme aurait été gouverneur, ou d'une province sénatoriale, comme la Sicile, où il aurait été légat du proconsul ou légat extraordinaire de l'empereur? Dans un cas comme dans l'autre, on aurait préféré trouver avant le mot prouinciae, qui figure deux lignes plus haut dans l'inscription. Faut-il restituer le nom des empereurs (Sleueri et Antonini Augustorum] ?) ou d'un proconsul d'Afrique ou d'Asie dont l'anonyme aurait été légat ? Aucune de ces solutions n'est vraiment satisfaisante, et ce n'est qu'avec la plus grande prudence que nous en envisagerons une dernière, celle d'un titre exceptionnel, comme celui de ce leg(atus) Augg(ustorum) su/[per] uexillationes in Cappa/[do]cia chargé d'un commandement prétorien pendant la guerre parthique de Lucius Verus $(C I L$, VIII, $7050=I L S, 1102)$.

La ligne 3 pose moins de difficultés, puisqu'on peut restituer à coup sûr le titre de XVuiro [sacris faciundis], le troisième des quatre grands collèges de la religion romaine, auquel on accédait souvent en fin de carrière prétorienne. Cette fonction prestigieuse confirme le rang sénatorial du personnage, comme le titre pro praetore à la ligne suivante, et sans doute déjà à la ligne 5 le poste de légat de légion, même si le titre de legatus n'est pas explicitement conservé. Il reste dans la seconde moitié de la ligne, après le quindécemvirat, place pour une fonction, qu'il est impossible de préciser.

La ligne précédente, qui est la première du fragment $\mathrm{F}$, présente le titre de leg(atus) Augíusti), qui, à ce stade du cursus, renvoie certainement à un gouvernement de province impériale. Si l'on admet la mise en page proposée ci-dessus, le fragment $G$ a d'ailleurs conservé, avec le mot [pr]ouin[ciae], un autre morceau de cette titulature, qui devait s'étendre sur toute la ligne, dans laquelle il faut reconnaitre la deuxième ligne du texte (1. 2), immédiatement en dessous de celle qui portait le nom du sénateur. La taille et surtout l'espacement un peu plus grand des lettres confirment parfaitement cette reconstitution, qui permet peut-être aussi d'identifier la province en question. En effet, le mot prouinciae étant proche du bord droit de la pierre, le nom devait déborder sur la ligne 3, et les lettres SIS au début du fragment $\mathbf{E}$ peuvent parfaitement en constituer la fin. Une fois écartées la Narbonensis, qui était gouvernée par un proconsul, et la Tarraconensis, parce que son gouverneur était consulaire, mais surtout parce qu'elle s'appelait normalement Hispania Citerior, la seule restitution convenable est bien [Lugudunen]sis, dont les douze lettres étaient peut-être réparties entre la fin de la ligne 2 et le début de la ligne 3. Cela convient parfaitement à une fin de carrière prétorienne, après plusieurs postes antérieurs et le quindécemvirat sacris faciundis. Et cela explique aussi la présence de cette dédicace à Allonnes, où le légat de Iyonnaise était honoré par une des cités placées sous son autorité. Il est possible que l'honneur lui ait été décerné au moment de sa nomination au consulat, qu'on pourrait placer à la fin de la première ligne ou dans la courte lacune du début de la deuxième. Mais cela reste hypothétique, car on pourrait très bien trouver à cet endroit une autre fonction, comme par exemple une courte prêtrise.

La ligne 1 est malheureusement la plus mystérieuse de toutes, une fin de cognomen en [-- - Janus ne favorisant guère les identifications. Une indication plus utile est fournie par la lettre S, qui pourrait être le début d'un second cognomen, plutôt que d'une prêtrise. La coupe Lugu/dunensis, qui est la plus plausible, ne laisse qu'une courte lacune à droite, ne permettant qu'un nom de cinq à six lettres tout au plus (voir fig. $76 \mathrm{~A}$ ). Mais l'adjonction de Galliae, qui trouve des parallèles, surtout à l'époque sévérienne, permet d'aller jusqu'à 9 ou 10 lettres, ce qui offre plus de possibilités (voir la fig. $76 \mathrm{~B}$ ).

L'anonyme garde son mystère, et il n'a pu être jusqu'à présent identifié, ni dans les fastes consulaires, ni dans les "Actes » des Jeux séculaires, qui donnent une liste des quindécemvirs sacris faciundis en 204. La carrière fragmentaire d'Allonnes fournit cependant quelques indications précieuses, surtout si on retient l'hypothèse d'un commandement légionnaire pendant l'expeditio Gallica de 196-197 : il aurait alors été légat de Lyonnaise dans la première décennie du $\mathrm{III}^{\mathrm{e}} \mathrm{s}$., période pour laquelle les fastes sont totalement vides. Il est plus difficile de reconstituer les étapes antérieures de sa carrière, même si les lignes sont un peu moins incomplètes. Il paraît logique d'envisager une participation à l'expeditio Germanica secunda de Marc Aurèle, pendant laquelle on pourrait placer ses décorations. Mais on peut toujours hésiter entre un début de cursus sénatorial qui serait très atypique, avec de nombreux tribunats légionnaires, et une carrière militaire équestre bien remplie et couronnée par une nomination au sénat, que de nombreux parallèles rendent plus vraisemblables à la fin $\mathrm{du} \mathrm{II}^{\mathrm{e}} \mathrm{s}$. ou au début du III"s.

Inscription $\mathrm{n}^{\mathrm{o}} \mathbf{7}$ (inv. AL.05.54-79.88). Découverte non localisée. Fragment de plaque en marbre blanc, brisé de tous côtés (fig. 77) ; il subsiste 7 lettres ou morceaux de lettres, répartis en deux lignes $(4+3)$. Dimensions : haut. : 4,5; larg. : 6 ; ép. : 2 ; haut.d.l. : 1,4. Lettres larges et pas très hautes, avec grands empattements, qui ne semblent pas très anciennes. Les boucles supérieures du $\mathrm{P}$ et des $\mathrm{R}$ descendent assez bas, et la barre oblique du $R$ est très incurvée et très longue, s'étendant, de façon un peu maniérée, jusque sous la lettre suivante. Point visible 1.1 entre G et PRO.

$$
\begin{aligned}
& \text { [-.]G PRO[- - ] } \\
& {[--] R O V[--]}
\end{aligned}
$$

L. 1-2 : peut-être [---leg(atus) Au]g(usti) pro [prae/tore plroulinc(iae)---l, mais la restitution ne convient, même si l'on écrit complètement praetore, qu'à une plaque de faible largeur (environ treize lettres), et il faut peut-être envisager que les deux lignes se rapportent à deux fonctions différentes, si bien sûr il s'agit d'un cursus, ce qui n'est qu'une hypothèse. À la ligne 1, proc(urator) serait également envisageable, mais paraît moins probable compte tenu des lettres précédentes et suivantes.

Même s'il est difficile de proposer une restitution exacte, en raison de l'ampleur des lacunes, la mention d'une (ou peut-être 


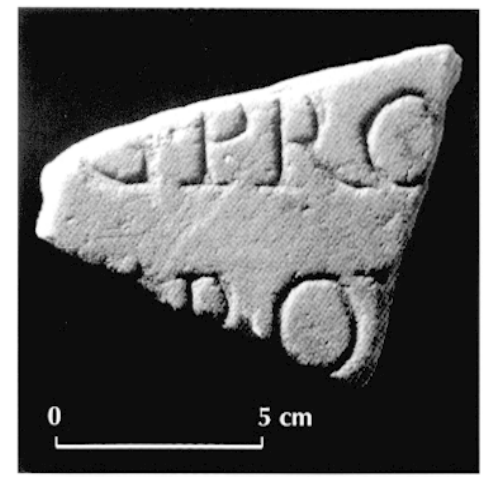

Fig. 77 - Dédicace à un sénateur romain.

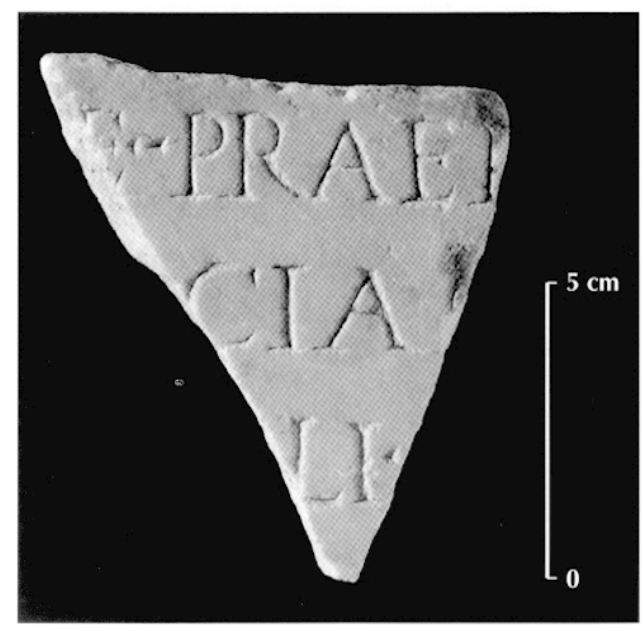

Fig. 78 - Dédicace à un sénateur ou un chevalier romain.

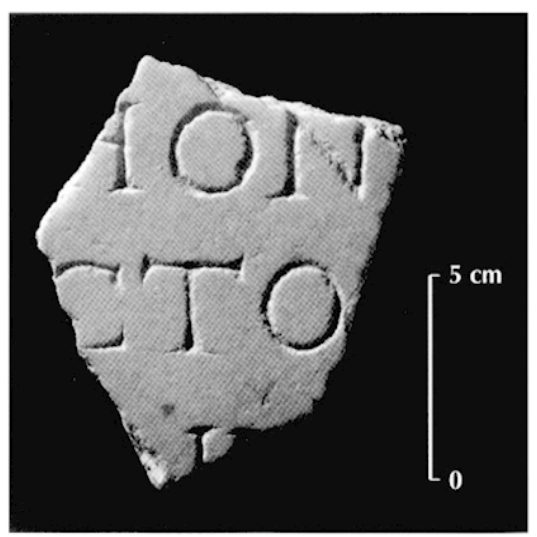

Fig. 79 - Dédicace à un notable.

deux) fonction sénatoriale paraît une hypothèse au moins plausible. Elle n'aurait en tout cas rien d'incongru dans le sanctuaire de Mars Mullo, qui a fourni tout récemment un fragment de cursus sénatorial (dédicace $n^{\prime} 6$ ). L'état lacunaire du texte ne permet naturellement pas de dire s'il s'agissait d'une carrière complète ou seulement du titre d'un fonctionnaire de passage, qui pourrait être, par exemple, un gouverneur de la province de Lyonnaise. La paléographie n'autorise pas de date précise, mais ne semble pas particulièrement ancienne, à en juger par exemple par la forme des $\mathrm{R}$ (voir supra).
Inscription $\mathbf{n}^{\circ} 8$ (inv. AL.05.00.194). En mai 2000, dans la couche de destruction. Fragment de plaque en marbre blanc, brisé de tous côtés (fig. 78). Dimensions : haut. : 8,5; larg. : 8,5; ép. : 2,3; haut.d.l. : 1,4 à 1,5 ; interligne: 1,1 . Lettres bien gravées, avec de grands empattements, mais parfois un peu maladroites ( $R$ trop grand et $\mathrm{E}$ penchant vers la gauche 1.1 , L penchant vers la droite l. 3) ; paléographie assez proche de celle de l'inscription $\mathrm{n}^{\circ} 6$ (notamment en ce qui concerne les $\mathrm{E}$ et les A, avec sommet aplati 1. 2). Ponctuation apparemment régulière, avec un point 1.3 après $\mathrm{LI}$ et deux 1 . 1 avant PRAEF.

$$
\begin{aligned}
& {[--] \text { E praef(ecto ?) [-- ] }} \\
& {[--] \text { cia }+[---]} \\
& {[--] l i[--]} \\
& -\ldots \text { - }[
\end{aligned}
$$

L. 1 : après $\mathrm{E}$, deux points triangulaires successifs ; la barre centrale de la dernière lettre est un peu basse pour un $\mathrm{P}$ : plutôt praef(ecto) que praep(osito).

L. 2 : [prouin]cia? difficilement [prouin]ciae, à cause du vacat qui suit le $\mathrm{A}$.

Le titre de praef(ectus), dont la restitution est assez probable à la 1 . 1 , permet de supposer une fonction administrative ou militaire, hypothèse qui serait confortée par la lecture [prouin]cia à la ligne suivante. Mais ces données sont trop fragmentaires pour que l'on puisse choisir entre une carrière sénatoriale ou équestre.

\section{LES DÉDICACES AUX NOTABLES LOCAUX}

Inscription $\mathrm{n}^{\circ} \mathbf{9}=I L T G, 348 \mathrm{bis} \mathrm{b}^{98}$ (inv. AL.05.54-79.100). En juin 1957, secteur 13 F 2, stylobate ouest M25, au sud de l'abside ouest. Fragment de plaque en marbre blanc, brisé de tous cótés (fig. 79). Dimensions : haut. : 10,5; larg. : 9,5; ép. : 1,3 ; haut.d.I. : 2,1. Lettres très larges, en particulier le $\mathrm{T}$ et le $\mathrm{C}$, avec empattements.

$$
\begin{aligned}
& {[---o m n i b u s] \text { hon[oribusv] }} \\
& {[-- \text {-fun]cto [v] }} \\
& {[---]++[---]} \\
& -\ldots-\ldots
\end{aligned}
$$

L. 1-2 : la formule omnibus honoribus... functus ne fait pas de doute, comme l'a bien noté Wuilleumier; mais il est difficile d'avancer une restitution précise, dans la mesure où il faut compter avec des compléments variables, comme in ciuitate sua, qui paraît le plus probable, mais n'est pas le seul possible.

L. 3 : traces de deux lettres, non notées par Wuilleumier ; la première, dont on voit le sommet d'une haste verticale, avec un empattement, et une haste oblique dans la cassure, pourrait être un $\mathrm{N}$; la seconde, dont il ne reste que le sommet d'une haste verticale, ne peut être précisée.

Bien qu'il n'ait conservé que six lettres, ce petit fragment est plein d'enseignements. La formule omnibus honoribus functus, d'abord, permet de l'attribuer à un notable qui a accompli toutes les magistratures dans sa cité, et peut-être même un peu plus, puisqu'elle est souvent utilisée pour résumer les cursus de

$\overline{98 . \text { Dondin-Payre, } 1999}$, p. 155, n" 21 et 157 (où le cursus est attribué par erreur à la colonie de lyon). 


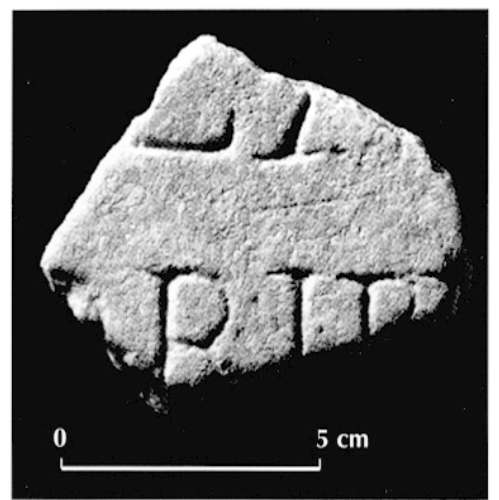

Fig. 80 - Dédicace à un notable.

personnages qui ont eu des carrières plus élevées que le cadre municipal, soit dans l'administration équestre, soit au niveau provincial, par exemple en Gaule au sanctuaire fédéral de Lyon. Il s'agit donc d'un personnage important, mais dont on ne peut être absolument sûr qu'il était Cénoman, dans la mesure où l'inscription pouvait aussi indiquer une autre cité, dans laquelle il aurait accompli tous les honneurs. L'indication globale de la carrière municipale pourrait éventuellement plaider en faveur d'un étranger, mais c'est un indice trop ténu pour qu'on puisse en tirer quelque certitude.

La formule fournit également un indice chronologique précieux, puisqu'on ne la trouve guère qu'à partir du $\operatorname{II}^{\text {" }} \mathrm{s}$. apr. J.-C. (Wierschowski, 1986), bien que le règne d'Hadrien soit peut-être un terminus post quem un peu trop tardif. Le datif, qui paraît assuré avec le participe [fun]cto à la l. 2, apporte aussi une indication importante, en montrant que la plaque n'était pas, comme on pourrait le penser, une dédicace faite par l'intéressé à un dieu, par exemple à Mars Mullo, mais faite à l'intéressé par des tiers, dont le nom a malheureusement disparu. Il s'agit d'une information précieuse sur la nature des inscriptions gravées sur les plaques de ce sanctuaire, dont une partie au moins paraît être de type honorifique ; c'est en tout cas ce que tendrait à confirmer l'inscription $\mathrm{n}^{\circ} 6$, qui est elle aussi rédigée au datif et offerte au bénéficiaire anonyme par la cité des Cénomans.

Inscription $\mathrm{n}^{\circ} 10$ (inv. AL.05.5479.101). Le 20 août 1959, secteur 13 E 2, portique ouest, au sud de l'abside ouest. Fragment de plaque en marbre rosé, brisée de tous côtés (fig. 80). Dimensions : haut.: 6,5; larg. : 8,2 ; ép.: 1,1 ; haut.d.l. : 1,9 (conservé : R).

$$
\begin{aligned}
& {[--] L A[--]} \\
& {[-- \text { hon]orib+[us ? - - ] }}
\end{aligned}
$$

L. I : on distingue le bas de deux lettres, une haste horizontale sur la ligne que l'on est tenté d'attribuer à un I., un F paraissant moins probable à cause de l'absence de barre centrale, et une haste oblique qui ne peut guère appartenir qu'à un $A$.

L. 2 : R et I semblent à peu près assurés, suivis d'une lettre que sa boucle supérieure invite à identifier comme un $\mathrm{B}$, un $\mathrm{P}$ ou un R ; au-delà, trace de l'extrémité d'un nouvelle lettre, non identifiable. Au début de la ligne, avant le R, tracé arrondi qui doit appartenir à un $\mathrm{O}$ (ou à la rigueur à un $Q$ ).

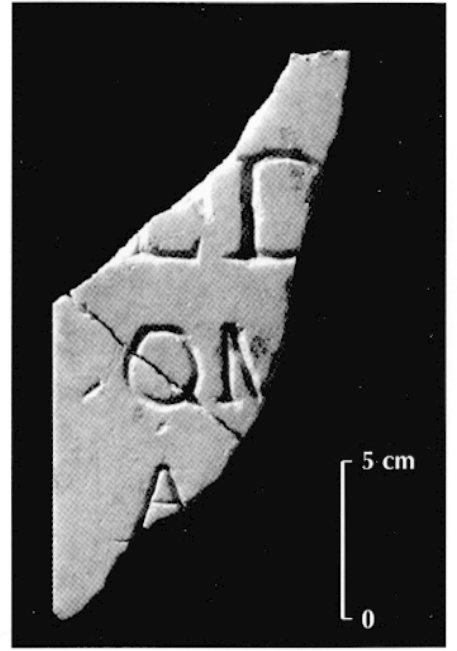

Fig. 81 - Dédicace à un notable (?).

La lecture [hon]orib[us], assez probable compte tenu des lettres conservées à la deuxième ligne, invite à rapprocher ce fragment du précédent, dont la première ligne portait justement les trois lettres manquantes hon[oribus]. Le fait que les deux fragments aient été trouvés dans le même secteur du portique ouest (13 F 2 et $13 \mathrm{E} 2$ ) plaiderait plutôt pour un recollage. Mais l'épaisseur $(1,3$ et $1,1 \mathrm{~cm})$ et les dimensions des lettres semblent légèrement différentes, puisque les $1,9 \mathrm{~cm}$ conservés pour le $\mathrm{R}$ du second fragment invitent à restituer une lettre un peu plus grande que les $2,1 \mathrm{~cm}$ du premier fragment. Les écarts sont plus nets en ce qui concerne les interlignes ( 1,7 pour le premier fragment contre 2,2 pour le second), mais cela peut peut-être s'expliquer si l'on considère que le second fragment conserve une partie supérieure du texte, qui pouvait être écrite en plus gros caractères. Les deux lettres LA de la première ligne, elles-mêmes hypothétiques, ne permettent aucune certitude, mais on pourrait penser soit au nom du personnage honoré, soit à une fonction plus importante qui aurait précédé l'indication des magistratures municipales (voir supra). C'est en tout cas les solutions qui paraissent, en l'état réduit de notre documentation, les plus vraisemblables. $\mathrm{Si}$ l'on refuse en revanche la réunion des deux fragments, il faut alors admettre qu'il y avait au moins deux personnages omnibus honoribus functi honorés dans le sanctuaire de Mars Mullo, ou que le même était honoré par plusieurs inscriptions.

Inscription $\mathrm{n}^{\circ} 11$ (inv. AL.05.95.126). Dans un remblai de destruction, au-dessus du sol du portique sud, à proximité de son angle sud-ouest. Deux fragments jointifs d'une même plaque en marbre blanc, dont le fragment inférieur conserve le bord gauche, mais qui est brisée en haut, en bas et à droite (fig. 81). Dimensions : haut. : 20,5; larg. : 7,9; ép. : 1,4; haut.d.l. : 1.1 : 3,$4 ; 1.2: 2,6 ; 1.3: 2,2$; interlignes : $1.1-2: 2,1 ; 1.2-3: 1,7$. Lettres très profondément gravées, avec empattements.

$$
\begin{aligned}
& \text { EI)[--.] } \\
& \text { OM[---] } \\
& A[-\cdots] \\
& \cdots \cdots
\end{aligned}
$$




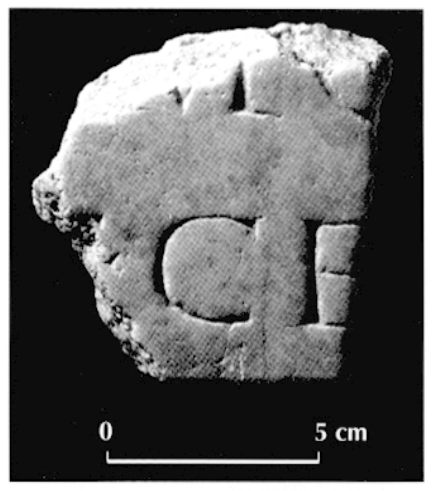

Fig. 82 - Dédicace faite par la cité des Cénomans.

L. 1 : le E n'est pas absolument assuré, la pierre étant endommagée à l'endroit où devrait être la barre centrale.

L. 2-3 : peut-être om[nibus honoribus]/a[pud suos functo---] ?

La restitution proposée peut se fonder sur le parallèle d'ILTG, 348bis b (dédicace $\mathrm{n}^{\circ} 9$ ), auquel s'ajoute le fragment $\mathrm{n}^{\circ} 10$. Mais elle est naturellement hypothétique.

\section{LES INSCRIPTIONS MENTIONNANT LA CITÉ DES CÉNOMANS OU SES INSTITUTIONS POLITIQUES}

Peu de sources nous renseignent sur les Aulerques Cénomans. Les découvertes autour de La Tour-aux-Fées d'Allonnes enrichissent considérablement la collection épigraphique de la cité des Cénomans, qui, parmi les cités gauloises, était particulièrement pauvre. Les fragments de plaques de marbre ont conservé trois mentions du nom des Cénomans Aul(erci) Ce[nomani] (cf. inscriptions $\mathrm{n}^{\circ} 4,12,13$ ) et une de la ciuit[as Aulerc(orum) Cenoman(orum) ?] ( $\mathrm{n}^{\circ} 6$ ).

Inscription $\mathrm{n}^{\circ} 12=I L T G, 348$ bis d (inv. AL.05.54-79.102). Le 12 juin 1956, secteur $11 \mathrm{~J} 2$, édifice 3, mur d'échiffre sud. Fragment de plaque en marbre blanc, brisé en haut, à droite et à gauche, mais dont le bord inférieur est conservé (fig. 82). Dimensions : haut. : 7,5 ; larg. : 7,5 ; ép. : 2,2 ; haut.d.1. : 1.1 : 1,2 (conservés) ; 1.2 : 2,3; interligne: 2,4. Lettres larges et pourvues d'empattements, mais qui semblent avoir été un peu irrégulières, à en juger d'après le $\mathrm{E}$, dont les barres ne sont pas rigoureusement parallèles, mais tendent à s'écarter. Point noté par Wuilleumier à la 1.2 , avant CE.

$$
\begin{aligned}
& \text { [-- -]MO[---] } \\
& \text { [Aul(erci) ?] Ce[nomani ? -.-]. } \\
& \text { "[A.... les Aulerques] Cénomans [...]." }
\end{aligned}
$$

L. 1 : MO, Wuilleumier, lecture qui paraît vraisemblable compte tenu des traces subsistant sur la pierre, en particulier la pointe inférieure centrale du M.

La restitution [Aul(erci)] est la plus rraisemblable et peut s'appuyer sur le parallèle d'ILTG, $346\left(n^{\circ} 4\right)$; elle reste cependant hypothétique, et d'autres compléments seraient possibles, comme par exemple [ciuitas] Ce[nomanorum]. Quelle que soit la formulation, il semble bien s'agir du nom de la cité des Cénomans, qui apparaît en position de dédicant et donc sans doute au nominatif à la dernière ligne de l'inscription,

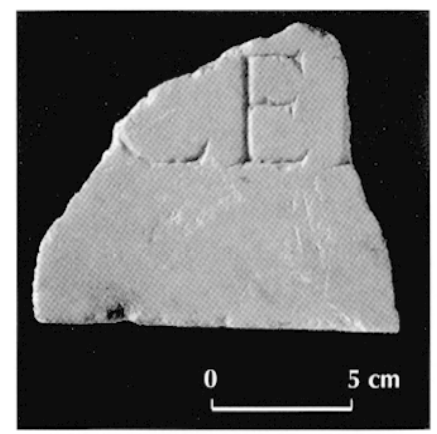

Fig. 83 - Dédicace faite par la cité des Cénomans.

comme dans ILTG, $346\left(\mathrm{n}^{\circ} 4\right)$, et dans deux des nouvelles plaques ( ${ }^{\circ} 6$ et 13). L'état fragmentaire du texte ne permet malheureusement pas de dire s'il s'agit d'une dédicace impériale, comme dans ILTG, 346 ( $\mathrm{n}^{\circ} 4$ ), ou d'une inscription honorifique en l'honneur d'un notable, comme dans au moins une des plaques $\left(\mathrm{n}^{\circ} 6\right)$. La date est, pour les mêmes raisons, très incertaine.

Inscription $n^{\circ} 13$ (inv. AL.05.97.460). Dans la cour au nord du pronaos du temple à podium (édifice 3), dans la couche supérieure de destruction (sondage 34 , us 484). Fragment de plaque en marbre blanc, brisé en haut, à droite et à gauche, mais dont le bord inférieur est conservé (fig. 83). Dans le côté inférieur, trou circulaire de $0,7 \mathrm{~cm}$ de diamètre pour la fixation de la plaque. Dimensions : haut. : 10,1; larg. : 12,5; ép. : 2,3; haut.d.1. : 3,6. Grandes lettres, hautes de $3,6 \mathrm{~cm}$, avec des empattements très soignés.

(.....

[Aul(erci) ?] Cen[omani ? -.--].

"[A... les Aulerques] Cénomans [...]. "

L. 1 : on ne voit de la troisième lettre qu'une haste verticale, avec l'extrémité des deux empattements.

Il s'agit probablement d'une inscription offerte par la cité des Cénomans, comme dans les fragments ILTG, 346 et $348 \mathrm{bis}$ d $\left(n^{\text {os }} 4\right.$ et 12 ) et la plaque $n^{\circ} 6$.

Inscription $\mathrm{n}^{\circ} 14$ (inv. AL.05.54-79.106). Le 22 janvier 1961, secteur 13 E 3, portique ouest, au sud de l'abside ouest. Fragment de plaque en marbre blanc, brisé en haut, à gauche et à droite, mais dont est conservé le bord inféricur, ainsi que la dernière ligne et le bas des lettres de l'avant-dernière (fig. 84). Dimensions : haut. : 10,8; larg. : 12,1 ; ép. : 1,4 ; haut.d.l. : 1,8. Lcttrcs trc̀s usées, comme l'ensemble de la plaque, qui présente une surface granuleuse.

$$
\begin{aligned}
& {[--]++++[---]} \\
& {[--d] e c r e u[i t ?---]}
\end{aligned}
$$

L. 1 : partie inférieure de quatre lettres non identifiables, sauf peut-être la deuxième, au-dessus du C, qui pourrait être un $\mathrm{V}$.

L. 2 : on reconnaît le bas d'un V à droite avant la cassure, ce qui invite à restituer, non [d]ecre[to decurionum], mais quelque chose comme [cui ? ---] decreu[it ?] ou decreu[erunt ?].

L'emploi du verbe decernere, à la dernière ligne, fait probablement allusion à la décision d'une assemblée municipale, qui 


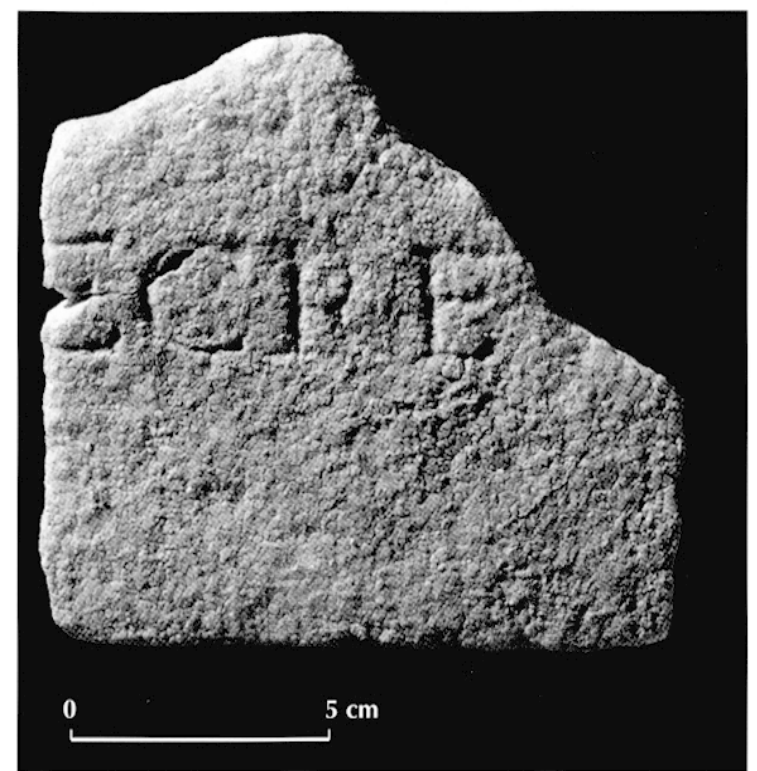

Fig. 84 - Fragment avec mention d'un décret (municipal ?).

pourrait être celle de la cité des Cénomans. Il est donc tentant d'attribuer cette inscription à un notable local, qui aurait pu être gratifié par l'ordo d'une fonction ou d'une magistrature, d'ornamenta ou plus simplement d'une statue ou d'autres honneurs. Mais nous sommes là dans le domaine de l'hypothèse, le décret pouvant se rapporter aussi à un personnage extérieur à la cité, à un simple particulier, ou encore à d'autres affaires.

\section{LE CULTE DE MARS MULLO}

Le sanctuaire gallo-romain est dès le $\mathrm{I}^{\mathrm{cr}} \mathrm{s}$. dédié à Mars identifié à un dieu gaulois Mullo dont on ignore tout, si ce n'est qu'il est honoré dans toute la région ; il est fortement associé au culte impérial et aux cités des Aulerques Cénomans, des Riédons et des Namnètes. La quinzaine de textes réunis est suffisamment fournie pour autoriser quelques observations qui complètent le dossier sur le culte de Mars Mullo ${ }^{99}$ (fig. 3).

La principale constatation est qu'il faut distinguer les trois bases à Mars Mullo ( $\left.\mathrm{n}^{\text {os }} 1-3\right)$, qui sont les monuments les plus anciennement connus et les seuls complets, et les fragments de plaque en marbre blanc, déjà pour une part connus depuis les années 1950, mais restés en partic inédits et dont le nombre et l'intérêt ont été complètement renouvelés depuis les découvertes intervenues à partir de 1994. Alors que les bases élevées à Mars Mullo sont le fait de personnes privées, même si l'une d'elles est un esclave public, un nombre significatif de plaques semble avoir été offert à titre public par la cité des Cénomans, dont le nom apparait dans au moins quatre textes $(n \% 4,6,12$ et 13, auxquels il faut sans doute ajouter le fragment $n^{\circ} 14$, qui fait mention d'une décision de l'assemblée). Une initiative publique est envisageable aussi pour la deuxième dédicace

99. Mowat, 1879 ; Ledru, 1911, p. 70-71 ; Térouanne, 1960 ; Meuret, 1993, p. 179-182; Naveau (dir.), 1998, p. 72, 74, 90 n" 288 ; Naveau, 2000. impériale $\left(\mathrm{n}^{\circ} 5\right)$, pour le second fragment de carrière sénatoriale $\left(n^{\circ} 7\right)$, ainsi que pour les notables municipaux $\left(n^{\prime *} 9-11\right)$. Certes, on ne peut exclure des monuments honorifiques qui auraient été élevés par des particuliers, mais il faut souligner qu'il n'y en a pas pour l'instant d'exemple sûr.

L'opposition se retrouve également dans la typologie des monuments (bases ou plaques), et dans leur chronologic, les bases datant du $\mathrm{I}^{\mathrm{er}} \mathrm{s}$., alors que les plaques nous orientent au plus tôt vers le milieu du II $^{*}$ s. et que les dates épigraphiquement les plus sûres sont de l'époque sévérienne. Cela recoupe bien les données archéologiques, puisque les bases, jetées au rebut dans un remblai, appartiennent à une phase plus ancienne du sanctuaire, tandis que les plaques peuvent être mises en relation avec la période de fonctionnement du temple à podium. Mais il ne faut pas en conclure que le culte de Mars Mullo, d'abord privé, serait devenu ensuite un culte public de la cité des Cénomans. Nous ne disposons en effet que de deux ensembles disjoints et l'un comme l'autre assez cohérents, qui ne sont qu'une toute petite partie de ce qu'était l'épigraphie du sanctuaire. Que l'on pense seulement à ce que devait être la dédicace du temple!

Un point paraît cependant avéré : le caractère public du culte de Mars Mullo, qui, à quelques kilomètres du centre politique du Mans, pourrait bien être, au moins aux II'-III" $s$. apr. J.-C., le sanctuaire principal de la cité des Cénomans. L'exemple parallèle de Rennes ${ }^{100}$, où Mars Mullo dispose en 135 d'un flamine et est honoré en même temps que les numina des pagi, va évidemment dans le même sens. Si le dossier rennais est beaucoup plus riche sur l'organisation institutionnelle du culte, la multitude des petits fragments d'Allonnes nous apporte un autre type d'informations, aussi précieuses, même si elles sont plus difficiles à décrypter. On observe ainsi que le sanctuaire abritait toute une série de dédicaces, non seulement aux empereurs et aux légats ou aux chevaliers romains, mais aussi sans doute aux notables locaux. Il serait intéressant d'en préciser l'aspect archéologique (s'agit-il de statues ou d'autres types de monuments ?) et la position relative dans le sanctuaire (cour, exèdres), et aussi d'observer si on trouve également des ex-voto privés, comme au $\mathrm{I}^{\mathrm{cr}} \mathrm{s}$. Malheureusement le dossier épigraphique ne fournit pas suffisamment de données sur ce point, et les seuls fidèles nommément connus sont les deux ou trois qui ont élevé les bases du $\mathrm{I}^{\mathrm{*r}} \mathrm{s}$. C'est là (provisoirement ?) une limite regrettable d'un ensemble qui est, notamment par le lien que l'on peut y faire entre documentations archéologique et épigraphique, un des plus intéressants que l'on possède en Gaule.

L'iconographie du $1^{\mathrm{cr}} \mathrm{s}$. est quasi absente excepté le personnage représenté sur le bloc $n^{\circ} 3$ : s'agit-il d'un Mars? Dans le sanctuaire du milieu du II $^{*}$ s., sous l'apparence d'unc grande diversité d'inspiration, les thèmes iconographiques retenus s'ordonnent autour de deux notions complémentaires correspondant sans doute aux deux aspects, guerrier et agraire, de Mars Mullo. Ce sont, d'une part, des motifs directement militaires qui illustrent les notions de virtus et de victoria (par exemple la frise d'armes de l'entablement de la cella circu-

100. CII. XIII, 3148, 3149, 3151; $A E, 1969-1970,405$ a-c (cf. Chastagnol, $1980=1995 \mathrm{~b})$. 


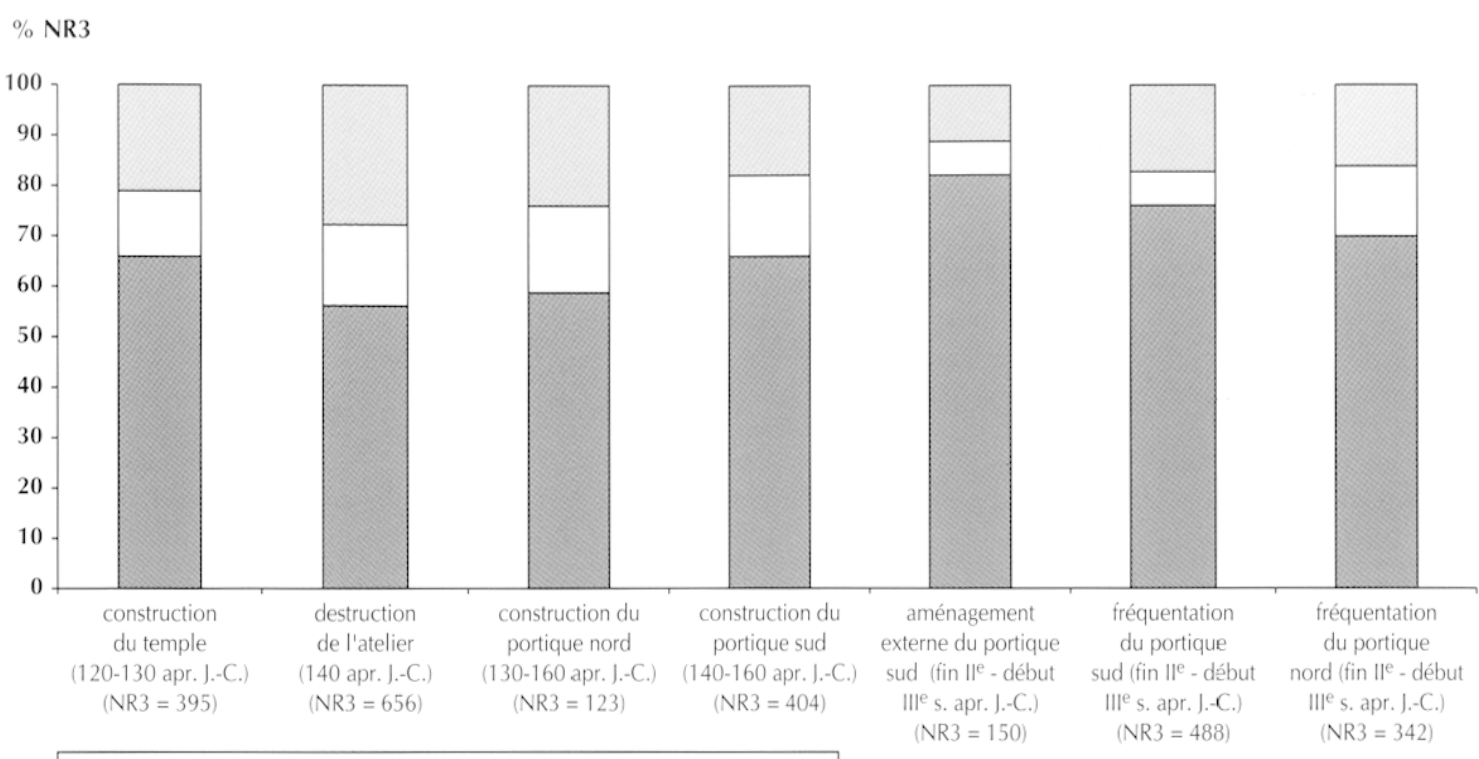

porc $\square$ bœuf $\square$ caprinés

laire) et, d'autre part, en contrepoint de cet aspect guerrier, le déploiement de toute une veine dionysiaque, non moins triomphale, en rapport avec la fécondité de la nature et la félicité. À la célébration de la virtus et de la victoria répond celle de l'abundantia et de la felicilas. Entre le victorieux et le fécond se tient Amor, démon ambigu. Ces notions qui sont au cœur de l'idéologie impériale sont assumées par un dieu polyvalent, promoteur de prospérité et protecteur de la communauté, rejoint par les empereurs dans la dévotion et les attentes des fidèles.

Les dédicaces $\mathrm{n}^{\circ} 1$ et 2 montrent une association entre le culte impérial et celui de Mars Mullo (Raepsaet-Charlier, 1993, p. 20-21 et n. 74). L'ordre varie entre les deux inscriptions d'Allonnes, alors qu'à Rennes Mars Mullo occupe toujours la première place. Les dédicaces offertes par la cité confirment le caractère officiel du culte. De nombreux monuments du culte impérial présentent des bassins autour ou devant le temple (Brouquier-Reddé, 2003), comme au temple de la Paix à Rome (Procope, Goth, IV, 21) ; Allonnes offre un exemple supplémentaire de fontaine dans un sanctuaire dédié à une divinité régionale associée au culte impérial.

\section{LA FAUNE DU SANCTUAIRE DE MARS MULLO}

Il ne semble pas que le dieu ait reçu des offrandes spécifiques. Les ossements prélevés sur le sanctuaire correspondent à des animaux domestiques et sauvages. S'y ajoutent des coquillages, des huîtres (Ostrea edulis), des coques (Cardium edule), des moules et des poissons avec quelques ossements de brochets (Esox lucius). Les vestiges de ces espèces se répartissent en nombre de restes (NR), en nombre de restes et en poids des restes des espèces de la triade: porc, bœuf, caprinés (NR3 et PR3) ${ }^{101}$.

101. La totalité du lot étudié représente 5538 ossements dont 2746 ont pu être déterminés.
Globalement, les restes osseux sont composés de manière ćcrasante par la triade porc, caprinés (moutons et chèvres), bœuf dans les niveaux liés à l'édification du monument et à sa fréquentation. Le porc domine très largement dans chaque niveau avec entre 55 et $73,8 \%$ du nombre de restes des espèces de la triade (fig. 85). Les caprinés viennent en deuxième position (entre 15,4 et $27,4 \%$ du NR3), suivis du bouf (entre 10,8 et $16,6 \%$ du NR3).

En poids des restes des espèces de la triade (PR3), la hiérarchie est bouleversée. Le porc reste l'espèce dominante, mais le bouf passe en seconde position au détriment des caprinés. Sans pouvoir chiffrer les apports respectifs en poids de viande, le poids des restes osseux donne tout de même une idée des masses de viande consommées (Chaix, Méniel, 1996, p. 57). L'alimentation carnée est donc basée en moyenne à $54,5 \%$ sur la viande de porc. Le bœuf intervient pour $33,8 \%$ en moyenne dans l'alimentation carnée et les caprinés à $11,7 \%$.

Outre ces espèces, quelques os épars de chien (us 370) et de cheval (us 512), sans traces de consommation, témoignent de la présence discrète ( $2 \%$ du NR) de ces animaux sur le site. Faisant l'objet d'un tabou alimentaire à la période galloromaine (Lepetz, 1996, p. 114) et n'étant donc plus consommés, il est logique que les os de ces deux espèces soient rares dans les nivcaux gallo-romains du sanctuaire de Mars Mullo.

Parmi les animaux de basse-cour, le coq domestique est le mieux représenté avec entre 2 et $8,5 \%$ du NR, suivi de l'oie (entre 1 et $5 \%$ ). Toutefois, ces deux espèces sont moins présentes dans les niveaux de destruction de l'édifice 6 pour le coq $(0,4 \%)$ et dans la fosse-dépotoir F 507 pour l'oic $(0,5 \%)$. Le canard colvert ainsi que le pigeon biset sont moins bien représentés (avec moins de $1 \%$ du NR), à l'exception des niveaux de fréquentation à l'extérieur de l'exèdre $\mathrm{A}$.

Pour la faune sauvage, le lièvre et le cerf sont les deux espèces les plus courantes sur le sanctuaire. La plupart des autres taxons (sanglier, bécasse des bois, grive musicienne) sont inférieurs à moins de $0,5 \%$ du NR. 


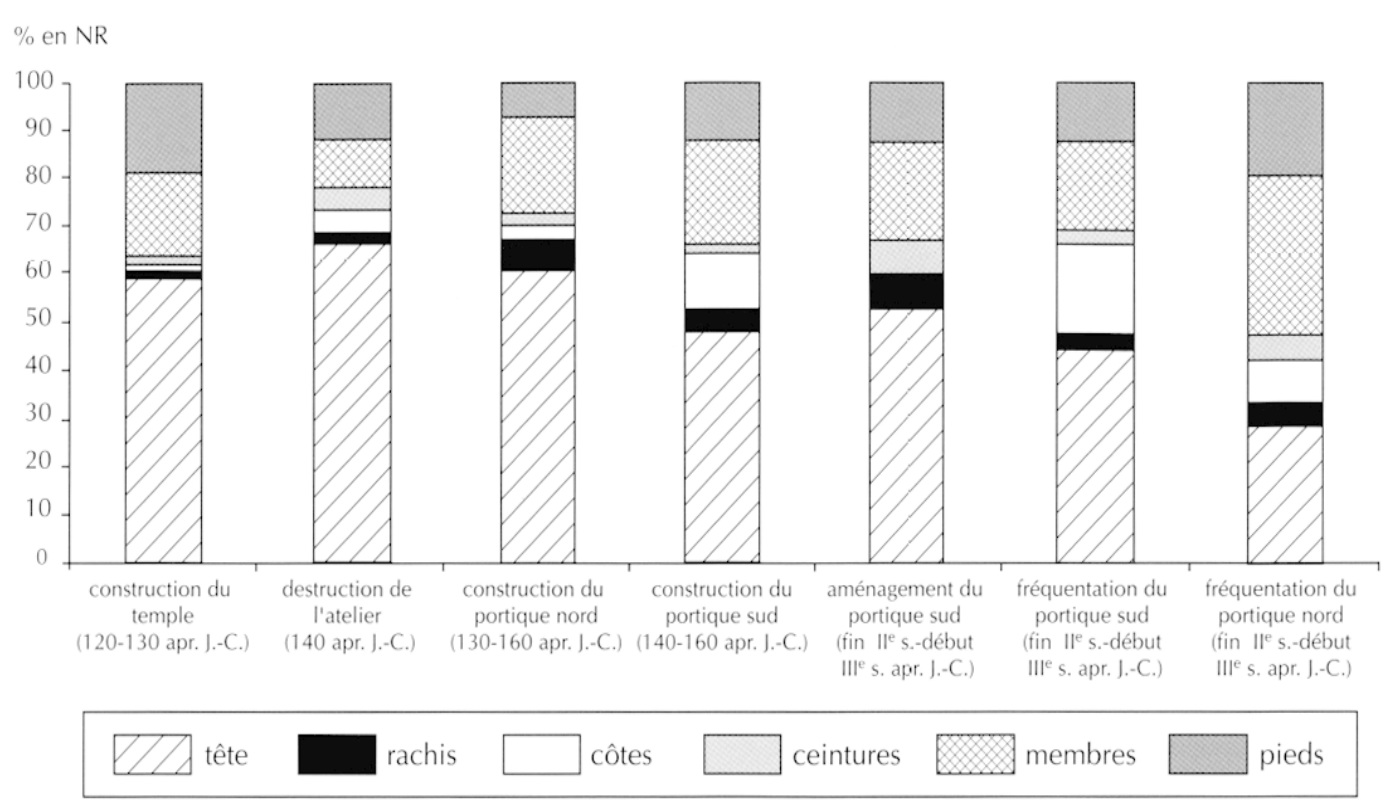

Fig. 86 - Répartition anatomique des caprinés.

À l'inverse des espèces de la triade, il existe une différence entre les niveaux de construction et de fréquentation du sanctuaire pour les espèces sauvages et les animaux de basse-cour. Les oiseaux domestiques et la faune sauvage sont peu présents dans les niveaux liés à la construction du temple, à la destruction des divers aménagements du chantier de construction (notamment de l'atelier du travail des métaux) et à l'édification du portique nord par rapport aux niveaux de fréquentation du sanctuaire. Cependant, il nous est impossible ici de dire si ces différences de fréquence des espèces sauvages et des animaux de basse-cour sont en relation directe avec le fait qu'il y ait deux phases distinctes.

Pour le porc, l'analyse de la répartition anatomique des os montre que, d'une manière générale, les membres sont les parties anatomiques les mieux représentées, suivis des pieds et de la tête. Les ceintures, les côtes et le rachis sont quasi absents. Pour les caprinés, la tête est l'élément le mieux représenté. Les membres viennent en deuxième position, suivis des pieds. Les ceintures, le rachis et les côtes sont plus faiblement représentés (fig. 86). Pour le bœuf, seuls les niveaux de fréquentation extérieurs à l'est de l'exèdre A ont fourni assez de restes osseux. Ces ossements montrent une présence quasi exclusive des pieds et des côtes. Tous les autres éléments du squelette sont souvent inférieurs à $10 \%$ du NR. Les autres niveaux, pour lesquels le nombre de restes est faible, tendent toutefois à montrer une répartition anatomique assez proche.

Dans l'ensemble, pour le porc (membres, pieds, têtes) et les caprinés (membres) les parties anatomiques présentes appartiennent à des morceaux riches en viande. Au contraire, pour le bœuf, les bas de pattes et les côtes correspondent à des déchets de boucherie, peu porteurs de viande, qui sont souvent éliminés (avec la tête) lors de la première phase de découpe de cet animal (Lignereux, Peters, 1996, p. 58). Nous pouvons nous demander pourquoi nous recensons autant de pieds de bœuf qui n'ont peu ou pas de valeur dans l'alimentation carnée, alors que les autres éléments riches en viande, tels que les membres, ne sont pas ou peu présents sur le sanctuaire ? Dans tous les cas, la présence de ces pieds et de ces côtes peut attester le fait que le sacrifice se soit déroulé dans le sanctuaire puisque nous retrouvons des éléments de la découpe primaire. La représentation des os des membres montre que seule une petite partie du bœuf a été consommée sur place et que le reste a pour l'essentiel été emporté ailleurs (fig. 87).

De tels exemples de sacrifices publics, où sacrifiants et sacrificateurs consommaient généralement leurs parts de l'animal sur place et la viande restante était vendue sur le lieu du sacrifice ou en boucheries aux autres citoyens, sont connus dans le monde antique et notamment à Rome (Scheid, 1998, p. 7980). Ces exemples pourraient peut-être expliquer ici la distribution des différentes parties anatomiques du bœuf sur le sanctuaire de Mars Mullo, mais la transposition dans l'ouest de la Gaule de ce qui se passe à Rome reste délicate. Toutefois, de telles sélections ont également été mises en évidence sur d'autres complexes cultuels gallo-romains comme sur le sanctuaire de La Bauve à Meaux (Magnan, Lepetz, 2002) ou celui du vicus de Jouars-Pontchartrain (Blin, Lepetz, 2002). Pour chacun d'entre eux, la répartition des restes osseux de bouf révèle également une nette sur-représentation des déchets de la découpe primaire (rachis et bas de patte) par rapport aux os longs, porteurs de viande (Lepetz, Van Andringa dir., 2002).

Sur 454 ossements de porc ${ }^{102}, 280$ proviennent de niveaux appartenant à la fréquentation du sanctuaire (fin $\mathrm{II}^{\mathrm{e}}$ s.-début III" s. apr. J.-C.) et 174 aux niveaux de construction de cet édifice cultuel (entre 120-160 apr. J.-C.). Dans les niveaux de fréquentation du sanctuaire, l'essentiel des animaux $(73,4 \%)$ est abattu avant 2,5 ans, soit au moment de la rentabilité bouchère maximale (Vigne, 1988, p. 133). Les porcs entre 2,5 et 4 ans

102. L'étude des âges d'abattage a été effectuée ici uniquement à partir de l'analyse des stades d'épiphysation. Seul le porc a fait l'objet d'une telle étude, les caprinés et le bouf n'ayant fourni qu'une très faible quantité de matériel osseux. 
représentent $13,9 \%$. Les individus réformés atteignent $12,7 \%$ des os étudiés. Dans les niveaux liés à la construction du sanctuaire (fig. 88), les animaux abattus avant 2,5 ans sont un peu moins nombreux $(63,6 \%)$. Les porcs tués entre 2,5 et 4 ans $(22,5 \%)$ sont plus présents que dans les niveaux de fréquentation. La proportion d'animaux réformés (13,9\%) est assez proche de celle des niveaux de fréquentation.

La faune du sanctuaire gallo-romain de Mars Mullo paraît donc assez homogène : le porc, le bœuf et les caprinés sont les espèces dominantes tout au long de l'occupation du monument. Quelques différences existent entre les niveaux de construction et de fréquentation du sanctuaire, notamment à travers les fréquences des espèces sauvages et des animaux de basse-cour. Toutefois, la distribution des parties anatomiques des espèces de la triade porc-bœuf-caprinés semble assez homogène sur l'ensemble du monument et ne met en évidence aucune opposition. Établir une distinction entre les rejets osseux provenant du chantier de construction et des niveaux de fréquentation liés au sanctuaire de Mars Mullo n'est donc pas aisé. Pour ces deux phases, les restes de porc et de caprinés renvoient avant tout à des déchets de préparation culinaire et à des reliefs de repas mêlés à des rejets de boucherie (bas de pattes et rachis de bœuf; têtes de caprinés) qui, d'un contexte à un autre, ne varient guère ici.

La représentation de toutes les pièces anatomiques pour le porc et les caprinés montre que la majeure partie de la viande devait être consommée sur place. À l'inverse, la présence d'éléments de la découpe primaire du boeuf au détriment des pièces de viande à haute valeur alimentaire semble indiquer que cet animal devait être abattu sur place, mais que certains morceaux ont été emportés à l'extérieur du sanctuaire (Brouquier-Reddé et al., 2002).

\section{OFFRANDES OU OBJETS DOMESTIQUES}

Comment évaluer sur un site de sanctuaire comme celui-ci ce qui est de l'ordre du religieux et ce qui est de l'ordre de l'économique?

Dans le cas présent, les inscriptions, l'iconographie, la gestion de l'espace apportent un certain nombre de réponses sur les divinités honorées, les thèmes mythologiques associés, la qualité des donateurs, la fréquentation du sanctuaire. Dédicaces et programmes iconographiques restent donc fondamentaux pour comprendre la religion et identifier les dieux honorés. Les rites, eux, se codifient à travers un usage spécifique d'objets de la vie quotidienne. C'est ce petit écart à la norme qu'il faut appréhender. Ici, l'occupation longue du sanctuaire, l'identification parfaitement individualisée, dans le temps et l'espace, de zones profanes (les ateliers de construction) montrent à la fois une évolution des rituels entre les périodes gauloise, julioclaudienne et antonine et quelques différences entre usage sacré et usage marchand.

La distribution des monnaies dans le sanctuaire montre une évolution entre les rites d'offrandes monétaires, la iactatio stipis de la fin de l'Indépendance gauloise et de l'époque augustéenne (Van Andringa, 2002, p. 120-121), et les pertes de pièces des II $^{\mathrm{e}}-\mathrm{III}^{\mathrm{e}}$ s. apr. J.-C., dans la cour, les portiques, les entrées qui dénotent plutôt d'une activité monétaire sur et autour du sanc-

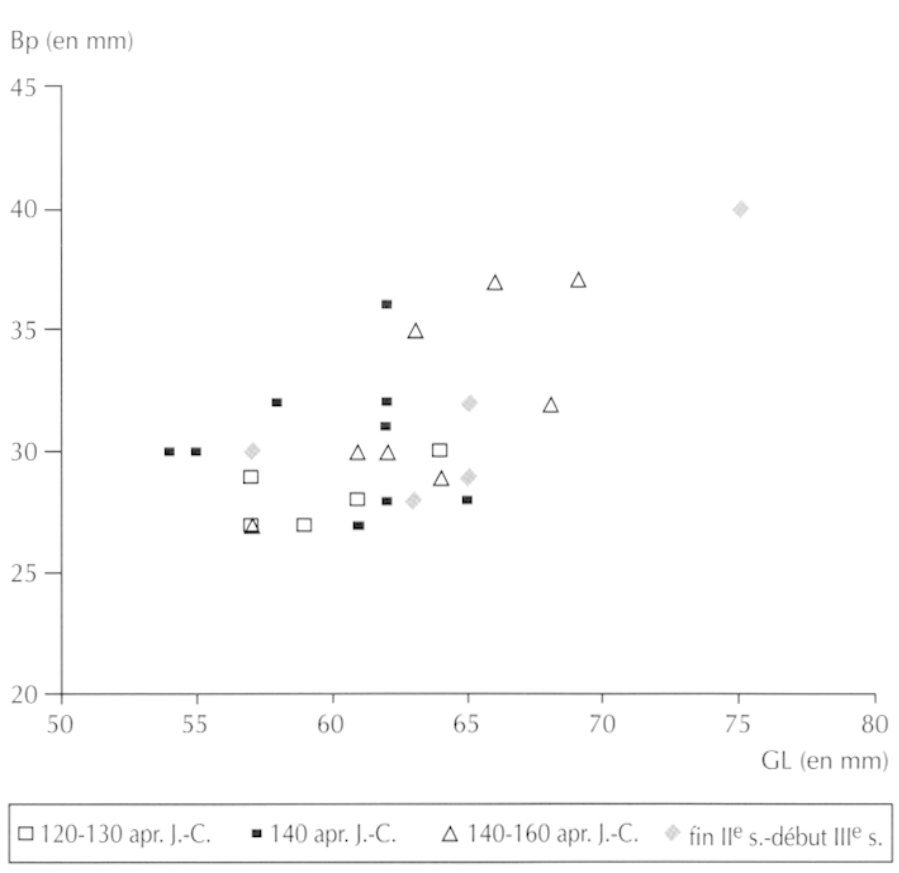

Fig. 87 - Distribution des phalanges I de boxuf.

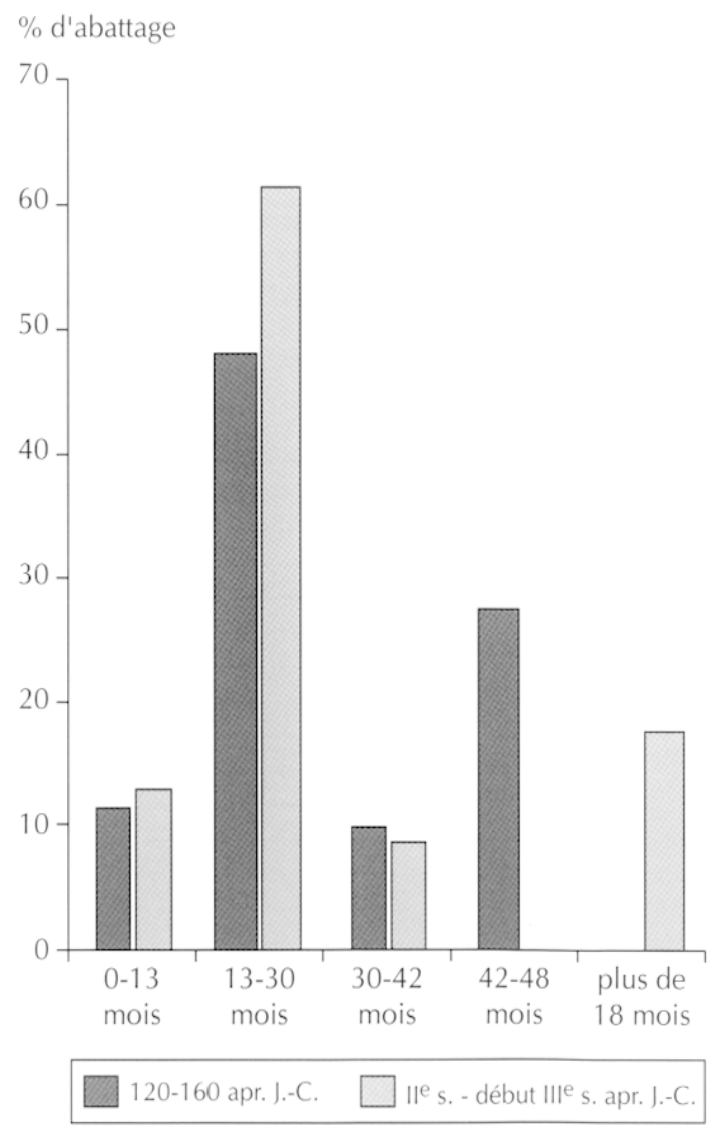

Fig. 88 - Âges d'abattage du porc pendant la construction du sanctuaire (120-160 apr: J.-C.) et pendant la fréquentation du sanctuaire (fin II' s.-début III' s. apr:J.-C.). 
Tabl. V - Liste des graffites sur céramique.

\begin{tabular}{|c|c|c|c|}
\hline $\mathrm{N}^{\circ}$ d'attribution & Support & Graphie proposée & Nature \\
\hline Al-graf-001 & sur panse de cruche & ].ATELLUM.[ & appartenance \\
\hline Al-graf-002 & sous col de cruche & |VITALIS| & appartenance \\
\hline Al-graf-003 & sur panse de cruche & |CAT.| & appartenance \\
\hline Al-graf-004 & sur panse de cruche & JFELIX.[ & appartenance \\
\hline Al-graf-005 & sur panse de cruche & ]COM.I & appartenance \\
\hline Al-graf-006 & sur panse de cruche & |CAR.I & appartenance \\
\hline Al-graf-007 & proche du fond de pot à cuire & JDOGE.| & appartenance \\
\hline Al-graf-008 & sur panse de pot & |DEGUMVS| & appartenance \\
\hline Al-graf-009 & sur panse de cruche & ICA.I & appartenance \\
\hline Al-graf-010 & proche du fond de mortier & INICCU.I & appartenance \\
\hline Al-graf-011 & sur panse de cruche & ].TIAES | & appartenance \\
\hline Al-graf-012 & sur panse de cruche & I.A.LIS[ & appartenance \\
\hline Al-graf-013 & sur panse de cruche & IMATERNUSI & appartenance \\
\hline Al-graf-014 & proche du fond de cruche & IPOTAE! (ivrogne) & appartenance \\
\hline Al-graf-015 & sur panse de cruche & $|\mathrm{AS}|$ & appartenance \\
\hline Al-graf-016 & sur panse de cruche & ISABINUS[ & appartenance \\
\hline Al-graf-017 & sur panse de cruche & JORBISSA[ (héritier) & appartenance \\
\hline Al-graf-018 & sur lèvre de pot à cuire & IIIXI[ & numéraire \\
\hline Al-graf-019 & sur panse de G. 4? & ].INALIS S. XI et MAT.I & contenu et numéraire \\
\hline Al-graf-020 & sur panse de cruche & ].NI.[ & indéterminé \\
\hline Al-graf-021 & sur panse de pot à cuire & $?$ & indéterminé \\
\hline Al-graf-022 & sur panse de cruche & ].R. [ & indéterminé \\
\hline Al-graf-023 & sur panse de cruche & ].N.I & indéterminé \\
\hline Al-graf-024 & sur panse de cruche & ].N.I & indéterminé \\
\hline Al-graf-025 & sur panse de cruche & ].CO.I & indéterminé \\
\hline Al-graf-026 & sur panse de cruche & I.R.I & indéterminé \\
\hline Al-graf-027 & sur fond & 15.1 & indéterminé \\
\hline Al-graf-028 & proche du fond d'une coupelle & I.NA.I & indéterminé \\
\hline Al-graf-029 & sur panse de cruche & ].IP.[ & indéterminé \\
\hline Al-graf-030 & sur panse de cruche & I.USI & indéterminé \\
\hline Al-graf-031 & sur panse de cruche & ].MUS[ & indéterminé \\
\hline Al-graf-032 & sur panse de cruche & ].NIA. [ & indéterminé \\
\hline Al-graf-033 & sur panse de cruche & I.ATE. [ & indéterminé \\
\hline Al-graf-034 & sous col d'amphore & $?$ & indéterminé \\
\hline Al-graf-035 & sous la collerette de bol & IEUI & indéterminé \\
\hline Al-graf-036 & sur panse de cruche & & indéterminé \\
\hline Al-graf-037 & sur panse de cruche & $?$ & indéterminé \\
\hline Al-graf-038 & proche du fond de cruche & JEU| & indéterminé \\
\hline Al-graf-039 & sur panse de cruche & ].ISOL.[ & indéterminé \\
\hline Al-graf-040 & sur panse de cruche & ].UNCE.I? & indéterminé \\
\hline Al-graf-041 & sur panse de cruche & & graphique \\
\hline Al-graf-042 & sur panse de cruche & ]IIIIIII [ & graphique (?) \\
\hline Al-graf-043 & sur panse de cruche & $|I I I|$ & graphique (?) \\
\hline Al-graf-044 & sur panse de cruche & & graphique \\
\hline Al-graf-045 & sur panse de cruche & & graphique d'un animal \\
\hline Al-graf-046 & près de l'anse d'une cruche & & graphique \\
\hline Al-graf-047 & sur panse de cruche & & graphique \\
\hline Al-graf-048 & sur fond de cruche & & graphique \\
\hline Al-graf-049 & sur panse de cruche & & graphique \\
\hline Al-graf-050 & sur panse de I'amphore Dr. 20 & & graphique \\
\hline Al-graf-051 & sur panse de cruche & ]MI.[? & indéterminé \\
\hline Al-graf-052 & sur panse de cruche & ].A.V.[ & indéterminé \\
\hline Al-graf-053 & sur panse de cruche & IM.I & indéterminé \\
\hline Al-graf-054 & sur panse d'amphore G. 12 & ].AD. I & indéterminé \\
\hline Al-graf-055 & sur panse de cruche & ].|IIIIIIIIIIIIIII.| & indéterminé \\
\hline Al-graf-056 & sur panse de cruche & & graphique \\
\hline Al-graf-057 & sur panse de cruche & & graphique (yeux) \\
\hline
\end{tabular}

tuaire. Les monnaies se concentrent autour de l'édifice 1, en grande quantité, seules ou par lot. Les monnaies sont des offrandes au même titre que les armes de la période précédente et on peut parler de dépôts votifs (Aubin, 1994; Gruel, à paraître b). La proportion de monnaies en circulation a plutôt tendance à augmenter pendant les travaux. Aux $\mathrm{II}^{\circ}-11 \mathrm{I}^{\prime \prime} \mathrm{s}$. apr. J.-C., les monnaies circulent dans le sanctuaire et une partie est perdue essentiellement dans les lieux de déambulation, avec des proportions comparables à l'intérieur et à l'extérieur. Rien n'indique un usage rituel ; en revanche, tout prouve un usage 
important de la monnaie sur le lieu de culte et conforte son rôle économique. Les modifications observées semblent plus être des marqueurs de la prospérité du sanctuaire qui apparaît comme un des centres de l'économic régionale, licu d'échanges et de tractations diverses, et lieu de vie des fidèles, qui y prient mais aussi y dépensent, y mangent. On achète et on vend des services, des offrandes, de la nourriture...

L'étude de la faune montre cette même ambivalence. Les os restent les mêmes que le festin soit rituel ou non. Malgré tout, les animaux dominants sont ceux de la triade bœuf, porc et caprinés. Ils sont abattus sur place comme l'atteste l'abondance des pieds de bouf, ce qui renvoie aux scènes de sacrifices connues par l'iconographie et les textes latins. On remarque une légère différence de l'âge des animaux, du choix des morceaux, et entre l'alimentation des ouvriers du chantier et celle des fidèles. Dans ce domaine encore, il semble que le sanctuaire joue un rôle dans la distribution de la viande carnée, car certains morceaux des animaux manquent systématiquement, qu'ils soient brûlés ou, plus probablement, distribués ou vendus à l'extérieur. La succession de phases profanes (reconstruction) et religieuses sur le sanctuaire montre la difficulté d'identification d'un usage rituel des mobiliers découverts. Banquets sacrés ou repas des ouvriers, la vaisselle utilisée (sigillée ou commune) ne change pas. La vaisselle céramique est indispensable pour stocker et présenter les offrandes. Il est cependant difficile de distinguer la vaisselle de table ordinaire de celle des banquets sacrés. On constate pourtant statistiquement une proportion plus élevée d'assiettes, plats, coupes et coupelles du $\mathrm{I}^{\mathrm{er}} \mathrm{s}$. jusqu'au milicu du II" s., et à l'inverse plus de mortiers et de formes fermées entre le milieu du II" $^{\prime \prime}$. et le III" $s$. Les graffites relevés sur les céramiques de l'atelier du travail des métaux et de la fosse-dépotoir F 507 du chantier de construction du temple renvoient à un usage domestique, marquant l'appartenance du vase à un individu qui y a inscrit son nom ou plus rarement la contenance (tabl. V; fig. $47 \mathrm{n}^{\circ} 10$ et fig. $50 \mathrm{n}^{\circ} 10$ ) (Gruel, Brouquier-Reddé dir., 2003, p. 162 et 168-169 n" 284 288 ; Guillier, Thauré, 2003).

\section{$* *$}

Les fouilles programmées de ce site ${ }^{10 ! 3}$, connu par les travaux et les trouvailles de P. Térouanne, ont apporté, depuis 1994, une nouvelle documentation aussi bien sur l'époque laténieme et le mobilier métallique que sur l'architecture et le matériel de ce grand sanctuaire romain. Cette recherche est menée parallèlement à d'autres programmes d'étude des sanctuaires romains entrepris à Alba, Barzan, Chateaubleau, Chartres, Corseul, Jublains, La Bauve à Meaux, Ribemont-surAncre, Vicil-Évreux... Des études plus spécifiques sur les temples à cella circulaire (Bost, Girardy dir., sous presse), sur les sacrifices dans les sanctuaires romains (Lepetz, Van Andringa dir., 2002) et sur l'évolution des sites entre les périodes laténienne et romaine, en particulier en Gaule belgique (Ribe-

103. La fouille programmée d'Allonnes est gérée par le CNRS, dans le cadre d'une convention recherche, associant le Service régional des Pars de la loire du ministère de la Culture, le CXRS, l'ENS, la mairie d:Allonnes, la communauté urbaine du Mans et le Conseil général de la Sarthe.
mont-sur-Ancre), permettent de confronter les résultats et dc mesurer les apports de la recherche menée sur Allonnes.

Le site laténien d'Allonnes montre, sinon l'existence de lieux de culte à une date fort ancienne, antérieure de plus d'un siècle aux grands ensembles rituels du nord de la France, du moins une fréquentation plus importante et plus précoce qu'on ne l'a cru. Sans préjuger de la nature de l'occupation à une date aussi haute, il n'est pas sans intérêt de constater que c'est sur les vestiges de ces dépôts métalliques aux couleurs guerrières qu'ont été érigés certains grands sanctuaires d'époque romaine. C'est aussi très probablement le cas du sanctuaire du Moulin-duFâ à Barzan en Charente-Maritime. Si l'ensemble daté de La Tène B2-début $\mathrm{Cl}$ est dominé par les armes, et celui de La Tène D2 par les monnaies, il est plus difficile de se prononcer sur le sens des " dépôts " antérieurs et postérieurs, et sur la nature de l'occupation. La construction à l'époque romaine d'un important sanctuaire, et les analogies qu'il présente avec les lieux de culte à dépôts d'armes du nord et de l'ouest de la France, permettent d'envisager, avec asse\% de vraisemblance, l'existence à Allonnes d'un lieu consacré, fréquenté à différentes époques. La documentation actuellement disponible ne permet cependant pas de préciser s'il s'agit d'un véritable sanctuaire comme celui de Gournay-sur-Aronde ou d'un complexe de type trophée/complexe religieux comme à Ribemont-sur-Ancre. Le faciès monétaire de la fin de l'époque gauloise montre l'importance du monument cultuel allonnais dont les vestiges sont mal connus. Contrairement à la plupart des édifices de la même période, les provenances dépassent largement la région et attestent la réalité de contacts avec le sud de la Gaule et de liens avec les cités du centre-ouest et du centreest. Les deniers gaulois associés à des éléments d'équipement militaire romain sont peut-être même le signe d'une fréquentation du temple par des auxiliaires gaulois de l'armée romaine. En effet, ces pièces sont régulièrement découvertes hors de leur zone d'émission en association avec des deniers romains (Gruel, à paraître $\mathrm{b}$ ) .

Les dédicaces à Mars Mullo et à l'empereur font la spécificité du temple romano-celtique parmi la multitude de ces édifices reconnus en Gaule. Les vestiges dégagés par P. Térouanne ont été identifiés en 1994 et placés en relation avec ces bases du I ${ }^{\mathrm{ct}} \mathrm{s}$. apr. J.-C. Des personnages privés et un esclave public sont les seuls dédicants connus. Ce n'est qu'avec sa reconstruction, à partir du milieu du II $^{\mathrm{e}}$ s., que le monument apparaît comme l'un des sanctuaires publics de la civitas des Aulerques Cénomans avec plusieurs inscriptions sur plaque, dont la plus longue à un gouverneur de Lyonnaise, affirmant ainsi le rôle politique du sanctuaire, à proximité de la capitale politique du Mans. Cette situation topographique est similaire à celle de Trèves, Allonnes n'est qu'à $5 \mathrm{~km}$ du Mans et la butte des Fondues, où est installé le sanctuaire, est visible de la butte du Vieux-Mans et d'une partie de la vallée de la Sarthe.

Allonnes fait partie de ces vastes programmes architecturaux du II s. apr. J.-C., observés aussi bien ici en Gaule lyonnaise qu'en Gaule belgique (Ribemont-sur-Ancre) et en Aquitaine (Barzan). L'une des particularités archéologiques du sanctuaire de Mars Mullo est d'avoir conservé les vestiges du chantier de construction du temple à podium et en particulier l'atelier lapidaire et l'atelier du travail des métaux. La fouille extensive 
de ces niveaux a pu mettre en évidence des structures temporaires, y compris des trous d'échafaudage, souvent passées inaperçues dans de nombreux sites, en raison de sondages limités. Le temple est construit d'après un modèle, fréquent dans l'ouest et le sud-ouest de la Gaule, mais également adopté à l'extérieur de cette zone: Avenches, Alise-Sainte-Reine... La restitution proposée s'appuie sur les vestiges archéologiques et sur les blocs épars. Les nouvelles recherches en cours à Périgueux et à Barzan permettront de l'affiner. La richesse de la décoration du quadriportique est reconstituée à partir des peintures murales et des revêtements d'applique muraux. La vaste cour n'est pas un espace vide, bases de statues ou d'autels et fontaine hexagonale font partie des aménagements indispensables au rituel. Les quelques nouvelles découvertes d'offrandes de statuettes mises en relation avec des bases encadrant la porte orientale, côté cour, n'éclairent guère sur les attributions de la divinité Mars Mullo.

Ainsi le site de La Forêterie, tout au long de ses huit siècles d'existence ( $V^{c}$ s. av. J.-C. - I $V^{c}$ s. apr. J.-C.), vit au rythme de la cité des Aulerques Cénomans. Il connaît des phases de fréquentation importantes à $\mathrm{La}$ Tène $\mathrm{B} 2 / \mathrm{C} 2$, à la fin de l'Indépendance gauloise, sous les Julio-Claudiens, et aux II ${ }^{\mathrm{e}}-\mathrm{III}^{\mathrm{e}} \mathrm{s}$. apr. J.-C. La prospérité de la cité voisine suscite des programmes de reconstruction et d'embellissements successifs. Le dernier, mieux connu par les résultats des fouilles actuelles, s'inscrit dans un agrandissement parallèle de la ville de Vindinum, toute proche. La baisse de sa fréquentation à la fin du III $^{\mathrm{e}} \mathrm{s}$. et au début $d u I^{*} s$. correspond probablement à une désaffection progressive du sanctuaire tandis que la capitale des Aulerques Cénomans s' est repliée derrière ses murailles. Le sanctuaire est définitivement fermé au milieu du $\mathrm{IV}^{\mathrm{e}} \mathrm{s}$. Les travaux de récupération des matériaux ont largement contribué à enlever toute trace d'une éventuelle réoccupation du site. La poursuite des fouilles ne pourra qu'apporter de nouvelles données sur le sanctuaire du $\mathrm{I}^{\mathrm{er}} \mathrm{s}$. apr. J.-C. et le site laténien. Nos connaissances sur les abords immédiats du sanctuaire restent, elles aussi, encore limitées et devraient s'enrichir à l'occasion de fouilles à venir.

\author{
Liste des auteurs de l'UMR 8546 du CNRS et de l'ENS : “ Archéologies d'Orient et d'Occident ", \\ École normale supérieure, 45 rue d'Ulm, F-75230 Paris Cedex 05 \\ Claudine Al.tac; CNRS (enduits peints). \\ Bruno BAZIN, doctorant (céramique). \\ François BÉRARI), université de Lyon III (épigraphie). \\ Estelle BERTRAND, université du Maine (assistante de fouilles). \\ Véronique BROUQUIER-REDDÉ, CNRS (coresponsable de l'opération). \\ Richard DEIAGE, postdoctorant (sigillée). \\ Vincent DROST, doctorant (numismatique romaine). \\ Katherine GRUEL, CNRS (responsable de l'opération, numismatique gauloise). \\ Françoise GLRY, CNRS (iconographie). \\ Thierry LejaRs, CNRS (mobilier laténien). \\ Cathy LEFÈvRE, architecte (relevés architecturaux). \\ Christophe LoIsEAL, doctorant (matériel métallique romain). \\ Frédéric PoLPON, doctorant (ossements animaux).
}

\title{
Liste des auteurs associés
}

Vincent BERNOL.LIN, ville d'Allonnes (assistant de fouilles).

Sébastien CoRmire, ville d'Allonnes (assistant de fouilles).

Arnaud COUTELAS, postdoctorant (mortiers).

Georges DePEIROT, CNRS (numismatique romaine).

Jean-Paul GUILAUME:, CNRS (atelier artisanal).

\author{
Assistance technique de l'UMR 8546 du CNRS et de l'ENS \\ Christophe BAIL.I (infographiste). \\ Marie-Bernadette ChaRdinoux (documentaliste). \\ Philippe Delancile (photographe). \\ Philippe MARTINEZ (infographiste). \\ François ORY (dessinateur).

\section{Crédit des illustrations} \\ UMR 8546 du CNRS, sauf fig. 4 et 20 n" 3. \\ C. AlliAg; : 58-59. \\ C. BAIL.Ly (DAO) : 2-3, 5, 7, 20-22, 24-25, 28, 33, 33-36, 40-41, 45, 56-57, $65,76$. \\ B. BAZIN (dessins et DAO) : 46-48, 50-51, 63-64, 67-70. \\ F. BÉRARD : 76.
}




\title{
BIBLIOGRAPHIE
}

\author{
Abréviations \\ $A E$ \\ AFAN \\ BAR \\ BJ \\ $C A G$ \\ CIL \\ DA \\ DAF \\ Espérandieu \\ IIA \\ ILS \\ ILTG \\ IIIMC \\ LT \\ $R M D$ \\ SFECAG

\section{L'Année éprigraphique.} \\ Association pour les fouilles archéologiques nationales. \\ British Archaeological Reports. \\ Bonner Jahrbücher: \\ Carte archéologique de la Gaule. \\ Corpus Inscriptionum Latinarum (voir Hirshfeld, Zangemeister, Bohn). \\ Dictionnaire des Antiquités grecques et romaines d'après les texles et les monuments \\ (voir Daremberg, Saglio, Pottier). \\ Documents d'archéologie française. \\ Recueil général des bas-reliefs de la Gaule romaine. \\ Inscriptions latines d'Aquitaine (voir Maurin, Thauré). \\ Inscriptiones Latinae Selectae (voir Dessau). \\ Inscriptions latines des Trois Gaules (voir Wuilleumier). \\ Lexicon Iconographicum Mythologiae Classicae. \\ La Tour. \\ Roman Military Diplomas (voir Roxan). \\ Société française d'ètude de la cèramique antique en Gaule.
}

\section{ADAM J.-P., VARÈNE P.}

1980 : «Une peinture romaine représentant une scène de chantier ", Revue archéologique, 2, p. 213-238

allain J., Fauduet I., Tufreau-Libre M.

1992 : La nécropole gallo-romaine du Champ de l'image à Argentomagus (Saint-Marcel, Indre), Saint-Marcel, musée d'Argentomagus, Mémoires du musée d'Argentomagus, 1 (coll. Suppl. à la Revue archéologique du Centre, 3), $237 \mathrm{p}$.

AMy R., Gros P.

1979 : La Maison Carrée de Nìmes, Paris, éd. du CNRS (coll. Suppl. à Gallia, XXXVIII), 2 vol., 211 p., $82 \mathrm{pl}$.

Aubin G.

1994 : "Répertoire des séries attribuées aux Cénomans ", in BarRandoN J.-N. IET A $I$. (DIR.), L'or gaulois -4- Le trésor de Chevanceaux et les monnayages de la fafade atlantique, Paris, CNRS Editions (coll. Cahiers Ernest-Babelon, 6), p. 249-258.

1997 : « Le mobilier du sanctuaire de Jublains -1- Les monnaies ", in NAVEAC J. (DIR.), Recherches sur Jublains (Mayenne) et sur la cilé des Diablintes, Rennes, Association pour la diffusion des recherches archéologiques dans l'ouest de la France (coll. Documents archéologiques de l'Ouest), p. 215-222.

AUBIN G. (DIR.)

1980 : Vingt-cinq années d'archéologie galloromaine, Nantes, Direction régionale des Affaires culturelles des Pays de Loire et musées, $291 \mathrm{p}$

\section{Aubin G., Meissonier J.}

1994 : «L'usage de la monnaie sur les sites de sanctuaires de l'ouest de la Gaule et de la Bourgogne ", in Goudinfal C., Fauduet I., Coul.on G. (DIR.), Les sanctuaires de tradition indigène en Gaule romaine, Actes du colloque d'Argentomagus (Argenton-
sur-Creuse/Saint-Marcel, Indre), 8-10 oct. 1992, Paris éd. Errance et musée d'Argentomagus, p. 143-152.

Audra A., Mathey P.

1992 : Monnaies romaines. Archéologie et numismatique à Lyon (fr s. av. J.-C., IIr s. apr. J.-C.), Lyon, Association lyonnaise pour la promotion de l'archéologie en RhôneAlpes, $81 \mathrm{p}$.

AUPERT P. (DIR.)

1997 : Le site archéologique de Barzan, "Le Moulin-du-Fâ ", Charente-Maritime, Saint-Jean-d'Angély, ASSA Barzan (coll. Guides archéologiques de la France), $30 \mathrm{p}$. Aupert P., Hiernard J., Finckert M.

1992 : Sanxay : un grand sanctuaire rural galloromain, Paris, Imprimerie nationale (coll. Guides archéologiques de la France, 25), $114 \mathrm{p}$.

AYMARD J.

1951: Les chasses romaines des origines à la fin $d u$ siècle des Antonins, Paris, De Boccard, $610 \mathrm{p}$.

Badie A., Sablayrolles R., Schenck J.-L.

1994 : Saint-Bertrand-de-Comminges -1- Le temple $d u$ forum et le monument à enceinte circulaire, Bordeaux, éd. de la Fédération Aquitania, $224 \mathrm{p}$.

Baratte F., MetzGer C. (DiR.)

1985: Musée du Louvre. Catalogue des sarcophages en pierre d'époques romaine et paléochrétienne, Paris, éd. de la Réunion des musées nationaux, $337 \mathrm{p}$.

BARBET A., Miniero P.

1999 : La villa San Marco a Stabia, Naples, Centre Jean-Bérard (coll. du Centre JeanBérard, 18), Rome, École française de Rome (coll. de l'École française de Rome, 258), Pompéi, Soprintendenza archeologia di Pompei, 3 vol.

\section{BARTHÉLÉMY F.}

1995 : "Les potins "à la tête diabolique" ", in
GRtFI. K. (DIR.), «Dossier : Les potins gaulois, typologie, diffusion, chronologie, état de la question à partir de plusieurs contributions ", Gallia, 52, p. 27-36.

Basalo L.

1944 : “Le temple du Moulin du Fâ à Barzan, près de Talmont-sur-Gironde ", Gallia, II, p. 143-165.

BaUCHHENSS G.

1984 : “ Ares/Mars ", LIMC, II, p. 559-580.

BÉRARD F.

À paraître : "Un nouveau cursus sénatorial à Allonnes (Sarthe) ", communication à la $X I^{r}$ rencontre sur l'épigraphie du monde romain, Rome, mai 2002, Rome (coll. Mélanges de l'École française de Rome, série Antiquité).

BERNIER N., BÉrard F., BROUQUier-REDDÉ V., Cormier S., Gruel K.

2002 : « 003. Allonnes », in BOLVET J.-P. (DIR.), La Sarthe, 72, Paris, Académie des inscriptions et belles-lettres (coll. $C A G$ ), p. 104137.

\section{BESOMBES P.-A.}

2001 : "Les monnaies de Monterfil II ", in KFRÉBFI. H. (DIR.), Les fouilles de Monterfil II à Corseul (Côtes-d'Armor). Étude d'un quartier de la ville antique, Paris, Maison des sciences de l'homme (coll. DAF, 88), p. 208-255.

BET P.

1988: Groupes de production et potiers à Lezoux (63) durant la période gallo-romaine, Mémoire de l'École pratique des hautes études, IV" section, Paris, 9 vol.

\section{Bet P., Delor A.}

2000 : "La typologie de la sigillée lisse de Lezoux et de la Gaule centrale du HautEmpire, révision décennale ", in RJVET $\mathrm{L}$. (DIR.), Actes du congrès de la SFECAG, Libourne, 1-4 juin 2000, p. 461-484. 
Bet P., Fenet A., Montinéri D.

1989 : " La typologie de la sigillée lisse de Lezoux, $\mathrm{I}^{\mathrm{IT}}-\mathrm{III}^{\mathrm{l}} \mathrm{s}$. Considérations générales et formes inédites ", in RIVET L. (DIR.), Actes du congrès de la SFECAC; lezoux, 47 mai 1989, p. 37-54.

Bet P., Henrique-Raba C.

1989 : "Les céramiques à parois fines de Lezoux ", in Rivkt L. (IIr.), Actes du congrès de la SFECAG, Lezoux, 4-7 mai 1989, p. 21-29.

BIARNE J. (DIR.)

1974 : Allonnes dans l'Antiquilé, Le Mans, Publication de la Faculté des lettres et sciences humaines du centre universitaire du Mans, $132 \mathrm{p}$.

Blanc N., Gury F.

1986 : "Eros/Amor, Cupido ", I.IMC; III, p. $952-1049$.

BLAZQuEZ J. M.

1986 : “ Bellona ", IIMC, III, p. 92-93.

Bun O., LePETZ S.

2002 : "Un sanctuaire du vicus de JouarsPontchartrain, cité des Carnutes : rituels et vestiges matériels ", in L.F.PFT\% S., VAn ANidringa W. (DIR.), Pré-acles de la Table ronde: "Archéologie du sacrifice animal en Gaule romaine. Rituels el pratiques alimentaires ", Paris, Muséum national d'histoire naturelle, 24-25 oct. 2002, p. 40-42 [Actes, à paraître].

Bloemers J. H. F., Sarfatij A.

1976 : « Roman Settlement at De Wocrd, Valkenburg (South Holland), Report I : the Potter's Stamps ", Berichten van de Rijksdienst voor het Oudheidkundig Bodemonderzoek, 26, p. 133-161.

BoARDMAN J., ARRIGONI G.

1984 : «Atalante », LIMC, II, p. 940-950.

BoNNAMOUR L. (DIR.)

1990 : Du silex à la poudre, 4000 ans d'armement en Val de Saône, Catalogue d'exposition, musée de Chalon-sur-Saône 1990-1991, Montagnac, Monique Mergoil, $196 \mathrm{p}$.

BOST J.-P., GIRARDY C. (DIR.)

Sous presse: Table ronde sur les temples circulaires, Bordeaux, Maison de larchéologie, 23 nov. 2002, Aquitania.

BOÜARD M. DE

1962 : «Informations archéologiques ", Callia, $\mathrm{XX}, 2$, p. $427-429$.

BOUCHER S.

1976 : Recherches sur les bronzes figurés de ('acule pré-romaine et romaine, Rome, École française de Rome (coll. Bibliothèque des Écoles françaises d'Athènes et de Rome, 228), 398 p., 101 pl.

BOUCHER S., TASSINARI S.

1976: Bronzes antiques du musée de la (ïvilisation gallo-romaine $a$ Lyon -1 - Inscriptions, statuaire, vaisselle, Lyon, musée de la Civilisation gallo-romaine, $155 \mathrm{p}$.

BRIDEL P.

1982 : Le sanctuaire du Cigognier, Lausanne, Bibliothèque historique vaudoise (coll.
Aventicum, III et Cahiers d'archéologie romande, 22), 2 vol., 207 p. et $108 \mathrm{pl}$.

BROUQUIER-REDDÉ V.

2003 : "La place du temple de la Victoire germanique de Caracalla dans la typologie de l'architecture religieuse paienne de l'Afrique romaine ", in KHANol'ss $M$. (DIR.), L'Afrique du Nord antique et médiéryale. Actes du VIII colloque international sur l'histoire et l'archéologie de l'Afrique du Nord, $I^{n}$ colloque international sur l'histoire et l'archéologie du Maghreb, Tabarka (Tunisie), 8-13 mai 2000, Tunis, Ministère de la Culture, de la Jeunesse et des Loisirs, Institut national du Patrimoine, p. 457-470.

Brouquier-Redné V., Gruel K., Poupon F. 2002 : "Allonnes, un grand sanctuaire public dédié à Mars Mullo che\% les Cénomans ", in LEPliz S., VAN ANDRINGa W. (DIR.), Préactes de la Table ronde: "Archéologie du sacrifice animal en Gaule romaine. Rituels et pratiques alimentaires ", P'aris, Muséum national d'histoire naturelle, 24-25 oct. 2002, p. 32-33 [Actes, à paraittre].

Brouquier-Reddé V., Cormier S., Gruel K, LEFEVRE C.

Sous presse : "Le sanctuaire de Mars Mullo à Allonnes (Sarthe) ", Table ronde sur les temples circulaires, Bordeaux, Maison de l'archéologie, 23 nov. 2002, Aquitania.

BrouQuier-Reddé V., GrUel K.

À paraître : "Variations autour d'un plan-type de sanctuaire ", in Autour d'Allonnes (Sarthe), les sanctuaires de Mars en Occident, Colloque du Mans, 4-6 juin 2003.

BRUNAUX J.-L.

1996 : Les religions gauloises, riluels celliques de la Gaule indépendante, Paris, éd. Errance, $216 \mathrm{p}$.

2000 : "Ribemont-sur-Ancre, du trophée celtique au lieu de culte public galloromain ", in VAN ANDRINGA W. (DIR.), Archéologie des sanctuaires en Gaule romaine, Saint-Étienne, Publications de l'univ. de Saint-Étienne (coll. Mémoires du Centre Jcan-Palerne, 22), p. 136-146.

BRUNAUX J.-L. (DIR.)

1999: "Ribemont-sur-Ancre (Somme). Bilan préliminaire et nouvelles hypothèses ", Gallia, 56, p. 177-283.

BRUNEAU $P$.

1984 : «Ares ", LIMC, II, p. 479-492.

BULARD M.

1906 : "Aphrodite, Pan et Éros. Groupe en marbre ", Bulletin de correspondance hellinique, 30, p. 610-631.

BuRnand Y.

1995 : "Lin officier méconnu $(\operatorname{IIT}(;, 347)$ ", in l.F. BoHfC: Y. (DIR.), la hierarchie (Rangordnung) de l'armée romaine sous le Haut-Lmpire, Actes du congrès de Lyon, 15 18 sept. 1994, Paris, De Boccard (coll. De l'archéologie à l'histoire), p. 193-200. Callu J.-P.

1969 : La politique monétaire des empereurs romains de 238 à 311, Paris, De Boccard (coll. Bibliothèque des Écoles françaises d'Athènes et de Rome, 214), $564 \mathrm{p}$.

Charx L., Méniel P.

1996 : Eléments d'archéozoologie, Paris, éd. Errance, $112 \mathrm{p}$.

Chardron-Picault P., Pernot M. (Dir.)

1999 : Un quartier antique d'artisanat métallurgique à Autun (Saône-t-Loire). Le site du Lycée militaire, Paris, éd. de la Maison des sciences de l'Homme (coll. DAF, 76), $320 \mathrm{p}$.

\section{Chastagnol A.}

1980 : "L’organisation du culte impérial dans la cité à la lumière des inscriptions de Rennes ", in ROLANNFT-LIF.SFENFFIT A.M., SANQler R. (DIR.), l.a civilisation des Riedones, Brest (coll. Suppl. à Archéologie en Bretagne, 2), p. 187-199.

1995a : "L'expression épigraphique du culte impérial dans les provinces gauloises", Recuce des Études anciennes, 97, p. 600-605.

1995b : "L'organisation du culte impérial dans la citć à la lumic̀re des inscriptions de Rennes ", in Chastaginol. A., La Gaule romaine et le droit latin. Recherches sur l'histoire administrative et sur la romanisation des habitants, Scripta Varia 3, Lyon, Paris, De Boccard (coll. Centre d'études romaines et gallo-romaines, 14), p. 29-35.

Ceguret G.

1977 : " La céramique commune de l'atelier de Thésée-la-Romaine ", Revue archéologique du Centre, 16, 3-4, p. 325-339.

CORDONNIER-DÉTRIE $\mathbf{P}$.

1957 : « Informations archéologiques ", Gallia, 15,2 , p. 207-208.

Curle J.

1911 : A Roman Frontier Post and its Poople : the Fort at Newstead in the Parisch of Melrose, Glasgow, Maclehose and sons, $431 \mathrm{p}$.

Daremberg C., Saglo E., Pottier E. (Dir.) 1877-1919: DA, Paris, Hachette, 10 vol.

DarLoT P.

1986 : «Découverte d'un ensemble galloromain proche des thermes antiques d'Allonnes, sondage CAPRA 1984-1986", Bulletin de la Société d'agriculture, sciences et arts de la Sarthe, 87, n" 618, p. 27-40.

DELAGE R.

1997 : "Premier aperçu de la diffusion de la céramique sigillée du groupe CentreOuest dans l'ouest de la Gaule (régions Pays de la Loire et Bretagne) ", in Rivtil L. (1)IR.), Actes du congrès de la SFECAG, Le Mans, 8-11 mai 1997, p. 279-292.

Delage R., Guillier G.

1997 : « La céramique confrontée au problème des niveaux du III" siècle : quatre exemples manceaux (Sarthe) ", in RIVFT L. (DIR.), Actes du congrès de la SFECAG, Le Mans, 811 mai 1997, p. 255-279.

Delage R., Simon L.

2000 : "Les céramiques d'importation : la sigillée ", in BERTHALD G. (DIR.), Mazièresen-Mauges gallo-romain (Maine-et-Loire) : un quartier à vocation artisanale et domestique, Angers, ARDA/AFAN, p. 111-121. 


\section{DEPEYROT G.}

1982 : Le numéraire gaulois du N' siècle : aspects quantitatifs, Oxford (coll. BAR, International Series, 127), 2 vol. : 271 p. et 190 p.

Deschamps S., Vaginay M. (DIR.)

1990 : Le Mans retrouvé : archéologie et mémoire de la ville, Catalogue d'exposition, Le Mans 1990, Circonscription des Antiquités préhistoriques et historiques des Pays de la Loire, 120 p., 105 fig.

Dessau $\mathbf{H}$.

1962 : ILS, Berlin, Weidmann, 5 vol.

Devambez P., Kauffmann-Samaras A.

1981 : “Amazones », LIMC, I, p. 586-653.

Di Filuppo Balestrazzi E.

1997 : “ Roma ", LIMC, VIII, p. 1049-1068. Dobson B.

1967 : “Introduction ", in DoMAS7EwskI A. voN, Die Rangordnung des römischen Heeres -2- Durchgeschesse Böhlau Auflage, Einführung, Berechtigungen und Nachträge von B. Dobson, Köln-Graz (coll. Beihefte $\operatorname{der} B J, 14)$, p. VI-L.VII.

DONDIN-PAYRe M.

1999 : « Magistratures et administration municipale dans les Trois Gaules ", in Donds:Payrf. M., RaepsakT-Charl.ler M.-T. (DIR.), Cités, municipes, colonies. Les processus de municipalisation en Gaule et en Germanie sous le Haut-Empire romain, Paris, Publications de la Sorbonne (coll. Histoire ancienne et médiévale, 53), p. 127-230.

DUPRAZ J.

2000 : "Sanctuaires et espaces urbains : Albala-Romaine, I $^{\text {er }}$ s. av.-III ${ }^{\mathrm{e}}$ s. apr. J.-C. (Ardèche) ", in VAN ANDRINGA W. (DIR.), Archéologie des sanctuaires en Gaule romaine, Saint-Étienne, Publications de l'université de Saint-Étienne (coll. Mémoires du Centre Jean-Palerne, 22), p. 47-72.

Duval A.

1990 : "Quelques aspects du mobilier métallique en fer anciennement recueilli à Tronoën, en Saint-Jean-Trolimon (Finistère) ", in DLval. A., Le Bihan J.-P., MÉNEZ. Y. (DIR.), Les Gaulois d'Armorique. La fin de l'âge du Fer en Europe tempérée, Actes du XII colloque de l'Association française pour létude de l'âge du Fer, Quimper, mai 1988, Rennes (coll. Suppl. à la Revue archéologique de l'Ouest, 3), p. 23-45.

Duval A., Pernot M., Comte F., Lacoste D. 1991 : « Les fouilles de 1988-1989 dans le secteur "extra-muros": l'atelier de bronzier ", in "Les fouilles du MontBeuvray, rapport biennal 1988-1989 ", Revue archéologique de l'Est, 42, p. 274-284.

\section{Duval P.-M.}

1958 : "Chronique gallo-romaine ", Revue des Etudes anciennes, 60, p. 371.

1961 : "Chronique gallo-romaine ", Rerue des Études anciennes, 63, p. 377-380.

1976 : Les dieux de la Gaule, Paris, Payot, 169 p. 1981 : Recueil général des bas-reliefs de la Gaule romaine -XVI- Table, Paris, Imprimerie nationale (coll. Presses universitaires de France).

ECKART BARTH F.

1987 : « Dic Wagen aus der Byci Skala-Höhle, Gem. Habruvka, Bez. Blansko, CSSR ", in Vierrädrige Wagen der Hallstatlzeit, Untersuchungen zu Geschichte und Technik, Mainz, Römisch-Germanischen Zentralmuseums (coll. Monographien RömischGermanisches Zentralmuseum, 12), p. 103-119.

ESPÉRANDIEU É.

1907-1938 : Recueil général des bas-reliefs de la Gaule romaine, I-XI, Paris, Imprimerie nationale [voir aussi Lantier, 1947-1966 et Duval P.-M., 1981].

Estiot S., AMANDRY M., Bompaire M.

1986 : " L.e trésor d'antoniniani d'Allonnes II ", in Trésors monétaires, VIII, Paris, Bibliothèque nationale, p. $51-110$, pl. XXV-XL.

FAIDER-FeYTMANS G.

1979 : Recueil des bronzes romains de Belgique, Bruxelles-Mayence, Philipp von Zabern, 2 vol.

Ferdière A., Villard A.

1993 : La tombe augustéenne de Fléré-la-Rivière (Indre) et les sépultures aristocratiques de la cité des Bituriges, Saint-Marcel, musée d'Argentomagus (coll. Suppl. à la Revue archéologique du Centre de la France, 7), $316 \mathrm{p}$.

FeUGÈRE M.

1989 : «Les vases en verre sur noyau d'argile en Méditerranée nord-occidentale ", in FEUG(èrRE M. (DIR.), Le verre préromain en Europe occidentale, Montagnac, Monique Mergoil, p. 29-62.

Fishwick D.

1991 : The Imperial Cult in the Latin West -II/1- Studies in the Ruler Cult of Western Provinces of the Roman Empire, Leiden, Brill, p. 375-626.

Fol A.

1991 : « Les garnitures de char de la tombe de Mezek ", in Les Celles, Catalogue d'exposition, Venise 1991, Palazzo Grassi, Milan, Bompiani, p. 384-385.

FORMIGÉ J.

1944 : "Le sanctuaire de Sanxay (département de la Vienne) ", Gallia, II, p. 43-97.

Fourmy R., GulleuX J.

1983 : "Fouille de sauvetage sur une fosse de la future résidence du Maine (décembre 1979) ", Bulletin de la Société d'agriculture, sciences et arts de la Sarthe, 84 , 588, p. 19-26.

1984 : "Fouille de sauvetage sur un dépôt gallo-romain du quai Louis-Blanc (juillet 1979) ", Bulletin de la Société d'agriculture, sciences et arts de la Sarthe, 85, 594, p. $27-60$.

Fox C.

1946 : A Find of Early Iron Age from Llyn Cerrig Bach, Anglesej; Cardiff, National Museum of Wales, $98 \mathrm{p} ., 38 \mathrm{pl}$.

\section{GaILLARD H.}

1997 : La Dordogne, 24/1, Paris, Académie des inscriptions et belles-lettres (coll. CAG), $300 \mathrm{p}$.

Ganschow T.

1997 : «Virtus », LIMC, VIII, p. 273-281.

GIARD J.-B.

1962 : "Le trésor d'Allonnes (Sarthe) ", Rerue numismatique, 4, p. 217-225.

GoMez de Soto J., LeJaRs T.

1991 : "Sanctuaires préromains en extrême occident ", in BruNauX J.-L. (DIR.), Les sanctuaires celtiques et leurs rapports avec le monde méditerranéen, Actes du colloque de Saint-Riquier, nov. 1990, Paris, éd. Errance (coll. Dossiers de Protohistoire, 3), p. $126-132$.

Gondard P., Guilleux J., Guiluier G.

1993 : " Note de céramologie : les puits P2 et P3 de la résidence Beauregard au Mans", Mémoire du Bulletin de la Société d'agriculture, sciences et arts de la Sarthe, 688, p. 37-45.

Grand K.

1995 : "Le répertoire de la céramique peinte gallo-romaine de Roanne (Loire) ", Revue archéologique du Centre, 34, p. 177-194.

Grenier A.

1957 : " Fragment d'inscription d'Allonnes (Sarthe) ", Gallia, XV, p. 145-146.

Gros P.

1996 : L'architecture romaine du début du IIT siècle av. J.C. à la fin du Haut-Empire -1- Les monuments publics, Paris, Picard, 503 p.

GRUEL $\mathbf{K}$.

À paraître a : « L'alignement du denier gaulois sur l'étalon romain, datation et impact économique ", in Les Celtes et Rome, nouvelles études numismatiques, Actes de la table ronde, Fond de Gras/Titelberg, Luxembourg, 30 avril-3 mai 1998.

À paraître b : " Monnaies et sanctuaires dans le nord-ouest de la Gaule ", in Strobri. K., LOSCHEIDER R. H. M. (DIR.), Forschungen zur Monetarisierung im Nordwesten des Imperium Romanum : die Entstehung eines europaiischen Wirtschaftsraumes, Akten des 2. Trierer Symposiums zur antiken Wirtschaftsgeschichte, 29. Sept.-2. Okt. 1999, Mainz, Trierer historische Forschungen.

À paraître c : "Étude comparée des découvertes monétaires sur quatre sanctuaires de la Gallia Comata : Allonnes (Sarthe), Bibracte (Nièvre), Les Bolards (Côted'Or), Mirebeau (Côte-d'Or) ", in Hasfigrove C., Wigg; D. (DIR.), Ritual and Iron Age Coinage in North-West Europe, Francfort.

Gruel K., Bernollin V., Brouquier-Reddé V., GOUFFE J.

2003 : Allonnes la romaine, 200 ans de fouilles archéologiques, cédérom réalisé par P. Wendling, Paris, Société Incandescence. 
Gruel K., BrouQuier-Reddé V. (DIR.)

2003 : Le sanctuaire de Mars Mullo, Allonnes (Sarthe), le Mans, éd. de la Reinette, 192 p. + cédérom.

Gruel K., Geiser A.,

1995 : “Les potins à la grosse tête ", in Grull. K. (DIR.), "Dossier : Les potins gaulois, typologic, diffusion, chronologic, état de la question à partir de plusicurs contributions ", Gallia, 52, p. 11-15.

Gruel. K, TACCOËN A.

1992 : "Petit numéraire de billon émis durant et après la conquête romaine dans l'ouest de la Gaule ", in MAYs M. (DIR.), Cellic Coinage : Britain and Beyond, Oxford (coll. BAR, British Series, 222), p. 165-188.

GuIlleux J.

2000 : L'enceinte romaine du Mans, Saint-Jeand'Angély, éd. Bordessoules, 268 p., 194 fig.

\section{Guillier G.}

1995 : «Un aspect méconnu de la céramique du Haut-Empire : la vaisselle modeléc, l'exemple du Mans (Sarthe) ", in RIvET I.. (DIR.), Actes du congrès de la SFF(CAG, Rouen, 25-28 mai 1995, p. 217-234.

1997 : “ Ia production céramique du HautEmpire de l'officine rurale de I a Bosse (Sarthe) ", in Rivit l. (DIR.), Actes du congrès de la SFLCAC;, I te Mans, 8-1I mai 1997 , p. 239-254.

Guillier G., Pouli M.

1991 : « Un atelier de tissage gallo-romain sur le site Étoile/Jacobins au Mans ", Bulletin de la Société d'agriculture, sciences et arts de la Sarthe, 93, 678, p. 33-48.

Guillier G., Pouli M., Rodet-Belarbi I.

1993 : “Un puits dépotoir gallo-romain sur le site Étoilc/Jacobin ", Province du Maine, 7, p. 121-141.

Guillier G., Thauré M.,

2003 : Les graffites antiques de la cité des Aulerques Cénomans, Montagnac, Monique Mergoil, $298 \mathrm{p}$.

HaNuT F.

À paraître : "Chronologie dı mobilier céramique daus les sépultures privilégiées du Hallt-Fmpire ", in Actes du $\sigma^{r}$ congrès de l'Association des cercles francophones d'histoire el d'archéologie de Belgique, Mons, 2001.

\section{HaRMand L.}

1962 : "I.es sculptures d'Allomnes ", in Hommages à Albert Crenier (coll. Latomus, LVIII, 2), p. 771-785.

HaTt J.-J.

1979 : "Le culte de Mars indigène dans le nord-est de la Gaule (sur les pas d'Émile Thévenot) ", Rerné archéologique de l'ist et du Centre-Est, XXX, 1-2, p. 121-138 et 3-4, p. 183-195.

HiERNARD J.

1984 : "Ies monnaies antiques de Niort (Deux-Sèvres) ", Aquitania, 2, p. 59-104.

Hirschfeid O., Zangemeister C., Bohn O. (DIR.) 1863-1906 : $C I I$, Berlin.

HoFmaNn B.

1985 : Catalogue des estampilles sur vaisselle sigillee, Gonfaron, Association française d'archéologie métropolitaine (coll. Revue archéologique Sites, hors série, 27), 103 p. HoRne P., KING A.

1980 : " Romano-Celtic Temples in Continental Europe : a gazetteer of those whith known plans ", in Ronwit.l. W. (DIR.), Temples, Churches and Religion, Oxford (coll. BAR, British Series, 77), vol. 2, p. 369-5.55.

HUMBert R.

1987 : «Note de céramologic : le mobilier gallo-romain provenant du puits n" l de la place de la République au Mans ", Bulletin de la Société d'agnicullure, sciences et arts de la Sarthe, 627, p. 17-36.

Joulla J.-C., Pailler J.-L., Thouin S.

2000 : "Le mausolée romain de Ianućjols, fouille, restauration et mise en valeur ", Bulletin de la Société française d'archéologie classique (XXXI, 1998-1999), Revue archéologique, 1, p. 144-150.

KAJANTO I.

1965 : The Latin Cognomina, Helsinki, Commentationes Humanarum Litterarum, $417 \mathrm{p}$.

\section{KING A., SoFre G.}

1994 : "Recherches récentes sur les temples romano-celtiques de Grande-Bretagne. L'exemple de Hayling lsland ", in Gotchal C., Fatdite I., Colion G. (1)IR.), Les sanctuaires de tradition indigène en Gaule romaine, Actes du colloque d'Argentomagus (Argenton-sur-Creuse/Saint-Marcel, Indre), 8-10 oct. 1992, Paris, éd. Errance et musée d'Argentomagus, p. 41-50).

Lagadec J.-P., Duval P., Eveillakd J., Leroy M., Ploquin A.

1993 : « Ia "cité d'Affrique", habitat fortifié du premier âge du Fer : l'apport des nouvelles fouilles ", in BOURA F., Metzi.fR J., MiRoN A. (DIR.), Internctions culturelles et économiques aux âges du Fer en I.orraine, Sarre et Luxembourg, Actes du $X I$ colloque de l'Association francaise pour l'ölude de l'âge du Fer en Fance non méditerranéenne, Sarreguemines (Moselle), $1-3$ mai 1993, Metz-Sarrbrücken-Luxembourg (coll. Arhaeologia mosellana, 2), p. 149-173.

LAMBert C., Rioufreyt J.

1976: " La villa gallo-romaine du Grand Teil a Avoise ", Province du Maine, 78, p. 338-370.

1985 : "Les épées des sanctuaires de la Touraux-Fées d'Allonnes (Sarthe) ", Études préhistoriques et historiques des Pays de la l.oire, 8, p. 69-72.

LANTIER R. (DIR.)

1947-1966: Recueil général des bas-reliefs de la Gaule romaine, suppl. XII-XV, Paris, Presses universitaires de France, 4 vol.

LA TOUR H. DE.

1892 : Atlas de monnaies gauloises, Paris.

LAUBENHEIMER $\mathbf{F}$.

1986 : " la production d'amphores de deux atcliers de potiers du bassin de la loire movenne ", Revue archéologique du Centre, 25,2 , p. $175-187$.

LAUFFRAY J.

1990 : La Tour de Vésone à Périgueux, temple de Vesunna Petrucoriorum, Paris, éd. du C.NRS (coll. Suppl. à Gallia, 49), 178 p., XXVIII pl.

\section{LAZZARO I.}

1993 : Esclaves et affranchis en Belgique et Germanies romaines d'après les sources épigraphiques, Paris, Ies Belles Icttres (coll. Anmales littéraires de l'université de Besançon, 430, Centre de recherches d'histoire ancienne, 102), $585 \mathrm{p}$.

\section{LEDRU A.}

1911 : Répertoire des monuments et objets anciens préhistoriques, gallo-romains, mérovingiens et carolingiens existant ou trouvés dans les départements de la Sarthe et de la Majenne, I.e Mans, Société des archives historiques du Maine, $431 \mathrm{p}$.

\section{LEJARS T.}

1989 : “Ies armes des sanctuaires poitevins d'époque préromaine de Faye-l'Abbesse (Deux-Sèvres) et de Nalliers (Vendée) ", Gallia, 46, p. 1-41.

1994 : Gournay -III- Les fonrreaux d'épée. Le sanctuaire de Gonornay-sur-Aronde et l'armement des Celtes de la Töne moyenne, Paris, éd. Errance, $234 \mathrm{p}$.

1999 : "Iieux de culte et dépôts d'objets laténiens des Pays d'Ouest ", in Santrot M.-H., Santrot J., Mritret J.-C. (DIR.), Nos ancêtres les Gaulois, aux marges de l'Armorique, Catalogue d'exposition, Nantes, musée Dobrée et Conseil général de Loirc-Atlantique, p. 112-113.

A paraître : "Le choix des armes dans les pratiques votives des Celtes occidentaux ", in Ises riles de victoire, Mélanges de l'École française de Rome, Antiquité.

Lejars T., Lambert C., Rioufreyt J.

À paraître : Aubigné-Racan.

LEón P.

1988 : Traianeum de Itálica, Séville, Monte de Piedad y Caja de Ahorros de Sevilla, 162 p., 12 pl. h. $t$.

\section{LEPETZ S.}

1996 : L'animal dans la sociélé gallo-romaine de la France du Nord (coll. Suppl. à la Revue archéologique de Picardie, 12), 174 p.

Lepetz S., VAN ANdringa W. (DIR.)

2002: : Pré-actes de la Table ronde: "Archéologie du sacrifice animal on Gaule romaine. Rituels et pratiques alimentaires ", Paris, Muséum national dhistoire naturelle, 24-25 oct. 2002 [Actes, à paraître].

\section{LERAT L.}

1965: : La ville d'Antre, mythes et réalités, Paris, Les Belles Lettres (coll. Annales littéraires de l'université de Besançon, 74, section Archéologic, 19), $107 \mathrm{p}$.

Lignereux Y., Peters J.

1996 : "Techniques de boucherie et rejets osseux en Gaule romaine ", Anthropozoologica, 24, p. 45-98. 
MAGNaN D., LePetz S.

2002 : "La Bauve à Meaux, sanctuaire suburbain de la cité des Meldes ", in

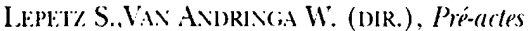
de la Table ronde : "Archéologie du sacrifice amimal en Giaule romaine. Rituels et pratiques alimentaires ", Paris, $24-25$ oct. 2002 (Muséum national d'histoire naturelle), p. 3437 [Actes, à paraître].

\section{MARIËN M. E.}

1972 : " Enochoé à scènes d'initiation ", Helinium, 12, p. 242-263.

\section{MARTIN-KILCHER S.}

1987 : Die römischen Amphoren aus Augst und Kaiserausgt-1-Die Südspanischen Ölamphoren, Augst, Römermuseum (coll. Forschungen in Augst, 7), $311 \mathrm{p}$.

\section{Maurin L., Thauré M.}

1994 : IIA -2- Santons, Bordeaux, Centre Pierre-Paris, $518 \mathrm{p}$.

MAYS M. (DIR.)

1992 : Celtic Coinage : Britain and Bejond. Oxford (coll. BAR, British Series, 222), $302 \mathrm{p}$.

MEdUNA J.

1991 : "La cruche de Brno-Malomerice", in Les Celtes, Catalogue d'exposition, Venise 1991, Palazoo (rassi, Milan, Bompiani, p. $376-377$.

MÉNEZ Y.

1985 : Les céramiques fumigées de louest de la Gaule, Quimper, Centre d'étude et de recherche archéologique (coll. Cahiers de Quimper antique, 2), $127 \mathrm{p.}, 44 \mathrm{pl}$.

MerCKLIN E. voN

1962 : Antike Figuralkapitelle, Berlin, De Gruyter, $354 \mathrm{p}$.

MEURET J.-C.

1993 : Peuplement, pouvoir et paysage sur la marche d'Anjou-Brelagne (des origines au Moyen Âge), Laval, Société d'histoire et d'archéologie de la Mayenne (coll. Suppl. à La Mayenne, archéologie, histoire, 4), $656 \mathrm{p}$.

\section{MITARD P.-H.}

1993 : Le sanctuaire gallo-romain des Vaux-de-laCelle à (ienainville (Val-d'Oise), Guiry-enVexin, Centre de recherches archéologiques du Vexin français (coll. Bulletin archéologique du Vexin français, 26), 449 p.

\section{Mócsy A., Marton E., Szilágyi M.}

1983 : Nomenclator provinciarum Europae Latinarum et Galliae Cisalpinae cum indice inverso, Budapest, Dissertationes Pamnonicac, Ser. 3, vol. 1, 397 p.

Moosleitner F., Pauli l., Penninger E.

1974 : Der Dürrnberg bei Hallein II, Katalog des Grabfunde aus der Hallstatt und Latèneseit, München, C. H. Beck (coll. München Beiträge zur Vor- und Frühgeschichte, 17), 194 p.. 288 pl.

MORFL. J.

1993 : "Ln nouveau temple rond gallo-romain à Avenches ", in Anmuaire de la Société suisse de préhistoire et d'archéologie, 76. p. 161-168.

Mowat R.

1879 : " Remarques sur les inscriptions antiques du Maine -II- Département de la Mavenne, $n^{\circ} 8$ ", in Congrès archéologique de France, 45' session, Le Mans-Laval, 1878, Paris, Champion, p. 249-256.

MC̈ller F

1990): Der Massenfund von der Tiefenau bei Bern, zur Deutung latènezeitlicher. Sammelfunde mit Waffen, Basel, Schweizerische Gesellschaft für $\mathrm{L}_{\mathrm{r}}$ - und Frühgeschichte (coll. Antiqua, Société suisse de préhistoire et d'archéologie, 20), $265 \mathrm{p}$.

NAVARRE N.

1997 : "La céramique gallo-romaine en plaine de Caen, des Antonins au Bas-Empire : trois exemples de lots céramiques issus de la fouille de La Corneille Nord (Brettevillel'Orgueilleuse, Calvados) ", in RIvet L. (DIR.), Actes du congrès de la SFECAC; I. Mans, 8-11 mai 1997, p. 407-429.

Naveau J.

1983 : "Le temple celto-romain et le camp protohistorique de Port-du-Salut à Entrammes (Mayenne) ", La Mayenne: histoire et archéologie, 5, p. 3-19.

1992 : La Mayenne, 53, Paris, Académie des inscriptions et belles-lettres (coll. $(A A)$ ), $176 \mathrm{p}$.

2000 : "Mullo, un dieu dans l'ouest de la Gaule ", La Mayenne : archéologie el histoire, 23, p. 3-33.

NAVEAU J. (DIR.)

1997 : Recherches sur Jublains (Mayenne) et sur la cité des Diablintes, Rennes, Association pour la diffusion des recherches archéologiques dans l'ouest de la France (coll. Documents archéologiques de l'Ouest), 352 p.

1998: Ie chasseur, l'agriculteur et l'artisan, Guide du Musée archéologique départemental de Jublains (Mayenne), Laval, Conseil général de la Mayenne, Service départemental de l'archéologie et des musées, $174 \mathrm{p}$.

Nerzic C.

1989 : I.a sculpture on (saule romaine, Paris, éd. Errance (coll. Patrimoine), $343 \mathrm{p}$.

\section{Oggiano-BitaR H.}

1984 : Bronzes figurés antiques des Bouches-duRhône, Paris, CNRS Éditions (coll. Suppl. à (Gallia, XLIII), 170 p., $112 \mathrm{pl}$.

OSWALD F.

1931 : Index on l'otlers' Stamps on Terra Sigillata, "Samian Ware", with a Supplement, East Bridgeford, F. Oswald, $428 \mathrm{p}$.

Oswal.d F., Pryce T. D.

1920 : An Introduction to the Study of Terra Sigillata, treated from a chromological standpoint, London, Iongmans \& Co, 286 p., $85 \mathrm{pl}$.

Passelac M., Vernhet A.

1993 : "Céramique sigillée sud-gauloise ", in PY M. (DIR.), Dictionnaire des céramiques antiques en Méditerranée nord-ocridentale. Lattes, ARt1.) (coll. L attara, 6), p. 569-580.

Pinon P., ADAM J.-P.

1994: Album Thiollet, Sens, Société archéologique de Sens, 35 et LIV $p$.

\section{Polak M.}

2000 : South Gaulish Terra Sigillata "Samian
Ware" with Potlers' Stamps from Vechten, Nijmegen, Katholieke Lniversiteit (coll. Suppl. à Rei Cretariae Romanae Fautorum Acta, 9), $440 \mathrm{p}$.

Provost A.

1999 : "I.e temple du Haut-Bécherel à Corseul ", in Mémoire d'âme(s). 20 ans de recherches archéologiques en Côtes-d'Armor, Catalogue d'exposition, Pločzal, Château de la Roche Jagu, mai 1999-avril 2000, s.l., s.n., p. 60-63.

\section{RAEPSAET-CHARLIER M.-T.}

1993 : Diis Deabusque sacrum. Formulaire votif $e t$ datation dans les trois Gaules et les deux Germanies, Paris, De Boccard (coll. Ciallia Romana, 1), 94 p.

\section{RAPIN A.}

2000 : « Les équipements militaires celtes dans la collection Lamarre ", Antiquités nationales, 32, p. 183-207.

Rebourg A.

1993 : Autun, 71/1, Paris, Académic des inscriptions et belles-lettres (coll. $C_{A} A G^{\prime}$ ), $238 \mathrm{p}$.

REECE R.

1967 : "Roman Coinage in Southern France ", Numismatic Chromicle, 7, p. 91-105.

1972 : « Roman Coins in Northern France and the Rhine Valley ", Numismatic Chromicle, 12 , p. 159-165.

1973: "Roman Coinage in the Western Empire ", Britannia, 4, p. 227-251.

RÉMY B.

1985 : Les monnaies romaines découvertes à Rodumna (Roanne, Loire) : essai de circulation monétaire, I.yon, Imprimerie de l'univ. Jean-Moulin (coll. Centre d'études romaines et gallo-romaines, nouvelle séric 4), 73 p., 9 pl.

ROGERS G. B.

1999 : Poteries sigillees de la Gaule centrale-II-Les potiers, Lczoux, Cahiers du Centre archéologique de Lezoux, l (coll. Sites, hors séric, 40), 2 vol.

Rolley C.

1979 : " Lne tête de Mars à Langres ", Revue archéologique de l'Est et du Centre-Est, 30, p. $196-208$.

Rovalet P., Charpy J.-J.

1991 : Les Celtes en Champagne, rinq siedes d'histoire, Catalogue d'exposition, muséc municipal d'Épernay, 22 juin-3 nov: 1991 , $280 \mathrm{p}$.

\section{ROXAN M. M.}

1978: RMD, L.ondon, Institute of Archaeology, 118 p., tabl.

SAVES G.

1976 : Les monnaies gauloises à la croix et assimilées du sud-ouest de la Gaule : examen et catalogue, Toulouse, Privat, $236 \mathrm{p}$., XXX pl.

SAXER R.

1967 : Lntersuchungen zu den Vexillationen des römischen Kaiserheeres von Augustus bis Diokletian, Epigraphishe Studien -1. I.andschaftsverband Rheinland Rheinisches Landesmuseum und Verein von Altertums. 
freuden im Rheinlande, Köln-Graz, Böhlau (coll. Beihefte der BJ, 18).

\section{SCHAAFF U.}

1988 : "Keltische Helme ", in Antike Helme, Sammlung Lipperheide und andere Bestände des Antikenmuseums Berlin, Mainz, Verlag des Römisch-fermanischen Zentralmuseums (coll. Monographien, 14), p. 293-317.

SCHEID J.

1998 : La religion des Romains, Paris, Armand Colin, $176 \mathrm{p}$.

\section{SeLLìs $\mathbf{H}$.}

1988 : "La céramique ", in Chartres 19781988: 10 années d'archéologie, 20 siècles d'histoire, Catalogue d'exposition, Cellier-deLoëns, 1988, Chartres, Adauc, p. 107-145.

2001 : Céramiques gallo-romaines à Chartres et en pays carnute : catalogue typologique. Tours, Ferac, Chartres, Adauc (coll. Suppl. à la Revue archéologique du Centre, 16), 254 p. Seulìs H., Gouvin F.

1993 : "Les officines céramiques de Chartres et les amphores produites localement ", in RIVET L. (DIR.), Actes du congrès de la SFECAG, Versailles, 20-23 mai 1993, p. 53-68. Selzer W., Decker K.-V., Do Paço A.

1988 : Römische Steindenkmäler, Mainz in römischer Zeit, Mainz, Philipp von Zabern, Landesmuseum Mainz, $267 \mathrm{p}$.

SichteRmanN H., KoCH G.

1975 : Griechische Mythen auf römischen Sarkophagen, Tübingen, E. Wasmuth (coll. Bilderhefte der Deutschen archäologischen Instituts Rom, 5-6), 73 p., 176 pl.

SimON E.

1984 : “Ares/Mars ", LIMC, II, p. 505-580.

SYMONDS R. P.

1992 : Rhenish Wares, Fine Dark Coloured Pottery from Gaul and Germany; Oxford (University Commitee for Archaeology, 23), 121 p., $53 \mathrm{pl}$.

Szabó M., Petres E. F.

1992 : Decorated Weapons of the La Tène Iron Age in the Carpathian Basin, Budapest, Magyar Nemzeti Muzeum (coll. Inventaria Praehistorica Hungariae, V), 259 p.

\section{TARDY D.}

Sous presse a : «L'origine du temple circu- laire ", Table ronde sur les temples circulaires, Bordeaux, Maison de l'archéologie, 23 nov. 2002, Aquitania

Sous presse $\mathrm{b}$ : " Modèle et décor corinthien en Gaule ", Colloque : Autour d'Allonnes, les sanctuaires de Mars en Occident, Ie Mans, 46 juin 2003.

TASSIGNON I.

1996 : Iconographie et religion dionysiaques en Gaule Belgique et dans les deux Cermanies, Liège, (coll. Bibliothèque de la Faculté de philosophie et lettres de l'université de Liège, CCL.XV), $376 \mathrm{p}$.

TÉrouanne $P$.

1960 : “ Dédicaces à Mars Mullo d'Allonnes ", Gallia, XVIII, 1, p. 185-189.

1967 : "Les sanctuaires d'Allonnes, Sarthe ", Gallia, XXV, p. 174-177.

1970 : " Vestiges gaulois et gallo-romains de la Tour-aux-Fées d'Allonnes ", in Actes du 93' congrès des Sociétés savantes, section Archéologie, Tours, 1968, Paris, CTHS, p. 305-311.

THÉVENOT É.

1955: Sur les traces des Mars celliques entre Loire et Mont Blanc, Brugge, De Tempel (coll. Dissertationes archaeologicae Gandenses, III), 171 p.

TURCAN R.

1982 : «Pour en finir avec la femme fouettée ", Revue archéologique, 2, p. 291-302.

ULRICH R. B.

1994 : The Roman Orator and the Sacred Stage: The Roman Templum Rostratum, Bruxelles (coll. Latomus, 222).

VAN ANDRINGA W.

2002 : La religion en Gaule romaine. Piété et politique ( $r^{r}-I I r^{r}$ siècle apr: J.-C.), Paris, éd. Errance, $335 \mathrm{p}$.

VAN EFFENTERRE E.

1959 : «Informations archéologiques ", Gallia, XVII, 2, p. 331-335.

VERGER $S$.

1994 : Les tombes à char de La Tène ancienne en Champagne et les rites funéraires aristocratiques en Gaule de l'Est au v's. av. J.C., thèse de Doctorat, univ. de Dijon, 3 vol.

\section{VERNHET A.}

1976 : "Création flavienne de six services de vaisselle à La Graufesenque ", Figlina, 1, p. 13-27.

VEZEAUX DE LAVERGNE E. DE

1999 : Ie sanctuaire gallo-romain de Mazamas à Saint-Léomer (Vienne), Paris, De Boccard (coll. Gallia Romana, III), 234 p.

VILLARONGA L.

1986 : "Imitaciones galliques de les dracmes de Rhodes i Emporion ", Acta Numismatica, 16, p. 21-51.

1994 : " Rhode e imitaciones ", in Corprus Nummum Hispaniae Ante Augusti Aetatem, Madrid, Herrero, p. 9-15.

Vouga P.

1923 : La Tène, monographie de la station, Leipzig, Hiersemann, $169 \mathrm{p}$.

WAURICK G.

1988 : "Römische Helme ", in Antike Helme, Sammlung Lipperheide und andere bestände des Antikenmuseums Berlin, Mainz, Vcrlag des Römisch-Germanischen Zentralmuseums (coll. Monographien, 14), p. 327-364.

\section{WIERSCHOWSKI L.}

1986 : « $A E$ 1980, 615 und das erste Auftreten der Formel omnibus honoribus in colonia sua functus in den westlichen Provinzen ", Zeitschrift für Papyrologie und Epigraphik, 64, p. 287-294.

WILSON JONES M.

1989 : "Designing the Roman Corinthian Order ", Journal of Roman Archaeology, 2, p. $35-65$.

2000 : Principles of Roman Architecture, New Haven, London, Yale University Press, $270 \mathrm{p}$.

WoImant G.-P.

1993 : "Le sanctuaire antique de Champlieu (commune d'Orrouy, Oise) ", Revue archéologique de Picardie, 1/2, p. 63-198.

WUILLEUMIER P.

1961 : "D'Auch au Mans ", Revue des Études anciennes, 63, 1-2, p. 55-58.

1963 : «Aulerci Cenomani », in ILTG (France), Paris, CNRS Éditions (coll. Suppl. à Gallia, XVII), p. 139-142. 


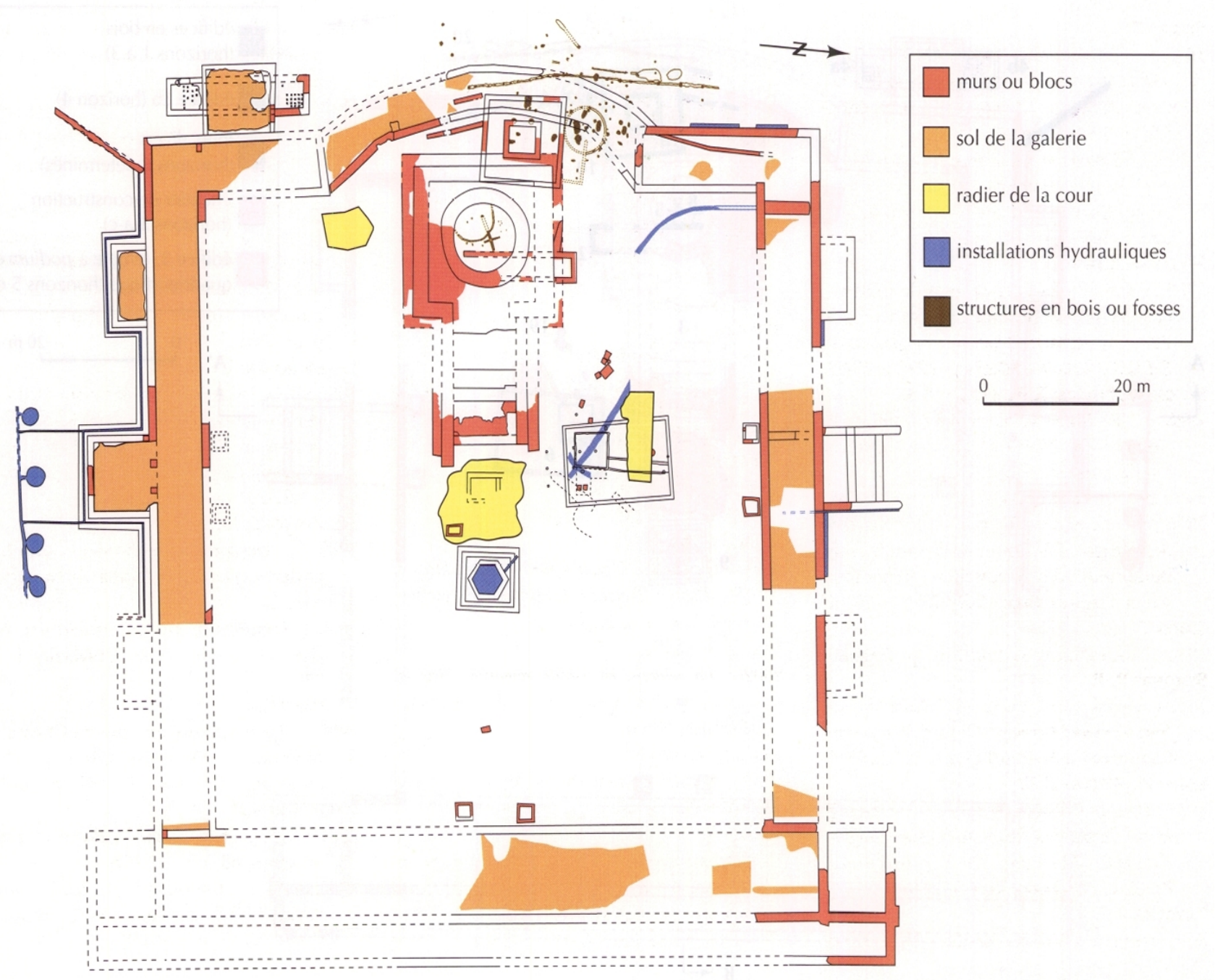

Fig. 5 - Ensemble des vestiges identifiés sur le site en 2003. 


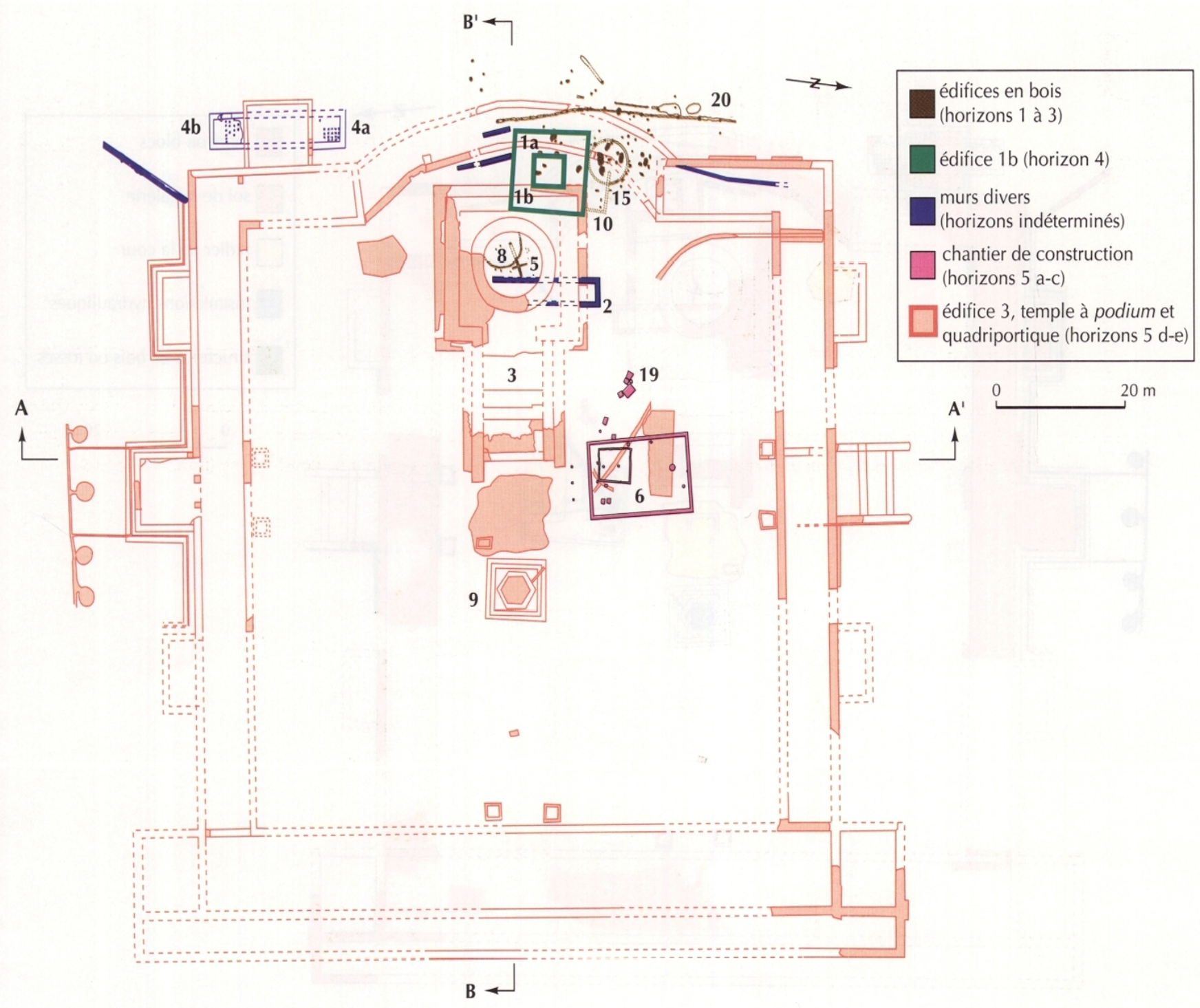

Fig. 7 - L'évolution du site (l'horizon 5 est à l'arrière-plan afin de faire apparaître les structures les plus anciennes) : 1, édifice 1; 2, édifice 2 ; 3, grand temple à podium ; 4, salle sur hypocauste ; 5, 8, 10, 15, édifices gaulois ; 6, atelier de seconde æuvre; 19, atelier lapidaire; 20 palissade gauloise. 


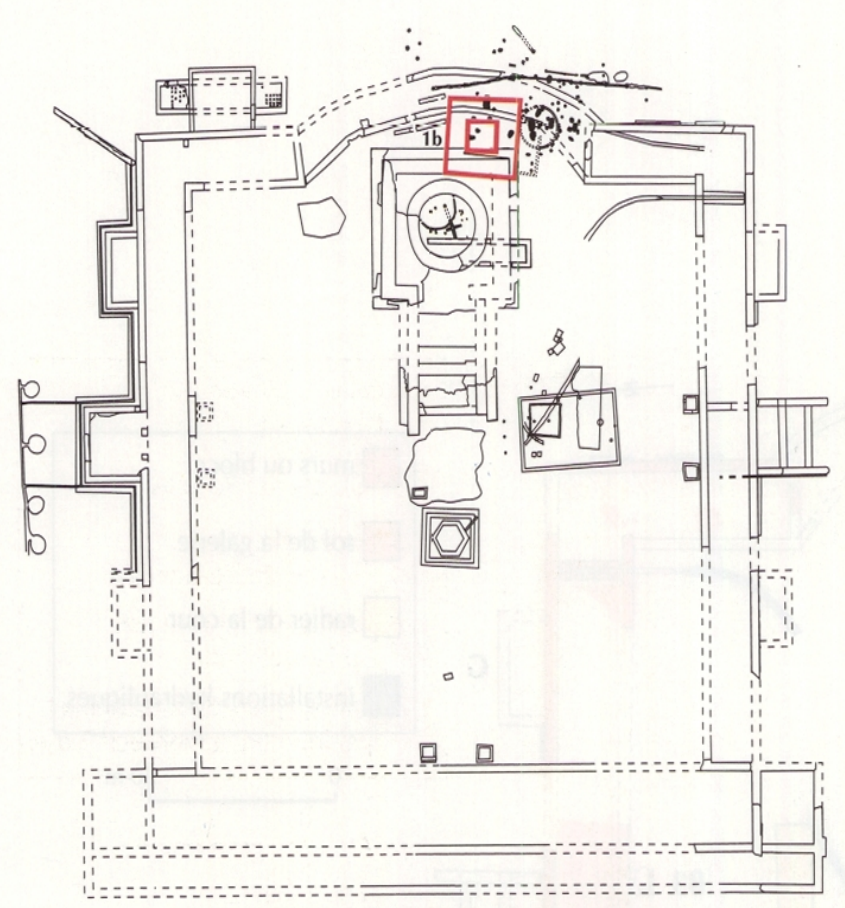

1 - le temple carré sans podium (horizon 4)

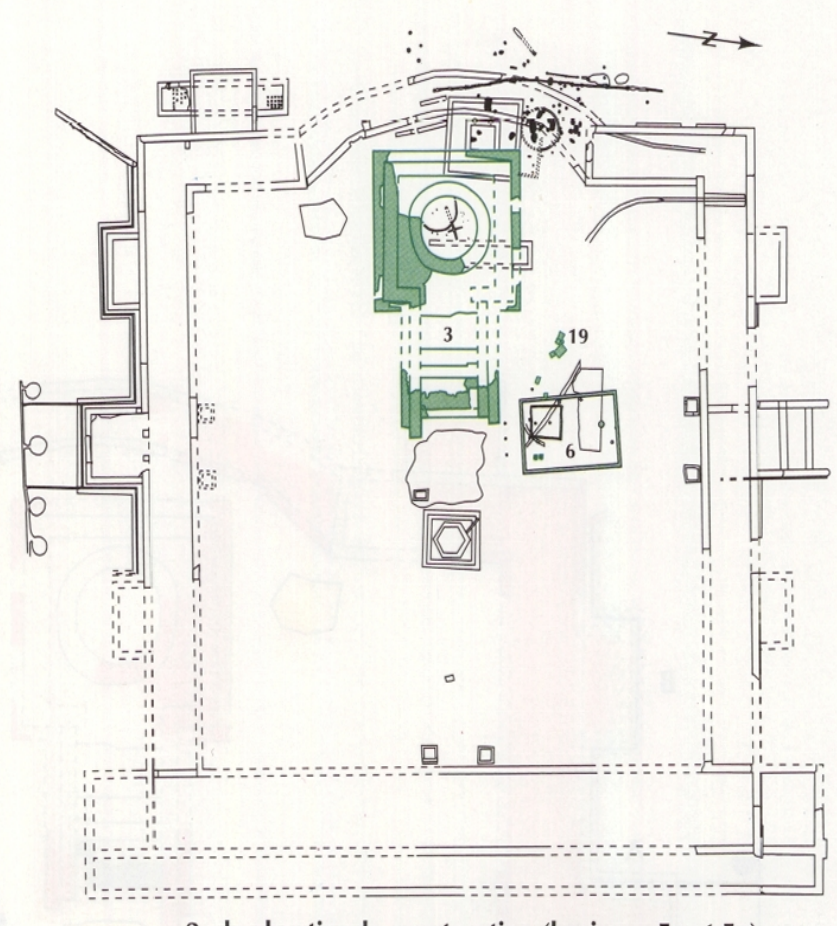

2 - le chantier de construction (horizons $5 a$ et $5 c$ )

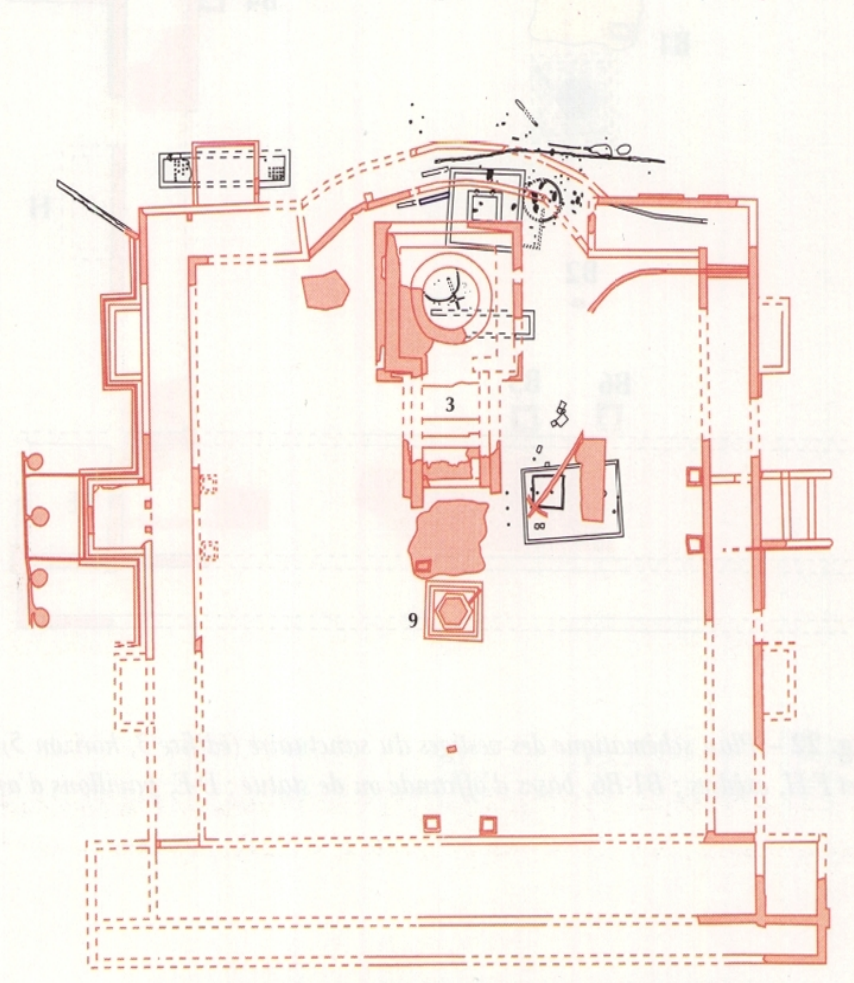

3 - le sanctuaire à quadriportique (horizons $5 \mathrm{~d}$ et $5 \mathrm{e}$ )

Fig. 21 - Principales phases de construction du sanctuaire de Mars Mullo (horizons 4 et 5). 


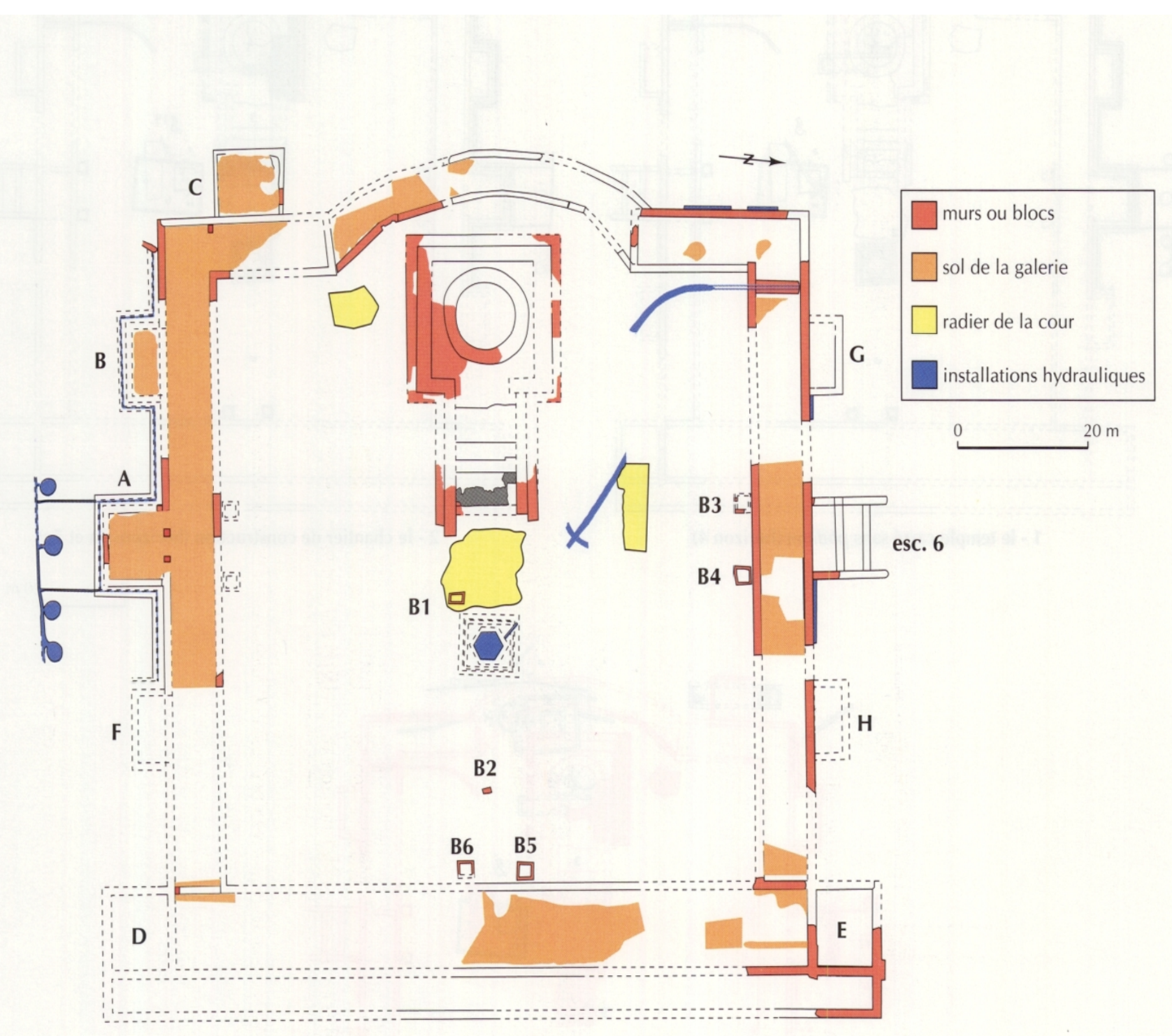

Fig. 22 - Plan schématique des vestiges du sanctuaire (édifice 3, horizon 5) : $A-C$ et $F-H$, exèdres; B1-B6, bases d'offrande ou de statue; $D-E$, pavillons d'angle. 

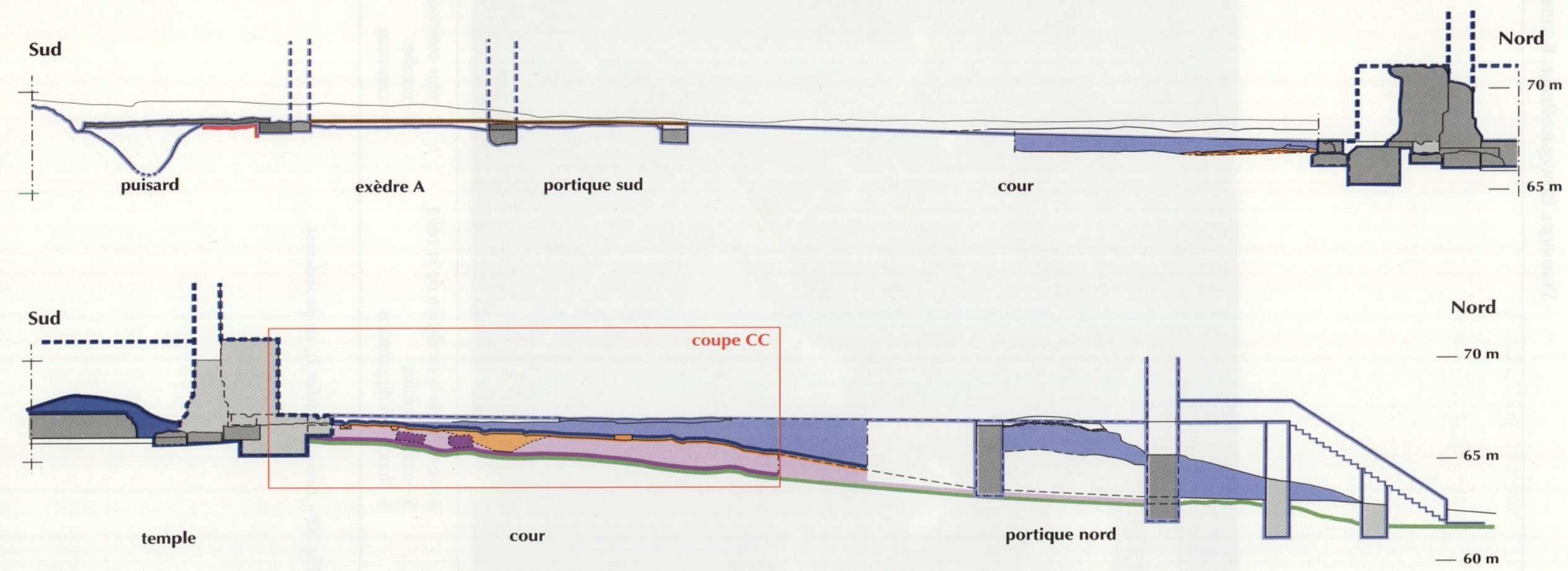

\begin{tabular}{|c|c|c|c|c|c|}
\hline $\begin{array}{l}\square \text { maçonnerie } \\
\square \text { fantôme }\end{array}$ & $\begin{array}{l}\square \text { horizon } 7 \\
\square \text { horizon } 6 b\end{array}$ & $\square$ horizon 6a & $\begin{array}{l}\square \text { horizon } 5 d \\
\square \text { horizon } 5 c\end{array}$ & $\begin{array}{l}\square \text { horizon } 5 b \\
\square \text { horizon } 5 a\end{array}$ & $\begin{array}{l}\square \text { hrizon } 4 \\
- \text { structures en brique }\end{array}$ \\
\hline
\end{tabular}

Fig. 25 - Détails de la coupe AA' sud-nord du sanctuaire (édifice 3, horizons 4 à 7). Certaines zones non fouillées au nord sont laissées en blanc. 


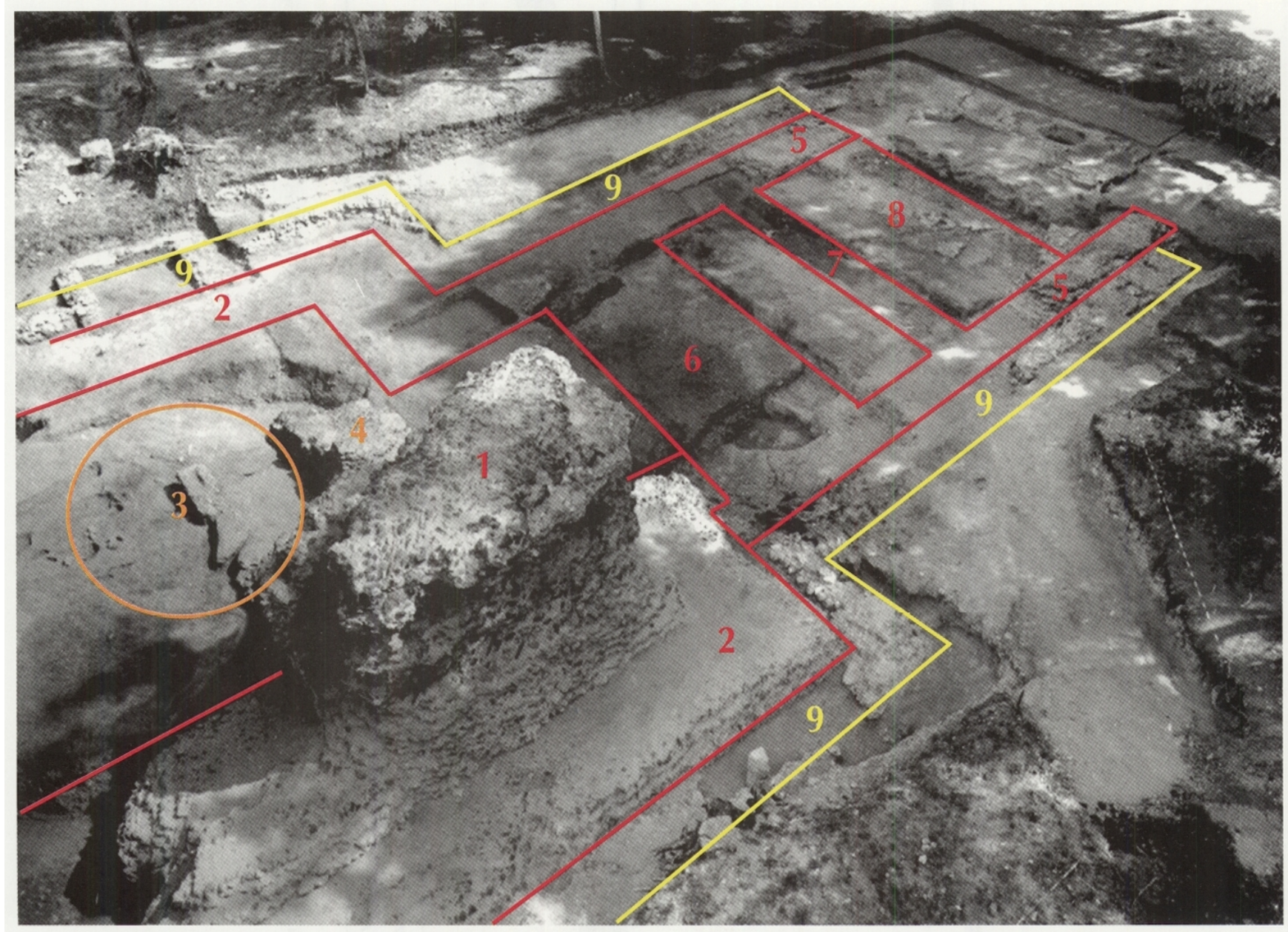

1 - sommet du podium

2 - semelle de fondation de la péristasis

3 - intérieur de la cella circulaire
4 - semelle de la fondation de la cella

5 - murs d'échiffre

6 - fondation du pronaos
7 - mur antérieur du podium

8 - escalier

9 - caniveau

Fig. 32 - Le temple (édifice 3), vu du sud-ouest. 


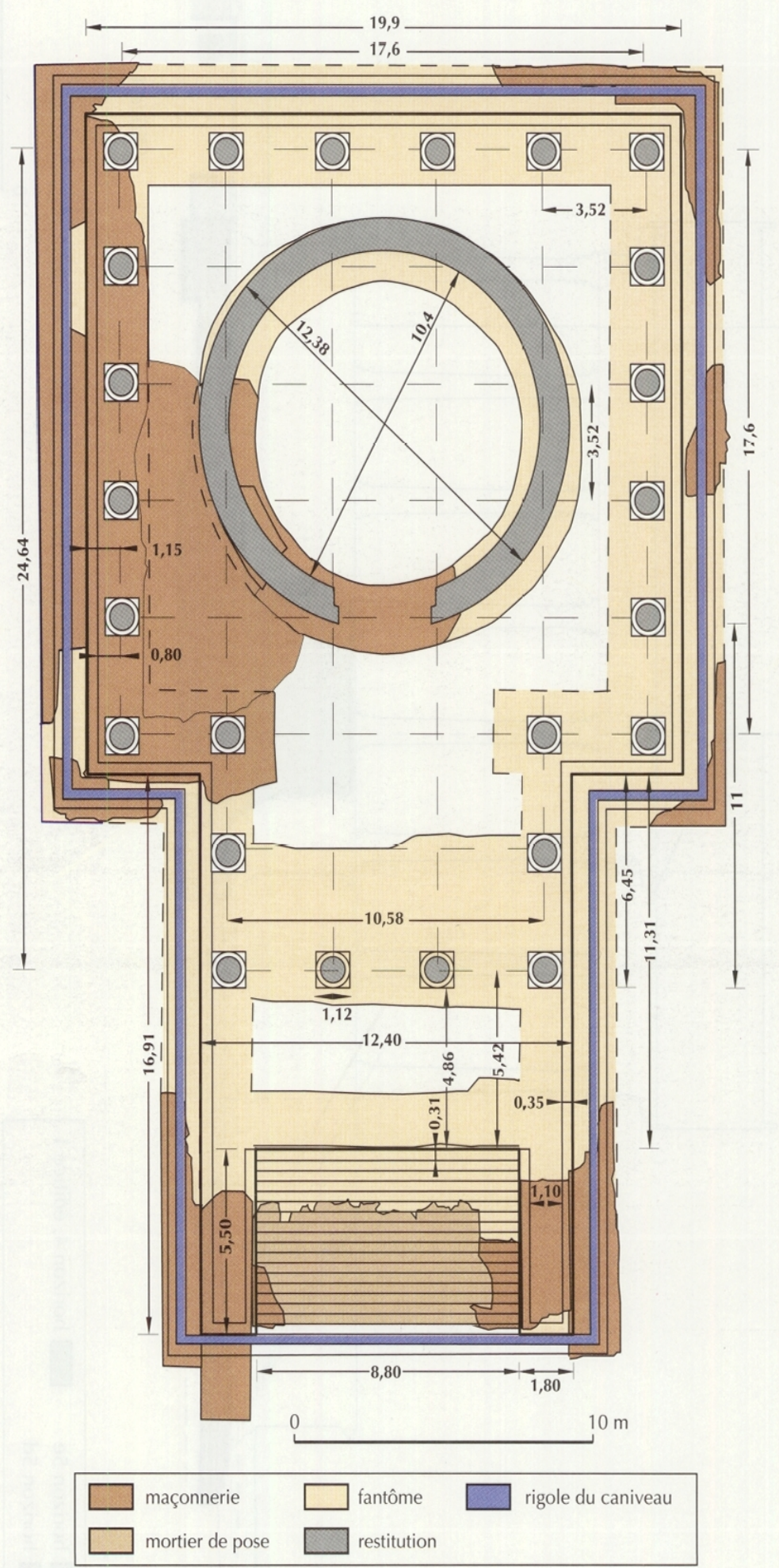

Fig. 33 - Plan restitué du temple (édifice 3, horizon 5; hypothèse 2003). 


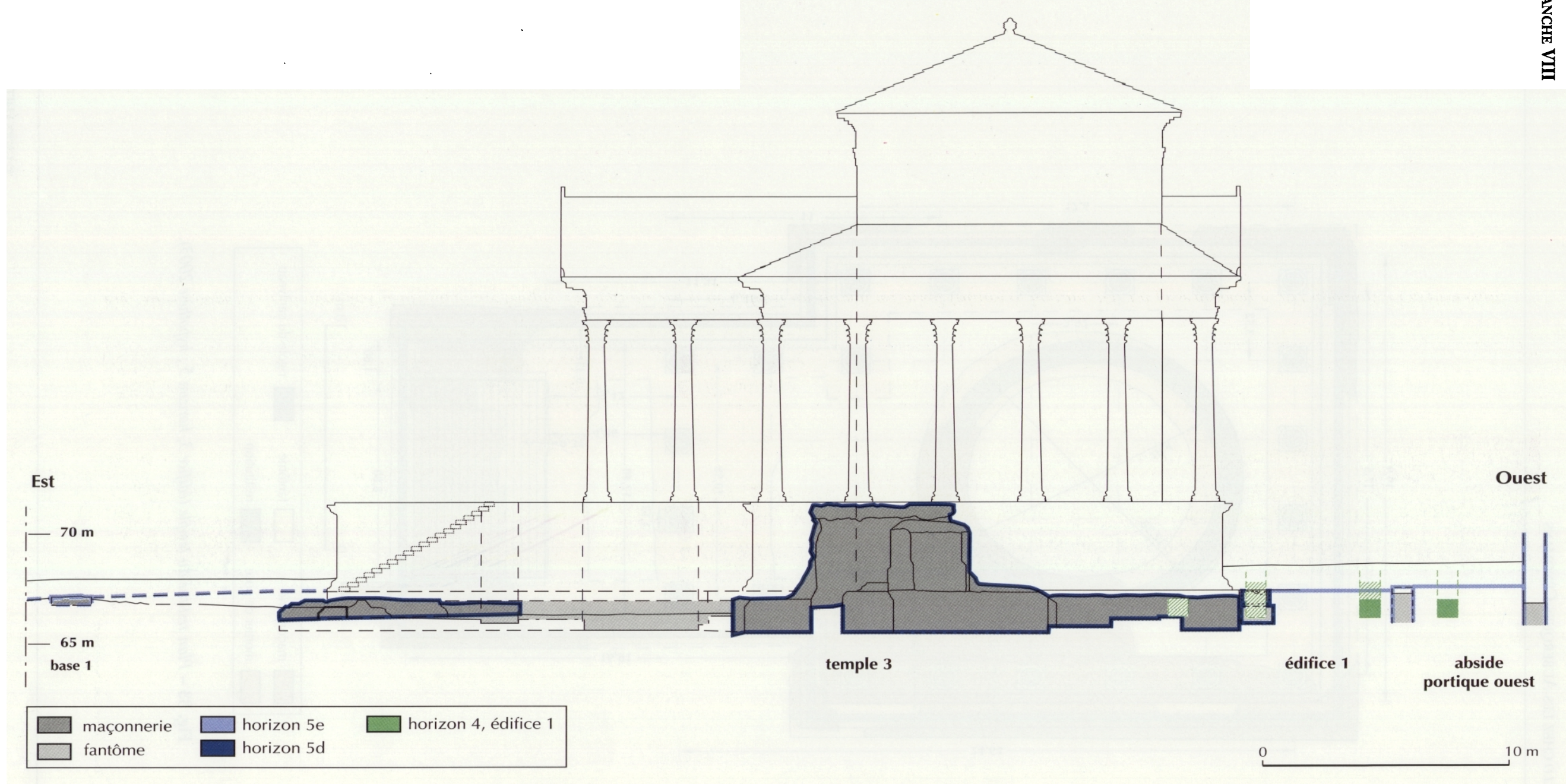

Fig. 35 - Coupe BB' est-ouest des édifices $1 b$ et 3 (horizons 4 et 5). 


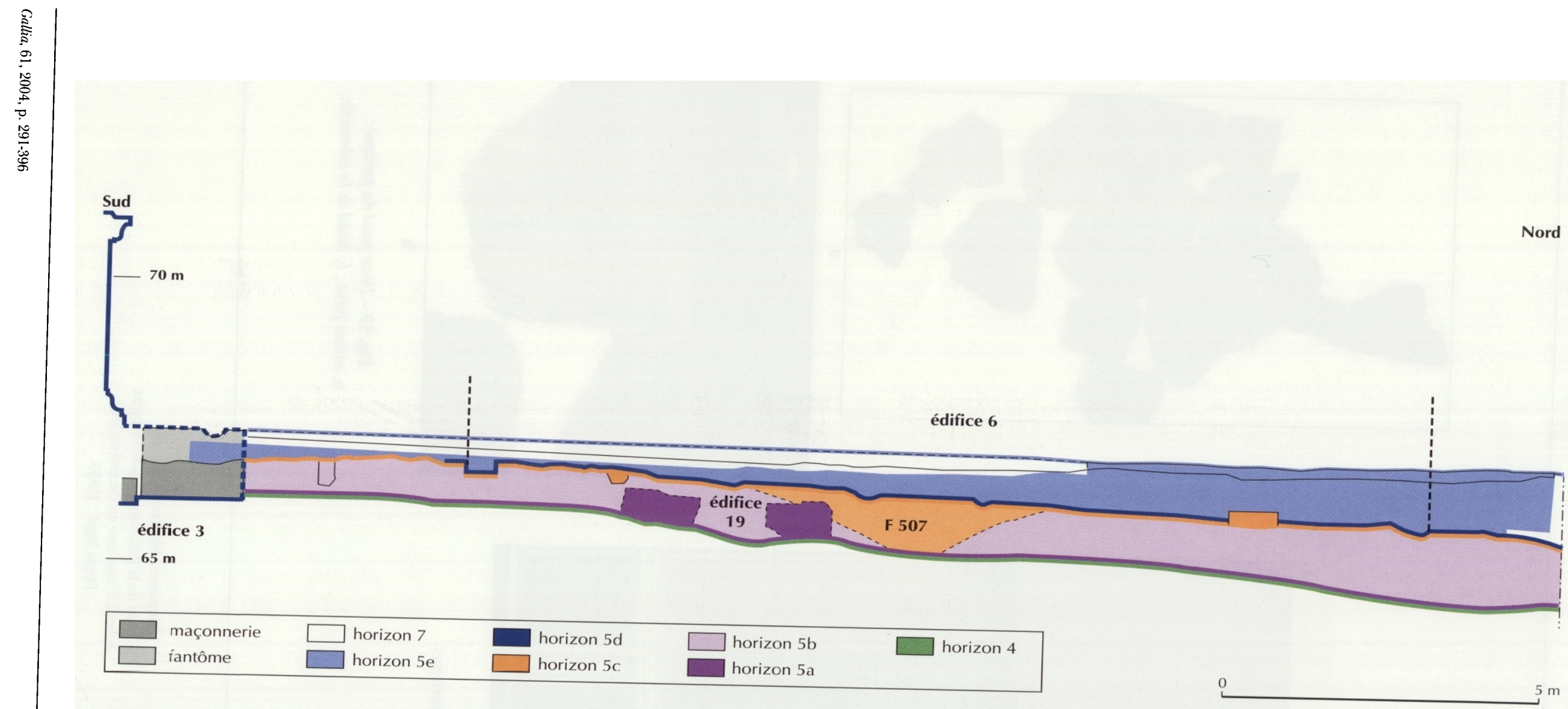

Fig. 40 - Coupe CC'sud-nord de l'atelier lapidaire (édifice 19, horizon 5a) et de l'atelier du travail du métal (édifice 6, horizon 5 c). La fosse-dépotoir F 507 apparaît à l'arrière-plan. 


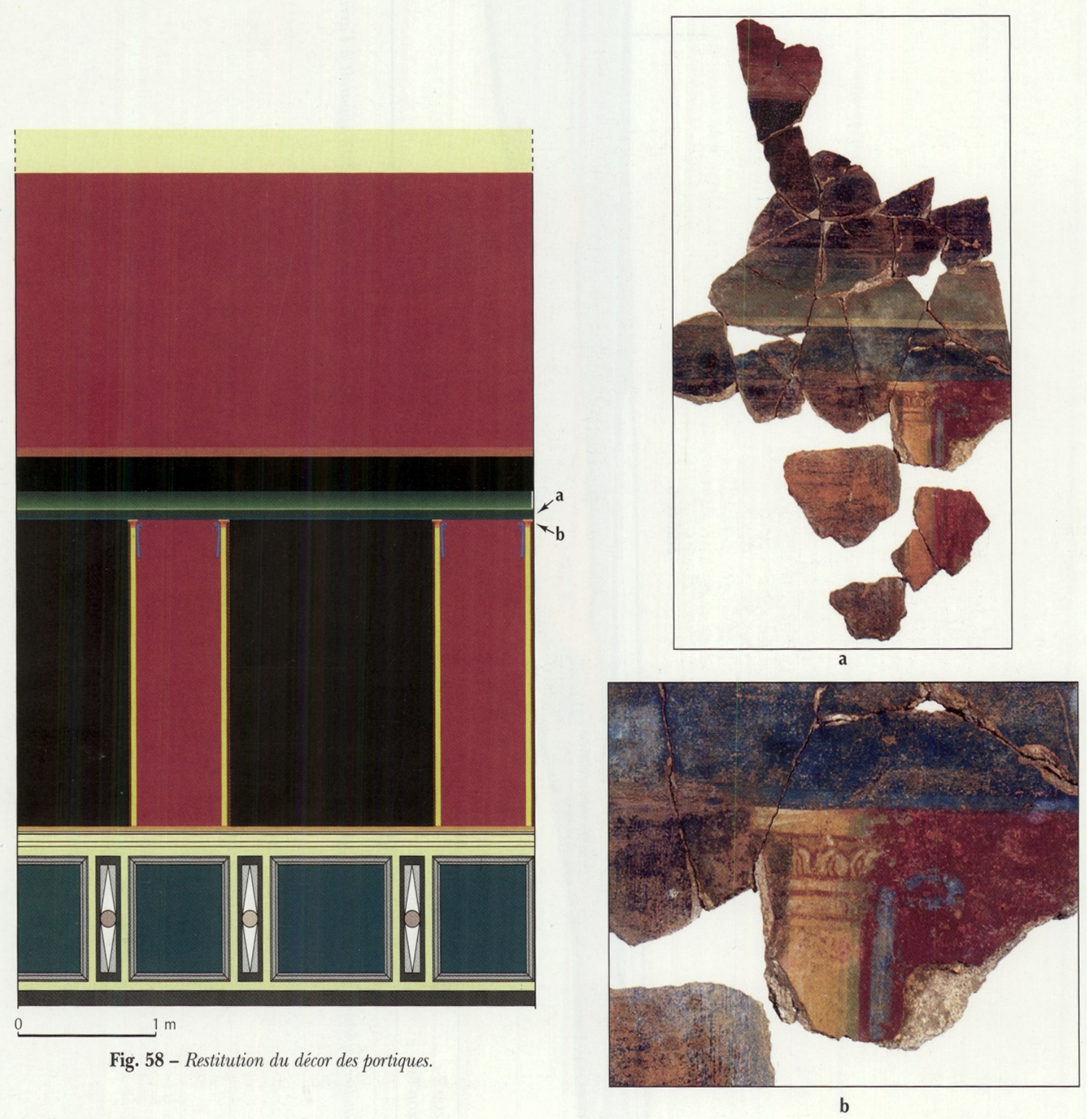

Fig. 59 - Décor peint du portique :

$a$, enduit peint; $b$, détail de la colonnette. 